\title{
WestVirginiaUniversity
}

THE RESEARCH REPOSITORY @ WVU

Graduate Theses, Dissertations, and Problem Reports

2009

\section{Optimization of a retrofit urea-SCR system}

Clinton R. Bedick

West Virginia University

Follow this and additional works at: https://researchrepository.wvu.edu/etd

\section{Recommended Citation}

Bedick, Clinton R., "Optimization of a retrofit urea-SCR system" (2009). Graduate Theses, Dissertations, and Problem Reports. 2914.

https://researchrepository.wvu.edu/etd/2914

This Dissertation is protected by copyright and/or related rights. It has been brought to you by the The Research Repository @ WVU with permission from the rights-holder(s). You are free to use this Dissertation in any way that is permitted by the copyright and related rights legislation that applies to your use. For other uses you must obtain permission from the rights-holder(s) directly, unless additional rights are indicated by a Creative Commons license in the record and/ or on the work itself. This Dissertation has been accepted for inclusion in WVU Graduate Theses, Dissertations, and Problem Reports collection by an authorized administrator of The Research Repository @ WVU.

For more information, please contact researchrepository@mail.wvu.edu. 


\title{
Optimization of a Retrofit Urea-SCR System
}

\author{
Clinton R. Bedick
}

Dissertation submitted to the College of Engineering and Mineral Resources

at West Virginia University in partial fulfillment of the requirements for the degree of

\author{
Doctor of Philosophy \\ in \\ Mechanical Engineering
}

\author{
Approved by \\ Nigel Clark, Ph.D., Chair \\ Gregory Thompson, Ph.D. \\ Mridul Gautam, Ph.D. \\ Benjamin Shade, Ph.D. \\ Kent Casleton, Ph.D.
}

Mechanical and Aerospace Engineering Department

\author{
Morgantown, West Virginia \\ 2009
}

Keywords: Diesel, Urea SCR, NOx, Control Optimization, SCR Modeling Copyright 2009 Clinton R. Bedick 


\title{
Optimization of a Retrofit Urea-SCR System
}

\author{
Clinton R. Bedick
}

\begin{abstract}
Oxides of nitrogen (NOx) emissions from legacy diesel engines are often many times over currently mandated standards, contributing significantly to degradation of air quality and negative environmental impact. A retrofit urea-SCR (selective catalytic reduction) aftertreatment system offers a viable solution for reducing NOx emissions from older diesel engines. A stand-alone retrofit urea-SCR aftertreatment system was previously developed by West Virignia University (WVU) engineers, implementing a pre-SCR NOx sensor, open-loop feed-forward control, and stoichiometric NOx reduction logic. During experimental testing at WVU, the urea-SCR system demonstrated NOx reductions of $2 \%$ to $53 \%$, depending on the test cycle. In order to optimize the system, this dissertation considered additional control configurations. To evaluate the emissions performance of each control strategy, a neural network heavy-duty diesel engine model was developed along with separate four-state chemical and thermal SCR catalyst models. Each model component was validated with experimental data recorded from the WVU Engine and Emissions Research Laboratory (EERL). The following control configurations were considered: (1) pre-SCR NOx sensor, open-loop feed-forward control, (2) post-SCR NOx sensor, closed-loop feed-back proportionalderivative (PD) control, (3) pre- and post-SCR NOx sensors, closed-loop feed-back proportional-integralderivative (PID) control, (4) pre-SCR NOx sensor, model-based control.
\end{abstract}

The evaluation process considered differences between a highly instrumented and highly engineered system. Emissions performance was evaluated over two transient on-road test cycles (FTP, ACES HHDDT_S) and one steady-state marine test cycle (ICOMIA E5), implying broad applicability of the aftertreatment system. The evaluation process was characterized by overall NOx reduction percentage, maximum ammonia slip in parts per million (ppm), and average ammonia slip (ppm). The complexity of the sensor configuration and control strategy calibration were evaluated, as well as how adaptable a given configuration was to variations in engine behavior and sensor measurement accuracy. Finally, total cost was compared between each control configuration, considering system capital, maintenance, operation, control strategy engineering, and system calibration. A final cost per ton of NOx reduced was presented for each control configuration, assuming a six year operational cycle in marine and on-road applications. Based on the collective emissions, complexity, and cost analyses, a configuration implementing pre- and postSCR NOx sensors and closed-loop PID control was identified as optimal for a retrofit application. Model results demonstrated NOx reductions of 44\%, 53\%, and 47\% over FTP, ICOMIA, and ACES High-Speed Cruise (HHDDT_S) cycles, respectively. The total annual NOx reduction cost was $\$ 8,800$ per ton of NOx reduced for an on-road application and \$3,651 per ton of NOx reduced for a marine application. 


\section{Acknowledgements}

I would like to acknowledge everyone that has helped me along my engineering path. I want to thank my parents, Robert and Jennifer for encouraging me to do well in school, pursue an engineering career, and for their help in financing my college education. I also want to thank my dad for inspiring me to become an engineer and work in the energy field. I want to thank my fiancé Seanna Donovan for supporting me and standing by me through all of these years of college, even when I was constantly working on schoolwork and just about broke trying to live on a GRA stipend. I want to thank my advisor Dr. Nigel Clark for the encouragement, lessons, guidance throughout Challenge $\mathrm{X}$ and graduate school, especially for hiring me as a GRA and allowing me to work with engines and emissions. I want to thank my other committee members, Dr. Gautam, Dr. Shade, Dr. Casleton, and Dr. Thompson for asking me tough questions and pushing me to produce quality work. I want to thank Derek Johnson, Francisco Posada, Feng Zhen, and all of the other graduate students I have worked with for their assistance on projects we worked on together. I want to thank Brad Ralson at the EERL for his patience teaching me the ropes of emissions testing and for his assistance during my experimental work. Finally, I would like to thank my brother, Ty, my grandparents, and all my other friends and family for the positive encouragement. 


\section{Table of Contents}

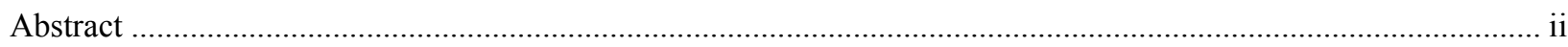

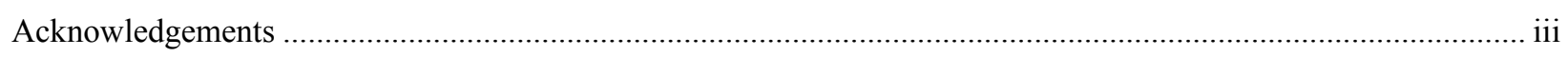

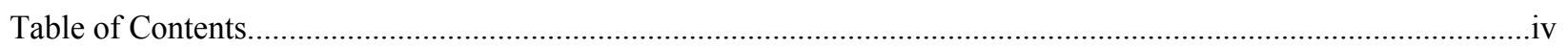

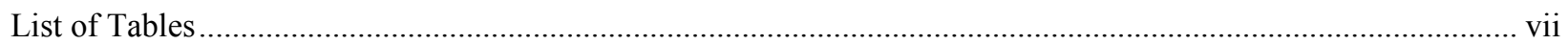

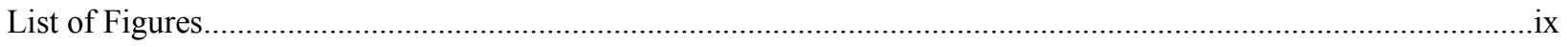

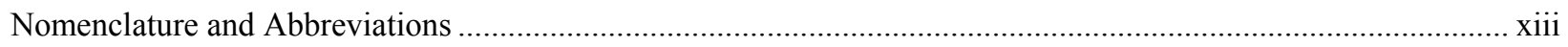

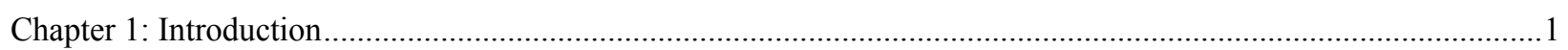

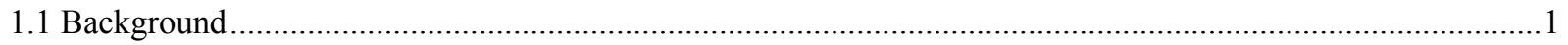

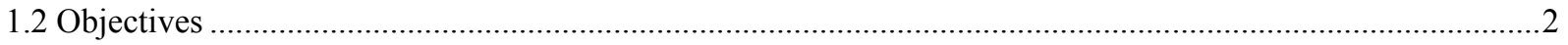

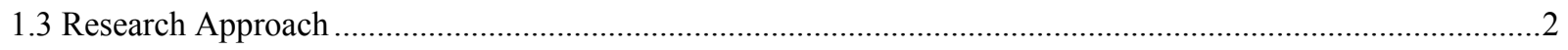

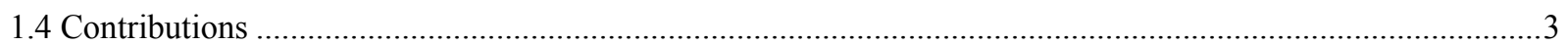

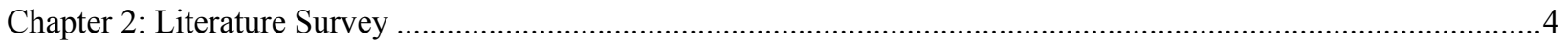

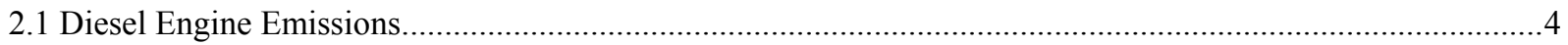

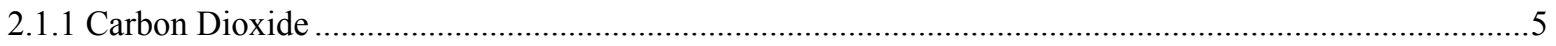

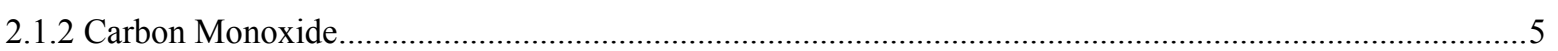

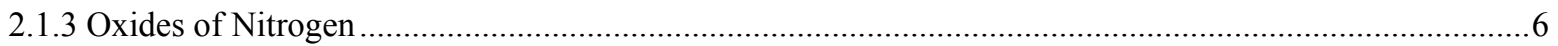

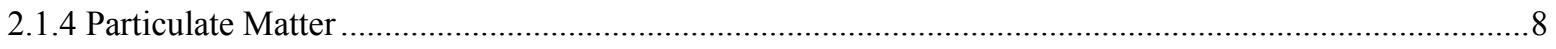

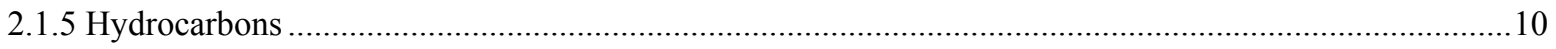

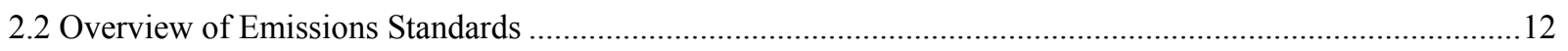

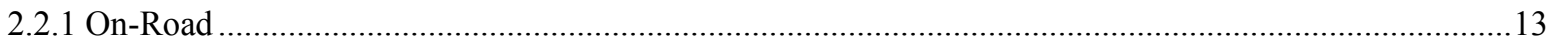

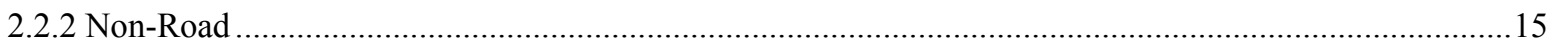

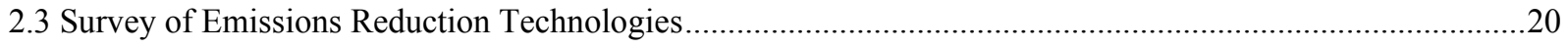

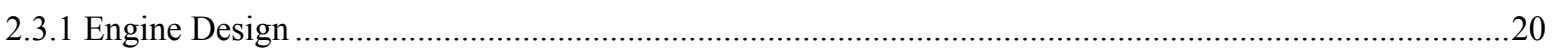

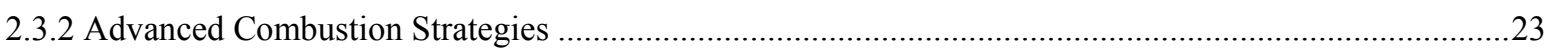

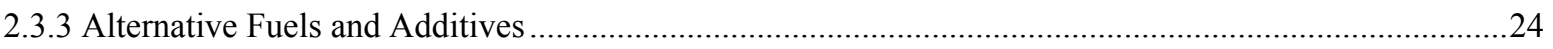

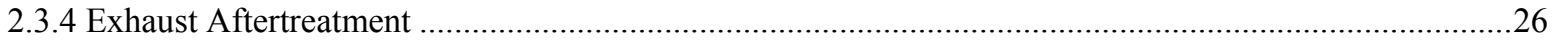

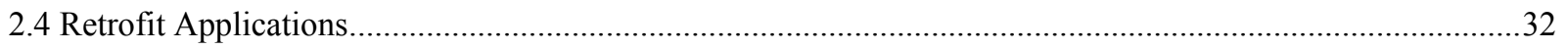

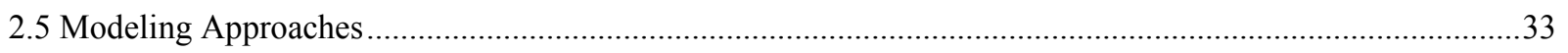

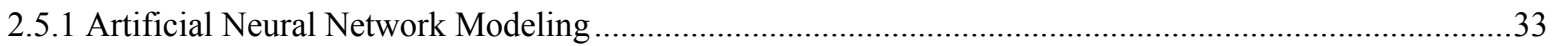

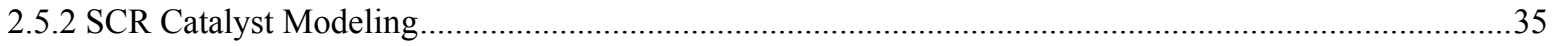

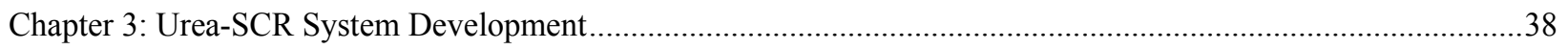

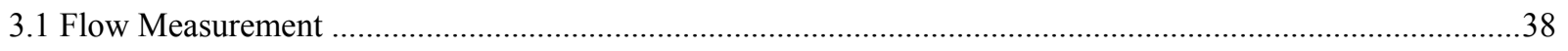

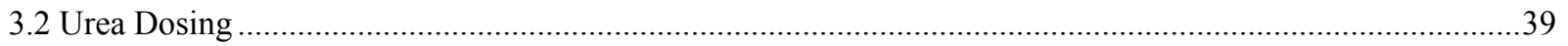

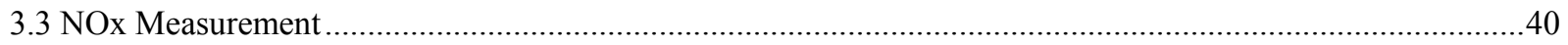

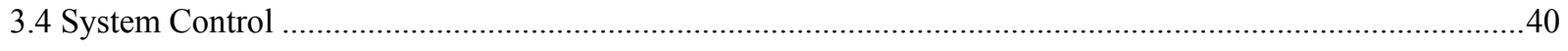

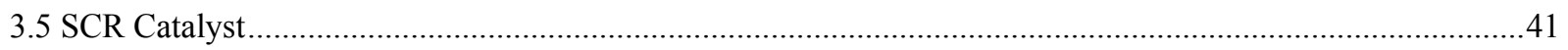




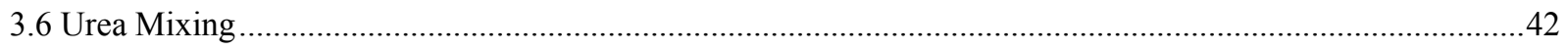

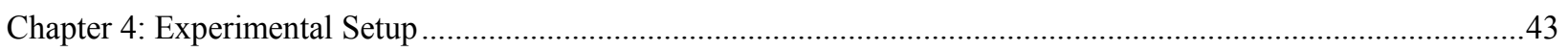

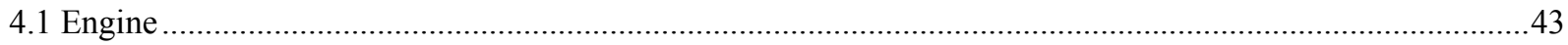

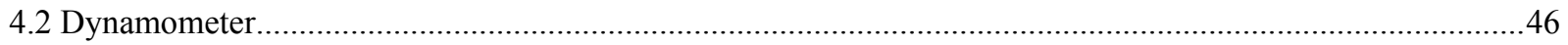

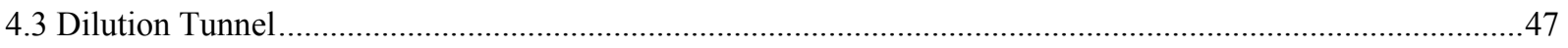

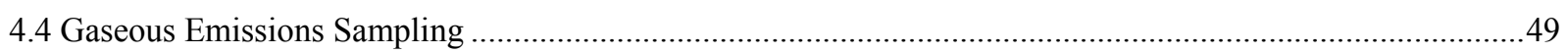

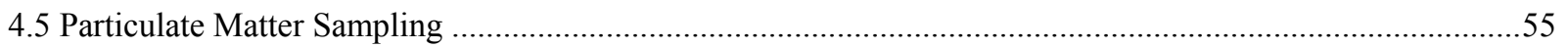

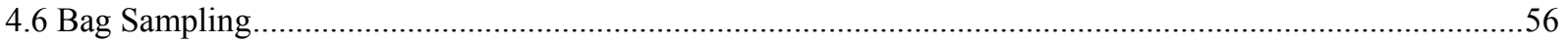

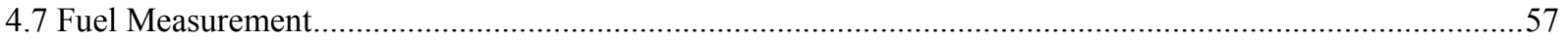

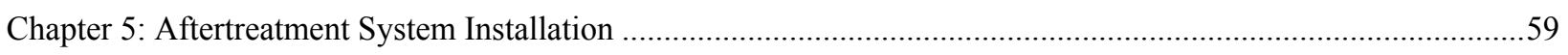

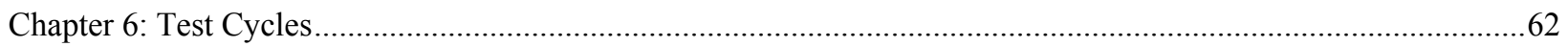

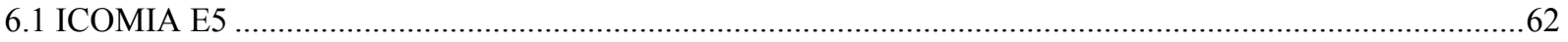

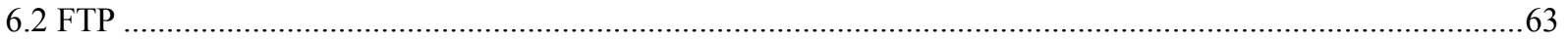

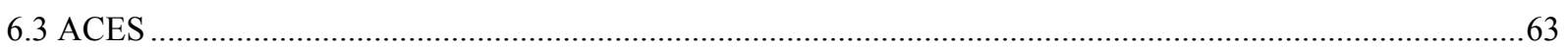

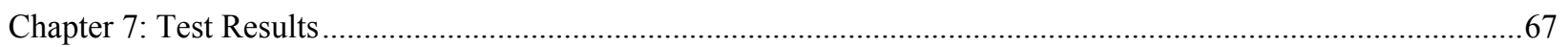

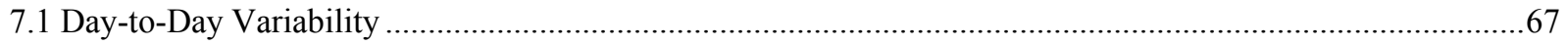

7.2 Correlation with Laboratory Measurements ...............................................................................................68

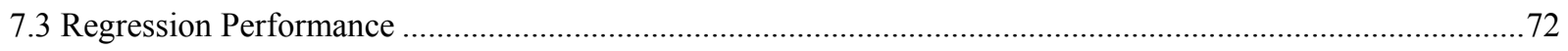

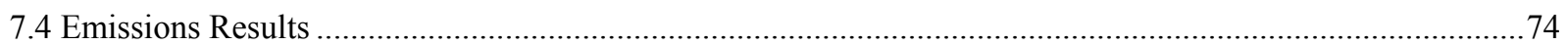

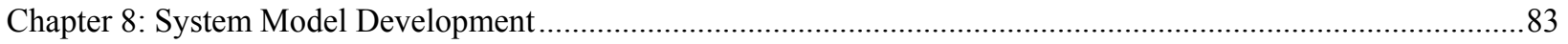

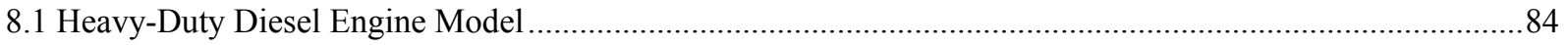

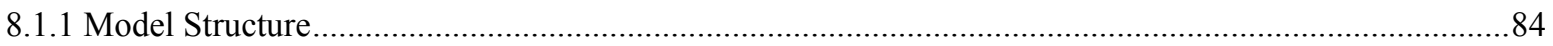

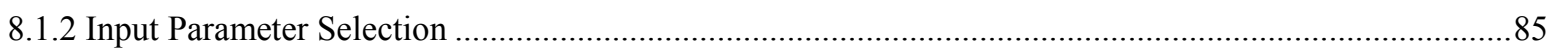

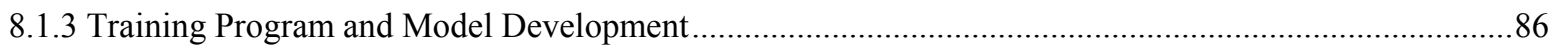

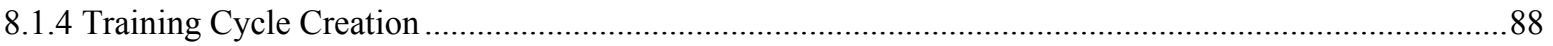

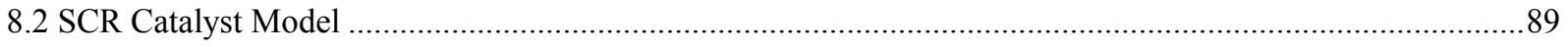

8.2.1 Four-State Chemical Reaction Sub-Model Description ...................................................................90

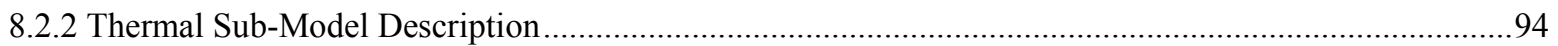

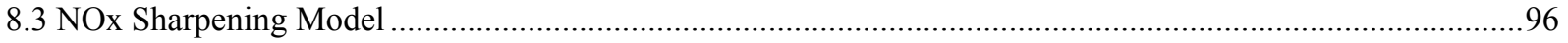

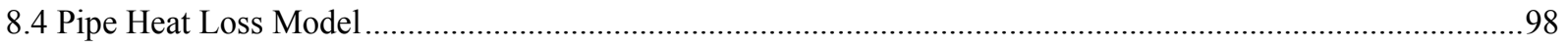

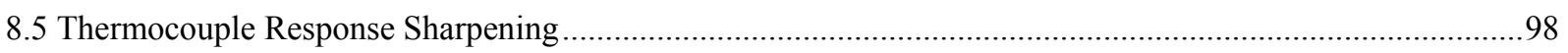

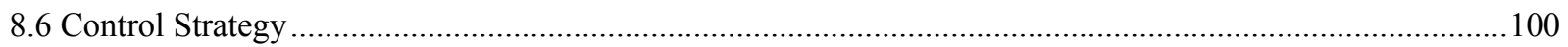

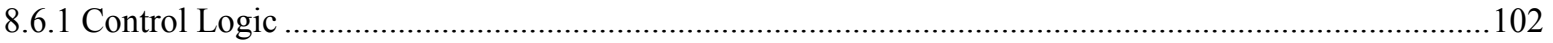

Chapter 9: System Model Validation and Results ............................................................................................... 104

9.1 Heavy-Duty Diesel Engine Model ..................................................................................................... 104

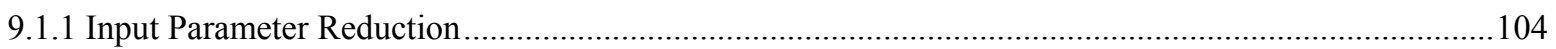

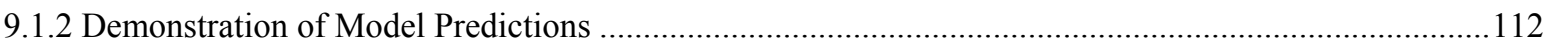




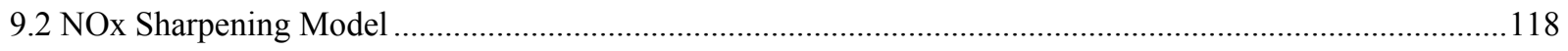

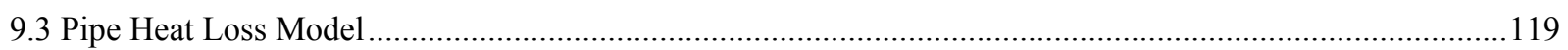

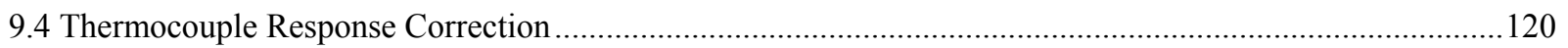

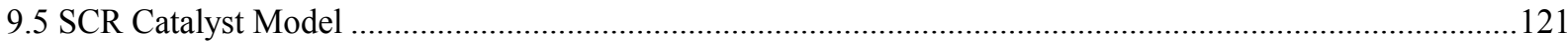

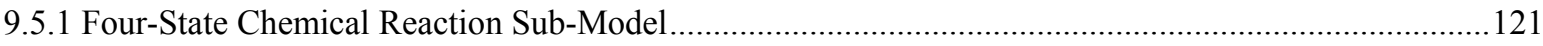

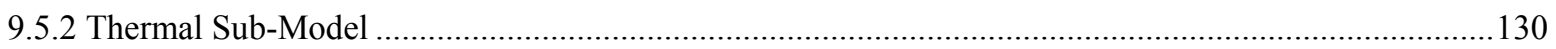

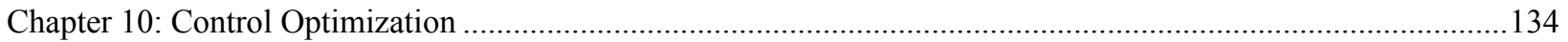

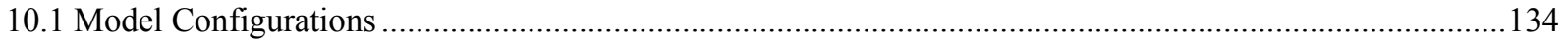

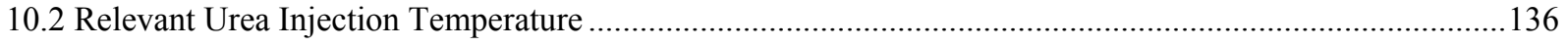

10.3 Configuration 1: Pre-SCR NOx Sensor, Open-Loop Feed-Forward Control .............................................138

10.4 Control Strategy Targets: NOx Reduction and Ammonia Slip ...............................................................141

10.5 Configuration 2: Post-SCR NOx Sensor, Closed-Loop Feed-Back Control................................................. 144

10.6 Configuration 3: Pre- and Post-SCR NOx Sensors, Closed-Loop Feed-Back Control ....................................152

10.7 Configuration 4: Pre-SCR NOx Sensor, Open-Loop Model-Based Control..................................................156

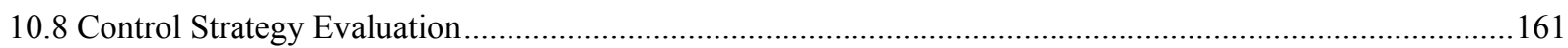

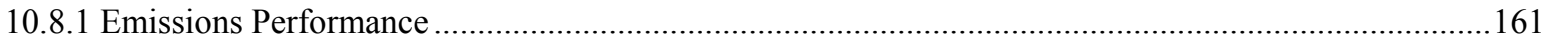

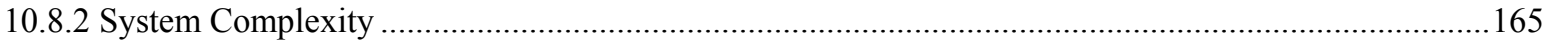

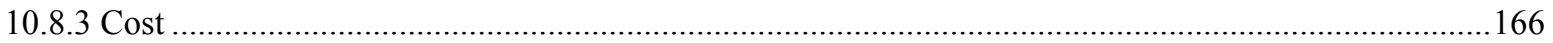

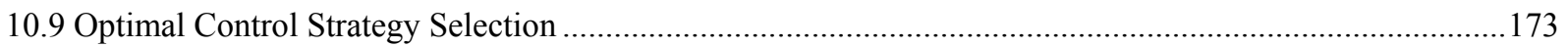

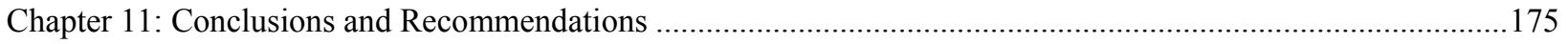

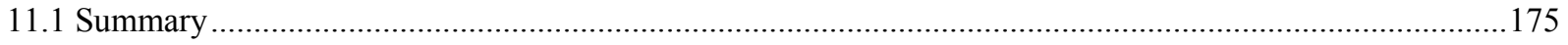

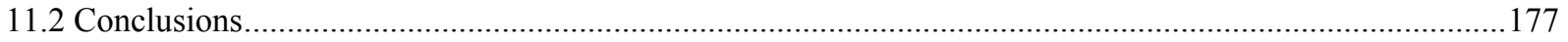

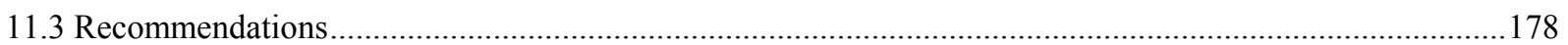

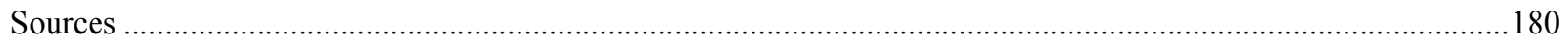

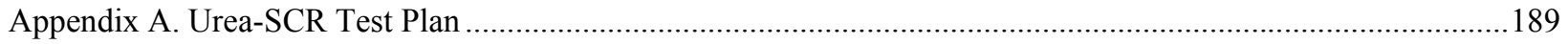

Appendix B. Transient Test Cycle Engine Speed and Torque Plots.......................................................................191

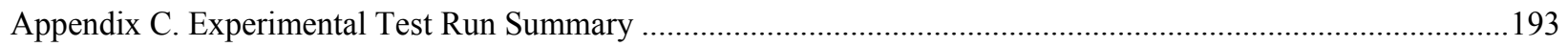

Appendix D. Urea-SCR System Individual Component Cost ……..................................................................... 194 


\section{List of Tables}

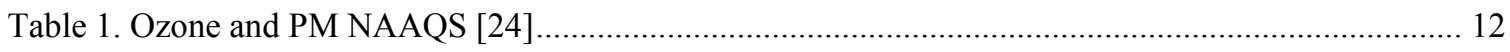

Table 2. On-road HHDDE emissions standards (g/bhp-hr) [8,27] ......................................................... 15

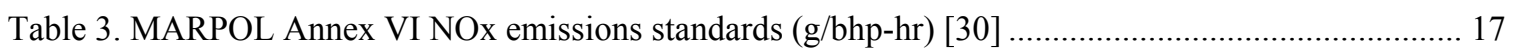

Table 4. Tier 1 non-road marine diesel engine emissions standards (g/bhp-hr) [8,31] ............................... 17

Table 5. Tier 2 non-road marine diesel engine emissions standards (g/bhp-hr) [8,31] .............................. 18

Table 6. Tier 3 non-road marine diesel engine emissions standards, $\mathrm{C} 1$ commercial, standard power density

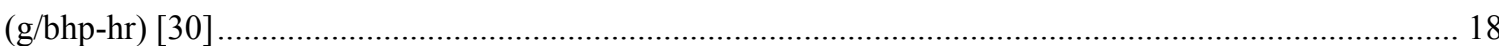

Table 7. Tier 3 non-road marine diesel engine emissions standards, $\mathrm{C} 1$ commercial, high power density and

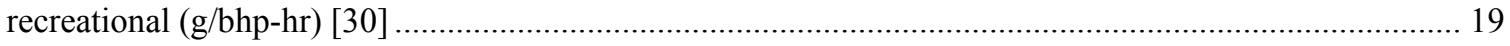

Table 8. Tier 3 non-road marine diesel engine emissions standards, C2 (g/bhp-hr) [30] ............................ 19

Table 9. Tier 4 non-road marine diesel engine emissions standards, $\mathrm{C} 1 / 2$ engines [30] ............................. 20

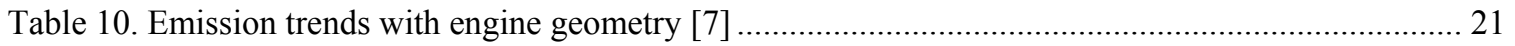

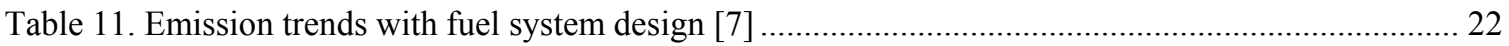

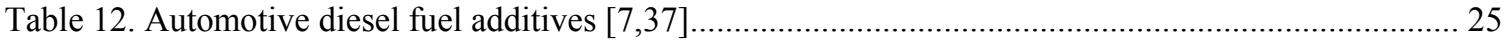

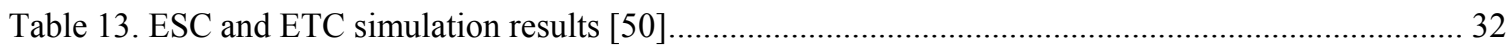

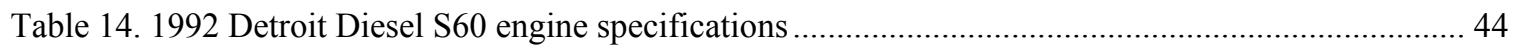

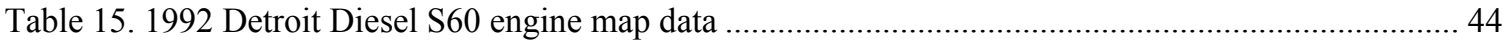

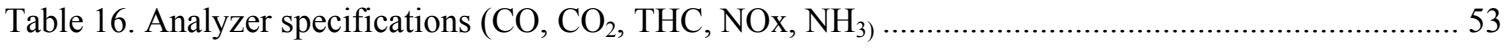

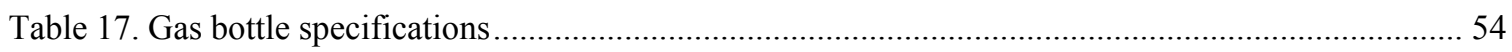

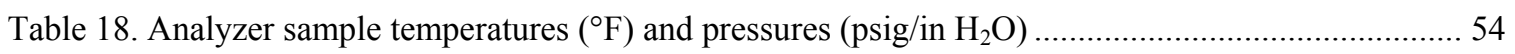

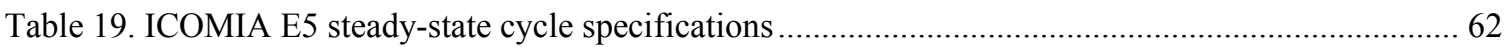

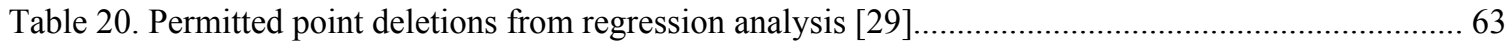

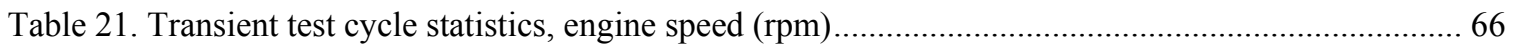

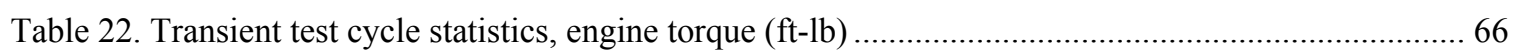

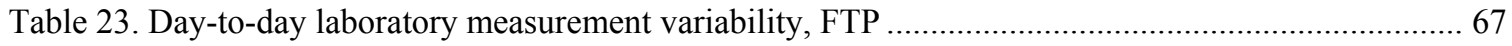

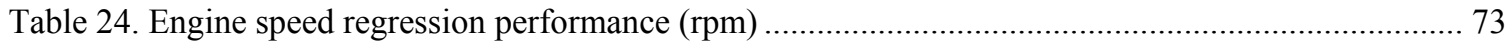

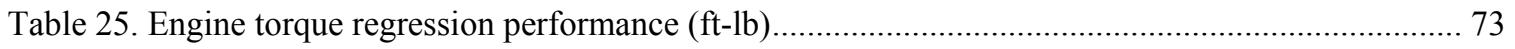

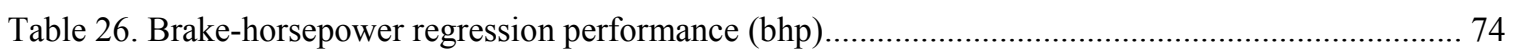

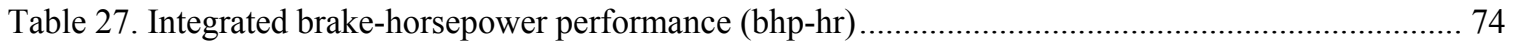

Table 28. THC, PM emissions performance (g/bhp-hr), with and without SCR catalyst............................ 75

Table 29. Total $\mathrm{CO}_{2}$, CO, THC, PM emissions comparison (g/bhp-hr) ………………............................. 76

Table 30. Work and fuel consumption comparison (bhp-hr, lb) .............................................................. 76

Table 31. Total NOx emissions (g/bhp-hr), NOx reduction (\%), and $\mathrm{NH}_{3}$ slip (ppm) ................................ 79

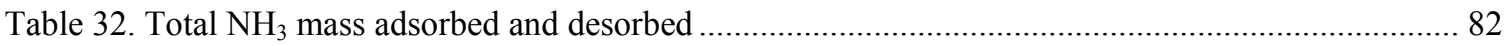

Table 33. Engine model inputs, outputs, and normalization ranges ........................................................ 86

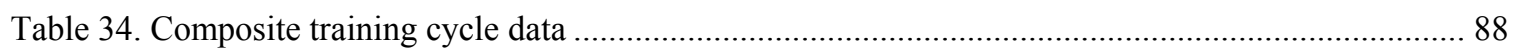




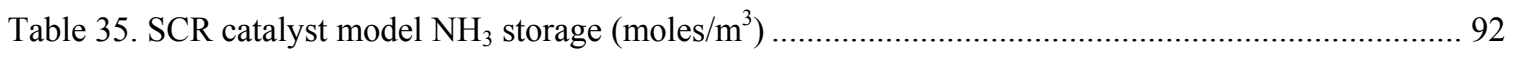

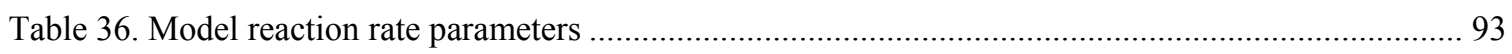

Table 37. ANN input comparison, correlation coefficient and standard error............................................106

Table 38. ANN engine model validation, correlation coefficient and standard error ..................................118

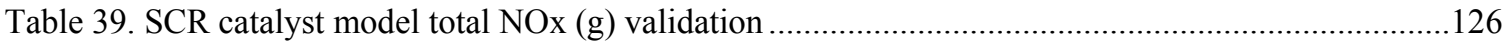

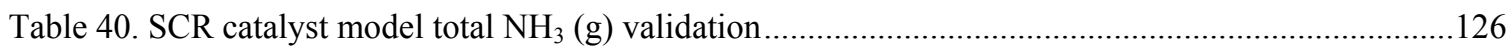

Table 41. Original open-loop feed-forward model NOx reduction (\%) and ammonia slip (ppm) results ...142

Table 42. Effects of independent P, I, and D tuning on closed-loop response [92] ...................................147

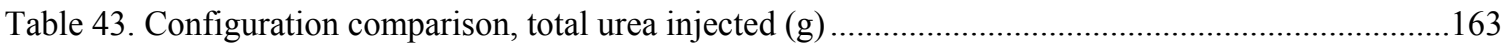

Table 44. Control configuration emissions performance comparison .....................................................164

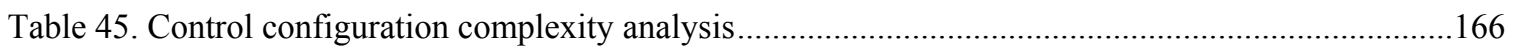

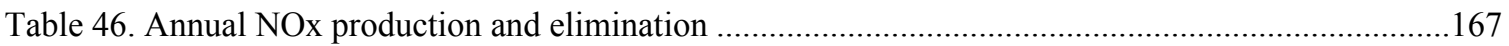

Table 47. Urea-SCR system fabrication and welding costs [103] ..........................................................168

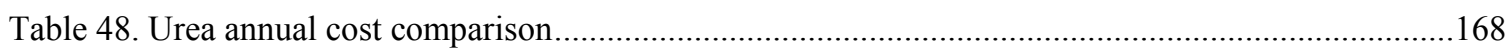

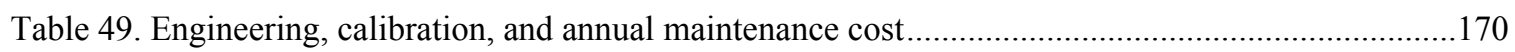

Table 50. Urea-SCR system and control configuration cost analysis......................................................172

Table 51. Experimental test run summary …………….....................................................................193

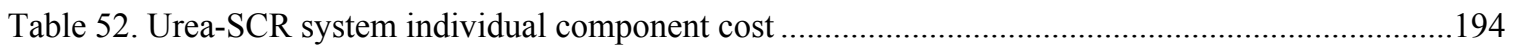




\section{List of Figures}

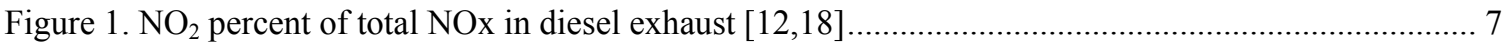

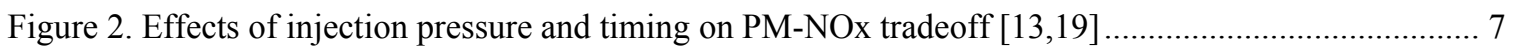

Figure 3. Manmade sources of NOx emissions (2003) [15] …...................................................................... 8

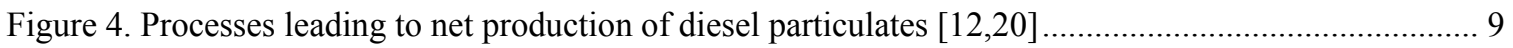

Figure 5. Diesel hydrocarbon formation schematic: (a) fuel injected during delay period; (b) fuel injected

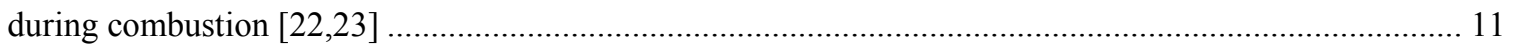

Figure 6. Ozone non-attainment zones: (a) 1-hour standard, (b) 8-hour standard [26] ............................... 13

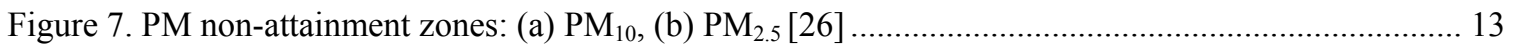

Figure 8. Schar et al. SCR model predictions: (a) temperature (C), (b) NOx (mmol/s) [50]..................... 35

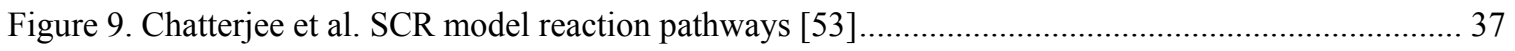

Figure 10. Chatterjee et al. model validation results: (a) HHDDE test bench (b) passenger car diesel engine

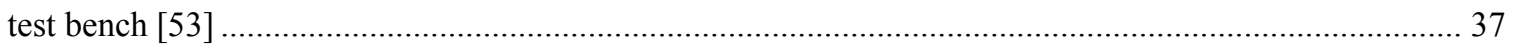

Figure 11. Urea-SCR system flow measurement section ..................................................................... 39

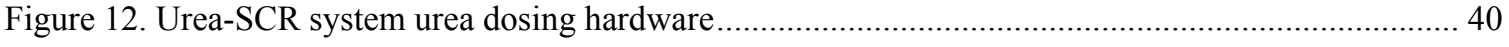

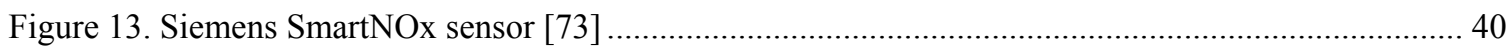

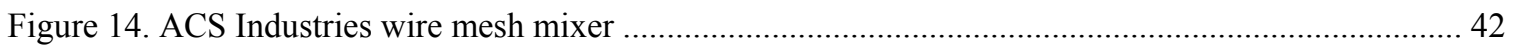

Figure 15. 1992 Detroit Diesel S60 engine map, torque (ft-lb) vs. speed (rpm). ....................................... 45

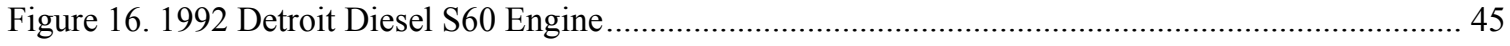

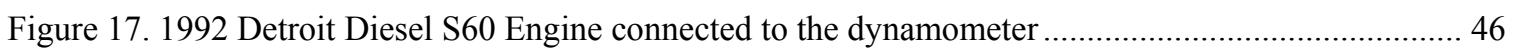

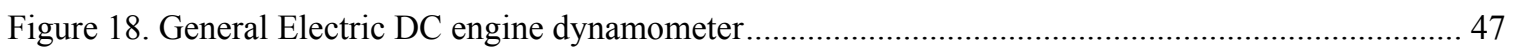

Figure 19. Dilution tunnel and sample plane

Figure 20. Propane injection kit connected to dilution tunnel ..................................................................... 49

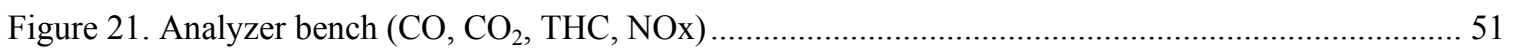

Figure 22. ABB AO2000 LIMAS11HW NDUV analyzer .................................................................... 52

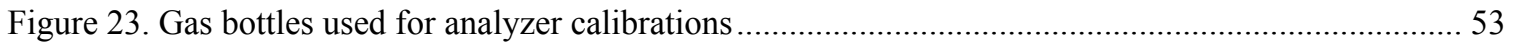

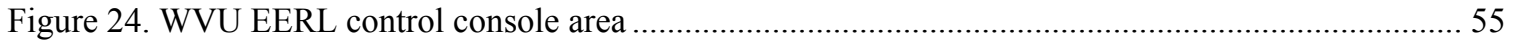

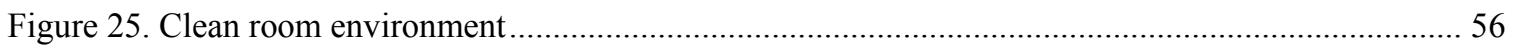

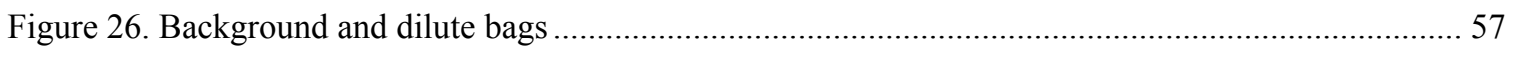

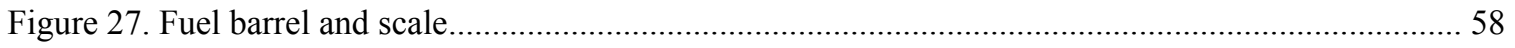

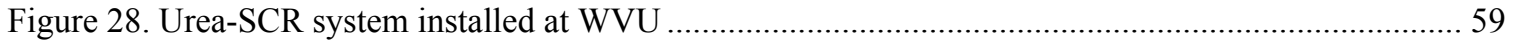

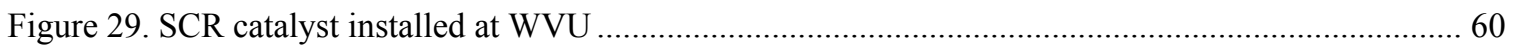

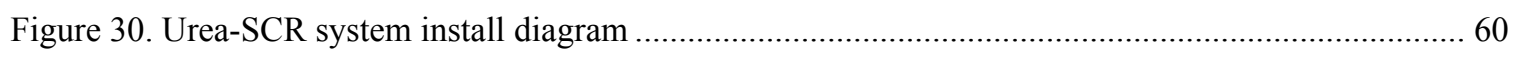

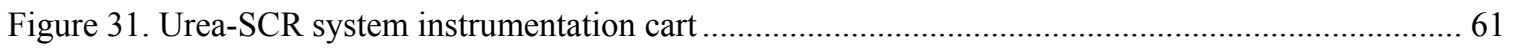

Figure 32. (a) Continuous flow comparison (scfm), (b) flow correlation (scfm), FTP ……………............. 70

Figure 33. (a) Continuous NOx Comparison (g/s), (b) NOx Correlation (g/s), FTP ................................. 71

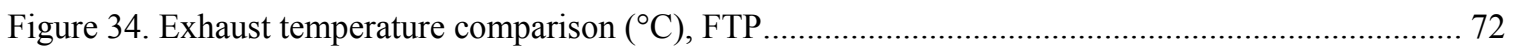


Figure 35. Continuous $\mathrm{NOx}$ and $\mathrm{NH}_{3}$

Figure 36. (a) NOx reduction (\%), (b) ammonia slip (ppm), exhaust temperature $\left({ }^{\circ} \mathrm{C}\right)$, FTP

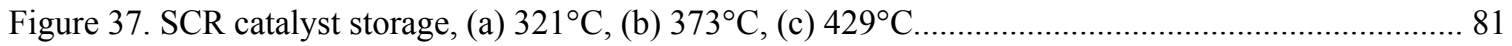

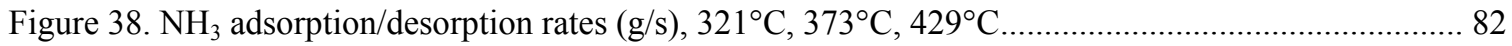

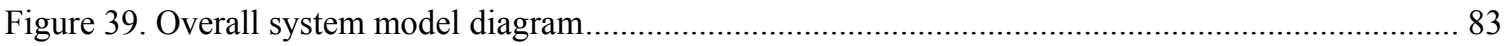

Figure 40. Single hidden layer feed-forward ANN architecture ..................................................... 84

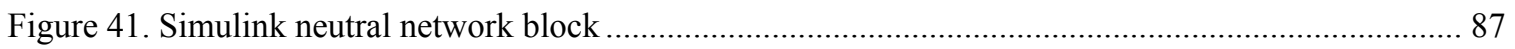

Figure 42. Composite training cycle (a) engine speed (rpm), (b) engine torque (N-m) ........................ 89

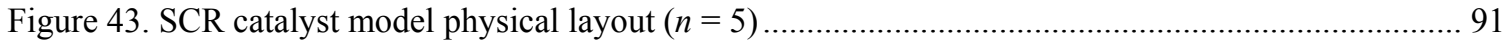

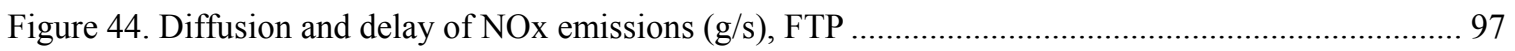

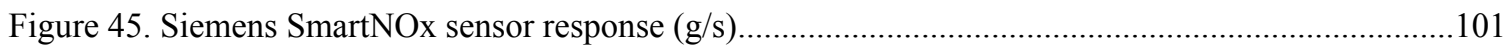

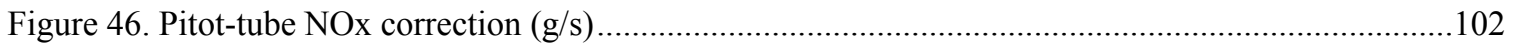

Figure 47. ANN engine model training results, all inputs: (a) NOx (g/s), (b) exhaust temperature (K), (c) exhaust flow $\left(\mathrm{m}^{3} / \mathrm{s}\right)$.

Figure 48. ANN engine model training results, engine speed and torque inputs: (a) NOx (g/s), (b) exhaust temperature $(\mathrm{K})$, (c) exhaust flow $\left(\mathrm{m}^{3} / \mathrm{s}\right)$......

Figure 49. ANN engine model training parity plot, engine speed and torque inputs: (a) NOx (g/s), (b)

exhaust temperature $(\mathrm{K})$, (c) exhaust flow $\left(\mathrm{m}^{3} / \mathrm{s}\right)$.

Figure 50. ANN engine model training results, engine speed, torque, oil temperature, boost inputs (final

inputs): (a) NOx (g/s), (b) exhaust temperature (K), (c) exhaust flow $\left(\mathrm{m}^{3} / \mathrm{s}\right)$.

Figure 51. ANN engine model training parity plot, engine speed, torque, oil temperature, boost inputs (final inputs): (a) NOx (g/s), (b) exhaust temperature (K), (c) exhaust flow $\left(\mathrm{m}^{3} / \mathrm{s}\right)$.

Figure 52. ANN engine model validation, continuous NOx (g/s), (a) ICOMIA, (b) FTP, (c) ACES

Transient, (d) ACES Creep, (e) ACES HHDDT_S

Figure 53. ANN engine model validation, continuous exhaust temperature (K), (a) ICOMIA, (b) FTP, (c)

ACES Transient, (d) ACES Creep, (e) ACES HHDDT_S

Figure 54. ANN engine model validation, continuous exhaust flow ( $\left.\mathrm{m}^{3} / \mathrm{s}\right)$, (a) ICOMIA, (b) FTP, (c) ACES

Transient, (d) ACES Creep, (e) ACES HHDDT_S

Figure 55. ANN engine model validation parity plot, FTP, (a) NOx (g/s), (b) exhaust temperature (K), (c) exhaust flow $\left(\mathrm{m}^{3} / \mathrm{s}\right)$. 116

Figure 56. ANN engine model validation parity plot, HHDDTS, (a) NOx (g/s), (b) exhaust temperature (K), (c) exhaust flow $\left(\mathrm{m}^{3} / \mathrm{s}\right)$ 117

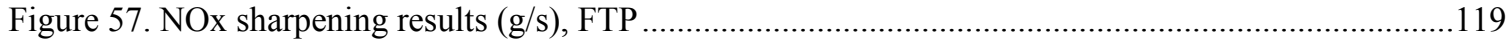

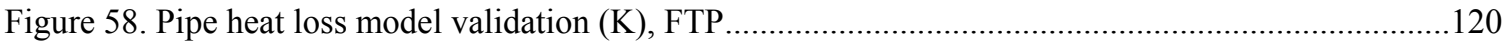

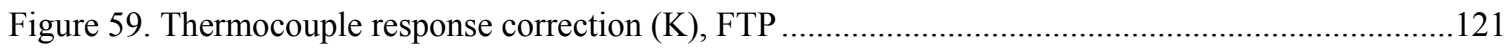

Figure 60. SCR catalyst model NOx validation (g/s): (a) FTP, (b) ACES HHDDT_S, (c) ICOMIA .........123

Figure 61. SCR catalyst model $\mathrm{NH}_{3}$ slip validation (g/s): (a) FTP, (b) ACES HHDDT_S, (c) ICOMIA ...124 
Figure 62. SCR catalyst model NOx validation $(\mathrm{g} / \mathrm{s})$, enlarged ...............................................................125

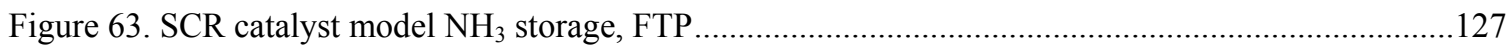

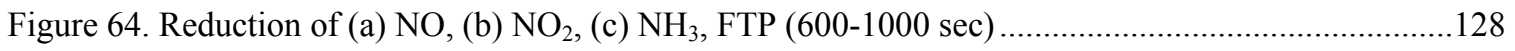

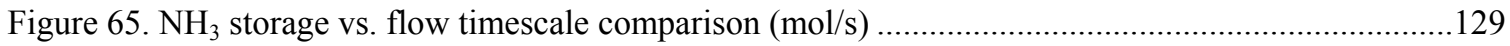

Figure 66. SCR thermal model outlet temperature (K) validation, NRTC (John Deere HHDDE) [69] .......130

Figure 67. SCR catalyst model exhaust temperature comparison (K), FTP ………….............................131

Figure 68. SCR catalyst model brick temperature comparison (K), FTP ………………………............132

Figure 69. SCR catalyst model gas temperature comparison (K), FTP …………....................................132

Figure 70. SCR catalyst model partition 2 temperatures (K), FTP .......................................................133

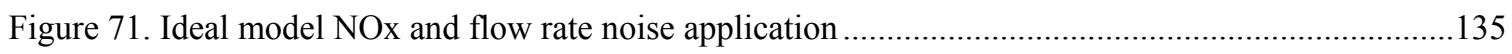

Figure 72. Ideal and exact (a) NOx (g/s), (b) exhaust temperature (K), (c) flow $\left(\mathrm{m}^{3} / \mathrm{s}\right)$, FTP ....................136

Figure 73. SCR Inlet Gas and Brick Temperature (K), FTP ...........................................................137

Figure 74. Pre-SCR NOx sensor, open-loop, feed-forward control diagram............................................138

Figure 75. Configuration 1 exact, continuous NOx (g/s) and $\mathrm{NH}_{3}$ (ppm): (a) FTP, (b) ACES HHDDT_S, (c) ICOMIA .

Figure 76. Configuration 1 ideal, continuous NOx (g/s) and $\mathrm{NH}_{3}$ (ppm): (a) FTP, (b) ACES HHDDT_S, (c)

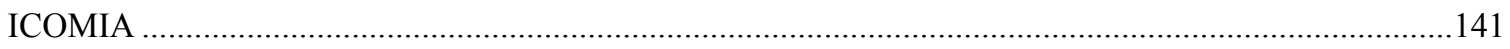

Figure 77. Post-SCR NOx sensor, feed-back PD control diagram ..........................................................144

Figure 78. Post-SCR control configuration NOx setpoint (ppm): (a) ICOMIA, (b) FTP .............................146

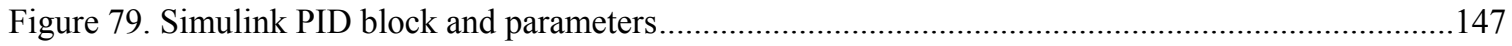

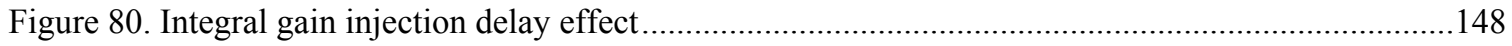

Figure 81. Configuration 2 exact, continuous NOx (g/s) and $\mathrm{NH}_{3}$ (ppm): (a) FTP, (b) ACES HHDDT_S, (c)

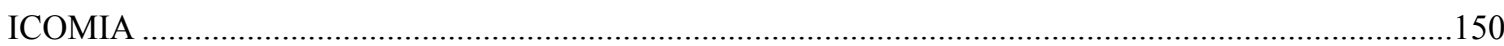

Figure 82. Configuration 2 ideal continuous NOx (g/s) and $\mathrm{NH}_{3}$ (ppm): (a) FTP, (b) ACES HHDDT_S, (c)

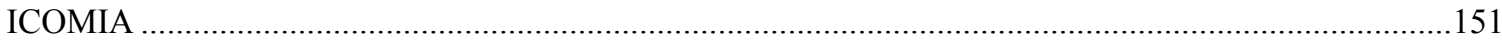

Figure 83. Pre- and post-SCR NOx sensors, closed-loop feed-back control diagram .................................152

Figure 84. Configuration 3 exact, continuous NOx (g/s) and $\mathrm{NH}_{3}(\mathrm{ppm})$ : (a) FTP, (b) ACES HHDDT_S, (c) ICOMIA

Figure 85. Configuration 3 ideal, continuous NOx (g/s) and $\mathrm{NH}_{3}$ (ppm): (a) FTP, (b) ACES HHDDT_S, (c)

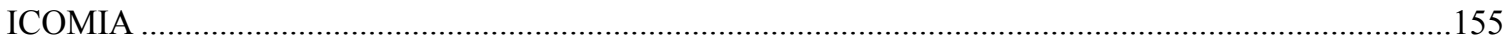

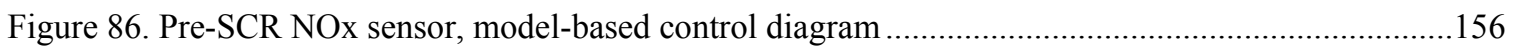

Figure 87. Membership functions (a) exhaust temperature (K), (b) $\mathrm{NH}_{3}$ storage, (c) $\mathrm{NH}_{3}$ storage rate ......157

Figure 88. $\mathrm{NH}_{3}$ storage rates, configuration 4, ACES HHDDT_S .........................................................158

Figure 89. Configuration 4 exact, continuous NOx (g/s) and $\mathrm{NH}_{3}$ (ppm): (a) FTP, (b) ACES HHDDT_S, (c)

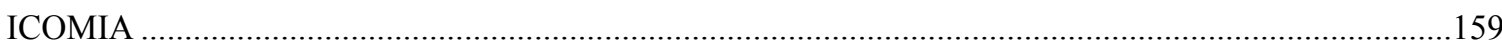

Figure 90. Configuration 4 ideal, continuous NOx (g/s) and $\mathrm{NH}_{3}$ (ppm): (a) FTP, (b) ACES HHDDT_S, (c)

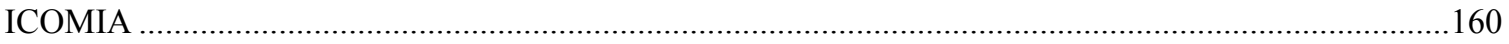




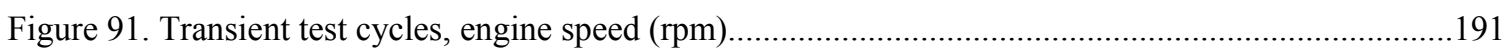

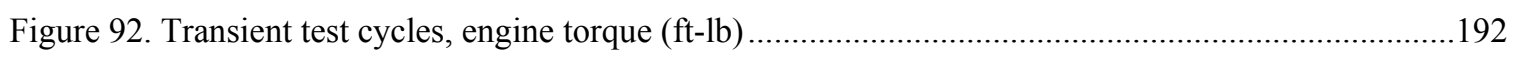




\section{Nomenclature and Abbreviations}

\begin{tabular}{|c|c|}
\hline$\left(\mathrm{NH}_{2}\right)_{2} \mathrm{CO}$ & Urea \\
\hline$\mu \mathrm{m}$ & Micrometer \\
\hline ACES & Advanced Collaborative Emissions Study \\
\hline ADALINE & Adaptive Linear \\
\hline $\mathrm{ADC}$ & Analog-to-Digital Converter \\
\hline $\mathrm{AF}$ & Air-to-Fuel Ratio \\
\hline ANN & Artificial Neural Network \\
\hline B20 & $20 \%$ Biodiesel \\
\hline B35 & $35 \%$ Biodiesel \\
\hline bhp & Brake Horsepower \\
\hline bmep & Brake Mean Effective Pressure \\
\hline BSFC & Brake-specific Fuel Consumption \\
\hline BSHC & Brake-specific Hydrocarbon \\
\hline BSNOx & Brake-specific Oxides of Nitrogen \\
\hline $\mathrm{C} 1$ & Category 1 \\
\hline $\mathrm{C} 2$ & Category 2 \\
\hline $\mathrm{C} 3$ & Category 3 \\
\hline CAFEE & Center for Alternative Fuels, Engines and Emissions \\
\hline CAN & Controller Area Network \\
\hline CARB & California Air Resources Board \\
\hline $\mathrm{cfm}$ & Cubic Feet Per Minute \\
\hline CFR & Code of Federal Regulations \\
\hline $\mathrm{CH}_{4}$ & Methane \\
\hline $\mathrm{CI}$ & Compression Ignition \\
\hline CIDI & Compression Ignition Direct Injection \\
\hline $\mathrm{CO}$ & Carbon Monoxide \\
\hline $\mathrm{CO}_{2}$ & Carbon Dioxide \\
\hline DC & Direct Current \\
\hline $\mathrm{DDC}$ & Detroit Diesel Corporation \\
\hline DOC & Diesel Oxidation Catalyst \\
\hline DOT & Degree-of-Transience \\
\hline DPF & Diesel Particulate Filter \\
\hline ECU & Engine Control Unit \\
\hline EERL & Engine and Emissions Research Laboratory \\
\hline EGR & Exhaust Gas Recirculation \\
\hline EMRAN & Extended Minimal Resource Allocating \\
\hline
\end{tabular}




\begin{tabular}{|c|c|}
\hline EPA & Environmental Protection Agency \\
\hline ESC & European Stationary Cycle \\
\hline ETC & European Transient Cycle \\
\hline FEL & Family Emissions Limit \\
\hline FID & Flame Ionization Detector \\
\hline FTP & Federal Test Procedure \\
\hline GE & General Electric \\
\hline GM & General Motors \\
\hline Gr & Grashof Number \\
\hline GVWR & Gross Vehicle Weight Rating \\
\hline $\mathrm{HC}$ & Hydrocarbon \\
\hline $\mathrm{HCCI}$ & Homogeneous Charge Compression Ignition \\
\hline HHDDE & Heavy Heavy-Duty Diesel Engine \\
\hline HHDDT & Heavy Heavy-Duty Diesel Truck \\
\hline HHDDT_S & High Speed Cruise \\
\hline $\mathrm{HNCO}$ & Isocyanic Acid \\
\hline $\mathrm{HNO}_{3}$ & Nitric Acid \\
\hline HONO & Nitrous Acid \\
\hline ICOMIA & International Council of Marine Industry Associations \\
\hline IMO & International Maritime Organization \\
\hline LFE & Laminar Flow Element \\
\hline $\mathrm{LNC}$ & Lean NOx Catalyst \\
\hline MAP & Manifold Air Pressure \\
\hline MARPOL & Maritime Pollution \\
\hline MECA & Manufacturers of Emissions Controls Association \\
\hline MJB\&A & MJ Bradley and Associates \\
\hline $\mathrm{N}_{2} \mathrm{O}$ & Nitrous Oxide \\
\hline NAAQS & National Ambient Air Quality Standards \\
\hline ND & Non-Dimensional \\
\hline NDIR & Non-Dispersive Infrared \\
\hline NDUV & Non-Dispersive Ultraviolet \\
\hline NFPA & National Fire Protection Agency \\
\hline $\mathrm{NH}_{3}$ & Ammonia \\
\hline $\mathrm{NH}_{4} \mathrm{NO}_{3}$ & Ammonium Nitrate \\
\hline NIST & National Institute of Standards and Technology \\
\hline $\mathrm{nm}$ & Nanometer \\
\hline NMHC & Non-Methane Hydrocarbon \\
\hline
\end{tabular}




\begin{tabular}{|c|c|}
\hline NO & Nitric Oxide \\
\hline $\mathrm{NO}_{2}$ & Nitrogen Dioxide \\
\hline NOx & Oxides of Nitrogen \\
\hline NRTC & Non-Road Transient Cycle \\
\hline NSR & Nominal Stoichiometry Ratio \\
\hline NTE & Not-to-Exceed \\
\hline $\mathrm{Nu}$ & Nusselt Number \\
\hline $\mathrm{O}_{3}$ & Ozone \\
\hline OEM & Original Equipment Manufacturer \\
\hline PAH & Polyaromatic Hydrocarbon \\
\hline $\mathrm{PM}$ & Particulate Matter \\
\hline ppm & Parts Per Million \\
\hline $\operatorname{Pr}$ & Prandtl Number \\
\hline $\mathrm{Re}$ & Reynolds Number \\
\hline RPI & Relative Performance Index \\
\hline $\mathrm{rpm}$ & Revolutions Per Minute \\
\hline $\mathrm{scfm}$ & Standard Cubic Feet Per Minute \\
\hline SCR & Selective Catalytic Reduction \\
\hline SET & Supplemental Emissions Test \\
\hline SHL & Single Hidden Layer \\
\hline SI & Spark Ignition \\
\hline SIP & State Implementation Plan \\
\hline SOF & Soluble Organic Fraction \\
\hline $\mathrm{SOx}$ & Oxides of Sulfur \\
\hline THC & Total Hydrocarbon \\
\hline TPM & Total Particulate Matter \\
\hline UDDS & Urban Dynamometer Driving Schedule \\
\hline ULSD & Ultra-low Sulfur Diesel \\
\hline US & United States \\
\hline VOC & Volatile Organic Compound \\
\hline WVU & West Virginia University \\
\hline$\lambda$ & Oxygen Concentration (lambda) \\
\hline
\end{tabular}




\section{Chapter 1: Introduction}

\subsection{Background}

The United States (US) Census Bureau estimates the current 2009 world population to be 6.777 billion [1]. According to population projections, the world population will continue to grow until 2050, reaching nine billion in 2040 [1]. With increasing population comes higher worldwide energy demand. Transportation and shipping industries in particular make use of gasoline and diesel fueled engines to move people and goods all over the world. It has been proven that gasoline and diesel engines produce emissions that are harmful to the environment and human health $[2,3,4,5,6]$. Compared to the impending US 2010 standards, fairly modest standards have been in place in the past to control harmful emissions from internal combustion engines. However, when considering the projected population increase, it is clear that additional measures must be applied to preserve air quality and reduce environmental impact for future generations.

Emissions standards are established by considering the relationship between the contribution of emissions to ambient air quality and the resulting health and environmental impacts. National Ambient Air Quality Standards (NAAQS) assign an attainment designation based on average pollutant concentrations. In the US, nearly 165 million people live in non-attainment zones for ground level ozone and 65 million people live in areas that do not meet particulate matter (PM) air quality standards [7]. These areas must submit State Implementation Plans (SIP), outlining how they will come into compliance over a prescribed amount of time. Diesel emissions regulations have become increasingly strict in an attempt to reduce pollution by mobile sources and improve air quality. In some non-attainment areas, the reduction of diesel oxides of nitrogen (NOx) emissions is included in the SIP because of their contribution to ground level ozone, smog, and acid rain.

Most engines in operation today are not new and do not meet current emissions standards. For example, in the light-duty segment, the 2008 average vehicle age was 8.1 years [8]. The service life of heavy-duty vehicles and marine vessels is typically much longer than for light-duty, implying even higher vehicle ages in those segments. While it is not necessary that older engines meet the most current and strict emissions standards, some are considered high-emitters, producing emissions many times over the current Environmental Protection Agency (EPA) limits. While high-emitting engines make up a small percentage of the engines in operation, they are responsible for a large percentage of harmful emissions [9]. These engines mainly include older model year engines without electronic control, advanced emissions control, or aftertreatment systems. Additionally, marine engine emissions were largely unregulated until 2004 and many engines remain in operation for up to 30 years [10]. Because of their large contributions, it is important to control the emissions from these older engines in addition to imposing strict standards for new engines. 
The simplest method to control emissions from older engines is with a retrofit aftertreatment system. There can be two approaches to developing a retrofit aftertreatment system. The first approach involves a highly instrumented system, which may be adapted to various engines and applications with minimal design changes, calibration, or engineering time. This approach may have higher capital cost and include more hardware and sensing equipment, but allows far greater adaptability. The stand-alone urea-SCR (selective catalytic reduction) system developed as part of the presented dissertation work falls into this category. The second approach is to develop a highly engineered system, where the control strategy is tailored to parameters specific to the engine on which it is being implemented. While this type of system may have lower capital cost due to hardware reduction, there may a higher cost associated with the engineering time required for each engine application. Additionally, highly engineered systems may not be as adaptable as a system implementing more sensing equipment.

\subsection{Objectives}

The objectives of the presented research focused on modeling and optimization of the urea-SCR control configuration. Separately, an objective in the development of the stand-alone urea-SCR system was that it not require electronic interfacing with the engine to simplify retrofit, avoid reliance on engine durability (consistency of NOx output, able to be moved to different engines), and accommodate retrofit of mechanically controlled engines that are typical in marine applications. This objective was met with the current system design, leading to optimization of the control configuration. The major objectives were as follows.

1. Identify control options for a stand-alone urea-SCR system in retrofit applications

2. Develop a modeling strategy that allows quantitative comparison of the control options under a variety of scenarios

3. Verify the model by comparison with experimental data

4. Determine the control options which are most suited to specific applications, where engine-out emissions may vary due to technology and activity

5. Suggest a final optimal system configuration while taking into account tradeoffs between reduction ability, system complexity, and cost

\subsection{Research Approach}

A retrofit urea-SCR aftertreatment system was considered for the reduction of NOx. First, diesel engine and urea-SCR aftertreatment system models were developed using Matlab/Simulink. The diesel engine model implemented a neural network approach and was trained with data collected at the WVU engine laboratory. The SCR catalyst was modeled using separate chemical and thermal components. A four-state chemical reaction approach was utilized, considering gaseous $\mathrm{NO}, \mathrm{NO}_{2}$, and $\mathrm{NH}_{3}$, as well as $\mathrm{NH}_{3}$ stored in the $\mathrm{SCR}$ catalyst. The thermal model considered energy balances for the flowing exhaust gas and SCR brick. 
Equations were solved within longitudinal partitions of the SCR and results were validated with experimental data recorded at WVU.

Four distinct control scenarios were identified and computationally evaluated to determine an optimal system configuration, including (1) pre-SCR NOx sensor, open-loop feed-forward control, (2) post-SCR NOx sensor, closed-loop feed-back PD (proportional-derivative) control, (3) pre- and post-SCR NOx sensors, closed-loop feed-back PID (proportional-integral-derivative) control, and (4) pre-SCR NOx sensor, model-based control. The chosen configurations illustrated differences between a highly instrumented and highly engineered system. Emissions performance was evaluated over two transient on-road test cycles (heavy-duty Federal Test Procedure (FTP), ACES (Advanced Collaborative Emissions Study) HHDDT_S (High-Speed Cruise)) and one steady-state marine test cycle (International Council of Marine Industry Associations (ICOMIA) E5), implying broad applicability. The evaluation process was characterized by overall NOx reduction percentage, maximum ammonia slip (parts per million, ppm), and average ammonia slip (ppm). The complexity of the sensor configuration and control strategy calibration were evaluated, as well as how adaptable a given configuration was to variations in engine behavior and sensor inputs. Finally, total cost was compared between each control configuration, considering system capital, maintenance, operation, control strategy engineering, and system calibration. A final dollar per ton of NOx reduced was presented for each control configuration assuming a six year operational cycle in marine and on-road applications. Based on the collective emissions, complexity, and cost analyses, a final control configuration was recommended.

\subsection{Contributions}

There is a great deal of research currently being conducted on methods of NOx control in order to meet the impending US 2010 standards for new on-road heavy-duty diesel engines. Urea-SCR technology is at the forefront of this research, offering a viable and cost-effective method of NOx control in many application segments. Less focus however has been placed on controlling emissions from older model year engines still in operation. As stated, these engines contribute significantly to diesel NOx emissions. Since it is not economically or logistically feasible to replace all older engines still in operation, emissions control retrofit offers an excellent solution. In the coming years more emphasis will likely be placed on universal retrofit packages, such as the urea-SCR system considered in this dissertation, in order to further reduce global diesel emissions. As the market for retrofit technologies broadens, the research presented here may be beneficial for future aftertreatment system developers. Moreover, the modeling results and cost analyses provide additional information regarding the chemistry, thermodynamics, and economics of urea-SCR to the scientific community. By presenting specific tabulated model parameter values, others can reproduce the modeling approaches and apply them in other applications. 


\section{Chapter 2: Literature Survey}

A survey of relevant literature was performed, highlighting general diesel engine emissions information, emissions standards for on-road and marine applications, emissions reduction technologies, retrofit applications, engine and SCR modeling approaches, and SCR control strategies. This information provides a basis for the completed dissertation work.

\subsection{Diesel Engine Emissions}

It is well established that diesel engines can achieve better fuel economy compared to gasoline sparkignition (SI) engines. In addition, they may offer a longer lifespan, produce more torque, and utilize less refined fuel compared to gasoline. The downside is that diesel engine emissions are difficult to control to a level similar to SI gasoline engines. Recent standards have significantly reduced emissions from light and heavy-duty diesel vehicles. However as diesel engine emissions standards continue to tighten, they become more difficult to meet. Previously, diesel engine emissions could be reduced using in-cylinder technologies such as exhaust gas recirculation and common rail fuel injection. For the future US 2010 regulations to be met, aftertreatment systems and fuel quality changes will have to be implemented.

Diesel engines produce emissions that have been shown to be harmful to people, animals, and the environment. The emissions produced are the result of the high temperature, chemical reaction of a hydrocarbon fuel and air. In a modern diesel engine, a turbocharger is employed to improve efficiency and power, delivering more air to the cylinder. Diesel engines are typically operated at lean air-to-fuel (AF) ratios between 18 and 70 [11,12,13]. As a result, conventional three-way catalytic converters cannot be used to control emissions. Very high AF ratios are possible in a diesel engine because of the nonhomogeneous fuel-air mixture in the cylinder [11]. The non-homogeneity allows ignition to occur in rich zones within the cylinder and propagate through the remaining leaner fuel-air mixture. This nonhomogeneity is also partly responsible for high NOx and PM emissions.

The main emissions that are produced from a diesel engine include carbon monoxide (CO), carbon dioxide $\left(\mathrm{CO}_{2}\right)$, hydrocarbons ( $\left.\mathrm{HC}\right)$, NOx, water vapor $\left(\mathrm{H}_{2} \mathrm{O}\right)$, and PM. Of these emissions, all are regulated by the EPA except water vapor and $\mathrm{CO}_{2}$ [14]. Water vapor is emitted from diesel engines as a result of the chemical reaction of fuel and air, but does not directly have any negative effects on people or the environment. $\mathrm{CO}_{2}$ could have an impact on the environment and is considered a greenhouse gas today along with methane $\left(\mathrm{CH}_{4}\right)$, nitrous oxide $\left(\mathrm{N}_{2} \mathrm{O}\right)$, and fluorinated gases [15]. Greenhouse gases are gases that trap heat in the atmosphere [15]. Some occur naturally in the environment and others are manmade. While $\mathrm{CO}_{2}$ emissions from diesel engines are not directly regulated by the EPA, greenhouse gas inventories are collected and submitted to the United Nations in accordance with the Framework Convention on Climate Change [15]. 
Of the harmful emissions emitted from diesel engines, legislation has focused on NOx and PM because of their contributions to global emission inventories and their potential to do harm to people and the environment. These emissions are also the most difficult to decrease. There are additional categories of unregulated species found in diesel exhaust that have the potential to cause negative health and environmental impact. But the concentration of these species is so low in diesel exhaust that it is near the ambient background levels and at or below the limit of detection using modern analyzers [16]. Some of these species include carbonyls, dioxins, metals, volatile organic compounds (VOC), soluble organic fraction (SOF), and polycyclic aromatic hydrocarbons (PAH) [16]. Many of these species comprise a portion of $\mathrm{HC}$ or PM emissions, and thus are accounted for in their measurement. The inclusion of such species in HC or PM measurements is classified as total hydrocarbons (THC) or total particulate matter (TPM).

\subsubsection{Carbon Dioxide}

Carbon dioxide is produced in large concentrations from any hydrocarbon fueled engine and is proportional to fuel consumption. The question of whether $\mathrm{CO}_{2}$ emissions are harmful to the environment has been heavily debated. At the time of writing there is substantial discussion as to the nature and cause of global climate change, but many scientists and nations have agreed that $\mathrm{CO}_{2}$ is implicated and is the largest contributor among diesel exhaust constituents [2]. As previously stated, $\mathrm{CO}_{2}$ reduction is important to global greenhouse gas inventories, yet $\mathrm{CO}_{2}$ emissions from diesel engines are not directly regulated. Diesel engines have high fuel economy and thus show $20-30 \%$ lower $\mathrm{CO}_{2}$ emissions when compared to similar gasoline SI engines [17]. The reduction of diesel engine $\mathrm{CO}_{2}$ emissions can be achieved directly by increasing engine efficiency or indirectly through the use of renewable or low-carbon resources. Although $\mathrm{CO}_{2}$ emissions from diesel engines have been linked to negative environmental effects, they do not pose a health threat to people through open exposure.

\subsubsection{Carbon Monoxide}

Carbon monoxide is a colorless, odorless, poisonous gas. It is produced when there is not enough oxygen to convert all fuel carbon to $\mathrm{CO}_{2}$ as a result of fuel-rich operation (gasoline SI engines), incomplete combustion, or incomplete fuel-air mixing [3,11,12]. Since diesel engines operate with lean AF ratios, they produce very little $\mathrm{CO}$. The $\mathrm{CO}$ that is produced by diesel engines is generated in the locally fuel-rich zones within the cylinder. In the United States, one third of the nation's $\mathrm{CO}$ emissions are produced by transportation sources, with the largest contributor being motor vehicles [3]. In urban areas, upwards of $90 \%$ of the $\mathrm{CO}$ pollution is from motor vehicles [3].

Carbon monoxide enters the body by inhalation, entering the blood through the lungs. Once in the blood, it forms carboxyhemoglobin, which inhibits the blood's capacity to carry oxygen to organs and tissues [3]. People with heart disease, infants, elderly, and those with respiratory illnesses are particularly sensitive. Once inhaled, CO may cause chest pain, impairment of visual perception, exercise capacity, manual 
dexterity, learning functions, and eventually death [3]. Carbon monoxide emissions from gasoline and diesel vehicles are closely regulated by the EPA, yet have not seen as sharp a reduction as NOx and PM.

\subsubsection{Oxides of Nitrogen}

The term oxides of nitrogen is used to describe a very reactive group of gases containing nitrogen and oxygen in varying amounts [4]. NOx is produced when the high temperature combustion process within the cylinder of a diesel engine causes some normally stable $\mathrm{N}_{2}$ molecules to dissociate into monatomic nitrogen $\mathrm{N}$ (Equation 1), which then combines with the reacting oxygen. This dissociation is highly dependent on temperature, with a more significant amount of monatomic nitrogen produced in the 2500-3000 K range [11].

$N_{2} \Leftrightarrow 2 N$

Equation 1

Because of this, high in-cylinder temperatures are the primary cause of NOx formation. Of the NOx formed in diesel compression-ignition (CI) engines, $70-90 \%$ is in the form of nitric oxide (NO), while nitrogen dioxide $\left(\mathrm{NO}_{2}\right)$ is also present in significant levels [11,12]. There are several formation mechanisms responsible for NOx emissions from a diesel engine. As stated, NO is the primary oxide of nitrogen formed. The most important is the thermal mechanism, also known as the extended Zeldovich mechanism. Associated with peak cylinder temperatures greater than $2000 \mathrm{~K}$, the three chemical reactions important to thermal NOx formation are [11,12]:

$$
\begin{array}{lr}
\mathrm{O}+\mathrm{N}_{2} \Rightarrow \mathrm{NO}+\mathrm{N} & \text { Equation 2 } \\
\mathrm{N}+\mathrm{O}_{2} \Rightarrow \mathrm{NO}+\mathrm{O} & \text { Equation 3 } \\
\mathrm{N}+\mathrm{OH} \Rightarrow \mathrm{NO}+\mathrm{H} & \text { Equation 4 }
\end{array}
$$

The critical time period for NO formation is when the gas temperature is at a maximum, occurring between the start of combustion and the time when peak cylinder pressure occurs [12]. Combustion at the beginning of this time period is especially important, since the NO reaction rates are subsequently increased as the cylinder pressure increases [12]. After this time period, temperature and pressure decrease, freezing the NO chemistry. This freezing effect occurs mainly in diesel engines, meaning that less decomposition of NO occurs compared to gasoline SI engines [12]. This behavior leads to maximum in-cylinder NO concentrations directly after maximum pressure.

Secondary to the above $\mathrm{NO}$ formation mechanism, $\mathrm{NO}_{2}$ is formed in significant quantities in diesel engines, usually at temperatures below $1200 \mathrm{~K}$, by the following two reactions $[11,12]$. 
The second $\mathrm{NO}_{2}$ reaction often occurs in reverse, converting some of the $\mathrm{NO}_{2}$ created by the first reaction back into $\mathrm{NO}$. Higher $\mathrm{NO} / \mathrm{NO}_{2}$ ratios occur when the $\mathrm{NO}_{2}$ created by the first equation (Equation 5) is quenched by mixing with cooler fluid [12]. This behavior often occurs at light load in diesel engines, where $\mathrm{NO}_{2}$ quantities may be highest, depending on engine speed.

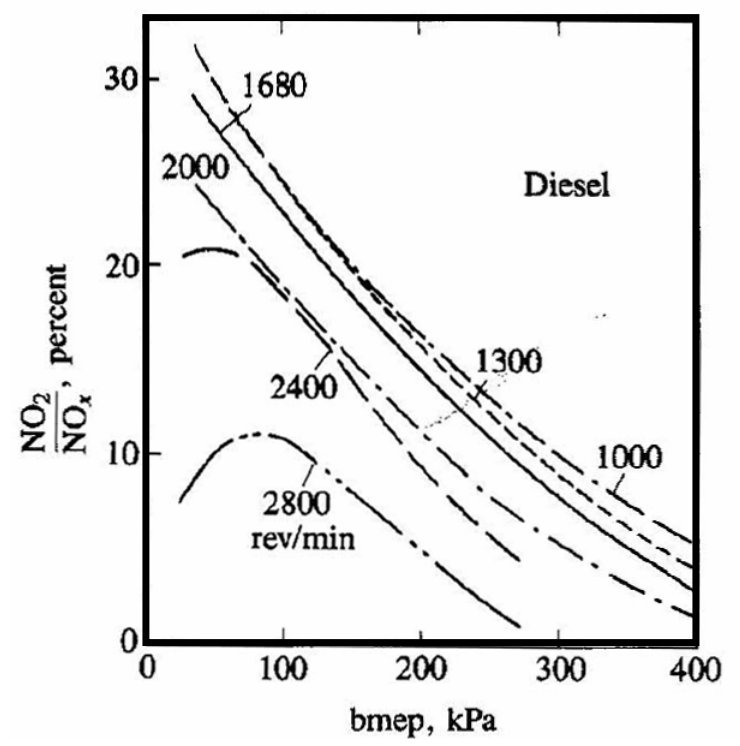

Figure 1. $\mathrm{NO}_{2}$ percent of total $\mathrm{NOx}$ in diesel exhaust $[12,18]$

The variation of $\mathrm{NO}_{2} / \mathrm{NOx}$ ratio as a function of load (bmep, brake mean effective pressure) and engine speed can be seen in Figure 1. Overall, the trend of higher $\mathrm{NO}_{2}$ at lower load is followed. However, when reaching higher engine speeds, this effect drops off at the lowest load points. $\mathrm{NO} / \mathrm{NO}_{2}$ ratios are often important for aftertreatment systems, where high $\mathrm{NO}_{2}$ concentrations may be desired.

In a typical diesel engine, there is a tradeoff between NOx and PM emissions. When controlling emissions in-cylinder, a reduction of one results in an increase of the other, and vice versa. Injection timing is a well known example of this behavior. Retarding injection timing can reduce NOx emissions, but only up to a certain point, when PM emissions become unacceptably high [13].

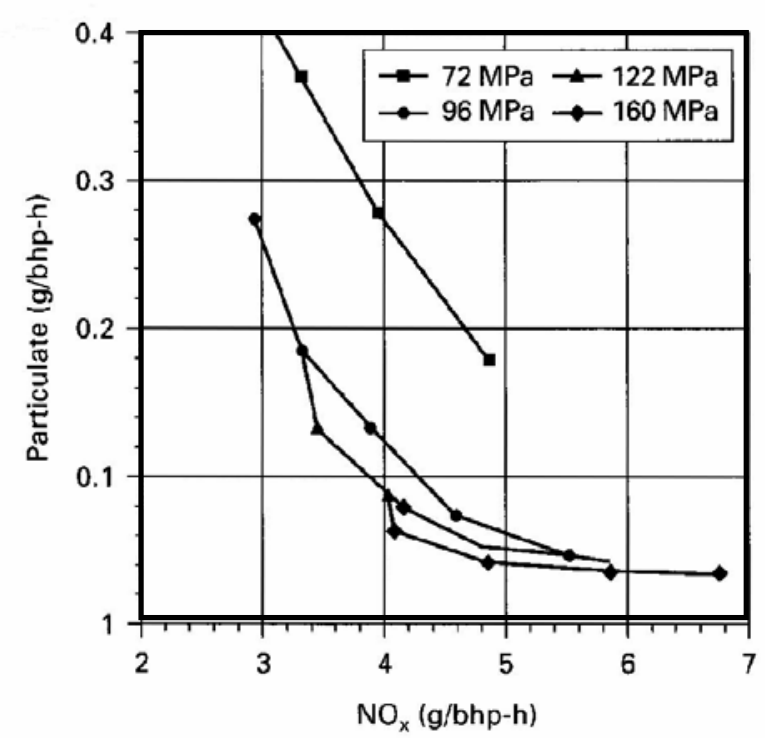

Figure 2. Effects of injection pressure and timing on PM-NOx tradeoff $[13,19]$

This NOx-PM tradeoff behavior can be seen in Figure 2 for a single-cylinder heavy-duty directinjection diesel engine operating at $1600 \mathrm{rpm}$ and $75 \%$ load $[13,19]$. Each injection pressure curve shows data points at $3^{\circ}$ intervals of retard, beginning with injection at $9^{\circ}$ before top-deadcenter. For all injection pressures, a decrease in one emission causes an increase in the other. 
Motor vehicles in general constitute $55 \%$ of the manmade NOx sources (see Figure 3) [7]. Oxides of nitrogen are colorless and odorless. NOx is a main contributor to ground level ozone, nitrate particles, acid aerosols, and $\mathrm{NO}_{2}$, all of which cause respiratory problems [4]. Ground level ozone is formed when $\mathrm{NOx}$ and VOCs (natural and manmade) react in the presence of sunlight [4].

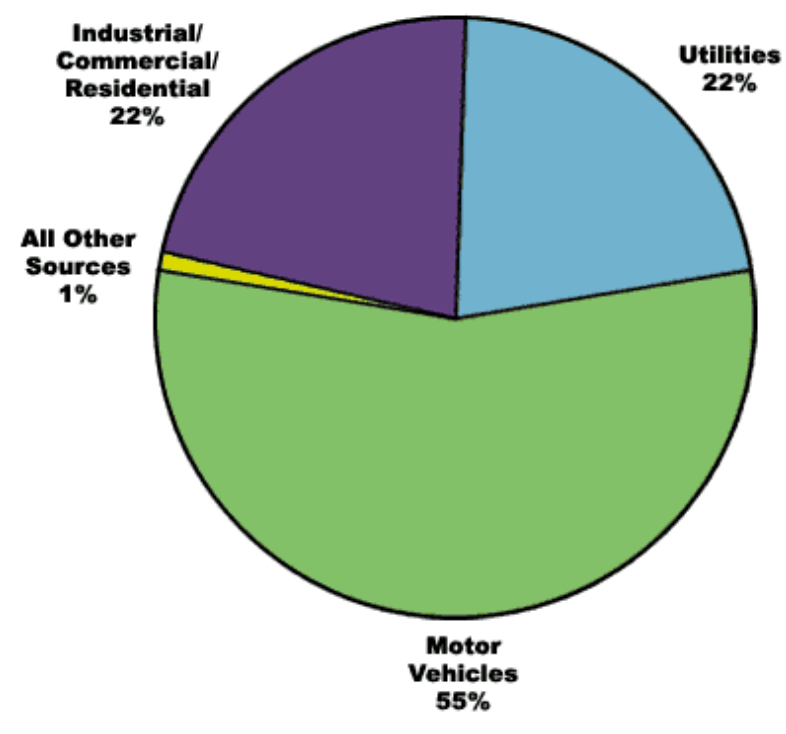

Figure 3. Manmade sources of NOx emissions (2003) [15]

Nitrogen dioxide along with particles in the air can be seen as a reddish brown layer over many urban areas [4]. This ground level ozone, or smog, can cause damage to lung tissue, reduction of lung function and can damage vegetation or reduce crop yields [4]. Being that $\mathrm{NO}_{2}$ is a greenhouse gas, NOx emissions also indirectly affect global greenhouse gas inventories. NOx contributes to the formation of

acid rain, soil nutrient overload that deteriorates water quality, atmospheric particles causing visual impairment, and the formation of toxic chemicals [4]. Acid rain is formed as NOx and sulfur dioxide react with other compounds in the atmosphere [4]. This acidic solution then falls to earth in the form of rain or snow, damaging buildings, cars, historic landmarks, and causing streams and lakes to become acidic and unstable for wildlife.

NOx has been linked to global climate change. The effects of NOx emissions are not only concentrated in urban areas. NOx and the pollutants formed by NOx can be transported over long distances following wind patterns [4]. These devastating health and environmental effects and the contribution that motor vehicles have to the manmade NOx emissions show why diesel NOx reduction is so important.

\subsubsection{Particulate Matter}

Diesel particulate matter is comprised of clusters of solid carbon particles (soot) with hydrocarbons and other traces species (sulfur, zinc, phosphorus, calcium, etc.) absorbed onto the surface [11,12]. Created in fuel-rich zones within the cylinder, maximum diesel PM emissions are generated during times of sudden acceleration or load, when a higher quantity of fuel is introduced. In older engines, this is often seen as a black plume from the exhaust pipe. Still, over $90 \%$ of the carbon particles generated during the combustion process are consumed within the cylinder, never reaching the exhaust [11]. Up to $25 \%$ of the carbon in soot and $80 \%$ of the extractable organic portion are derived from lubricating oil, with the remainder from fuel $(0.2-0.5 \%$ of fuel) $[11,12]$. 
There exists a distribution of size and position of soot particles within the cylinder. Soot particles may be arranged as clusters or chains of up to 4000 or more smaller spherules [11,12]. The spherules have sizes between 10 and 80 nanometers $(\mathrm{nm})$, with most being between 15 and $30 \mathrm{~nm}$ [11,12]. In direct-injection diesel engines, the highest concentration of PM exists in the fuel spray core, meaning pyrolysis of fuel is a significant source of soot [12]. Soot concentrations increase rapidly as combustion initiates, and then quickly decrease at the end of combustion as the rich spray core diffuses to leaner equivalence ratios [12].

Soot is formed at in-cylinder temperatures between 1000 and $2800 \mathrm{~K}$, and pressures between 50 and 100 atmospheres [12]. The PM formation process and structure is extremely complex, summarized in Figure 4 below.

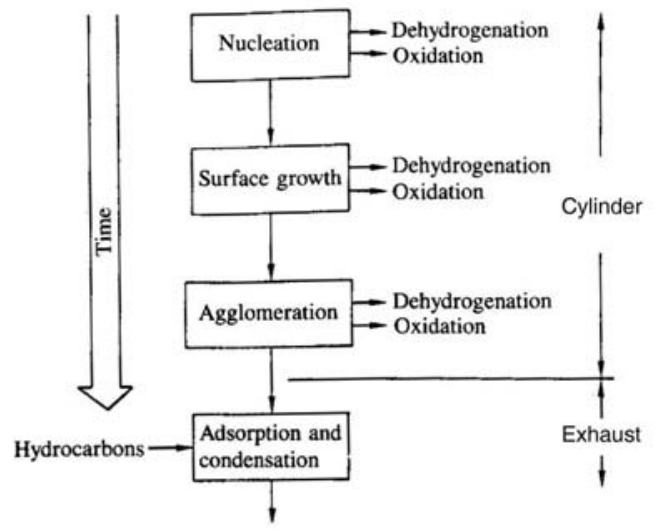

Figure 4. Processes leading to net production of diesel particulates $[12,20]$

Incomplete combustion of fuel due to rich local AF ratios allows a large number of very small particles (soot nuclei) to be formed by saturation of condensable precursor molecules (unsaturated hydrocarbons and PAH) [12,13]. After nucleation, surface growth occurs through condensation of high-boiling point components (SOF) [12,13]. Condensation and growth occur until the high-boiling point species are depleted or formation is ceased by in-cylinder conditions. A majority of soot volume is generated by surface growth. At light loads, SOF can make up 50\% of the total PM mass, while at higher temperatures where less condensation occurs, SOF may drop to $3 \%$ [11]. Once the particles have formed, the number of particles decreases and their size increases due to particle collisions during agglomeration [12]. Throughout the soot formation process, dehydrogenation and oxidation reactions also occur simultaneously [13]. The final step in the formation of PM involves the adsorption and condensation of hydrocarbons onto the soot particle surface [12]. This process mainly occurs once the products of combustion are exhausted from the cylinder.

Particulate matter size is directly linked to its potential for causing health problems. Health concerns are greatest for particle sizes smaller than 10 micrometers $(\mu \mathrm{m})$ since they generally are able to pass through the throat and nose and enter the lungs [21]. The EPA groups PM into two size categories. "Inhalable coarse particles", found near roadways and dusty industries, are less than 10 and greater than $2.5 \mu \mathrm{m}$ in aerodynamic diameter [21]. "Fine particles," found in smoke and haze, are smaller than $2.5 \mu \mathrm{m}$ in aerodynamic diameter [21]. They are formed directly from sources such as forest fires, or can be formed when gases emitted from automobiles and power plants react in the air [21]. 
Diesel exhaust contains over 40 cancer-causing substances, most of which are absorbed by the PM particles [5]. California and the EPA have classified PM as a toxic air contaminant because of its potential to cause cancer, premature death, and other health effects [5]. The US EPA estimates that diesel PM contributes to 15,000 premature deaths due to respiratory and cardiovascular illnesses nationwide each year [6]. When comparing the average life expectancy of the cities with the highest and lowest PM levels, a difference of 1.5 years was found [2]. Of all pollutants and other sources of PM, diesel PM is of particular concern because it is typically emitted close to people, so high exposure is likely [5]. Typically, people with existing respiratory illnesses and children, who breathe $50 \%$ more air per pound of body weight than adults, are most affected by diesel PM [6]. Health risks from PM emitted by motor vehicles are of the greatest importance since fine PM $\left(\mathrm{PM}_{2.5}\right)$ from vehicles accounted for three times as many deaths as fine PM from coal combustion sources [2].

In addition to the numerous health risks that PM poses, it causes haze and contributes to the formation of ozone and acid rain [6]. PM has also been linked to global climate change [2]. Diesel PM causes a reduction in visibility as particles remain in the air. Diesel vehicles make up only around 5\% of road vehicles, yet are responsible for $10-75 \%$ of the visibility reduction in urban areas [2]. Even from an economic standpoint, the reduction of PM is logical, as the value of the health benefits of reducing diesel PM exceeds the control costs [2].

\subsubsection{Hydrocarbons}

Diesel CI engines have high combustion efficiency, typically around $98 \%$ [11]. Of the $2 \%$ combustion inefficiency, half appears as $\mathrm{HC}$ emissions, some of which are in the form of carbon particles and classified as PM [11]. The components in diesel fuel have higher molecular weights compared to gasoline, causing higher boiling and condensation temperatures, allowing some unburnt $\mathrm{HC}$ emissions to condense on the solid carbon particles [11]. In general, diesel engine HC emissions are low; on the order of one fifth that of a typical gasoline SI engine [11,12]. Additionally, HC emissions are much higher during idle or light-load operation compared to high-load operation [12].

Fuel HCs may pass through the engine unburned as a result of the local AF ratio, becoming too lean or too rich to auto-ignite or support a propagating flame [12]. HC emissions are formed in diesel engines through several main mechanisms, which can be seen for two injection strategies in Figure 5. Over-leaning occurs when the local AF ratio becomes leaner than the lean combustion limit during the ignition delay period [12]. Under-mixing occurs when the fuel and air do not sufficiently mix, creating very fuel rich and fuel lean zones within the combustion chamber. In particular, fuel rich zones are created by fuel remaining on the injector tip or within the nozzle holes, leading to a nozzle sac volume or 'dribble' from the injector nozzle $[11,12]$. This fuel evaporates and mixes slowly, some escaping the primary combustion process and leading to additional $\mathrm{HC}$ emissions [11,12]. Also, fuel-rich zones may also be created when over-fueling occurs, especially during transient engine behavior. 


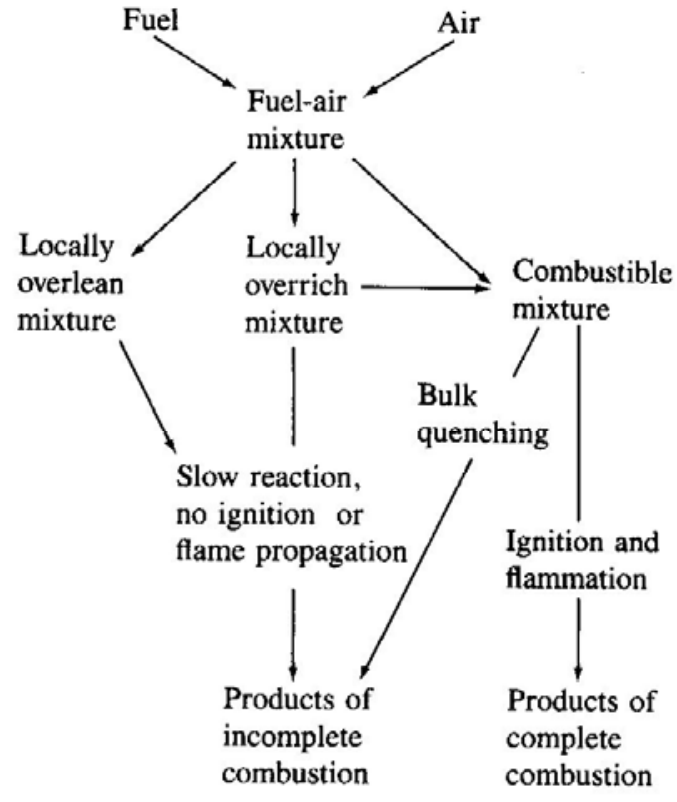

(a)

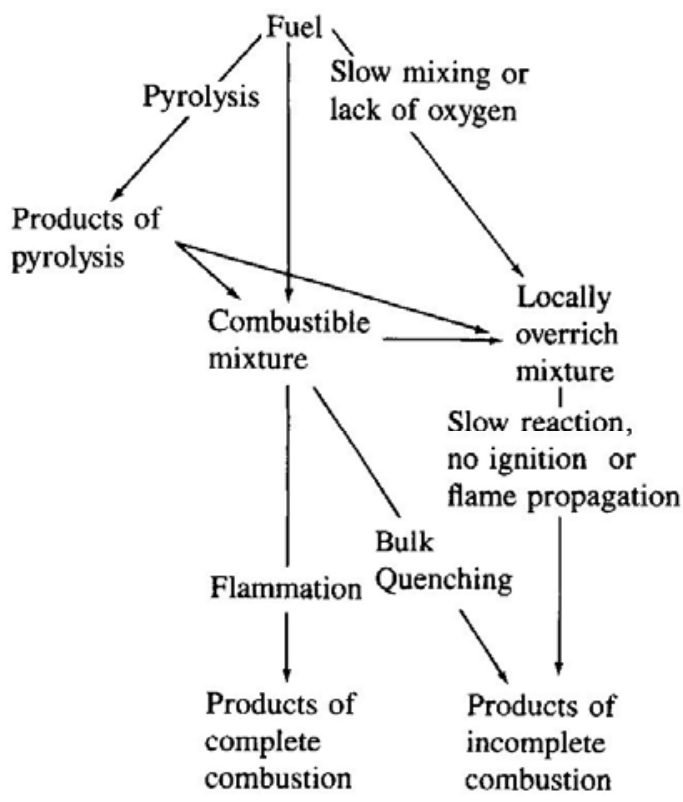

(b)

Figure 5. Diesel hydrocarbon formation schematic: (a) fuel injected during delay period; (b) fuel injected during combustion $[22,23]$

Quenching of the propagating flame front on the combustion chamber walls and piston can also leave a small volume of unreacted air and fuel, which is a source of $\mathrm{HC}$ emissions [12]. This quench layer thickness is typically on the order of tenths of a millimeter, and is thinnest at light load [11,12]. HC emissions may also arise as a result of fuel being trapped in crevice volumes, fuel absorbed in deposits on the combustion chamber walls, and fuel absorbed in oil on the combustion chamber walls $[11,12,13]$. The largest crevice volumes exist between the piston, piston rings, and cylinder wall, but are also present around intake and exhaust valve heads and head gasket.

Hydrocarbons found in diesel exhaust are very reactive. They often combine with other compounds found in the air to form smog and ozone (in the presence of NOx) [24]. Some hydrocarbon species are respiratory tract irritants and considered to be mutagenic, carcinogenic and toxic [24]. Additionally, by creating smog, hydrocarbon species are indirectly responsible for causing difficulty breathing, lung damage, and reduced cardiovascular function. 


\subsection{Overview of Emissions Standards}

The EPA regulates certain emissions from diesel engines. This includes diesel vehicles that operate on US roadways, diesel off-road vehicles (such as construction equipment), diesel locomotives, and marine vessels with diesel engines. The EPA organizes diesel vehicles into two categories: on-road, including light and heavy-duty vehicles, and non-road, including off-road vehicles, locomotives, and marine vessels. The emissions regulations for heavy-duty and non-road diesel vehicles are formulated in work-specific units, meaning that the allowable emissions levels are applicable to a variety of engine sizes and power levels.. Light-duty vehicles have emissions standards in distance specific units.

Diesel engine emissions standards are partially driven by air quality, which is monitored and regulated by NAAQS. A compliance designation is assigned, based on pollutant concentrations averaged over certain time periods. NAAQS regulate $\mathrm{CO}, \mathrm{NO}_{2}, \mathrm{PM}_{10}, \mathrm{PM}_{2.5}, \mathrm{SO}_{2}$, ozone, and lead [25]. Ozone concentrations are averaged over 8-hour and 1-hour time periods, in units of ppm, with the 8-hour standard being most recent and stringent. The 1-hour standard was revoked in 2005 except for in 8-hour ozone non-attainment Early Action Compact areas [25]. Particulate matter is averaged over a 24-hour period, in units of $\mu \mathrm{g} / \mathrm{m}^{3}$. The ozone and PM NAAQS are summarized in Table 1 below.

Table 1. Ozone and PM NAAQS [25]

\begin{tabular}{|c|c|c|}
\hline Pollutant & Level & Averaging Time \\
\hline \multirow{3}{*}{ Ozone } & $0.075 \mathrm{ppm}(2008)$ & 8-hour \\
\hline & 0.08 ppm (1997) & 8-hour \\
\hline & $0.12 \mathrm{ppm}$ & 1-hour \\
\hline $\mathrm{PM}_{10}$ & $150 \mu \mathrm{g} / \mathrm{m}^{5}$ & 24-hour \\
\hline $\mathrm{PM}_{2.5}$ & $35 \mu \mathrm{g} / \mathrm{m}^{3}$ & 24-hour \\
\hline
\end{tabular}

In the US, nearly 165 million people live in non-attainment zones for ground level ozone and 65 million people live in areas that do not meet PM air quality standards [7]. These zones are shown in Figure 6 and Figure 7, respectively, classified by the level of non-attainment. These areas must submit SIPs, outlining how they will come into compliance over a prescribed amount of time. Diesel emissions regulations have become increasingly strict in an attempt to reduce pollution by mobile sources and improve air quality.

In some non-attainment areas, reduction of diesel emissions may be included in the SIP. 


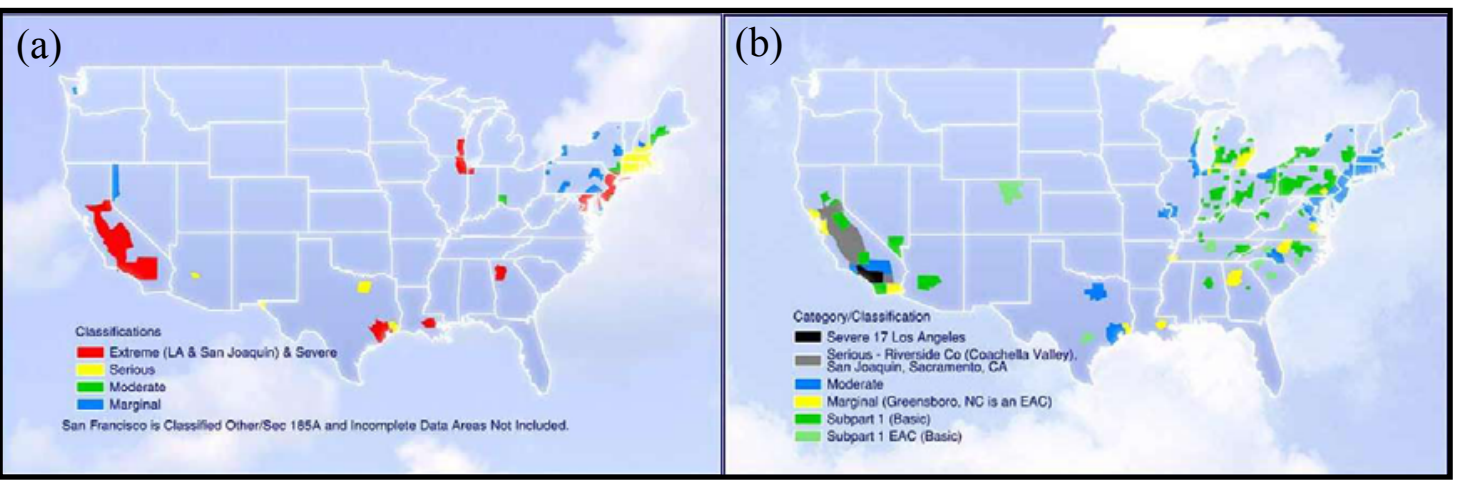

Figure 6. Ozone non-attainment zones: (a) 1-hour standard, (b) 8-hour standard [26]

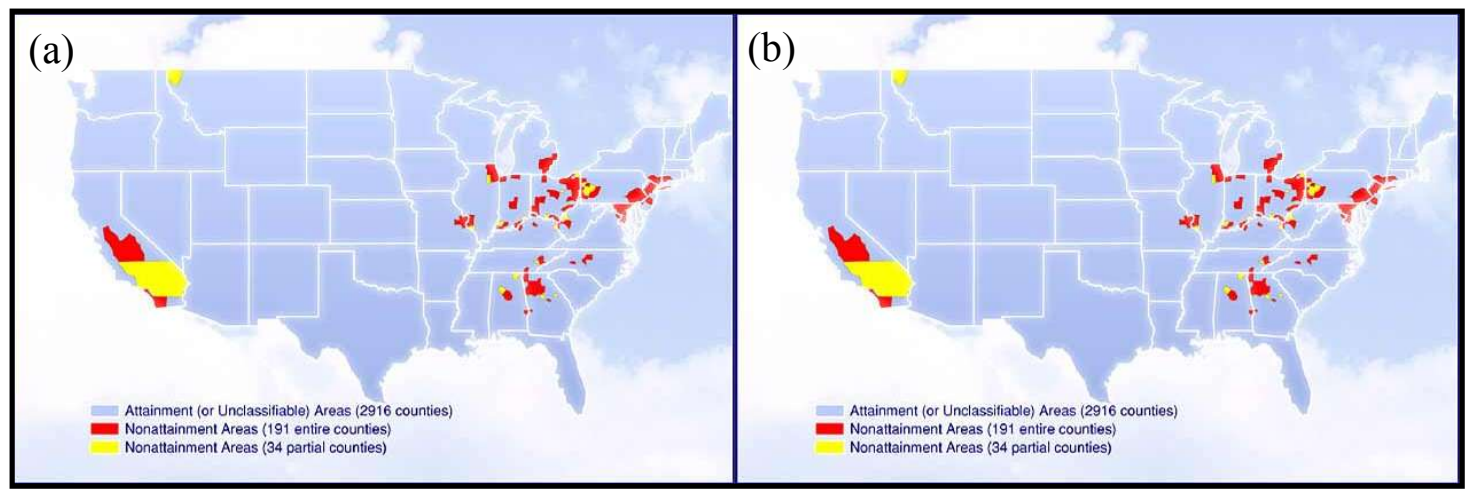

Figure 7. PM non-attainment zones: (a) $\mathrm{PM}_{10}$, (b) $\mathrm{PM}_{2.5}$ [26]

Vehicles do not solely emit emissions from the exhaust pipe as a result of burning fuel in a combustion process. Evaporative emissions are comprised of unburnt fuel that escapes from a vehicle's fuel tank, lines, and other components and evaporates into the atmosphere. These emissions are mainly VOCs [27]. They contribute to ground-level ozone and cause health and environmental problems just as exhaust emissions do. Similarly, there are standards and testing procedures to regulate them. These standards, not discussed here, can be found through the EPA.

Emissions regulations are also accompanied by fuel quality regulations. Beginning in 2006, on-road diesel fuel contained $97 \%$ less sulfur $(15 \mathrm{ppm})$ than it did in the past (500 ppm) [6]. This is particularly important for new on-road aftertreatment devices that require ultra-low sulfur diesel (ULSD) fuel. Combining these aftertreatment devices with ULSD fuel, new trucks and buses being produced after 2007 will be $95 \%$ cleaner than previous models [6].

\subsubsection{On-Road}

All diesel vehicles in operation on public roads today are grouped into classes based on the vehicle size, payload/weight, or use. Accordingly, different classes of vehicles must meet different emissions standards. Light-duty vehicles are classified as any passenger vehicle (non-truck) that seats twelve passengers or less 
[27]. Within this category are light-duty trucks. A light-duty truck is considered any vehicle with $8500 \mathrm{lb}$ or less Gross Vehicle Weight Rating (GVWR), which has a vehicle curb weight of less than $6000 \mathrm{lb}$, a frontal area of 45 square feet or less, and is designed primarily for transporting property, seating more than 12 people, or has features for off-road use [27]. A heavy-duty vehicle is any vehicle which has a GVWR of greater than $8500 \mathrm{lb}$ [27]. Within these two main designations, there are further subdivisions according to tested vehicle weight.

In addition to different emissions standards, there are different certification procedures for the two main onroad vehicle classes. Light-duty diesel vehicles (cars and trucks) are certified as a complete vehicle, testing tailpipe emissions from the vehicle on a chassis dynamometer while exercising a prescribed test cycle. Heavy-duty diesel vehicles however are certified as only an engine. This means that for certification purposes (non in-use) the emissions are measured directly from the engine while exercising a prescribed test cycle on an engine dynamometer, completely independent of the vehicle chassis.

Heavy-duty diesel engines are certified using the engine dynamometer FTP cycle. In addition, two other test procedures were required for heavy-duty diesel vehicles starting in 1998 [28,29]. The first is the Supplemental Emissions Test (SET), a steady-state test, similar to the European Stationary Cycle (ESC), designed to ensure emissions are within allowable limits during steady-state type operation [29]. For SET testing of 2004-2006 model year engines, a discree mode cycle is implemented, while 2007+ model year engines require a ramped mode cycle. The second is the Not-to-Exceed (NTE) testing procedure. This includes engine operation that occurs within pre-defined regions, known as the NTE zone, where engine emissions could be high.

Starting in the early 1990's, heavy-duty diesel engine manufacturers were installing engine control software that would switch to more fuel-efficient modes during times of steady highway operation or into lower emitting modes during chassis or engine dynamometer emissions testing [28,29]. As a result, the vehicles would produce emissions levels far above allowable limits as specified by the EPA, specifically NOx. Because of this, court settlements, called the Consent Decrees, were reached between the EPA, Department of Justice, California Air Resources Board (CARB), and engine manufacturers (Caterpillar, Cummins, Detroit Diesel, Volvo, Mack Trucks/Renault, and Navistar) making these "defeat devices" illegal $[28,29]$. Specifically the engine manufacturers were required to pay civil penalties and fines, upgrade existing engines to lower NOx standards, addition of the SET and NTE zones, and meeting 2004 emissions standards 15 months ahead of time [28,29].

For model year 1998+, the allowable limits for the SET were equal to the FTP and the NTE zone had limits of $1.25 \mathrm{x}$ FTP (with the exception of Navistar) [28,29,30]. For 2004+, the SET limits remained equal to the FTP and the NTE zone limits were changed to $1.5 \mathrm{x}$ FTP for engines with less than or equal to $1.5 \mathrm{~g} / \mathrm{bhp}-\mathrm{hr}$ 
NOx Family Emissions Limit (FEL) and 1.25 x FTP for engines with greater than $1.5 \mathrm{~g} / \mathrm{bhp}$-hr NOx FEL $[28,29,30]$.

Heavy heavy-duty diesel engine (HHDDE) emissions have gone through significant revisions over the years, with California having its own set of standards more strict than the federal requirements. Here, only the federal standards are presented for heavy-duty trucks and buses. Table 2 shows the emissions standards since 1988 for heavy-duty diesel engines, including the standards specific to urban buses for years 1993 through 1998. It should be noted that for model year 2004 engines (effective October 2002), there were two certification options, one measuring only total non-methane hydrocarbons (NMHC) plus NOx and another measuring the two separately. Additionally, the 2007 model year NOx and NMHC standards are not immediately effective in 2007. Rather they are being be phased in from 2007 to 2009 , mandating $1.1 \mathrm{~g} / \mathrm{bhp}$ hr NOx (fleet average) from 2007-2009 and $0.2 \mathrm{~g} / \mathrm{bhp}-\mathrm{hr}$ NOx in 2010 [14,28]. The 2007 PM standards however are effective starting in 2007 [14,28].

Table 2. On-road HHDDE emissions standards (g/bhp-hr) [14,28]

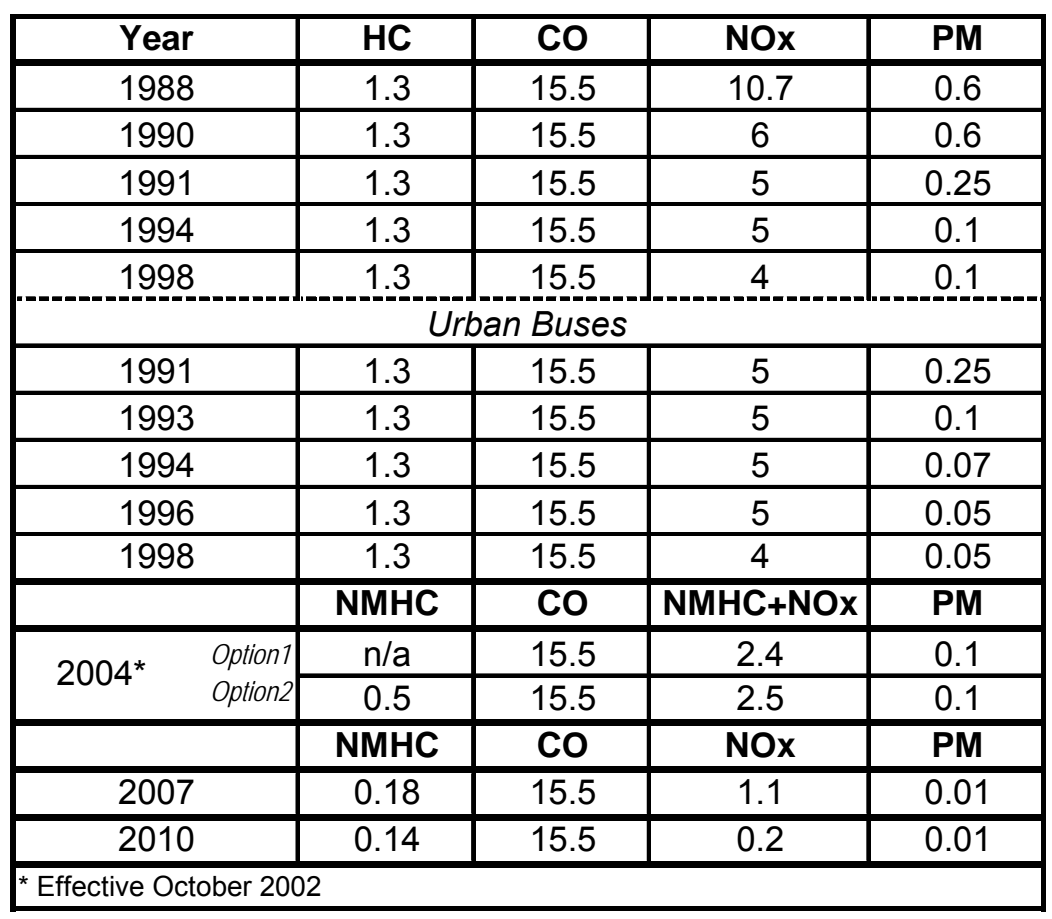

\subsubsection{Non-Road}

Non-road diesel vehicles include construction equipment, agricultural equipment, material handling equipment, industrial equipment, and utility equipment [7]. Non-road diesel vehicles are certified as engines in a manner similar to heavy duty on-road diesel vehicles. These engines must meet fairly modest emissions requirements when compared to on-road vehicles and thus continue to emit large amounts of PM and NOx. 
For example, a new 2004 model year engine with $350 \mathrm{hp}$ would be required to comply with a NOx+NMHC standard of $2.5 \mathrm{~g} / \mathrm{bhp}-\mathrm{hr}$ and PM standard of $0.1 \mathrm{~g} / \mathrm{bhp}-\mathrm{hr}$ in an on-road application. However for the same engine in a non-road application, a $4.8 \mathrm{~g} / \mathrm{bhp}-\mathrm{hr} \mathrm{NOx}+\mathrm{NMHC}$ standard and $0.15 \mathrm{PM}$ standard must be met [7]. The non-road NOx+NMHC and PM standards for such an engine are nearly equivalent to the NOx and PM on-road standard for a 1994 engine. Depending on engine model year, non-road emissions standards lag on-road standards by as much as 5-10 years. It is noted that different test cycles are used between onroad and off-road certification tests.

In 1994, Tier 1 non-road diesel engine emissions regulations were adopted for engines greater than $50 \mathrm{hp}$, except those used in marine vessels or locomotives [7]. In 1998, more stringent emissions standards were adopted for NOx, HC, and PM from diesel engines [7]. The first set of standards for non-road diesel engines less than $50 \mathrm{hp}$ was introduced, including marine engines. Tier 2 marine emissions standards were phased in from 2001 to 2006 [7]. Tier 3 and 4 emissions standards are the most stringent regulations to ever be imposed on marine diesel engines by the US EPA. The Tier 3 standards are being phased between 2009 and 2014, while the Tier 4 standards will be phased in from 2014 to 2017 [31]. One variation in these new standards is the differentiation between a standard power density and high power density engine, with a transition point at $47 \mathrm{hp} / \mathrm{dm}^{3}[31]$.

Beginning in 2004 along with the EPA's Clean Diesel Program, the allowable sulfur level in non-road diesel fuel began to be reduced from $3000 \mathrm{ppm}$ to the current $500 \mathrm{ppm}$, with the eventual goal of $15 \mathrm{ppm}$ [7]. When fully implemented, this corresponds to a $99 \%$ reduction in sulfur content. These fuel regulations along with more strict engine standards will reduce the PM and NOx emitted by non-road engines by $90 \%$ [7]. These regulations will have public health benefits and the EPA estimates that by 2030, controlling these emissions will prevent 12,000 premature deaths, 8,900 hospitalizations, and 1 million work days lost annually [7]. Because of the number of specific categories and sub-categories of non-road diesel engines, they will not all be presented here. Instead only the standards for marine diesel engines will be presented because of their relevance to this project. Additional information regarding non-road diesel engine emissions standards can be found through the EPA.

Marine engines are separated into several categories. Small marine diesel engines include those with less than $50 \mathrm{hp}$. Category 1 (C1) commercial includes diesel engines similar to land-based non-road diesel engines and Category 2 (C2) includes diesel engines similar to locomotive engines [32]. Category 3 includes large diesel engines used for propulsion power in ocean-going vessels. An engine is considered recreational if it is installed on a vessel used primarily for recreational purposes. These engines must be greater than $50 \mathrm{hp}$ and have less than $5 \mathrm{~L} /$ cylinder of displacement to be subject to the recreational standards [32]. 
Emissions standards for the largest Category 3 (C3) engines are specified by the International Maritime Organization (IMO) Maritime Pollution (MARPOL) and can be seen in Table 3. Introduced in 1997 for controlling NOx emissions, Tier 1 and 2 standards are globally applicable, while Tier 3 standards (NOx and oxides of sulfur (SOx)) are only applicable within specific "emissions control areas". Currently, SOx emissions control areas include the North Sea and Baltic Sea [31], with future application possible for NOx and SOx control in specific port areas. For each tier, the applicable NOx limit is specified according to the maximum engine speed $(n, \mathrm{rpm})$. The US EPA adopted the Tier 1 MARPOL standards for Category 3 engines beginning in 2003 [7].

Table 3. MARPOL Annex VI NOx emissions standards (g/bhp-hr) [31]

\begin{tabular}{|c|c|c|c|c|}
\hline \multirow{2}{*}{ Tier } & \multirow{2}{*}{ Date } & \multicolumn{3}{|c|}{ NOx Limit, g/bhp-hr } \\
\cline { 3 - 5 } & & $\mathrm{n}<130$ & $130 \leq \mathrm{n}<2000$ & $\mathrm{n} \geq 2000$ \\
\hline Tier I & 2000 & 12.73 & $34 \cdot \mathrm{n}^{-0.2}$ & 7.34 \\
\hline Tier II & 2011 & 10.79 & $33 \cdot \mathrm{n}^{-0.23}$ & 5.77 \\
\hline Tier III & 2016 & 2.55 & $6.74 \cdot \mathrm{n}^{-0.2}$ & 1.47 \\
\hline
\end{tabular}

The Tier 1 and Tier 2 marine emissions standards are summarized in Table 4 and Table 5, respectively. The Tier 3 emissions standards and their applicability are summarized below in Table 6 through Table 8. It should be noted that there are no Tier 2 emissions standards for $\mathrm{C} 3$ marine diesel engines. Tier 1 standards were voluntary for engines through model year 2003, and mandatory for engines $\geq 2.5 \mathrm{~L} /$ cylinder beginning in 2004 [32].

Table 4. Tier 1 non-road marine diesel engine emissions standards (g/bhp-hr) [14,32]

\begin{tabular}{|c|c|c|c|c|c|c|c|c|}
\hline Category & $\begin{array}{c}\text { Power } \\
\text { [hp] }\end{array}$ & $\begin{array}{l}\text { Displacement } \\
\text { [liter/cylinder] }\end{array}$ & \begin{tabular}{|c}
$\begin{array}{c}\text { Engine Speed } \\
{[\mathrm{rpm}]}\end{array}$ \\
\end{tabular} & \begin{tabular}{|c|} 
Tier 1 \\
Model Year \\
\end{tabular} & $\begin{array}{c}\text { NOx } \\
{[\mathrm{g} / \mathrm{bhp}-\mathrm{hr}]}\end{array}$ & \begin{tabular}{|c}
$\mathrm{HC}+\mathrm{NOx}$ \\
{$[\mathrm{g} / \mathrm{bhp}-\mathrm{hr}]$}
\end{tabular} & $\begin{array}{c}\text { PM } \\
\text { [g/bhp-hr] } \\
\end{array}$ & $\begin{array}{c}\text { CO } \\
\text { [g/bhp-hr] }\end{array}$ \\
\hline \multirow{3}{*}{ Small } & $\mathrm{hp}<10$ & --- & --- & 2000 & --- & 7.83 & 0.75 & 5.97 \\
\hline & $10 \leq \mathrm{hp}<25$ & --- & --- & 2000 & --- & 7.08 & 0.60 & 4.92 \\
\hline & $25 \leq \mathrm{hp}<50$ & --- & --- & 1999 & --- & 7.08 & 0.60 & 4.10 \\
\hline \multirow{3}{*}{$\begin{array}{c}1,2,3, \\
\text { including } \\
\text { recreational }\end{array}$} & $h p \geq 50$ & $\geq 2.5 \mathrm{l} / \mathrm{cyl}$ & $n \geq 2000$ & 2004 & 7.3 & -- & -- & -- \\
\hline & -- & --- & $130 \leq n<2000$ & 2004 & $34 \mathrm{xn}^{-0.2}$ & -- & -- & -- \\
\hline & --- & --- & $\mathrm{n}<130$ & 2004 & 12.7 & --- & --- & --- \\
\hline
\end{tabular}


Table 7. Tier 3 non-road marine diesel engine emissions standards, $\mathrm{C} 1$ commercial, high power density and recreational (g/bhp-hr) [31]

\begin{tabular}{|c|c|c|c|c|}
\hline $\begin{array}{c}\text { Power (P) } \\
\text { [hp] }\end{array}$ & $\begin{array}{c}\text { Displacement (D) } \\
\text { [liter/cylinder] }\end{array}$ & $\begin{array}{c}\text { NOx+HC } \\
\text { [g/bhp-hr] }\end{array}$ & \begin{tabular}{|c|} 
PM \\
[g/bhp-hr]
\end{tabular} & Date \\
\hline$P<25$ & $\mathrm{D}<0.9$ & 5.59 & 0.30 & 2009 \\
\hline \multirow{2}{*}{$25 \leq P<100$} & \multirow{2}{*}{$\mathrm{D}<0.9_{\mathrm{a}}$} & 5.59 & 0.22 & 2009 \\
\hline & & $3.50_{b}$ & $0.22_{b}$ & 2014 \\
\hline \multirow{5}{*}{$100 \leq P<4962$} & $D<0.9$ & 4.33 & 0.11 & 2012 \\
\hline & $0.9 \leq \mathrm{D}<1.2$ & 4.33 & 0.10 & 2013 \\
\hline & $1.2 \leq \mathrm{D}<2.5$ & 4.33 & 0.09 & 2014 \\
\hline & $2.5 \leq \mathrm{D}<3.5$ & 4.33 & 0.09 & 2013 \\
\hline & $3.5 \leq D<7$ & 4.33 & 0.08 & 2012 \\
\hline \multicolumn{5}{|c|}{$\begin{array}{l}a-P<100 \text { hp engines } D \geq 0.9 \text { liter/cylinder are subject to the corresponding } \\
100-4962 \text { hp standards. } \\
b \text { - Option: } 0.15 \text { a/bho-hr PM \& } 4.3 \text { a/bhp-hr NOx+HC in } 2014\end{array}$} \\
\hline
\end{tabular}

Table 8. Tier 3 non-road marine diesel engine emissions standards, C2 (g/bhp-hr) [31]

\begin{tabular}{|c|c|c|c|c|}
\hline $\begin{array}{l}\text { Power (P) } \\
\text { [hp] }\end{array}$ & $\begin{array}{c}\text { Displacement (D) } \\
\text { [liter/cylinder] }\end{array}$ & $\begin{array}{l}\text { NOx+HC } \\
{[g / b h p-h r]}\end{array}$ & \begin{tabular}{|c|} 
PM \\
{$[$ g/bhp-hr] }
\end{tabular} & Date \\
\hline \multirow{4}{*}{$P<4962$} & $7 \leq \mathrm{D}<15$ & 4.62 & 0.10 & 2013 \\
\hline & $15 \leq \mathrm{D}<20$ & 5.22 & $0.20_{a}$ & 2014 \\
\hline & $20 \leq \mathrm{D}<25$ & 7.31 & 0.20 & 2014 \\
\hline & $25 \leq \mathrm{D}<30$ & 8.20 & 0.20 & 2014 \\
\hline \multicolumn{5}{|c|}{$\begin{array}{l}\text { T Tier } 3 \mathrm{NOx}+H C \text { standards do not apply to } 2682-4962 \mathrm{hp} \text { engines. } \\
\text { a - } 0.25 \mathrm{~g} / \mathrm{bhp}-\mathrm{hr} \text { for engines below } 4425 \mathrm{hp} \text {. }\end{array}$} \\
\hline
\end{tabular}

In Table 8, it should be noted that there exists an optional Tier $3 \mathrm{PM} / \mathrm{NOx}+\mathrm{HC}$ standard at $0.10 / 5.8 \mathrm{~g} / \mathrm{bhp}-$ hr in 2012, and subsequently Tier 4 levels in 2015 [31]. In addition to Tier 3 NOx and PM emissions standards, existing Tier 1 and 2 CO standards (3.73-5.97 g/bhp-hr) remain applicable, grouped by engine power for all $\mathrm{C} 1$ and $\mathrm{C} 2$ marine diesel engines. 
Table 9. Tier 4 non-road marine diesel engine emissions standards, $\mathrm{C} 1 / 2$ engines [31]

\begin{tabular}{|c|c|c|c|c|}
\hline $\begin{array}{c}\text { Power (P) } \\
\text { [hp] }\end{array}$ & $\begin{array}{c}\text { NOx } \\
\text { [g/bhp-hr] }\end{array}$ & $\begin{array}{c}\text { HC } \\
\text { [g/bhp-hr] }\end{array}$ & $\begin{array}{c}\text { PM } \\
\text { [g/bhp-hr] }\end{array}$ & Date \\
\hline \multirow{2}{*}{$P \geq 4962$} & 1.34 & 0.14 & $0.09_{a}$ & $2014_{c}$ \\
\hline & 1.34 & 0.14 & 0.04 & $2016_{b, c}$ \\
\hline $2683 \leq \mathrm{P}<4962$ & 1.34 & 0.14 & 0.03 & $2014_{c, d}$ \\
\hline $1879 \leq \mathrm{P}<2683$ & 1.34 & 0.14 & 0.03 & $2016_{c}$ \\
\hline $806 \leq P<1879$ & 1.34 & 0.14 & 0.03 & $2017_{d}$ \\
\hline \multicolumn{5}{|c|}{$\begin{array}{l}\text { a - } 0.19 \mathrm{~g} / \mathrm{bhp} \text {-hr for engines with } 15-30 \text { liter/cylinder displacement. } \\
\text { b - Optional compliance start dates can be used within these model } \\
\text { years. }\end{array}$} \\
\hline \multicolumn{5}{|c|}{$\begin{array}{l}\text { d - The Tier } 3 \text { PM standards continue to apply for these engines in } \\
\text { model years } 2014 \text { and } 2015 \text { only. }\end{array}$} \\
\hline
\end{tabular}

\subsection{Survey of Emissions Reduction Technologies}

Emissions reduction technologies can be split into several distinct groups: engine design, advanced combustion strategies, fuel related, and exhaust aftertreatment. Starting in the 1970s and continuing through the end of the $20^{\text {th }}$ century, diesel engine emissions reductions were mainly accomplished through engine design. However, the impending US 2010 emissions standards have become so strict that engine design and fuel related technologies alone may not provide adequate NOx and PM reductions for diesel engines. While some advanced combustion strategies show potential for reducing diesel emissions to these levels, none appear ready for implementation in a production engine. Additionally, exhaust aftertreatment shows great promise as a retrofit technology, for controlling emissions from older engines still in operation. In conjunction with any emissions reduction technology, advanced control techniques will be required to meet impending emissions standards. This may involve applying traditional control methods or more advanced, model-based approaches [33]. Emissions reduction technologies are discussed in each of the four categories below.

\subsubsection{Engine Design}

Significant emissions reductions from diesel engines were first achieved by improving mixture formation and using higher intake pressures [11]. This was accomplished by increasing air turbulence, generating swirl through intake port design and optimized combustion chamber geometry [11]. By increasing turbulence and optimizing combustion chamber design, nearly all harmful emissions produced in a diesel engine are reduced. Compression ratio is another design parameter that affects emissions. Diesel compression ratios are typically between 12 and 24 [11]. Traditionally, this tended to be above the optimal value for efficiency and emissions to ensure cold-start reliability [10]. Through advances in engine design, cold start reliability has been improved, allowing lower compression ratios. Some engine manufacturers have even developed variable compression ratio mechanisms, allowing the compression ratio to change 
with engine speed and load. These mechanisms tend to be fairly complex, and none have gone into production to date. These and other design parameters are shown below in Table 10, along with their effect on brake-specific fuel consumption (BSFC), brake-specific NOx (BSNOx), brake-specific hydrocarbons (BSHC), and particulate matter.

Table 10. Emission trends with engine geometry [13]

\begin{tabular}{|c|c|c|c|c|}
\hline Design Parameter & BSFC & BSNOX & BSHC & PM \\
\hline \multicolumn{5}{|l|}{ Compression ratio } \\
\hline Stroke/bore ratio & & & & \\
\hline \multicolumn{5}{|l|}{ Piston-to-head clearance } \\
\hline \multicolumn{5}{|l|}{ Crevice volumes } \\
\hline \multicolumn{5}{|l|}{ Piston crater shape } \\
\hline \multicolumn{5}{|l|}{ Swirl } \\
\hline \multicolumn{5}{|l|}{ Port geometry } \\
\hline \multicolumn{5}{|l|}{ Ring pack } \\
\hline \multicolumn{5}{|l|}{ Valve size and number } \\
\hline \multicolumn{5}{|l|}{ Valve timing } \\
\hline Controllability & & $\rightarrow$ & $\rightarrow$ & $\rightarrow$ \\
\hline \multicolumn{5}{|c|}{$\begin{array}{l}\text { Symbol key: No effect } \longrightarrow \text {; increase } \rightarrow \text {; decrease } \longrightarrow \text {; accelerating } \\
\text { increase } \underset{A}{-1} \text {; decelerating increase } \rightarrow \text {; decelerating decrease } \longrightarrow \text {; } \\
\text { accelerating decrease } \longrightarrow \text {; reaches an extremum }\end{array}$} \\
\hline
\end{tabular}

Another aspect of engine design related to emissions reduction is the fuel system. This includes injector placement and design, higher injection pressures for better atomization, and better control over injector timing. An important aspect of the fuel delivery system related to emissions reduction is electronic control of the components.

The fuel injector nozzle design and fuel pressure determine the spray pattern of the injector [11]. Optimization of the fuel injector nozzle design (including number and size of holes) reduces or eliminates unintended release of fuel from the nozzle. Good injector design reduces sac volume to limit injection "dribble" [33]. Sac volume may include fuel hanging from the injector tip and the volume of liquid fuel inside the injector holes. By limiting the introduction of fuel droplets, overly rich zones near the injector are reduced, decreasing PM, NOx, and $\mathrm{HC}$ emissions. Increased fuel pressure has been achieved by using high pressure common rail direct injection systems in both heavy and light-duty vehicles. Typically these injection pressures are upwards of 20,000 psi, allowing for complete atomization of the fuel. 
The injection strategy can affect emissions greatly and typically there is a tradeoff between NOx and PM emissions (see Figure 2) [33]. In particular, retarded injection timing is sometimes used to control NOx emissions. However it will traditionally cause a decrease in fuel economy and an increase in PM emissions $[13,33]$. Using multiple injections per engine cycle or controlling the flow of fuel during injection can also reduce PM and NOx emissions. Controlling the flow of fuel during injection, known as rate shaping, can change the heat release pattern within the cylinder to find an optimal balance of power and emissions. These and other fuel system design parameters are shown below in Table 11, along with their effect on BSFC, BSNOx, BSHC, and particulates.

Table 11. Emission trends with fuel system design [13]

\begin{tabular}{|c|c|c|c|c|}
\hline Design Parameter & BSFC & BSNOX & BSHC & PM \\
\hline \multicolumn{5}{|l|}{ High-pressure injection } \\
\hline \multicolumn{5}{|l|}{ Retarded timing } \\
\hline \multicolumn{5}{|l|}{ Rate shaping } \\
\hline Pilor injection & & & & \\
\hline Dual fuel injection & & & & \\
\hline \multicolumn{5}{|l|}{ Sac volume } \\
\hline \multicolumn{5}{|l|}{ Number and size of holes } \\
\hline \multicolumn{5}{|l|}{ Spray angle } \\
\hline \multicolumn{5}{|l|}{ Eccentricity of nozzle } \\
\hline \multicolumn{5}{|l|}{ Tip projection } \\
\hline \multicolumn{5}{|l|}{ Air assist } \\
\hline \multicolumn{5}{|l|}{ Impingement on pedestal or bowl } \\
\hline \multicolumn{5}{|l|}{ Quality and uniformity of injection } \\
\hline \multicolumn{5}{|l|}{ Controllability } \\
\hline \multicolumn{5}{|c|}{ 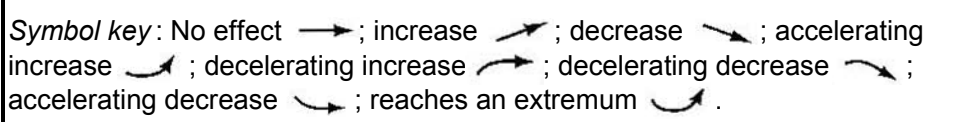 } \\
\hline
\end{tabular}

Most modern on-road and $\mathrm{C} 1 / \mathrm{C} 2$ marine diesel engines employ turbochargers. Turbochargers rely on the pressure of exhaust gases to drive a turbine, which in turn drives a compressor. The intake air passes through the compressor, allowing more air to enter the cylinder. Increasing the amount of air entering the combustion chamber through turbocharging allows additional fuel to be introduced for higher power output. However this also heats the intake air, increasing NOx formation [33]. Cooling the charge air through intercooling can decrease NOx emissions but may cause an increase in PM if the temperature is overly decreased. By optimizing this temperature, lower NOx and PM can be achieved. Better air cooling 
in turbocharged-aftercooled engines and electronic control of the diesel engine and its subsystems has allowed for increased emissions reduction potential.

During periods of quick acceleration the driver is requesting more air and fuel to be delivered to the cylinder in order to increase power output and maintain the appropriate AF ratio. Electronic control of the engine allows fuel delivery to be nearly instantaneous. However to increase airflow, the turbocharger must overcome inertia. A fixed geometry turbocharger cannot typically keep up with fueling, causing a delay in power known as turbocharger lag. Turbocharger lag can produce large amounts of PM because additional fuel is introduced before the air, causing rich conditions. By introducing variable geometry or sequential turbochargers, turbocharger lag can be substantially reduced along with the PM emissions associated with it. Between 1980 and 1990, advances in fuel injection systems, air charging systems, combustion chamber design, and electronic control of engine components led to approximately a $90 \%$ reduction in PM, $75 \%$ reduction in NOx and additional reductions in $\mathrm{HC}$ and $\mathrm{CO}$ emissions [10].

Exhaust gas recirculation (EGR) is a NOx reduction strategy that involves displacing some of the engine's intake air with inert exhaust gas. By diluting the fuel air mixture with inert gases, the peak combustion temperatures are reduced, thereby hindering the formation of thermal NOx. Often times, the EGR supply is cut off at idle and very high engine speeds to prevent unstable combustion at low speed and a loss of performance at high speed. EGR is more difficult in diesel engines compared to gasoline engines because of the abrasiveness of the PM in the exhaust stream and the recirculation of acidic gases with high sulfur fuels. This may cause accelerated wear of the engine and turbocharger as well as forming deposits in the EGR and intake systems. Diesel applications typically use a cooled EGR system which may reduce fuel economy as a result of increased cooling burden. In addition, since the amount of oxygen available to react with the fuel is decreased, incomplete combustion may occur, causing an increase in HC emissions. As previously stated, when NOx is decreased, there is a corresponding increase in PM emissions. In order to circumvent this, a low PM strategy should be implemented in conjunction with EGR. Despite these complications, EGR is a very effective method of NOx control, achieving a 30-50\% reduction [10].

\subsubsection{Advanced Combustion Strategies}

Another engine design strategy being researched by government, engine manufacturers, universities, and research agencies worldwide is homogeneous charge compression ignition (HCCI) combustion. HCCI is a combustion technique used to reduce emissions from a CI engine while maintaining high efficiency, similar to that of a compression-ignition direct-injection (CIDI) diesel engine [34]. HCCI utilizes a homogeneous air/fuel mixture, similar to spark ignited systems, but the combustion is initiated by fuel auto-ignition due to the increase in temperature associated with the compression stroke. This process is characterized by the absence of flame propagation, the almost simultaneous reaction of the entire cylinder charge, rapid heat release rates and small pressure coefficient of variation between combustion events [35]. The elimination of highly heterogeneous zones, which is a characteristic of conventional CI combustion, leads to a reduction 
in pollutant formation, especially PM. The quasi-homogeneous operation generates lower gas temperatures and NOx, compared to both SI and CI systems.

Although HCCI has emerged as an alternative to SI and CI combustion, there are still technical barriers involved with the development of the HCCI engine, including extending its operational range to higher power densities, gaining complete control over ignition of the fuel/air mixture, and handling transient conditions [35]. For SI engines, the ignition timing is controlled by the spark timing and for CI engines by the fuel injection timing. The rate of heat release is controlled in SI engines by finite flame propagation and in CI engines by the rate of fuel injection [12]. In the case of HCCI, the combustion process is controlled by chemical kinetics, which are a function of the charge composition and temperature-pressure history [36]. The control over ignition timing and the rate of heat release rely on the ability to control these parameters [34].

Currently, HCCI is limited to low to mid power engines. Two general directions have been investigated in an effort to extend the operational range of HCCI and to provide the required control: modifying air/fuel mixture properties and modifying engine operation and design parameters [37]. The final purpose of each of these strategies is to modify the composition and/or temperature of the in-cylinder charge. While at the time of writing there are no production $\mathrm{HCCI}$ engines available, significant research is being performed and the HCCI engine may offer an alternative to aftertreatment devices for meeting future emissions regulations.

\subsubsection{Alternative Fuels and Additives}

Diesel fuel and lubricating oils also affect diesel emissions. Because of this, advances in diesel fuel technology accompany engine design and aftertreatment systems. By far the most important trend in diesel fuel properties is the reduction of sulfur content. In 2006, the sulfur content was reduced from $500 \mathrm{ppm}$ to $15 \mathrm{ppm}$ [6]. While this reduction in sulfur content reduces sulfur dioxide and sulfate particulate emissions, the ultimate goal of ULSD fuel is the implementation of aftertreatment devices, which show sensitivities to sulfur. The cetane number of the fuel affects the ignition delay, with most commercially available fuels having cetane numbers between 40 and 55 [12]. The cetane number of the fuel is important so that ignition timing may be optimized for emissions and power output.

Reductions in PM can also be achieved by changing the composition of the lubricating oil and reducing the amount of oil consumed. This may be done by replacing metal additives with non-metallic compounds to reduce the noncombustible portion of the oil and changing the temperature at which the oil evaporates, reducing the contribution this has to PM $[12,13]$. Additionally, additives may be used to lower emissions or prevent the buildup of undesired compounds on engine parts. Several diesel additives and their function are summarized below in Table 12. 
Table 12. Automotive diesel fuel additives [13,38]

\begin{tabular}{|c|c|c|}
\hline Additive & Type & Function \\
\hline Detergents & $\begin{array}{l}\text { Polyglycols, basic nitrogen- } \\
\text { containing surfactants }\end{array}$ & $\begin{array}{l}\text { Prevent injector deposits, } \\
\text { increase injector life }\end{array}$ \\
\hline Dispersants & $\begin{array}{l}\text { Nitrogen-containing } \\
\text { surfactants }\end{array}$ & $\begin{array}{l}\text { Peptize soot and products of fuel } \\
\text { oxidant; increase filter life }\end{array}$ \\
\hline Metal deactivators & Chelating agents & Inhibit gum formation \\
\hline $\begin{array}{l}\text { Rust and corrosion } \\
\text { inhibitors }\end{array}$ & $\begin{array}{l}\text { Amines, amine carboxylates, } \\
\text { and carboxylic acids }\end{array}$ & $\begin{array}{l}\text { Prevent rust and corrosion in } \\
\text { pipelines and fuel systems }\end{array}$ \\
\hline Cetane improvers & Nitrate esters & Increase cetane number \\
\hline Flow improvers & Polymers, wax crystal & Reduce pour point modifiers \\
\hline $\begin{array}{l}\text { Antismoke additions or } \\
\text { smoke suppressants }\end{array}$ & Organic barium compounds & Reduce exhaust smoke \\
\hline Oxidation inhibitors & Low-molecular weight amines & $\begin{array}{l}\text { Minimize deposits in filters and } \\
\text { injectors }\end{array}$ \\
\hline Biocides & Boron compounds & $\begin{array}{l}\text { Inhibit growth of bacteria and } \\
\text { microorganisms }\end{array}$ \\
\hline
\end{tabular}

Water injection can be used to reduce NOx emissions by diluting the intake air and decreasing peak combustion temperatures within the cylinder. Although not widely used in automotive applications, $\mathrm{H}_{2} \mathrm{O}$, $\mathrm{N}_{2}$, or $\mathrm{CO}_{2}$ dilution is often seen in stationary and marine engines [33]. However there does exist an upper limit where the concentration of diluent is too high for combustion to be initiated. EGR is a form of intake air dilution, with the diluent being the inert products of combustion.

By implementing renewable fuels such as biodiesel, greenhouse gas emissions can be reduced. Biodiesel is a renewable fuel created from fat or vegetable oil. It is made through a process called transesterification [39]. It can be used in diesel CI engines with little or no modification. Typically, biodiesel is blended together with some percentage of petroleum diesel fuel. This type of fuel is then labeled as B20 or B35 to represent $20 \%$ or $35 \%$ biodiesel fuel. It is also the only alternative fuel to have a complete evaluation of emissions results and potential health effects submitted to the US EPA [39]. According to the EPA, pure biodiesel fuel has shown a $67 \%$ drop in unburned hydrocarbons, a $48 \%$ drop in carbon monoxide, and a $47 \%$ drop in particulate matter when compared to petroleum based diesel fuel [39]. This fuel has however caused a $10 \%$ increase in NOx emissions [43]. Biodiesel blends such as B20 have shown smaller improvements in $\mathrm{HC}, \mathrm{CO}$, and $\mathrm{PM}$, however displayed between a $2 \%$ increase and $2 \%$ decrease in $\mathrm{NOx}$ emissions [39]. By combining biodiesel fuel with some form of NOx aftertreatment, a large overall reduction in emissions may be achieved. 


\subsubsection{Exhaust Aftertreatment}

In order to reduce diesel NOx and PM emissions to US 2010 levels, exhaust aftertreatment is the only currently available technology. The use of engine design technologies (common rail fuel injection, EGR, etc.) and fuel related technologies (ULSD fuel, biodiesel, etc.) should accompany aftertreatment components for maximum emissions reductions, while maintaining fuel economy and drivability.

\subsubsection{Diesel Particulate Filters}

Diesel particulate filters (DPF) are devices that filter particulate matter from the exhaust stream and oxidize the captured particles. The filter material is typically a "ceramic wall-flow monolith" [10], and contains many passages for exhaust particles to become trapped within. An essential part of DPF design is the removal of trapped particles, or "regeneration" of the filter. There are two approaches to DPF regeneration, passive and active. Passive regeneration involves the addition of a catalytic agent, during normal operation, which oxidizes the particles and returns the filter to its original state. Active regeneration does not require the introduction of a catalytic agent. Instead, an external heat source is used to periodically raise the filter temperature, oxidizing the particles [10]. This can be accomplished by a late fuel injection, allowing the excess fuel to travel downstream into the filter where an exothermal reaction takes place, raising the filter temperature and oxidizing the trapped particles. Regeneration is often triggered by measuring an increase in pressure drop across the filter due to PM clogging. In automotive applications active regeneration is favored because an additional reductant does not have to be stored on-board. DPF systems are very effective, with filtration efficiencies greater than $90 \%$ [40]. These systems have shown durability upwards of 100,000 miles, yet may cause a decrease in fuel economy due to the increased exhaust backpressure and active regeneration [40].

\subsubsection{Diesel Oxidation Catalyst}

In modern diesel engines, a typical three-way-catalyst found in most gasoline spark ignition engines cannot be employed. This is because diesel engines operate at lean conditions and three-way-catalysts employ nonselective catalytic reduction of NOx by $\mathrm{CO}$ and $\mathrm{HC}$, which requires near stoichiometric operation. Despite this, $\mathrm{PM}, \mathrm{HC}$ and $\mathrm{CO}$ emissions, including material such as SOF and PAH, can be controlled using diesel oxidation catalyst (DOC) technology. The EPA has verified that DOCs can provide greater than $40 \%$ reduction in $\mathrm{CO}, 50 \%$ reduction in $\mathrm{HC}$, and $20 \%$ reduction in PM [41]. In independent testing performed by the Manufacturers of Emission Controls Association (MECA), 54-68\% of 19 PAH compounds and 68$91 \%$ of THC and CO were removed using DOCs [42].

DOCs along with ULSD fuel, have made it possible to achieve even higher PM reductions. These systems mainly reduce the SOF portion of PM and have little effect on the carbonaceous portion [42]. Under certain conditions, SOF reductions of up to $90 \%$ have been achieved; however, typical reductions of $20-50 \%$ are seen [43]. DOCs can be optimized for CO and HC reduction or for PM reduction through the use of 
different materials. High conversion efficiencies for $\mathrm{CO}$ and $\mathrm{HC}$ can be seen by using highly active metals such as platinum in the catalyst washcoat [10]. However typically catalysts optimized for PM reduction have poor $\mathrm{CO}$ and $\mathrm{HC}$ reduction efficiencies. In the US, widespread use of DOCs was specifically triggered in 1994 when the EPA introduced more stringent PM emission standards. DOC technology is relatively inexpensive and durable. System costs are around \$1,000-2,000 for a heavy-duty application [43]. DOCs have shown durability of 100,000-150,000 miles for on-road applications, (4,000-10,000 hrs. off-road [43]) and can last 7-10 years [41].

\subsubsection{Lean NOx Catalyst}

The reduction of NOx in diesel exhaust has long been researched. Currently diesel and lean burn gasoline engines are designed to reduce in-cylinder NOx while sacrificing fuel economy and greenhouse gas emissions. If efficient NOx reduction could be achieved by an aftertreatment system, these engines could be calibrated for maximum efficiency and fuel economy. Lean NOx catalysts (LNC) reduce NOx emissions through selective reaction with hydrocarbons $[10,44]$. There are two configurations for LNC systems, passive and active. A passive system uses the available hydrocarbon species in the diesel exhaust to complete the reactions. An active configuration injects additional hydrocarbons ahead of the catalyst in the form of diesel fuel.

Modern diesel engines have very low $\mathrm{HC}$ emissions. As a result, a passive system can only achieve up to a $10 \%$ NOx reduction [44]. An active configuration is necessary to achieve significant reductions, demonstrating greater than $25 \%$ NOx reduction, with an $8 \%$ fuel economy penalty [44,45]. Peak NOx conversions may be higher. However the narrow temperature window that allows for efficient NOx reduction may not correspond to the available exhaust temperature in transient automotive applications, causing the lower overall NOx reduction. LNCs are comprised of different materials, including noble metals and zeolite $[10,44]$. Typical heavy-duty system costs can be $\$ 15,000-20,000$, not including the cost of a $3 \%$ fuel economy penalty [44].

\subsubsection{NOx Absorber}

Still being adapted for diesel engine use, NOx absorbers incorporate NOx trapping materials in the washcoat to absorb nitrogen oxides from the exhaust stream $[42,10]$. The systems have two stages of operation, storage of NOx in the washcoat during lean operation and regeneration of the trap through desorption and non-selective catalytic reduction of NOx during rich operation [10]. These absorbers require frequent, short duration spikes of rich AF mixtures to regenerate the NOx storage sites [10].

Recently developed NOx absorber systems have demonstrated $80-95 \%$ efficiencies over transient test cycles $[42,45]$. These systems also show less than 3\% fuel economy penalty as a result of the required bursts of rich operation [45]. Because of issues with durability and regeneration strategies, NOx absorbers 
have been shown to be more suitable for light-duty diesel engines. However recent advancements have shown satisfactory light-duty durability and are close to hitting medium heavy-duty regulatory life [42]. Difficulties with the technology include regeneration strategies and the corresponding increase in emissions and decrease in fuel economy, as well as sulfur intolerance and long term durability [42]. NOx absorber catalysts require large quantities of rhodium and platinum [42,45]. This causes NOx absorber systems to be more expensive compared to technologies implementing less expensive base metals.

Another application of NOx absorbers is in the production of ammonia. It is possible to configure a NOx absorber system to produce ammonia, which could then be used in an SCR system to alleviate the need for on-board reductant storage [10].

\subsubsection{Selective Catalytic Reduction}

Selective catalytic reduction is a method of NOx reduction where a nitrogen containing compound such as ammonia or urea is injected into the exhaust stream prior to passing through a catalyst. Capable of greater than $90 \%$ steady-state Nox reduction (60-80\% transient), urea-SCR systems have been used for years in stationary applications and only recently have been proposed for transient on-road automotive or marine use $[10,46]$. It should be noted that large reductions such as these are not typically on the same order as required by the 2010 US EPA standards. Developing a system to achieve $90 \%$ reduction from the standpoint of a $2.5 \mathrm{~g} / \mathrm{bhp}-\mathrm{hr}$ diesel engine may prove difficult compared to reducing a $6 \mathrm{~g} / \mathrm{bhp}-\mathrm{hr}$ engine. Additionally, there are barriers involved with doing multiple stages of SCR. The availability of components such as $\mathrm{O}_{2}$ and $\mathrm{H}_{2} \mathrm{O}$ in the exhaust stream and the potential for ammonia slip typically limit urea-SCR systems to a single stage of reduction.

SCR is also possible using a HC compound, such as diesel fuel, instead of urea. Very similar to a lean-Nox catalyst, these systems are typically less prevalent and achieve a lower reduction compared to urea-SCR, on the order of $15-50 \%[46]$.

\subsubsection{5-1 Urea}

Urea (in aqueous solution) is the preferred way to deliver ammonia to the exhaust stream because it can be safely transported and easily injected. In addition, urea has very low toxicity and is already widely used in fertilizer applications [17]. A $32.5 \%$ by weight urea in water solution is preferred to create the lowest freeze point [17]. Once the solution is injected into the exhaust stream, the urea undergoes a decomposition process (see §2.3.4.5-3) resulting in ammonia as the final reductant. The downsides of using urea as a reductant include developing an infrastructure to deliver it to the customer and requiring customer compliance to maintain NOx reduction. 


\subsubsection{5-2 SCR Catalyst}

In the past, urea-SCR systems have shown durability for well over 300,000 miles in heavy-duty applications [17]. There are three main types of materials used in SCR catalyst washcoats, noble (precious) metals, base metals, and zeolite [47]. Noble metals can include platinum, rhodium, and palladium, while base metals include titanium, vanadium, and tungsten [47]. Base metal formulations are limited to $650^{\circ} \mathrm{C}$ [48]. Noble and base metals are used in SCR catalysts containing a macropore surface, while the zeolite material is used in micropore surfaces [47]. Zeolite catalysts have excellent low temperature performance when compared to base and noble metal catalysts, but show sensitivities to hydrocarbon and sulfur compounds [49]. Zeolite catalysts demonstrate high performance in particular when combined with a preoxidation catalyst [48].

\subsubsection{5-3 Chemistry Involved}

There are three main chemical processes involved with urea-SCR aftertreatment. The first process involves decomposition of urea into ammonia. The second involves reactions of ammonia with NOx in the exhaust. The third involves adsorption, storage, and desorption of ammonia $\left(\mathrm{NH}_{3}\right)$ in the SCR catalyst.

After urea $\left(\left(\mathrm{NH}_{2}\right)_{2} \mathrm{CO}\right)$ is injected into the exhaust, it is vaporized by the heat of the exhaust gases. Then, it is converted to $\mathrm{NH}_{3}$ by thermal decomposition and hydrolysis. This process can be described the following two chemical equations [50].

$$
\begin{array}{lr}
\left(\mathrm{NH}_{2}\right)_{2} \mathrm{CO} \Rightarrow \mathrm{HNCO}+\mathrm{NH}_{3} & \text { Equation 7 } \\
\mathrm{HNCO}+\mathrm{H}_{2} \mathrm{O} \Rightarrow \mathrm{NH}_{3}+\mathrm{CO}_{2} & \text { Equation 8 }
\end{array}
$$

The $\mathrm{NH}_{3}$ generated by decomposition of urea then reacts with $\mathrm{NOx}$ in the exhaust. This process is fairly complex, including many reactions. It can however be described in a more simplified manner by three main reactions, which can be seen below $[49,50,51,52]$.

$$
\begin{array}{lr}
4 \mathrm{NO}+4 \mathrm{NH}_{3}+\mathrm{O}_{2} \Rightarrow 4 \mathrm{~N}_{2}+6 \mathrm{H}_{2} \mathrm{O} & \text { Equation 9 } \\
6 \mathrm{NO}_{2}+8 \mathrm{NH}_{3} \Rightarrow 7 \mathrm{~N}_{2}+12 \mathrm{H}_{2} \mathrm{O} & \text { Equation 10 } \\
\mathrm{NO}+\mathrm{NO}_{2}+2 \mathrm{NH}_{3} \Rightarrow 2 \mathrm{~N}_{2}+3 \mathrm{H}_{2} \mathrm{O} & \text { Equation 11 }
\end{array}
$$

The most desired pathway to NOx reduction is the third equation (Equation 11). This reaction is much faster (up to an order of magnitude at low temperatures) compared to the other two equations; however it requires a $\mathrm{NO} / \mathrm{NO}_{2}$ molar ratio of $1: 1$. In raw exhaust gases, $\mathrm{NO}_{2} / \mathrm{NOx}$ ratios are between $0 \%$ and $30 \%$ [50]. Higher $\mathrm{NO}_{2}$ concentrations can be produced by including a pre-oxidation catalyst ahead of the SCR catalyst. Without a pre-oxidation catalyst, the two slower reactions (Equation 9, 10) become dominant, and 
may hinder the NOx reduction ability of the system. Catalyst space velocity and exhaust temperature also affect NOx reduction. At high temperatures $\left(>450^{\circ} \mathrm{C}\right)$, maximum $\mathrm{NOx}$ reduction is constrained by $\mathrm{NH}_{3}$ oxidation (Equation 12.) [51].

$4 \mathrm{NH}_{3}+5 \mathrm{O}_{2} \Rightarrow 4 \mathrm{NO}+6 \mathrm{H}_{2} \mathrm{O}$

Equation 12

Additionally, other side reactions can play a role in NOx reduction by forming ammonium nitrate $\left(\mathrm{NH}_{4} \mathrm{NO}_{3}\right)$ and $\mathrm{N}_{2} \mathrm{O}$, at temperatures below $200^{\circ} \mathrm{C}$ and above $450^{\circ} \mathrm{C}$, respectively [51]. The adsorption and desorption of $\mathrm{NH}_{3}$ on the SCR catalyst is a more complex process, typically described by a 1-D set of partial differential equations, which are solved along the length of the catalyst [50,52,53]. Any $\mathrm{NH}_{3}$ not consumed by NOx or adsorbed in the catalyst is considered ammonia slip. Ammonia slip can also be caused by $\mathrm{NH}_{3}$ being desorbed from the catalyst and not reacting with NOx.

\subsubsection{5-4 Advantages/Disadvantages}

One advantage of urea-SCR systems is the lack of a direct fuel penalty since it can provide large reductions at low temperatures without the use of fuel to reduce NOx. This means that the engine can then be tuned for optimum efficiency and fuel economy rather than low emissions. An engine tuned in such a manner can typically achieve $3-5 \%$ better fuel economy [54]. Exhaust temperature is very important in urea-SCR. Depending on engine or vehicle operation, this can be a great disadvantage. High exhaust temperatures $\left(>250^{\circ} \mathrm{C}\right)$ are desired to ensure decomposition of urea and SCR reactions take place. Engines in applications with generally low exhaust temperatures may have difficulties achieving high NOx reductions. Secondly, applications with extremely hot exhaust temperatures may have decreased NOx reduction performance as a result of catalyst efficiency. This may be remedied however by selecting an SCR catalyst with temperature performance appropriate for the indended application. There can be an equivalent fuel penalty associated with the energy required to manufacture the urea, however this is small, typically between 0.2 and $0.7 \%$ for a US EPA 2010 type reduction [17]. Additionally, it has been shown that CO and $\mathrm{HC}$ emissions may be reduced by up to $90 \%$, depending on catalyst formulation and engine-out concentrations [54].

\subsubsection{5-5 Cost}

As a result of impending emissions regulations, urea-SCR systems are being developed for heavy and lightduty diesel engines. Urea-SCR systems are very cost effective when compared to other diesel NOx reduction technologies. SCR catalysts are typically constructed of base metals as opposed to precious metals, which translates to significant savings when the current average precious metal to base metal price ratio is on the order of 2000 [17]. Urea cost is also very low, with future average consumer prices being projected as low as $\$ 1 /$ gallon [17]. MECA estimated the cost of a urea-SCR system for engines in the 300- 
$500 \mathrm{hp}$ range could vary between $\$ 11,000$ and $\$ 50,000$ depending on production volume [55]. Other authors have presented lower costs for SCR technology, around \$3,000 in a heavy-duty application [49].

\subsubsection{5-6 Control}

Sophisticated and accurate control systems are required for urea-SCR systems so that the appropriate amount of reducing agent is delivered. If too much reductant is introduced, ammonia slip can occur, causing equipment to be fouled with ammonium sulfate (a hazardous waste) and posing an immediate health risk to anyone in the vicinity. Ammonia slip is made more complex by $\mathrm{NH}_{3}$ stored in the SCR catalyst. This combined with transient engine operation causes ammonia slip to be particularly hard to predict. Many modern systems employ an additional "cleanup" catalyst to help circumvent $\mathrm{NH}_{3}$ slip. Although ammonia slip is not officially regulated, it is usually desired to keep ammonia slip below 10-25 ppm average and 30-50 ppm peak [50,51,52]. Control of urea-SCR is particularly difficult in an automotive application because of the highly transient conditions. To achieve the reductions required to meet impending emissions regulations, modern systems are now implementing forms of model-based and closed-loop control.

Schär et al. were able to achieve an $80 \%$ NOx reduction over the ESC and $90 \%$ reduction over the European Transient Cycle (ETC) using a transient control system implementing a NOx sensor, SCR inlet temperature, and SCR kinetic model [49]. Additionally, for the ESC, the NOx sensor was not used, but is required to minimize ammonia slip.

Shost et al. [52] also developed and tested different forms of model-based control for a urea-SCR system. A 1-D SCR model was developed and validated, considering ammonia adsorption and desorption, ammonia oxidation, SCR NOx reactions (Equation 9-11) and an additional NO oxidation reaction. The control logic used the SCR model to determine SCR surface coverage, based on engine speed, pedal position, mass air flow, inlet NOx (map or sensor) and SCR inlet pressure. Anhydrous ammonia and urea were utilized in open- and closed-loop control. During closed-loop testing, ammonia slip was controlled using a mid-brick ammonia sensor. The NOx conversion efficiencies for open-loop control with anhydrous $\mathrm{NH}_{3}$, closed-loop control with anhydrous $\mathrm{NH}_{3}$, and closed-loop control with aqueous urea were $91 \%, 87 \%$, and $74 \%$, respectively over the FTP. The peak $\mathrm{NH}_{3}$ for each case was 184 ppm, 20 ppm, and 3.4 ppm, respectively. The average $\mathrm{NH}_{3}$ slip for each case was $19 \mathrm{ppm}, 2.5 \mathrm{ppm}$, and $0.2 \mathrm{ppm}$, respectively.

Willems et al. [51] evaluated whether closed-loop control may be required to meet impending emissions regulations with urea-SCR. Open-loop control can achieve optimal performance over a test cycle; however, it requires considerable calibration and engineering effort. Open-loop strategies have been proven to meet Euro- 4 and 5 standards, requiring $50-60 \%$ and $70-80 \%$ NOx reductions, respectively. As the NOx reduction of open-loop systems becomes even higher, if becomes difficult to achieve low $\mathrm{NH}_{3}$ slip. By using closed- 
loop control, calibration and engineering efforts can be reduced, and even higher NOx reductions may be achieved with minimal ammonia slip. These strategies typically rely on ammonia surface coverage control and NOx sensor feedback. The authors [51] identified three main aspects that limit the success of a closedloop SCR control strategy. This included slow catalyst dynamics, $\mathrm{NH}_{3}$ slip prevention, and time delay in the urea dosing system. Additionally, if a post-SCR NOx sensor is used, they state that sensor crosssensitivity may limit performance.

Three control strategies were studied including map based open-loop control, NOx sensor feedback control, and adaptive surface coverage $/ \mathrm{NH}_{3}$ slip control [51]. Each of the three control strategies was simulated using the TNO Automotive simulation tool SimCat for the ESC and ETC. Two different NOx outputs were implemented for each control strategy, nominal and 30\% increased. The SCR-out $\mathrm{NOx}$, average $\mathrm{NH}_{3}$, and maximum $\mathrm{NH}_{3}$ are presented for each case in Table 13

Table 13. ESC and ETC simulation results [51]

\begin{tabular}{|c|c|c|c|c|c|}
\hline & Engine- & Control Strategy & $\begin{array}{c}\text { SCR-Out } \\
\text { NOx }\end{array}$ & $\begin{array}{c}\text { Average } \\
\mathrm{NH}_{3} \\
\end{array}$ & $\operatorname{Max} \mathrm{NH}_{3}$ \\
\hline & & & {$[g / k W-h]$} & [ppm] & [ppm] \\
\hline \multirow{6}{*}{ ESC } & \multirow{3}{*}{ Nominal } & Map based open-loop & 0.78 & 9 & 91 \\
\hline & & NOx sensor feedback & 0.83 & 8 & 89 \\
\hline & & Adaptive surface coverage & 0.87 & 6 & 24 \\
\hline & \multirow{3}{*}{$\begin{array}{c}30 \% \\
\text { Increased }\end{array}$} & Map based open-loop & 2.09 & 2 & 12 \\
\hline & & NOx sensor feedback & 1.25 & 6 & 45 \\
\hline & & Adaptive surface coverage & 1.63 & 3 & 15 \\
\hline \multirow{4}{*}{ ETC } & \multirow{2}{*}{ Nominal } & Map based open-loop & 2.67 & 3 & 48 \\
\hline & & Adaptive surface coverage & 1.66 & 3 & 34 \\
\hline & \multirow{2}{*}{$\begin{array}{c}30 \% \\
\text { Increased }\end{array}$} & Map based open-loop & 4.22 & 1 & 29 \\
\hline & & Adaptive surface coverage & 2.88 & 2 & 33 \\
\hline
\end{tabular}

\subsection{Retrofit Applications}

The best method for reducing emissions from older engines is to replace them with newer ones that meet the most stringent emissions standards. However this is clearly not economical. In some cases, older diesel engines may be in operation for 20-30 years before being replaced with new ones [10]. Additionally, standards have been introduced for rebuilt engines, further increasing their lifespan and potential to pollute. Marine engines in particular have a very long operational life, even after rebuild. Clearly, there is a need to reduce emissions from existing engines as well as developing new technologies to meet future emissions. Four ways have been identified to reduce emissions from existing engines [10]:

- Engine replacement: Accelerated replacement of old technology engines with new engines or with engines rebuilt to a lower emissions level 
- Emissions control retrofit: Installation of exhaust gas aftertreatment devices or later model original equipment manufacturer (OEM) components in existing engines

- Alternative fuels: Use alternative diesel fuels or fuel additives

- Engine operation and maintenance: Reduce unnecessary engine idling, improve driving or operating habits, implement proper maintenance programs

Of these methods, emissions control retrofit offers the possibility of the largest reduction while remaining economically viable and having universally applicability. Additionally, it does not require an engine rebuild, the addition of costly additives, or changes in driving or operating habit (which may or may not be possible). By simply installing an aftertreatment system, the owner will also save time and money by eliminating the cost and downtime of rebuilding the engine. These systems offer a reduction of NOx, PM, $\mathrm{CO}$, and $\mathrm{HC}$ emissions and allow the engine to meet tighter emissions standards, but may cause a reduction in fuel economy or require reductants to be used (urea). The most common retrofit technologies include diesel particulate filters, diesel oxidation catalysts, and more recently urea-SCR systems.

\subsection{Modeling Approaches}

Two main modeling approaches have been reviewed because of their relevance to the dissertation topic. First, literature related to artificial neural network (ANN) modeling was reviewed in a general manner, including a discussion of possible applications. Second, SCR catalyst and urea injection modeling approaches were reviewed. Additional detail regarding model-based control can be found in above sections. Aspects of approaches reviewed here are included in the final urea-SCR system model used for control optimization.

\subsubsection{Artificial Neural Network Modeling}

An ANN model attempts to model the structure of a biological neuron using an information processing unit that has several inputs and one output. Each input has a separate synaptic weight. The weighted sum of the inputs is modified by an activation function, leading to an output. The activation function is typically a real, non-linear function defined on a sub-set of real numbers [56]. Once the model is initially developed, the synaptic weight of each input is adjusted as part of a "learning" process using predefined training data. Training must be performed carefully to ensure the model is not over-trained. If this occurs, the model becomes very sensitive to small changes in input data and does not reliably predict results for new input data [56].

ANNs have shown broad applicability as a predictive tool for many engineering problems. While modeling engine emissions is a common application of ANN models, they may be applied to a variety of other engine applications. For example, ANNs have been used to control AF ratio and ignition timing [57], determine mechanical efficiency [58], diagnose engine failure [59], and predict cylinder pressure and engine torque [60]. 
In predicting engine emissions, it has been shown that engine speed and torque are the dominant input variables [61]. Perhinschi et al. [62] developed neural network models for predicting $\mathrm{NOx}, \mathrm{CO}_{2}, \mathrm{CO}$, and $\mathrm{HC}$ emissions from medium-duty trucks using engine speed, torque, and their time derivatives as inputs. In these models, the data were time aligned for each emission to correct for the time delay. Time delay included the time it takes for the engine exhaust to travel through the exhaust pipe, dilution tunnel, and sampling lines before reaching the probe, and analyzer response time [62]. To align $\mathrm{CO}_{2}, \mathrm{CO}$, and $\mathrm{HC}$, the time shift was determined to be the value that yielded the highest cross-correlation coefficient between each emission and vehicle speed [62]. The researchers found that the time delay for NOx was best determined by cross-correlating with vehicle acceleration rather than speed [62]. It has been demonstrated that NOx emissions may be predicted by ANNs to within 5\% error for chassis modes trained using torque and speed as inputs [63]. Other models have been developed using engine dynamometer data rather than chassis dynamometer data. In these cases, the best results were obtained when time alignment was performed by correlating all emissions with engine power [64]. The researchers in [62] investigated the performance of four types of neural networks: adaptive linear (ADALINE), single hidden layer (SHL), non-linear polynomial Sigma Pi, and the Extended Minimal Resource Allocating (EMRAN). The Sigma Pi and ADALINE neural networks best predicted NOx emissions, the EMRAN and Sigma Pi models best predicted $\mathrm{CO}_{2}$ emissions, and the Sigma Pi and ADALINE models best predicted $\mathrm{CO}$ and $\mathrm{HC}$ emissions [62].

In some instances, many more input variables may be used to predict transient engine emissions. Thompson et al. [65] used input variables of engine speed, intake air temperature, exhaust temperature, engine oil temperature, engine coolant temperature, intake air pressure, injection pressure, injection pulse width, start of injection, and accelerator position. By using these ten input variables, they were able to accurately predict output torque and emissions of $\mathrm{HC}, \mathrm{CO}, \mathrm{CO}_{2}, \mathrm{NOx}$, and $\mathrm{PM}$ to within $5 \%$ of measured values over the FTP cycle and two other random cycles [65].

Often times, rather than including a large number of independent variables, additional inputs may be included that define variability of existing input variables. For example, Hashemi and Clark [66] developed an ANN to predict $\mathrm{NOx}, \mathrm{CO}_{2}, \mathrm{HC}$, and $\mathrm{CO}$ emitted from heavy duty diesel vehicles using input variables of axle speed, torque, their time derivatives, and two variables which define speed variability over 150 seconds. In this instance, speed variability was included to aid in predicting off-cycle emissions. The model was trained on the highway cycle and applied to the city/suburban heavy vehicle route and Urban Dynamometer Driving Schedule (UDDS). Even with the inclusion of the speed variability inputs, off-cycle NOx emissions were still difficult to model. 


\subsubsection{SCR Catalyst Modeling}

There are a number of different approaches that can be used to develop an SCR catalyst model. Model complexity can vary greatly between approaches, yet each is essentially based on the same idealized chemistry (see Equation 7-12).

Schar et al. [50] developed a 1-D model for an SCR catalytic converter, assuming homogeneous, incompressible flow of ideal gas. The model included four components: molten urea, gaseous $\mathrm{NH}_{3}$, adsorbed $\mathrm{NH}_{3}$, and gaseous NOx. Five reactions were considered, describing urea decomposition, adsorption and desorption of ammonia on the catalyst, consumption of $\mathrm{NOx}$ by adsorbed $\mathrm{NH}_{3}$ (Eley-Rideal mechanism), and oxidation of adsorbed $\mathrm{NH}_{3}$. The Eley-Rideal mechanism (Equation 13) is very similar to Equation 9, except that the $\mathrm{NH}_{3}$ being consumed is assumed to be adsorbed onto the catalyst and $\mathrm{NOx}$ is generically considered as opposed to $\mathrm{NO}$ alone.

$$
4 \mathrm{NO}_{x}+4 \mathrm{NH}_{3}(\mathrm{ads})+\mathrm{zO}_{2} \Rightarrow 4 \mathrm{~N}_{2}+6 \mathrm{H}_{2} \mathrm{O}
$$

Equation 13

Rate expressions were established for each reaction. By applying mass and energy balances, a system of coupled partial differential equations (PDEs) was established. In order to allow the system of equations to be solved, it was approximated by ordinary differential equations. This was possible by partitioning the SCR cell into a finite number of idealized cells along its axis and making some simplifications: homogeneous variables within each cell, neglect heat conduction, assume the gas temperature leaving each cell was equal to the cell temperature. While most model parameters were known, some (activation energies, pre-exponential factors, time constants) had to be determined experimentally. The final model was validated against experimental data at several operating points. It was able to almost exactly match experimental temperature data (Figure 8 (a)), and for NOx showed a maximum relative error of $5.3 \%$ with respect to the NOx feed (Figure 8 (b)).

(a)

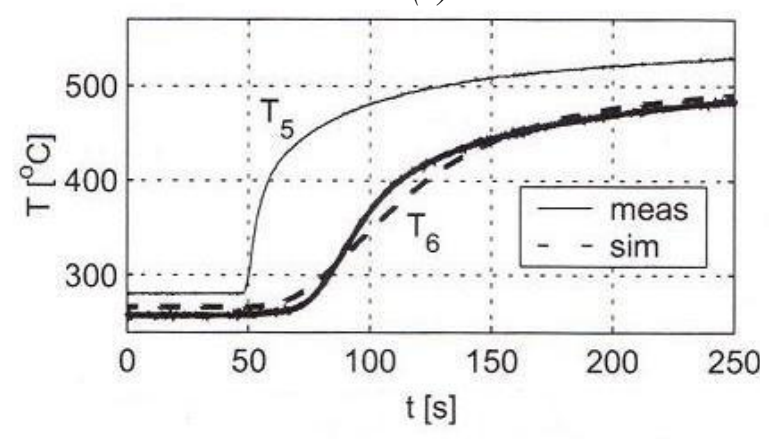

(b)

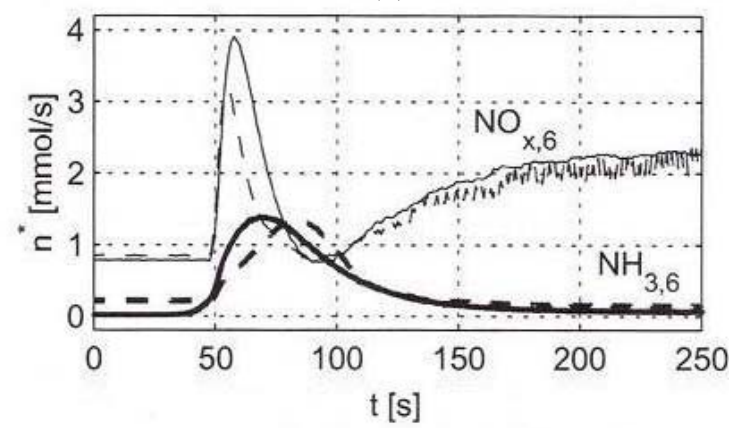

Figure 8. Schar et al. SCR model predictions: (a) temperature (C), (b) NOx (mmol/s) [50] 
Song et al. [67] developed a unique SCR modeling approach for integration in a closed-loop control strategy. While the model was ultimately based on idealized urea decomposition and NOx reactions (Equation 7-11), the main focus was on measurement error and inefficiency within the system. The authors pointed out that NOx reduction became trivial if (1) it is known how much $\mathrm{NO}$ and $\mathrm{NO}_{2}$ are in the exhaust stream exactly, (2) the catalyst has $100 \%$ selectivity and efficiency characteristics, (3) all the chemical reactions are perfect. However this is never the case. The SCR model included four major subsystems: urea vaporization/atomization, mixing, exhaust pipe, and catalyst. The urea vaporization/atomization subsystem contained the most important dynamics of the system.

Pipe and catalyst subsystems were arranged from a control point of view, and were divided into four dynamic blocks: pipe transport delay, catalyst mixing dynamics, catalyst efficiency limitation, and catalyst transport delay. Finally, the model was used to perform steady-state error analyses for two given NOx reductions. First open-loop control was considered. For a 75\% NOx reduction (2002/2004 EPA, 8 to 2 $\mathrm{g} / \mathrm{bhp}-\mathrm{hr}$ ), the overall error was around $20-30 \%$. But when the reduction is increased to $90 \%$ (US 2010, 2 to $0.2 \mathrm{~g} / \mathrm{bhp}$-hr), the error increased to above $50 \%$, which may be deemed uncontrollable. Performing a similar error analysis for the closed-loop system showed that a NOx sensor was required with excellent measurement accuracy around the $20-40 \mathrm{ppm}$ range. However, the authors pointed out that most NOx sensors have high accuracy ( $\pm 5 \%$ ) in the 200 -400 ppm range, which may make it difficult to achieve US 2010 emissions targets with such a system.

Upadhyay et al. [68] developed a three state dynamic catalyst model, including four primary reactions. This model considered (1) adsorption of gas phase ammonia, (2) reduction of gas phase NO by the adsorbed ammonia, (3) oxidation of adsorbed ammonia to gas phase NO, and (4) desorption of adsorbed ammonia leading to ammonia slip over the catalyst. The first two reactions represented the three state, lumped parameter, single-in-single-out model of the catalyst. The three states included were gas phase NO concentration, surface coverage fraction due to adsorbed ammonia, and gas phase concentration of $\mathrm{NH}_{3}$.

Chatterjee et al. [53] developed a chemically and physically based fully transient two-phase mathematical model of an SCR honeycomb monolith converter. The model development was limited to standard $\mathrm{NH}_{3}$ and $\mathrm{NO}$ reactions, and was validated with reactive experiments over a commercial $\mathrm{C}_{2} \mathrm{O}_{5}-\mathrm{WO}_{3} / \mathrm{TiO}_{2} \mathrm{SCR}$ catalyst. A number of reactions were utilized in the model, including: the fast-SCR reaction, ammonia adsorption-desorption, ammonia oxidation, the standard SCR reaction, $\mathrm{NO}_{2}$ disproportion, nitrous acid (HONO) reaction with ammonia, $\mathrm{NH}_{4} \mathrm{NO}_{3}$ adsorption-desorption, nitric acid $\left(\mathrm{HNO}_{3}\right)$ reaction with $\mathrm{NO}$, and $\mathrm{N}_{2} \mathrm{O}$ formation. The reaction network and available pathways can be seen below in Figure 9. 


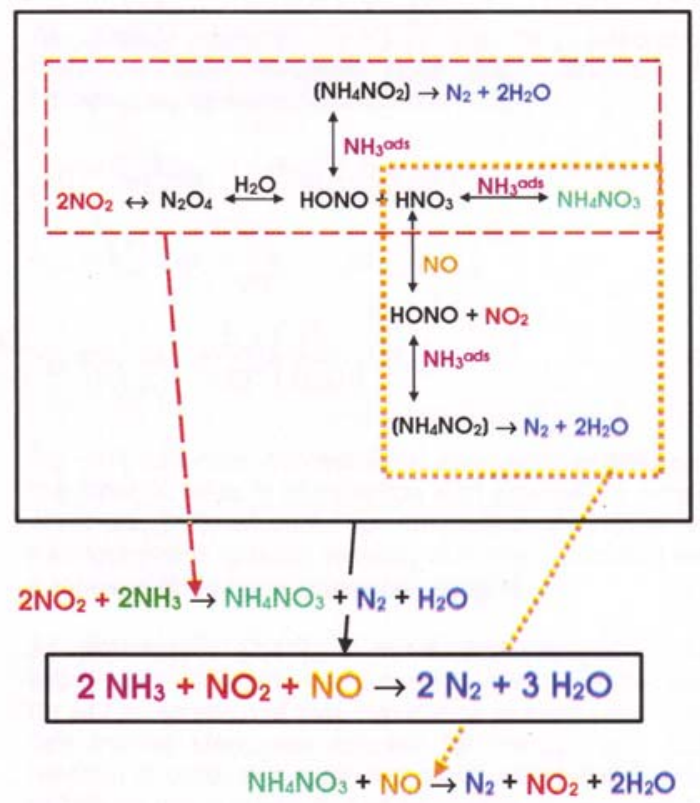

Figure 9. Chatterjee et al. SCR model reaction pathways [53]

Expressions for $\mathrm{NH}_{3}$ adsorption, desorption, and oxidation rates were established. A "novel dual-site redox rate expression" [53] was included, assuming that $\mathrm{NH}_{3}$ may block sites for $\mathrm{NO}$ activation and reoxidation of such sites was the rate limiting step. A transport model considered the unsteady differential mass balance of six gaseous species $\left(\mathrm{NH}_{3}, \mathrm{NO}, \mathrm{NO}_{2}, \mathrm{~N}_{2}, \mathrm{~N}_{2} \mathrm{O}, \mathrm{HNO}_{3}\right)$ and two adsorbed species $\left(\mathrm{NH}_{3}{ }^{*}, \mathrm{NH}_{4} \mathrm{NO}_{3}{ }^{*}\right)$. The resulting set of partial differential equations was solved numerically. Model validation showed that NOx and $\mathrm{NH}_{3}$ showed good agreement with experimental results, as shown in Figure 10. Here, $\alpha$ represents the measured $\mathrm{NH}_{3}$ dosing ratio.

(a)

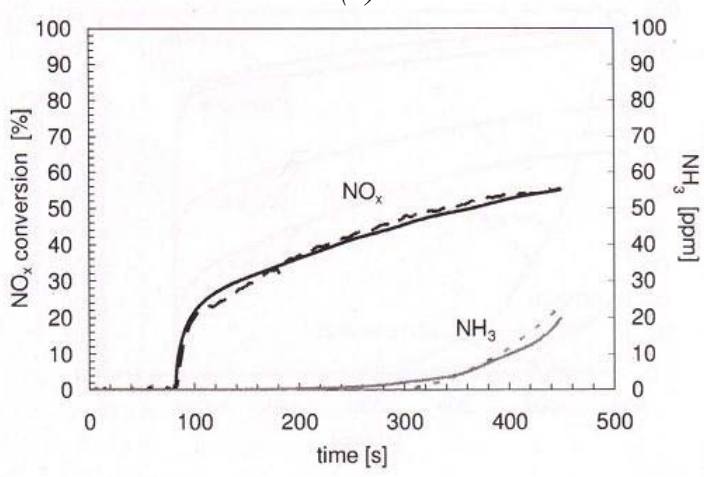

$T_{\text {exh. }}=200^{\circ} \mathrm{C}, \mathrm{NO}_{2} / \mathrm{NO}_{x}=3 \%, \mathrm{GHSV}=21500 \mathrm{~h}^{-1}$ and $\alpha=1.24$. (b)

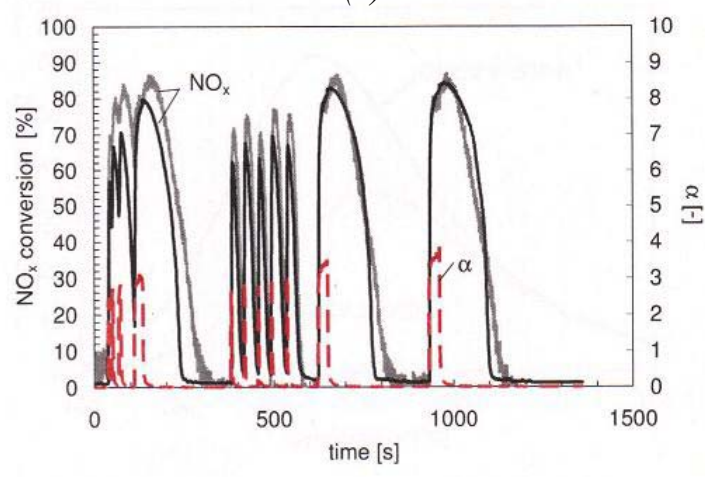

$\mathrm{T}_{\text {exh. }}=229^{\circ} \mathrm{C}, \mathrm{NO}_{2} / \mathrm{NO}_{\mathrm{x}}=44 \%, \mathrm{GHSV}=73200 \mathrm{~h}^{-1}$.

Figure 10. Chatterjee et al. model validation results: (a) HHDDE test bench (b) passenger car diesel engine test bench [53] 


\section{Chapter 3: Urea-SCR System Development}

A stand-alone urea-SCR system was previously developed by WVU researchers as part of a cooperative project between WVU and MJB\&A. The system targeted a marine diesel retrofit application, specifically for reducing NOx emissions from tugs and towboats at ports in the Houston-Galveston area of Texas. A key design feature was independence of electronic interfacing with the engine to simplify retrofit, avoid reliance on engine durability, and accommodate retrofit of mechanically injected engines. The design criteria specifically addressed requirements for older, mechanically controlled engines found in many marine vessels, but the overall approach can be easily scaled to adapt to on- and off-road vehicles in the light- and heavy-duty engine categories. The stand-alone urea-SCR system has six main parts which are discussed below: flow measurement, urea dosing, NOx measurement, system control, SCR catalyst, and urea mixer.

\subsection{Flow Measurement}

Flow measurement was accomplished using an oversized pitot-tube system and implementing the Bernoulli equation. In this application, the Bernoulli equation was valid because the mach number of the exhaust gas was less than 0.3 [69]. A constant velocity over the cross section was assumed, and a calibration constant was included for tuning of the system. The Bernoulli equation was used in the following form to determine the exhaust flow velocity.

$V_{\text {exhaustflow }}=K_{\text {calib }} \cdot \sqrt{\frac{2 \cdot\left(P_{\text {dynamic }}-P_{\text {static }}\right)}{\rho}} \quad$ Equation 14

Large pitot-tubes were chosen so that particulate matter clogging did not become an issue and so that the system did not require frequent cleaning. A 5 inch exhaust pipe diameter was chosen for the research-grade system. Based on the expected differential pressures to be measured, high required accuracy, corrosive nature of diesel exhaust gas, and presence of water vapor, an Omega PX2300 Series 0-1 psi differential pressure transducer was chosen to measure the difference between dynamic and static pressures [70]. The density of the flowing exhaust gas was determined using the ideal gas law and assuming a gas constant equal to that of air. The absolute pressure and temperature of the flowing exhaust gas were measured using an MSD 2 bar automotive manifold air pressure (MAP) sensor and a Type K Chromel/Alumel thermocouple. The thermocouple output was connected to an Omega STCTX-K2 signal converter in order to convert the low level thermocouple voltage to a useable 4-20mA output [71]. The Omega PX2300 pressure transducer and STCTX-K2 signal converter's 4-20mA signals were converted to $1-5 \mathrm{~V}$ signals using $250 \Omega$ resistors. A diagram of the flow measurements system and a photograph of the flow section can be seen below in Figure 11. 


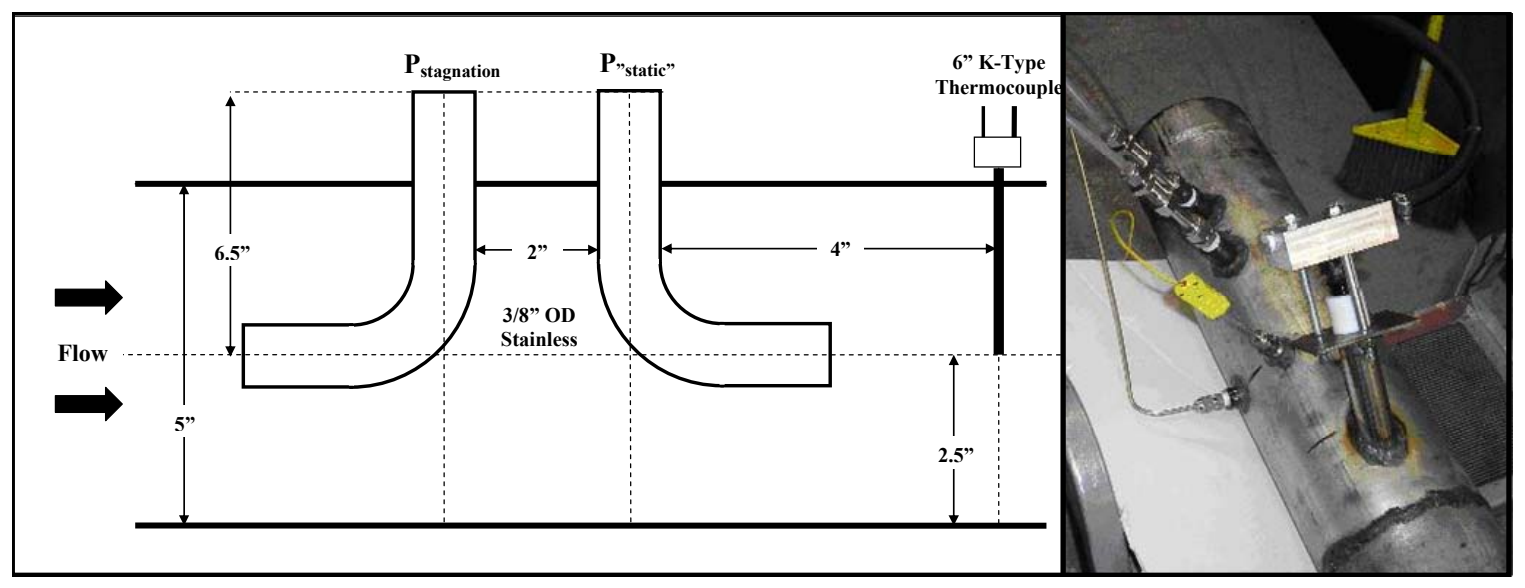

Figure 11. Urea-SCR system flow measurement section

\subsection{Urea Dosing}

The urea dosing system consisted of an automotive E85 compatible spark ignition gasoline fuel injector, rated at 28 pounds per hour, and accompanying 12VDC in-tank fuel pump, regulated at 58 psi, from a General Motors (GM) 5.3L flex fuel gasoline engine. Because the injector and pump assemblies were designed for E85 ethanol compatibility, there should be no lubricity or corrosive issues when using aqueous urea solution. The urea was stored in a 4-gallon aluminum tank, which has not exhibited any significant corrosive issues. The urea used in this system was TerraCair SCR grade urea. It is an aqueous solution of $32.5 \%$ in water and is formaldehyde free as a result of the Terra Industries production processes [72].

The urea injector was mounted to a 2.5 inch stainless steel standoff tube angled at $45^{\circ}$ with the flow to circumvent any heat damage. The standoff tube length was determined using simple fin heat transfer calculations assuming an ambient temperature of $20^{\circ} \mathrm{C}$, base temperature of $450^{\circ} \mathrm{C}$, and maximum fin tip temperature of $200^{\circ} \mathrm{C}$ (see [69] for additional details). Additional heat resistance was provided by a Teflon spacer, exhaust gasket material, and a heat shield. The urea tank and dosing system (including standoff tube) can be seen below in Figure 12. 


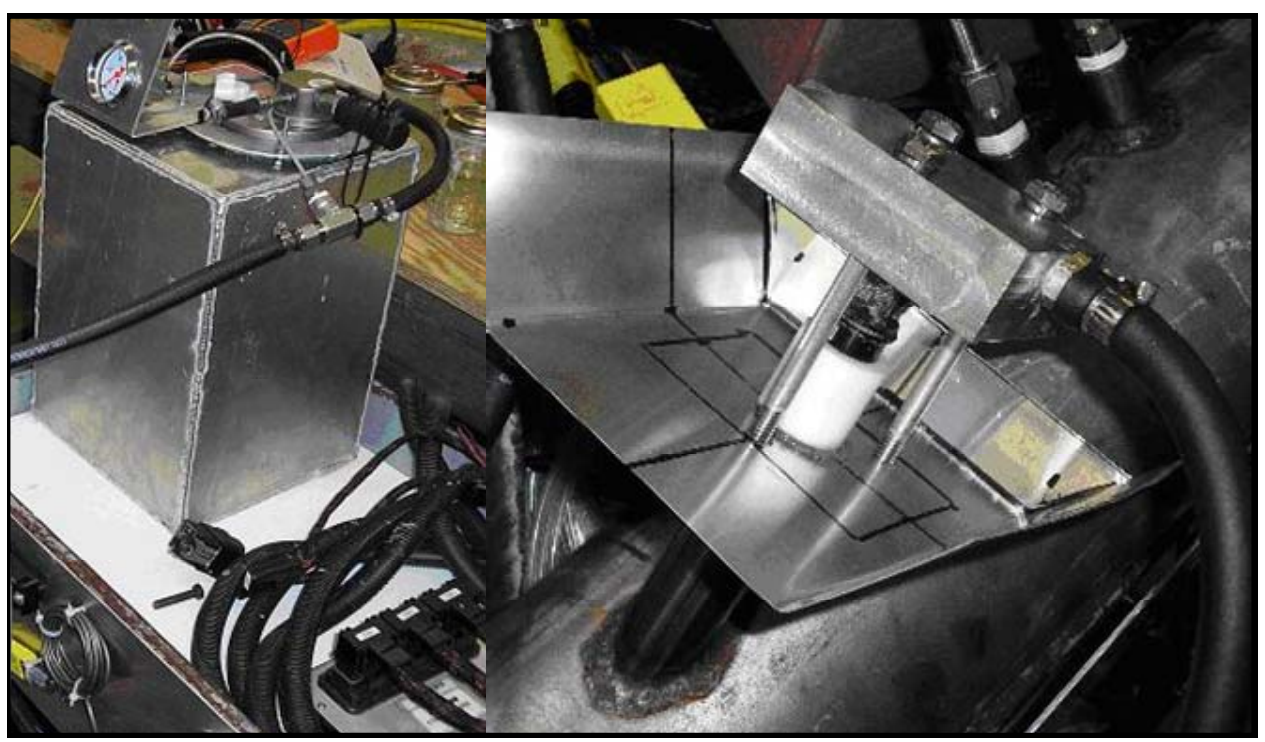

Figure 12. Urea-SCR system urea dosing hardware

\subsection{NOx Measurement}

In order to provide the appropriate amount of urea according to transient exhaust conditions without communicating with the engine, an accurate method of NOx measurement was required. The Siemens SmartNOx sensor was found to be a good fit for this application. It is a multi-function sensor capable of measuring NOx concentration (0-1500ppm) and oxygen concentration $(\lambda)$ in the exhaust stream [73]. The Siemens sensor measures total $\mathrm{NOx}\left(\mathrm{NO}+\mathrm{NO}_{2}\right)$ with maximum error of $\pm 10 \%$ and is not affected by $\mathrm{NO} / \mathrm{NO}_{2}$ split as sensors directly measuring $\mathrm{NO}_{2}$ concentration may be [73]. Additionally, Siemens suggests use of the sensor in on-board diagnostics and closed-loop control of SCR applications in light and heavy-duty vehicles [73]. The sensor uses a Zirconia multi-layer ceramic sensing material inside a metal housing and includes its own controller allowing communication with other modules. The output NOx and $\lambda$ signals are transmitted to other controllers via Controller Area Network (CAN) communication protocol.

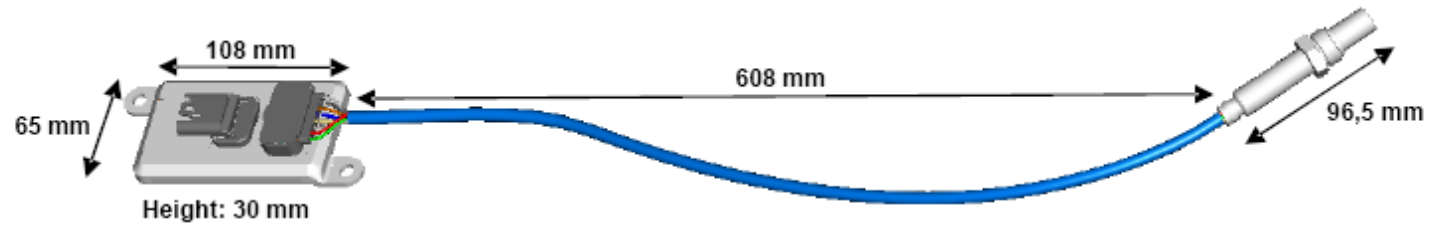

Figure 13. Siemens SmartNOx sensor [73]

\subsection{System Control}

The entire urea-SCR system was controlled by a Mototron Motohawk controller. Motohawk controllers are designed specifically for automotive applications. The controllers have various analog and digital inputs and outputs as well as the ability to send and receive CAN messages. The control system utilized an openloop feed forward type of architecture. This simple control approach was sufficient to achieve the $50 \%$ 
reduction called for in the in the original WVU/ MJB\&A project proposal [74]. By using a more complex control system and optimizing sensor placement, a higher reduction may be possible.

The Bernoulli equation described above (Equation 14) was used along with the sensor inputs to determine the total mass flow of exhaust gas through the system. The Siemens NOx sensor output was converted from $\mathrm{ppm}$ to $\mathrm{g} / \mathrm{s}$ using an expression similar to those defined in CFR 40 \$86.1342-90 [30]. Additional information regarding these calculations can be found in subsequent sections. Using the mass flow rate of NOx flowing through the system and the following reduction stoichiometry, the amount of urea requested was calculated. The reduction stoichiometry assumed that all NOx was present in the form of NO, considering one NOx reduction equation (Equation 9) and one for urea decomposition (Equation 15).

$\left(\mathrm{NH}_{2}\right)_{2} \mathrm{CO}+\mathrm{H}_{2} \mathrm{O} \Rightarrow 2 \mathrm{NH}_{3}+\mathrm{CO}_{2}$

Equation 15

The urea dosing calculation was translated to a pulse-width-modulation signal and sent to the injector. The control architecture used a $250^{\circ} \mathrm{C}$ exhaust temperature threshold for urea injection.

\subsection{SCR Catalyst}

The vanadium/titanium catalyst bricks supplied for this system measured 18 inches long and had a 5.9 inch by 5.9 inch face area. There were 130 cells per square inch. This low cell count was desired to ensure PM clogging would not occur over long periods of time and allow the 50\% reduction target to be met. Based on calculations to ensure laminar flow through each passage, the chosen configuration for this system was four bricks in a two by two parallel configuration, with a total volume of 40.5 liters. The bricks were wrapped in a fibrous material, allowing for thermal expansion, and housed in stainless steel. 


\subsection{Urea Mixing}

Testing (described in Chapters 4-7) included the installation of an ACS Industries wire mesh mixing device between the urea injection plane and SCR catalyst. The mixer arrived pre-installed in a piece of 5 inch exhaust pipe and was two inches thick. The ACS wire mesh mixer was constructed of thin stainless-steel wire, woven in a circular pattern and featuring interlocking-loop construction. A photograph of the mixer installed in a section of exhaust pipe and a zoomed view of the wire mesh construction can be seen in Figure 14.

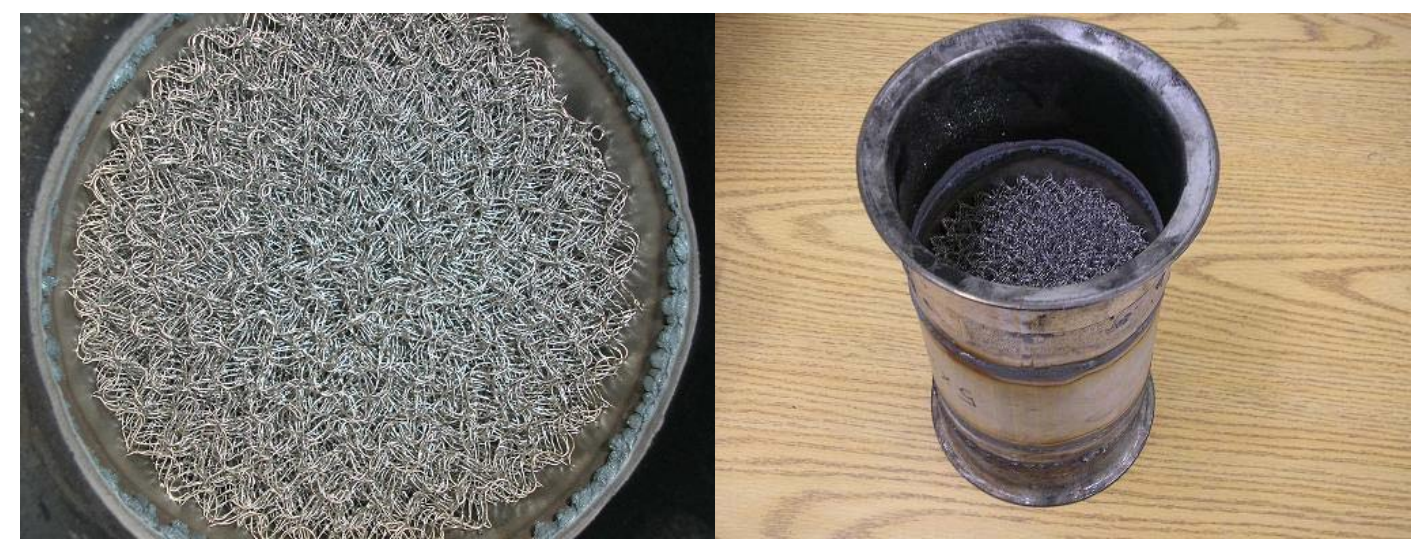

Figure 14. ACS Industries wire mesh mixer 


\section{Chapter 4: Experimental Setup}

The stand-alone urea-SCR system was tested at the WVU Engine and Emissions Research Laboratory (EERL) on January 5-14, 2009. During testing, the system's performance was experimentally determined over transient on-road and steady-state marine cycles using an on-road HHDDE. This testing period represents the second round of testing for the system since it was originally developed under a contract between WVU and MJB\&A. The complete test plan can be seen in Appendix A.

\subsection{Engine}

In order to demonstrate the NOx reduction capability of the stand-alone urea-SCR system, a 1992 Detroit Diesel Corporation (DDC) Series 60 HHDDE, model 6067GU60, was implemented. The engine was turbocharged, had direct-injection, an inline six cylinder configuration, and a displacement of 12.7 liters. Complete specifications for the 1992 Detroit Diesel engine can be seen in Table 14. As specified by the manufacturer, the Detroit Diesel engine produces $360 \mathrm{hp}$ at 1810 revolutions per minute (rpm), $1450 \mathrm{ft}-\mathrm{lb}$ of torque at $1200 \mathrm{rpm}$, and has an idle speed of $600 \mathrm{rpm}$. By mapping the engine prior to testing, it was shown that the engine actually produced $367.7 \mathrm{hp}$ at $1639 \mathrm{rpm}, 1346.9 \mathrm{ft}-\mathrm{lb}$ at $1225 \mathrm{rpm}$, and had an idle speed of $604 \mathrm{rpm}$. By mapping the engine prior to testing, actual horsepower and torque curves were used to determine setpoint values. The manufacturer specified and mapped values for horsepower, torque, and idle speed can be seen in Table 15, and the engine map used to determine setpoint values for all testing can be seen in Figure 15. There are inherent differences between manufacturer specified engine torque and power as a result of differences in dynamometers used, environmental conditions, and engine age. However, the decrease in maximum torque seen here was primarily attributed to the high backpressure created by the installation of the SCR catalyst and wire mesh mixer. Additionally, prior to testing (January $5,2009)$ the oil was changed with $15 \mathrm{~W}-40$ Rotella-T heavy-duty engine oil and the oil and fuel filters were replaced. The engine was certified at a level of $5 \mathrm{~g} / \mathrm{bhp}-\mathrm{hr}$ NOx, which maintained compliance with diesel emissions standards in 1991. The 1992 Detroit Diesel S60 engine can be seen below in Figure 16 and Figure 17.

During testing, the engine intake air flow was measured using a laminar flow element (LFE), Meriam Instruments model 50MC2-6. LFE differential pressure and air inlet temperature were measured in order to determine air flow to the engine. Additionally, the intake air humidity was measured in order to correct NOx measurements during data reduction. The engine exhaust was routed out of the turbocharger, through the aftertreatment system, and into the dilution tunnel through five inch exhaust pipe. Any bare exhaust pipe was insulated by wrapping fiberglass insulation mats around the pipe. Prior to entering the dilution tunnel, the exhaust pipe was fitted with a butterfly valve to adjust exhaust backpressure for different engines. For this testing, the valve was in the wide-open position to allow as little restriction as possible.

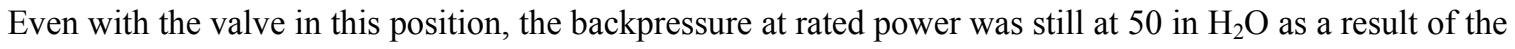
backpressure created by the aftertreatment system. 
Table 14. 1992 Detroit Diesel S60 engine specifications

\begin{tabular}{|l|c|}
\hline Engine Manufacturer & Detroit Diesel \\
\hline Model Year & 1992 \\
\hline Engine Model & Series 60 \\
\hline Model Number & $6067 \mathrm{GU} 60$ \\
\hline Serial Number & $06 \mathrm{R} 0105610$ \\
\hline Configuration & Inline-6 \\
\hline Displacement (L) & 12.7 \\
\hline Compression Ratio & $15: 1$ \\
\hline Bore x Stroke (mm x mm) & $135 \times 165$ \\
\hline Exhaust Gas Recirculation & $\mathrm{NO}$ \\
\hline Intercooled & YES \\
\hline
\end{tabular}

Table 15. 1992 Detroit Diesel S60 engine map data

\begin{tabular}{|r|c|c|}
\hline & $\begin{array}{c}\text { DDC } \\
\text { Specified }\end{array}$ & $\begin{array}{c}\text { Mapped } \\
\text { Value }\end{array}$ \\
\hline Max Power [hp] & 360 & 367.7 \\
\hline$@[\mathrm{rpm}]$ & 1810 & 1639 \\
\hline Max Torque [ft-lb] & 1450 & 1346.9 \\
\hline$@[\mathrm{rpm}]$ & 1200 & 1225 \\
\hline Idle Speed [rpm] & 600 & 604 \\
\hline
\end{tabular}




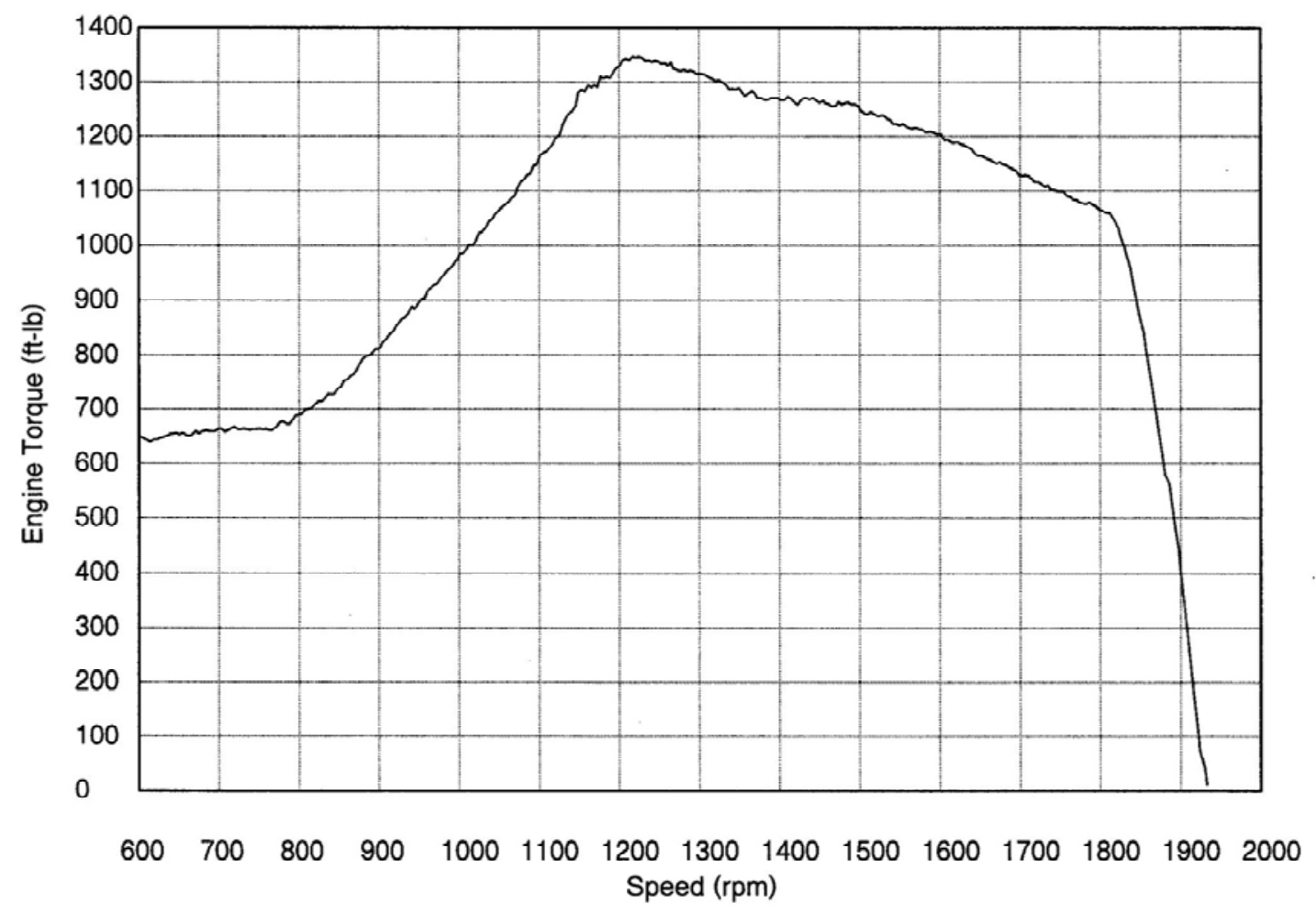

Figure 15. 1992 Detroit Diesel S60 engine map, torque (ft-lb) vs. speed (rpm).

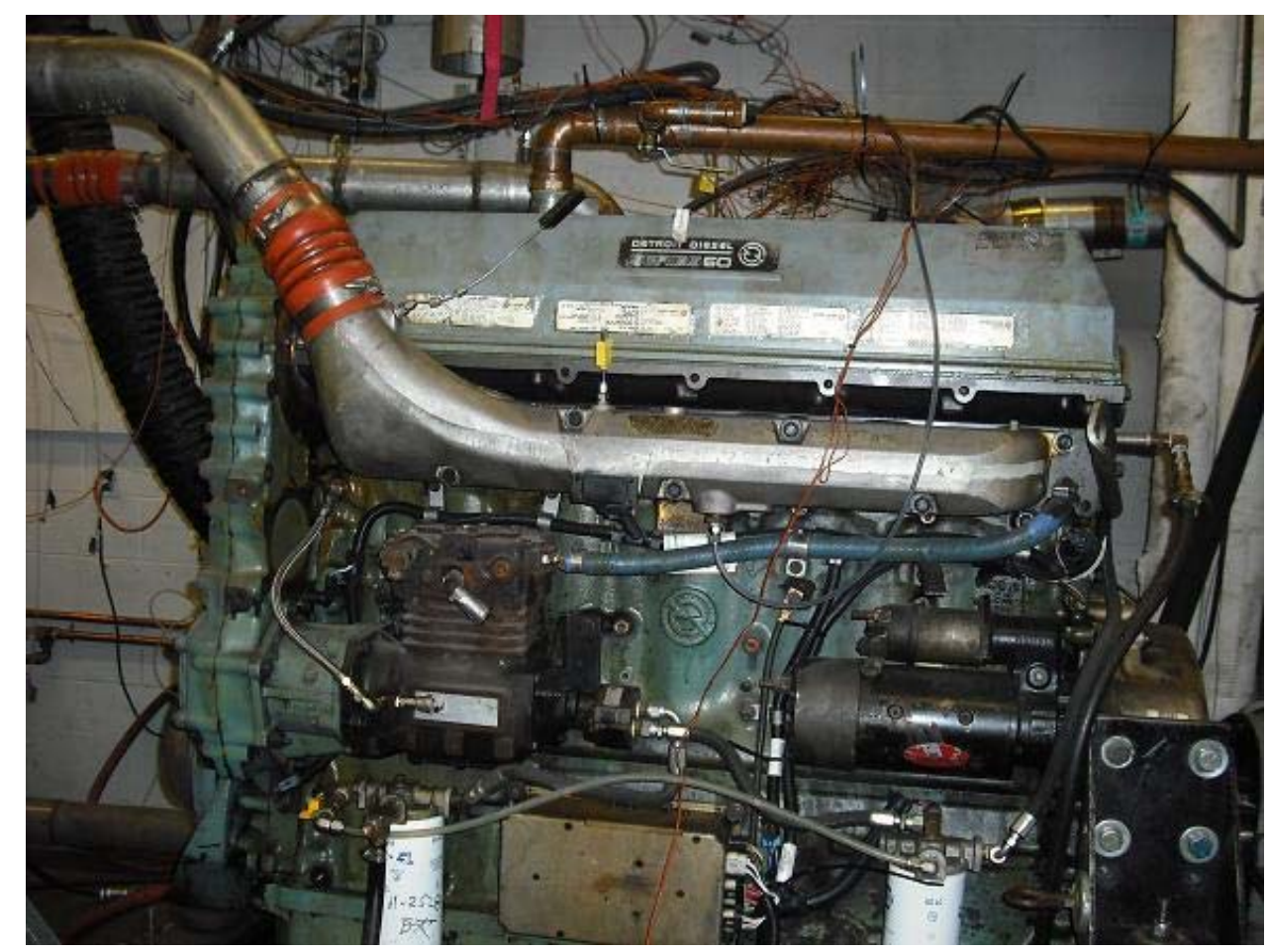

Figure 16. 1992 Detroit Diesel S60 Engine 


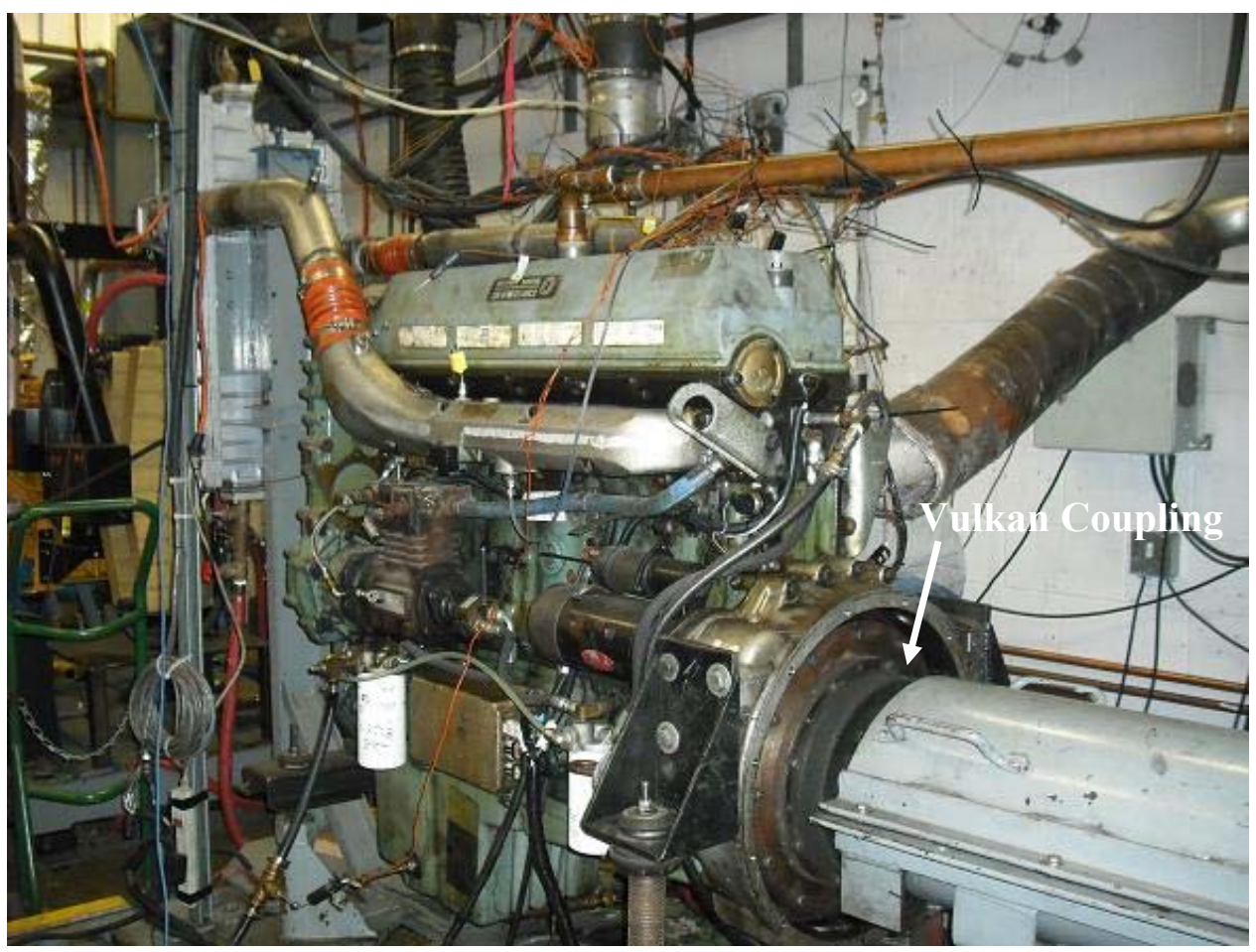

Figure 17. 1992 Detroit Diesel S60 Engine connected to the dynamometer

\subsection{Dynamometer}

The engine was installed in a transient test cell and connected to a General Electric (GE) DYC243 direct current (DC) engine dynamometer via a driveshaft and Vulkan coupling. A Vulkan coupling (see Figure 17) is a flexible coupling that is placed between the rigid driveshaft and engine flywheel in order to damp out vibrations that may cause mechanical failure of engine or driveshaft components at certain engine speeds. The General Electric dynamometer was capable of absorbing $550 \mathrm{hp}$ and delivering $500 \mathrm{hp}$. Prior to testing, the dynamometer was calibrated according to Center for Alternative Fuels, Engines, and Emissions (CAFEE) protocol [75].

The engine and dynamometer were controlled together electronically. Dimensionless setpoint engine speed and torque files for each test cycle were converted to engineering units using the engine map shown in Figure 15. Then, the engine and dynamometer were made to follow the setpoint values using PID control. Control of the engine and dynamometer must be sufficiently accurate as to comply with strict regression requirements regarding how closely the speed, torque, and power setpoints are followed. This is well established for the FTP and defined in the CFR $40 \$ 86.1341-90$ [30]. Regression requirements have also been established for the ACES modes during their creation at WVU [76]. Regression performance and standards for each cycle are discussed later in this document. A photograph of the GE engine dynamometer can be seen in Figure 18. 


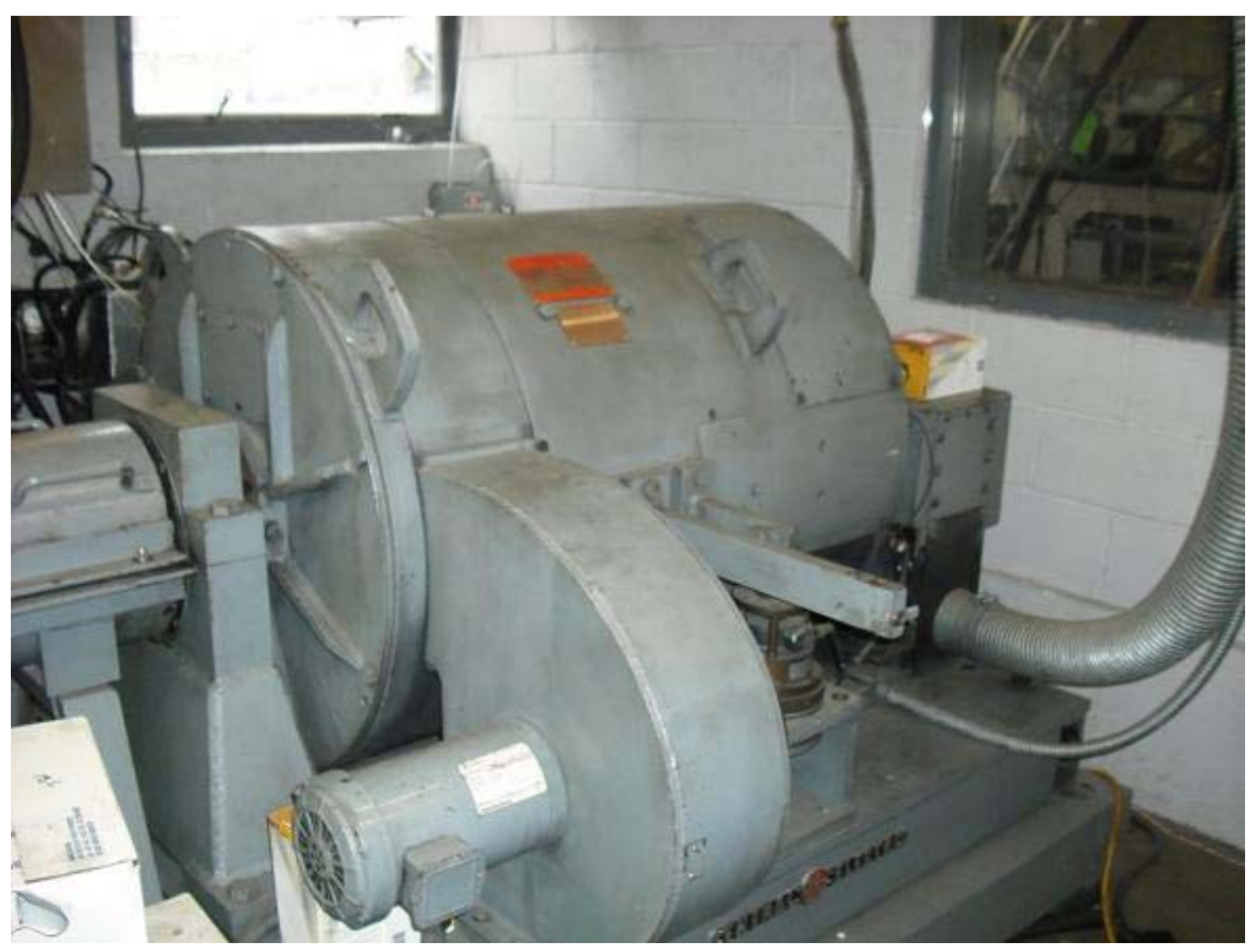

Figure 18. General Electric DC engine dynamometer

\subsection{Dilution Tunnel}

For emissions measurement, a full-scale dilution tunnel with constant volume sampling was implemented. The WVU EERL contains two separate dilution tunnels and analyzer sets. For this round of testing, the older of the two dilution tunnels was implemented, which complies with CFR $40 \$ 86.110-90$ for pre-2007 model year engines [30]. The dilution tunnel had a diameter of 18 inches and a set of four critical flow venturis (three 1000 cubic feet per minute $(\mathrm{cfm})$, one $400 \mathrm{cfm}$ ) were used to control dilution air flow. During testing, three of these venturis were in the open position, setting the tunnel flow to 2400 standard $\mathrm{cfm}(\mathrm{scfm})$. Air was pulled through the tunnel with a $75 \mathrm{hp}$ blower. Temperature and humidity were carefully controlled with air conditioning units and by varying steam flow in order to comply with CFR Part 86 standards for diesel emissions testing. The dilution air temperature and relative humidity were measured ahead of the dilution tunnel using a wet/dry bulb system and verified with an Edgetech DewPrime II hygrometer. With the chosen engine and tunnel flow settings, the average dilution factor varied, depending on cycle, from 12.05 (ACES HHDDT_S) to 116.66 (ACES Creep) for transient cycles, and 4.5 (rated speed/torque) to 153.77 (idle) for steady-state modes. The dilution tunnel, sample plane, and probes can be seen in Figure 19. 


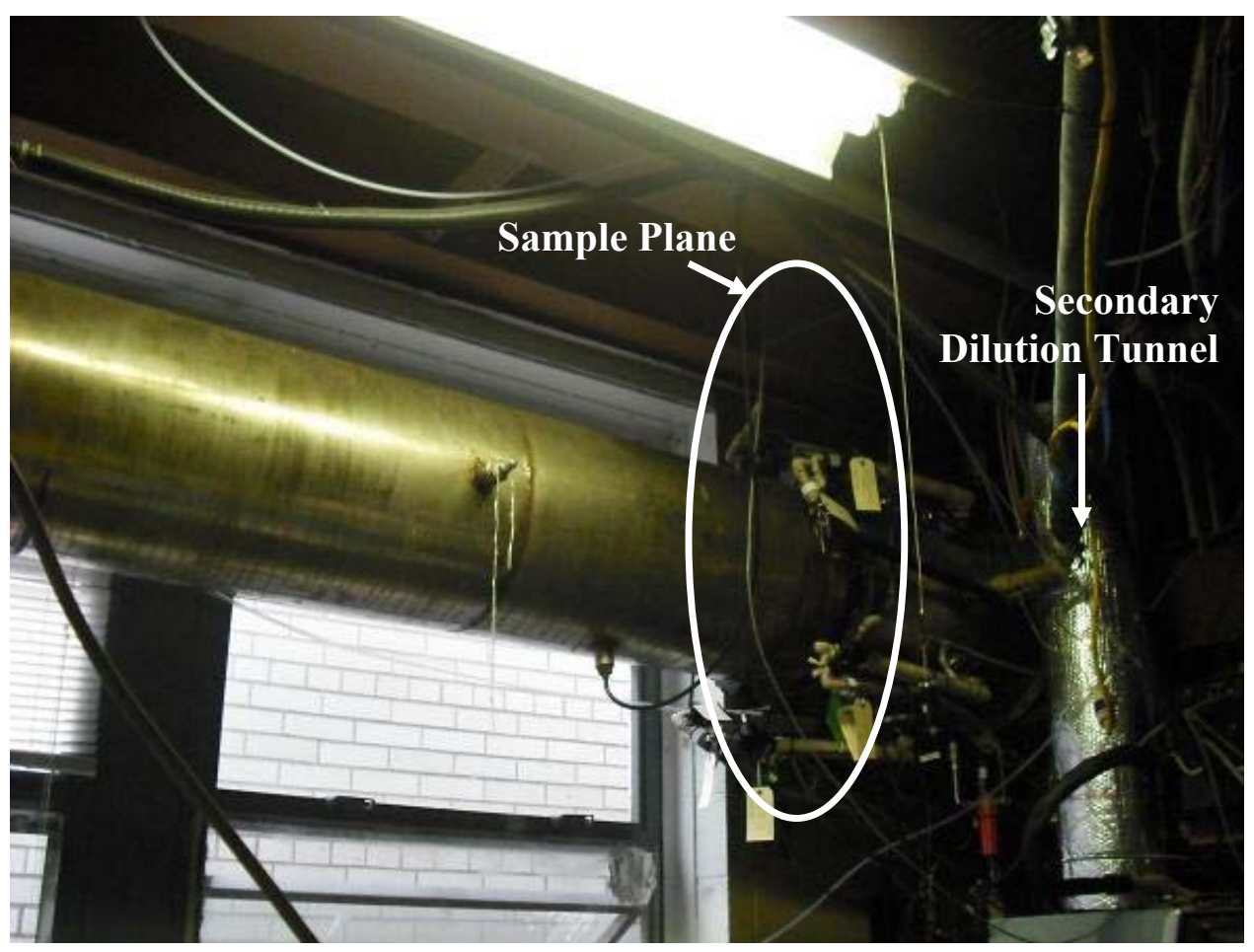

Figure 19. Dilution tunnel and sample plane

Prior to testing, propane injections were performed to ensure no leaks exist in the dilution tunnel or sampling lines. Propane was injected at the mixing orifice ahead of the tunnel. The same hydrocarbon analyzer as used for testing was implemented to verify that the concentration recovered at the sampling plane was the same as the concentration injected. According to CFR $40 § 86.1319-90$, the difference between the injected concentration and recovered concentration measured by the $\mathrm{HC}$ analyzer must be between $\pm 2 \%$ and WVU requirements dictate that three consecutive injections must fall within a $\pm 0.5 \%$ range [30]. The propane injection kit hooked up to the dilution tunnel at the mixing orifice can be seen in Figure 20. 


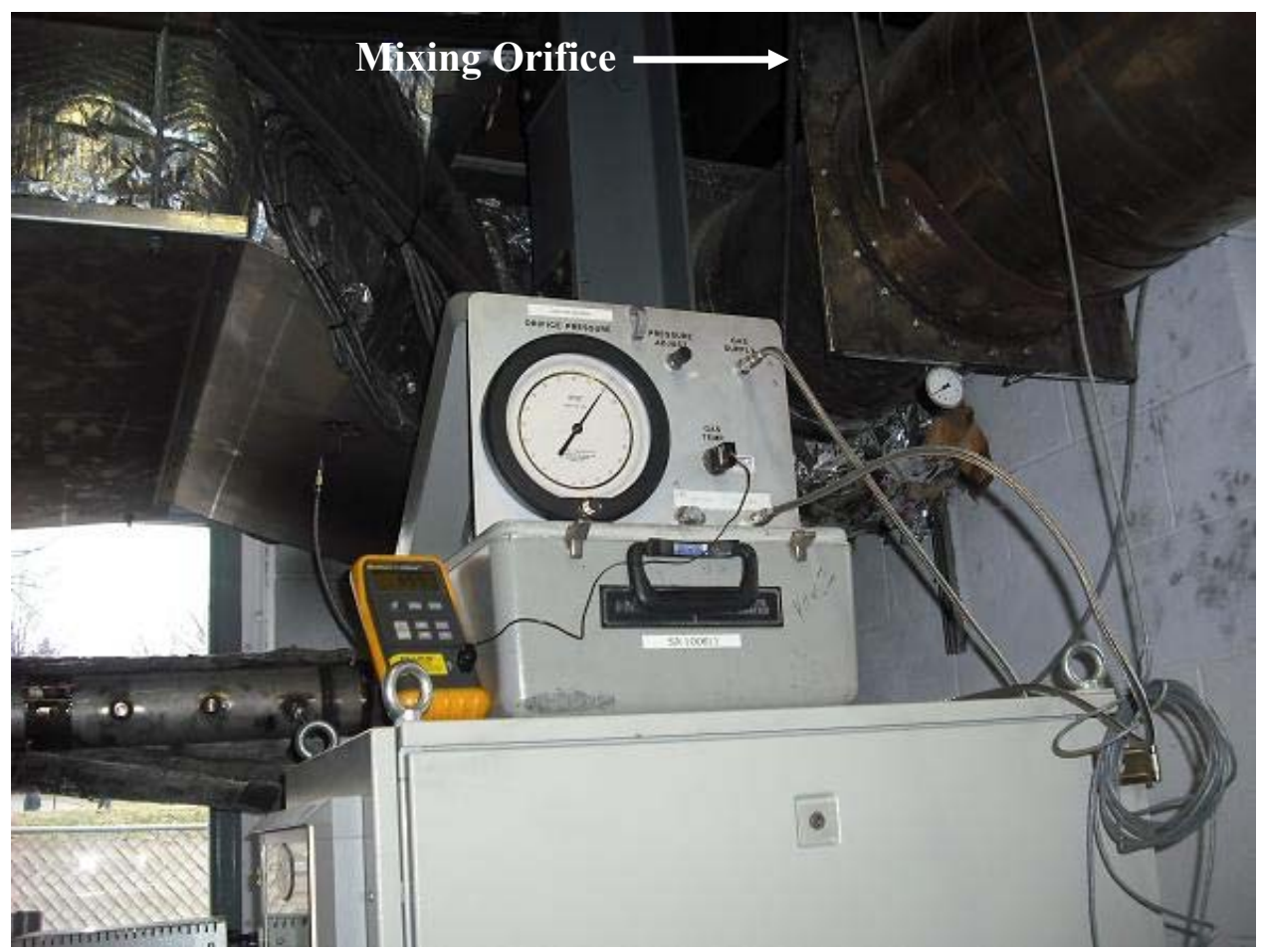

Figure 20. Propane injection kit connected to dilution tunnel

\subsection{Gaseous Emissions Sampling}

Gaseous emissions of $\mathrm{CO}, \mathrm{CO}_{2}, \mathrm{THC}$, and $\mathrm{NOx}$ were measured during testing. In addition, $\mathrm{NH}_{3}$ was measured for urea injection runs. PM was measured using a gravimetric approach and secondary dilution tunnel. A mixing orifice was at the tunnel inlet to allow mixing of dilution air and exhaust gases. All gaseous emissions were measured in a common sample plane within the dilution tunnel, a distance of 10 tunnel diameters from the inlet as specified by CFR Part 86 [30].

THC emissions were measured using a heated flame ionization detector (FID), California Analytical 600HFID. Operation of a FID relies on a continuous flame, produced by burning a FID fuel. The FID fuel used for the analyzer was $40 \% \mathrm{H}_{2}$, with the balance $\mathrm{He}$. The THC analyzer was spanned using a $10.1 \mathrm{ppm}$ bottle of $\mathrm{C}_{3} \mathrm{H}_{8}$ (propane) and zeroed using dry air, which was generated at the EERL. Prior to testing, an elevenpoint calibration was performed using a gas divider and the span gas. The THC analyzer produced a linear response. The THC analyzer sample lines, pump, filter, and probe were all heated to $375 \pm 20^{\circ} \mathrm{F}$ to ensure condensation of water vapor and heavier hydrocarbon species did not occur.

$\mathrm{CO}$ and $\mathrm{CO}_{2}$ emissions were measured using Horiba AIA-220 analyzers. These analyzers are nondispersive infrared (NDIR) devices, which operate on a principal of infrared absorption in gases. Different gases absorb different wavelengths of light in the infrared spectrum. At a given wavelength, the concentration of a gas is proportional to the amount of infrared light absorbed. The sample lines, pump, filter, and probe of the $\mathrm{CO} / \mathrm{CO}_{2}$ analyzers were heated to $235 \pm 20^{\circ} \mathrm{F}$ to ensure condensation of water vapor 
did not occur. Prior to entering the actual analyzer module, water vapor was removed using a chiller unit. For this testing period a single $\mathrm{CO}$ analyzer was used because the expected $\mathrm{CO}$ emissions were fairly low $(<1000 \mathrm{ppm})$. Span gas concentrations for the $\mathrm{CO}$ and $\mathrm{CO}_{2}$ analyzer were $986.6 \mathrm{ppm}$ and $3.494 \%$, respectively. The $\mathrm{CO}$ and $\mathrm{CO}_{2}$ analyzers produced non-linear responses, as expected, and were eleven-point calibrated with a gas divider and span gases.

For this round of testing, two different NOx analyzers were used, an Ecophysics CDL $822 \mathrm{CMh}$ and Rosemount 955. Both of these are heated, wet chemiluminescent analyzers. These analyzers first convert any $\mathrm{NO}_{2}$ to NO. Ozone $\left(\mathrm{O}_{3}\right)$ is generated within the analyzer and reacts with the NO sample. This reaction produces activated $\mathrm{NO}_{2}$ and generates photographns, which can be measured and are proportional to the concentration of NOx in the sample. To ensure good NOx measurement resolution, high and low analyzer calibrations and span gas concentrations were employed, depending on the test cycle being run. High NOx modes included the ACES Cruise, ACES HHDDT_S, and the ICOMIA steady-state. Low NOx modes included the ACES Transient, Creep, and the FTP. The high NOx span gas concentration was $506 \mathrm{ppm}$, while the low concentration was $251 \mathrm{ppm}$. Both NOx analyzers were also eleven-point calibrated using a gas divider and produced a linear response.

The Rosemount analyzer measured total NOx and NO using this principal. The Ecophysics analyzer however can measure $\mathrm{NOx} / \mathrm{NO}$ and $\mathrm{NOx} / \mathrm{NOx}+\mathrm{Am}$. For urea injection runs, the Ecophysics analyzer was run in the NOx/NOx+Am mode to quantify ammonia slip. This measurement mode does have its drawbacks. It assumed that the difference between total nitrogen compounds and $\mathrm{NOx}$ was $\mathrm{NH}_{3}$. As a result of this differencing, errors may occur at low concentrations and transient response may be limited. The sample lines, pump, filter, and probe were maintained at $235 \pm 20^{\circ} \mathrm{F}$ to ensure condensation of water vapor did not occur. A photograph of the $\mathrm{CO}, \mathrm{CO}_{2}, \mathrm{NOx}$ and THC analyzer bench can be seen below in Figure 21. 


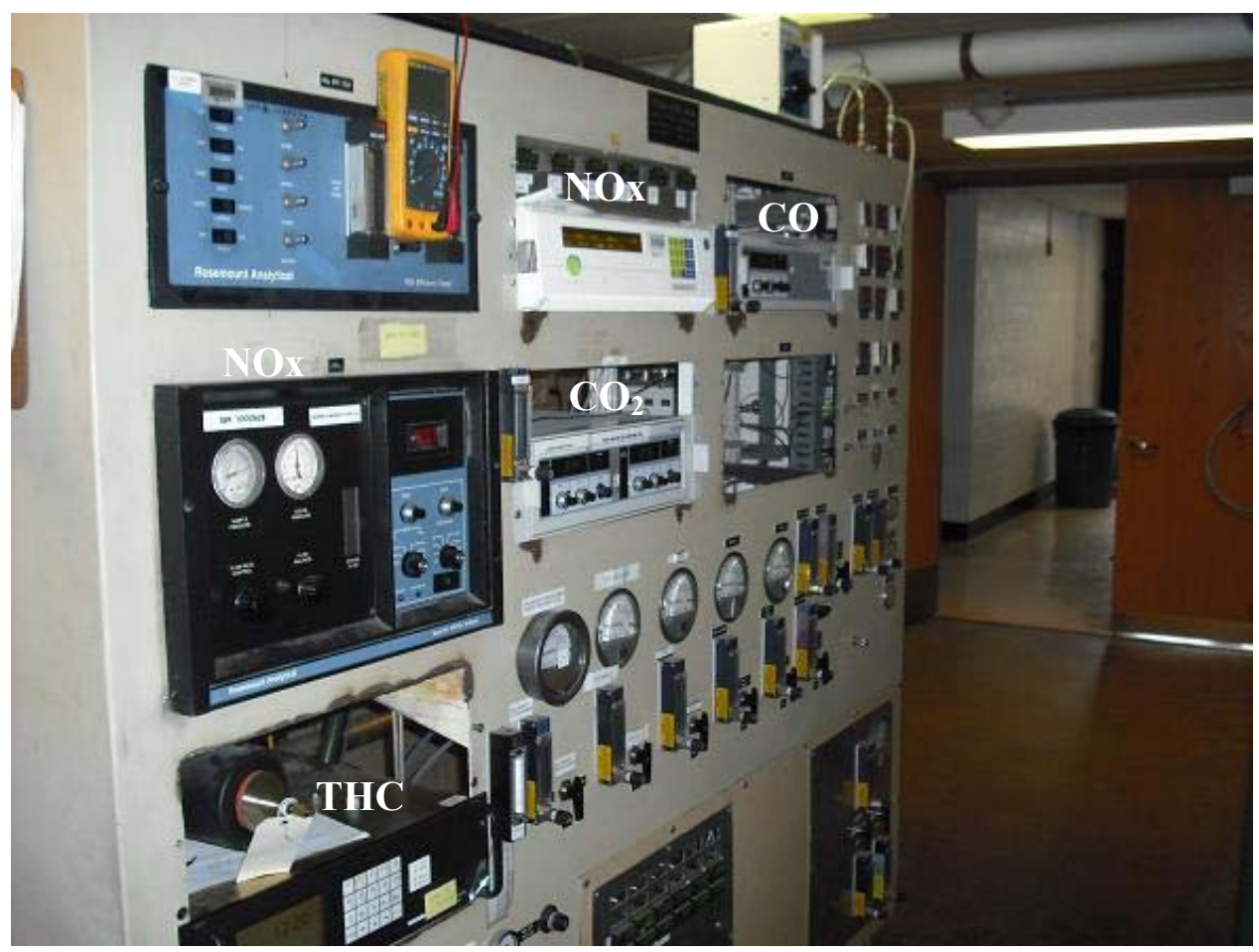

Figure 21. Analyzer bench (CO, $\left.\mathrm{CO}_{2}, \mathrm{THC}, \mathrm{NOx}\right)$

In order to accurately measure ammonia slip during testing, particularly during steady-state operation, an ABB AO2000 LIMAS11HW non-dispersive ultraviolet (NDUV) analyzer was employed. The NDUV analyzer is a process photographmeter, for measuring gas filter correlation or wavelength comparison in ultraviolet and visible light spectrum ranges [77]. The analyzer had three separate modules for measuring $\mathrm{NO}, \mathrm{NO}_{2}$, and $\mathrm{NH}_{3}$, which were each zeroed, spanned, and calibrated separately. Prior to and during testing, eleven-point calibrations were performed using bottled $\mathrm{NO}(506 \mathrm{ppm})$ and $\mathrm{NO}_{2}(261 \mathrm{ppm})$. The $\mathrm{NH}_{3}$ channel was two-point calibrated using an internal calibration cell $(410.33 \mathrm{ppm})$ and verified with bottled $\mathrm{NH}_{3}(50 \mathrm{ppm})$. Gas bottle details can be seen in Table 17 below.

During setup of the NDUV analyzer, several different sample pressures were used. The manufacturer documentation specified that sample pressures of 0.02-7.5 psig may be used [77]. It was found that a sample pressure of $0.2 \mathrm{psig}$ provided good results, and higher pressures did not increase transient response. The filter, pump, and probe were maintained at $350 \pm 20^{\circ} \mathrm{F}$, while the sample line was maintained at $300 \pm 20^{\circ} \mathrm{F}$ because of tolerances of the heated line. The NDUV analyzer does suffer from slow transient response. However, it can measure steady-state $\mathrm{NH}_{3}$ very well, and help to quantify periods of high $\mathrm{NH}_{3}$ slip during transient testing. 


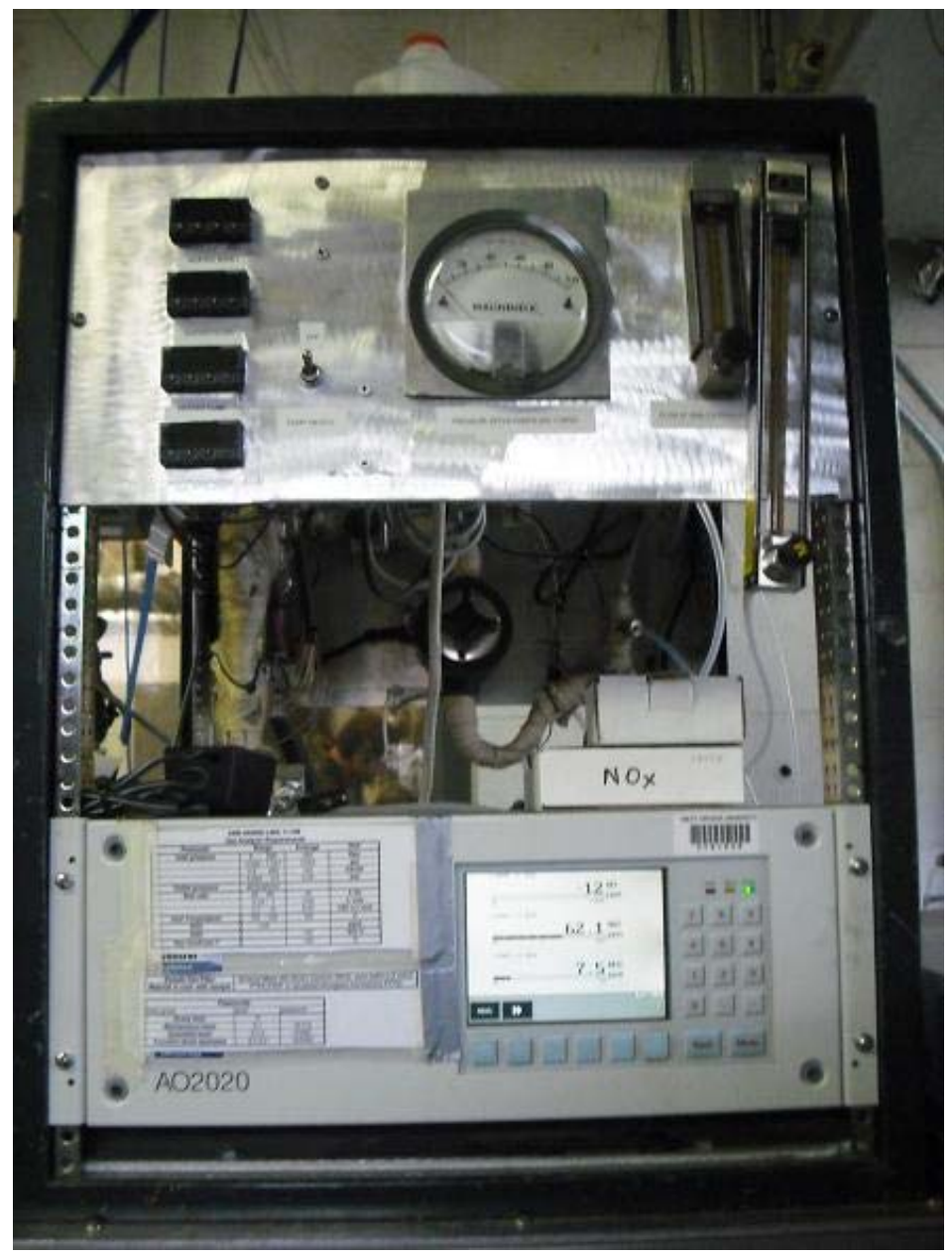

Figure 22. ABB AO2000 LIMAS11HW NDUV analyzer

Complete specifications for all analyzers and gas bottles can be seen in Table 16 and Table 17, respectively. Sample temperatures and pressures for all analyzers can be seen in Table 18. A photographgraph of the gas bottles (except $\mathrm{NH}_{3}$ and $\mathrm{NO}_{2}$ ) used for all analyzers can be seen in Figure 23 . 


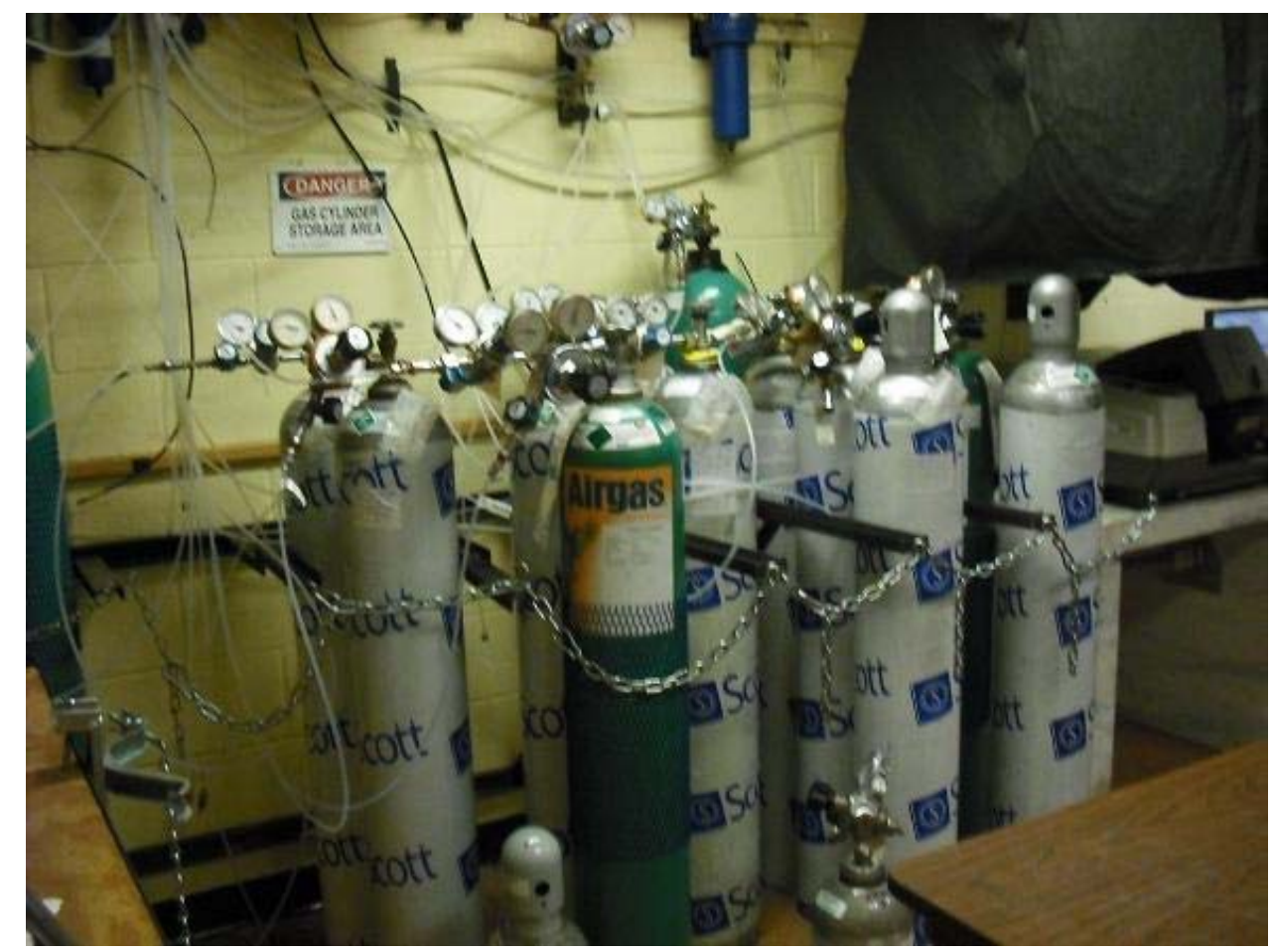

Figure 23. Gas bottles used for analyzer calibrations

Table 16. Analyzer specifications $\left(\mathrm{CO}, \mathrm{CO}_{2}, \mathrm{THC}, \mathrm{NOx}, \mathrm{NH}_{3}\right)$

\begin{tabular}{|c|c|c|}
\hline Analyzer & Model No. & Serial No. \\
\hline THC & California Analytical 600-HFID & 507071 \\
\hline $\mathrm{CO}$ & Horiba AIA-220 & 4345863004 \\
\hline $\mathrm{CO}_{2}$ & Horiba AIA-220 & 4345863004 \\
\hline $\mathrm{NOx}$ & Ecophysics CDL 822 CMh & $822 \mathrm{CMh0279}$ \\
\hline $\mathrm{NOx}$ & Rosemount 955 & 1000628 \\
\hline $\mathrm{NH}_{3}\left(\mathrm{NO}, \mathrm{NO}_{2}\right)$ & ABB A02000 LIMA 11HW & $24911-0-0336404050602$ \\
\hline
\end{tabular}


Table 17. Gas bottle specifications

\begin{tabular}{|c|c|c|c|c|}
\hline Gas & Conc. & Pressure (psig) & Part No. & Cylinder No. \\
\hline $\mathrm{C}_{3} \mathrm{H}_{8}(\mathrm{THC})$ & $10.1 \mathrm{ppm}$ & 1100 & 1023411 & ALM054135 \\
\hline $\mathrm{CO}$ & $986.6 \mathrm{ppm}$ & 850 & 01020000860DAL & 1 L2623 \\
\hline $\mathrm{CO}_{2}$ & $3.494 \%$ & 700 & X02N196P15A62F4 & CC97892@ \\
\hline $\mathrm{NOx} / \mathrm{NO}$ & $506 / 505 \mathrm{ppm}$ & 800 & $01020002470 \mathrm{DL}$ & ALM017193 \\
\hline $\mathrm{NOx}^{2}$ & $251 \mathrm{ppm}$ & 600 & $01020002470 \mathrm{DL}$ & ALM060961 \\
\hline $\mathrm{NO}_{2}$ & $261 \mathrm{ppm}$ & 2150 & & ALM0629 \\
\hline Zero Air & $999999 \mathrm{ppm}$ & 80 & -- & Lab Generator \\
\hline $\mathrm{N}_{2}$ & $999990 \mathrm{ppm}$ & 2500 & -- & AFW414 \\
\hline $\mathrm{THC} \mathrm{FID}^{2}$ & $40 \% \mathrm{H} 2, \mathrm{Bal} \mathrm{He}$ & 2200 & X02HE60A3003005 & SG869199A@ \\
\hline $\mathrm{NH}_{3}$ & $50 \mathrm{ppm}$ & 1800 & -- & A1M064883 \\
\hline
\end{tabular}

Table 18. Analyzer sample temperatures $\left({ }^{\circ} \mathrm{F}\right)$ and pressures $\left(\mathrm{psig} /\right.$ in $\left.\mathrm{H}_{2} \mathrm{O}\right)$

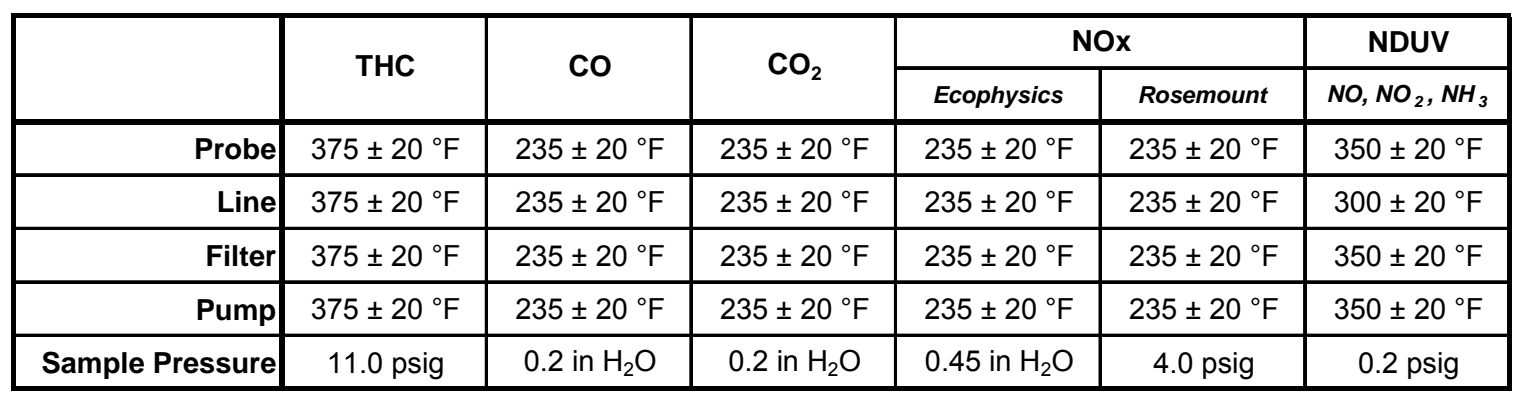

All of the analyzers discussed above had analog voltage outputs. These outputs were fed into 3B analog-todigital converter (ADC) modules. These modules produced digital outputs (or ADC codes), which were read by the data acquisition/control computer. The 3B module itself may be adjusted to produce appropriate zero and span ADC values similar to how the analyzer outputs may be adjusted. Each 3B module had an accuracy of $\pm 2 \%$ of full scale $( \pm 0.1 \mathrm{~V}, \pm 82 \mathrm{ADC}$ codes). The data acquisition software then converted ADC values into engineering units using calibration curves generated from the multi-point calibrations. The eleven (or two for NDUV) point calibrations performed for each analyzer adjusted the data acquisition software in order to obtain desired engineering-unit responses. The data acquisition/control computer can be seen in Figure 24. 


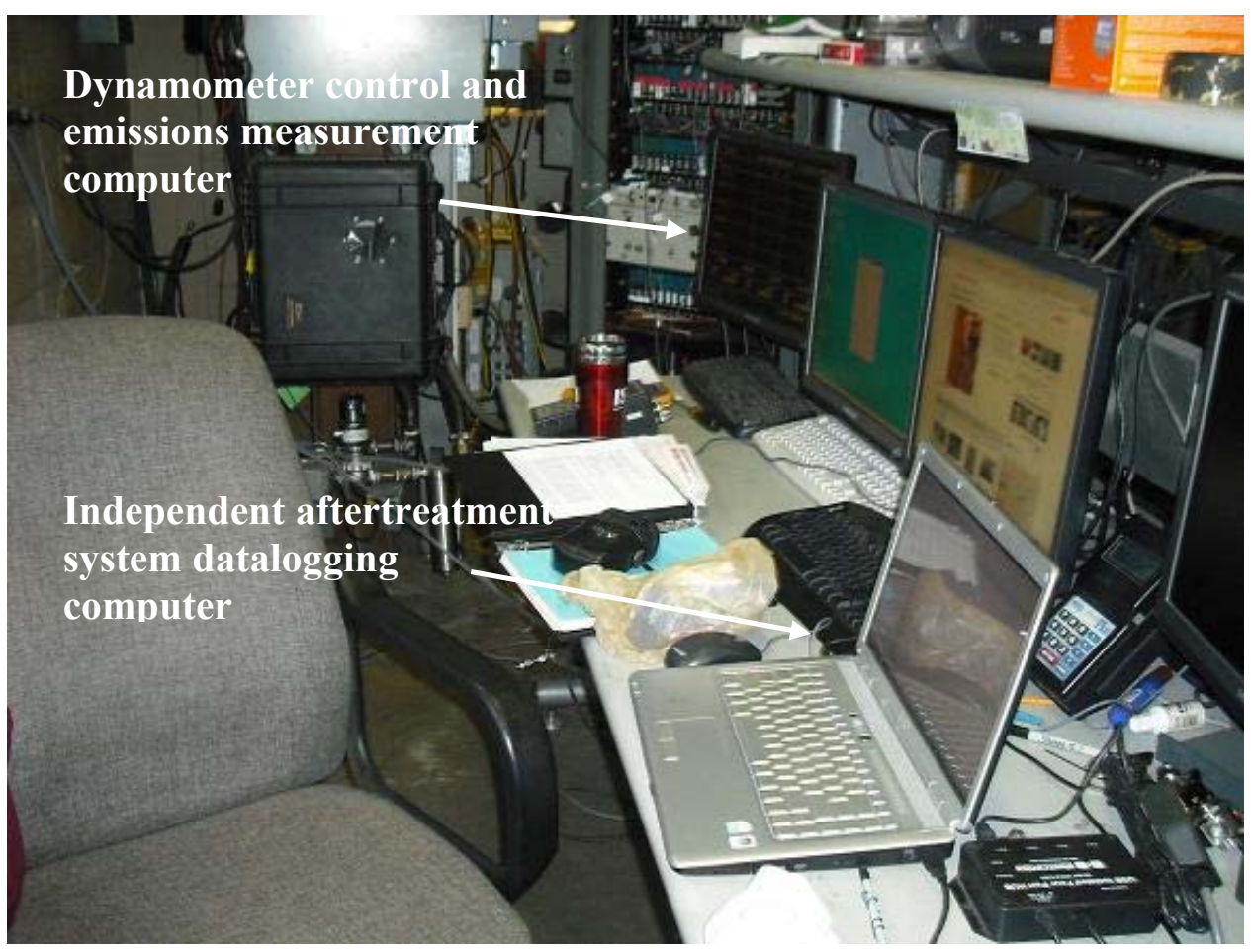

Figure 24. WVU EERL control console area

\subsection{Particulate Matter Sampling}

A gravimetric approach was used for particulate matter measurement. A slipstream of diluted exhaust gas was taken from the primary dilution tunnel. The slipstream entered a secondary dilution tunnel (seen in Figure 19), where it was further diluted before flowing into a stainless steel filter holder, housing a $70 \mathrm{~mm}$ fluorocarbon-coated glass fiber filter, model T60A20. The double-diluted sample was maintained at $125^{\circ} \mathrm{F}$ in accordance with CFR $40 \S 86.1310-90$ [30]. Similar to the primary dilution ratio, the secondary dilution ratio also varied with test cycle. Prior to testing, each $70 \mathrm{~mm}$ filter was pre-conditioned for at least an hour and pre-weighed in a clean room environment, according to CFR $40 \S 86.1312-2007$ [30]. Pre and postweighing was performed within a clean room using a Sartorius SE2-F ultra-microbalance. Again, prior to post-weighing, the filter was conditioned for at least an hour. At the beginning or end of each day, a timed background run was performed to correct measurements for ambient PM levels. This filter was pre and post-weighed using the same procedure as for test filters. A photograph of the clean room environment can be seen in Figure 25. 


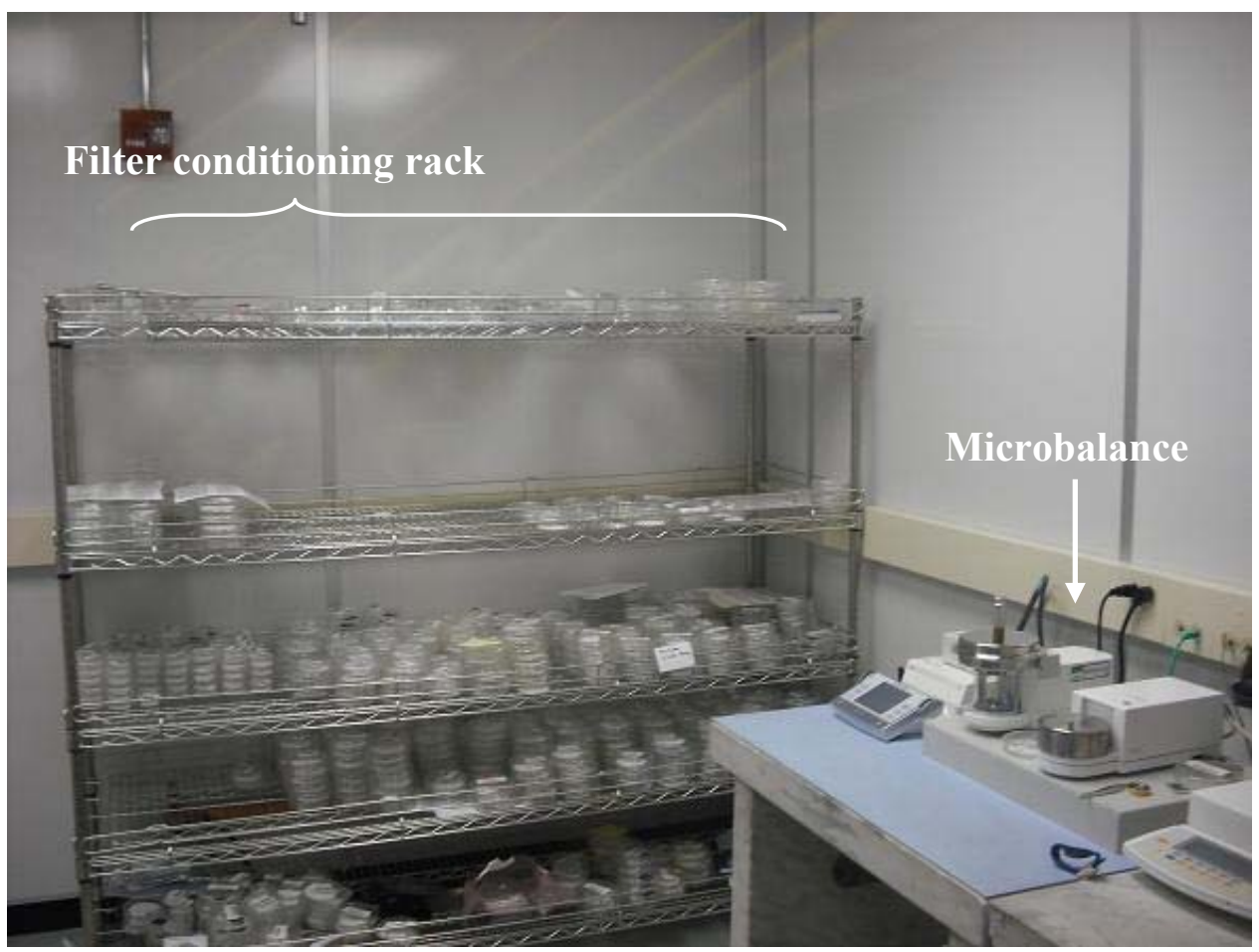

Figure 25. Clean room environment

\subsection{Bag Sampling}

In order to correct the measured gaseous emissions for ambient levels, samples of the dilution air (background) and diluted exhaust (dilute) were collected. The background sample was taken prior to entering the dilution tunnel, while the dilute sample was taken at the sample plane. During each test, a portion of the dilution air and diluted exhaust were routed into separate 80 liter Teldar bags. The flow rate into each bag was set according to the test cycle length in order to fill the bags enough to provide stable background and dilute readings. After each run, the contents of the background and dilute bags were pumped into the analyzers. After waiting approximately two minutes for analyzer readings to stabilize, the values were saved in the control software to be used during data reduction. A photograph of the background and dilute bags can be seen in Figure 26 . 


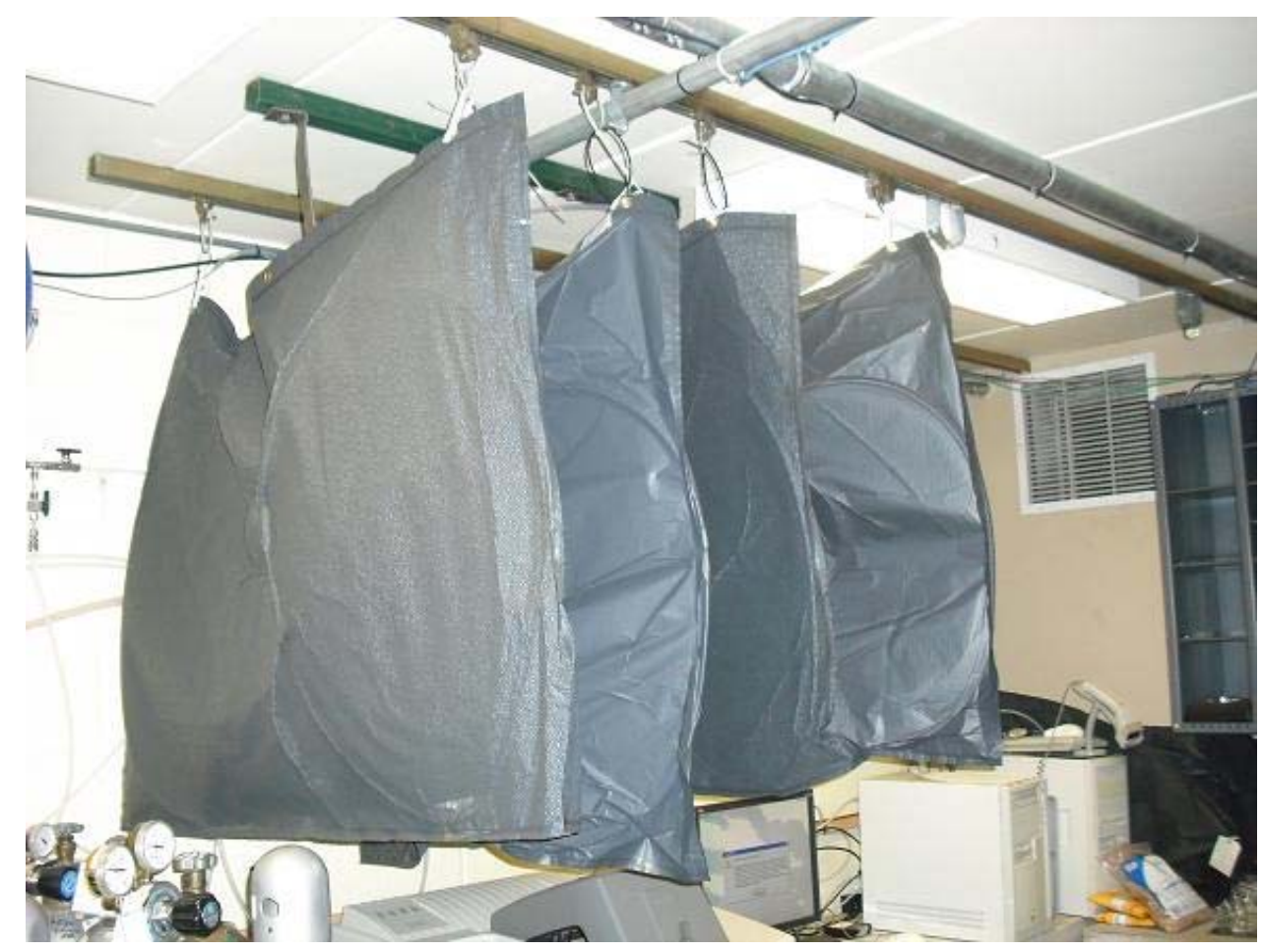

Figure 26. Background and dilute bags

\subsection{Fuel Measurement}

The fuel utilized for testing was Guttman ULSD fuel from a 500-gallon fuel tank at the WVU EERL. Fuel was moved into a 16-gallon barrel, where the fuel pickup and return from the DDC engine were connected. Three methods were used for determining fuel consumption. The first method was to directly measure the fuel barrel weight during testing with a scale and record before and after weights. The fuel barrel and scale can be seen in Figure 27. The second was to record the fuel flow rate measured by a Max Machinery, model 710, fuel conditioning system. The last method was to perform a carbon balance according to the measured emissions. By knowing properties of the fuel (chemical formula, molecular weight) and total $\mathrm{CO}$, $\mathrm{CO}_{2}$, and THC emissions for a given test, a chemical reaction formula could be used to determine fuel consumption during the test. A comparison of the three fuel consumption methods for each run can be seen in the results section below. 


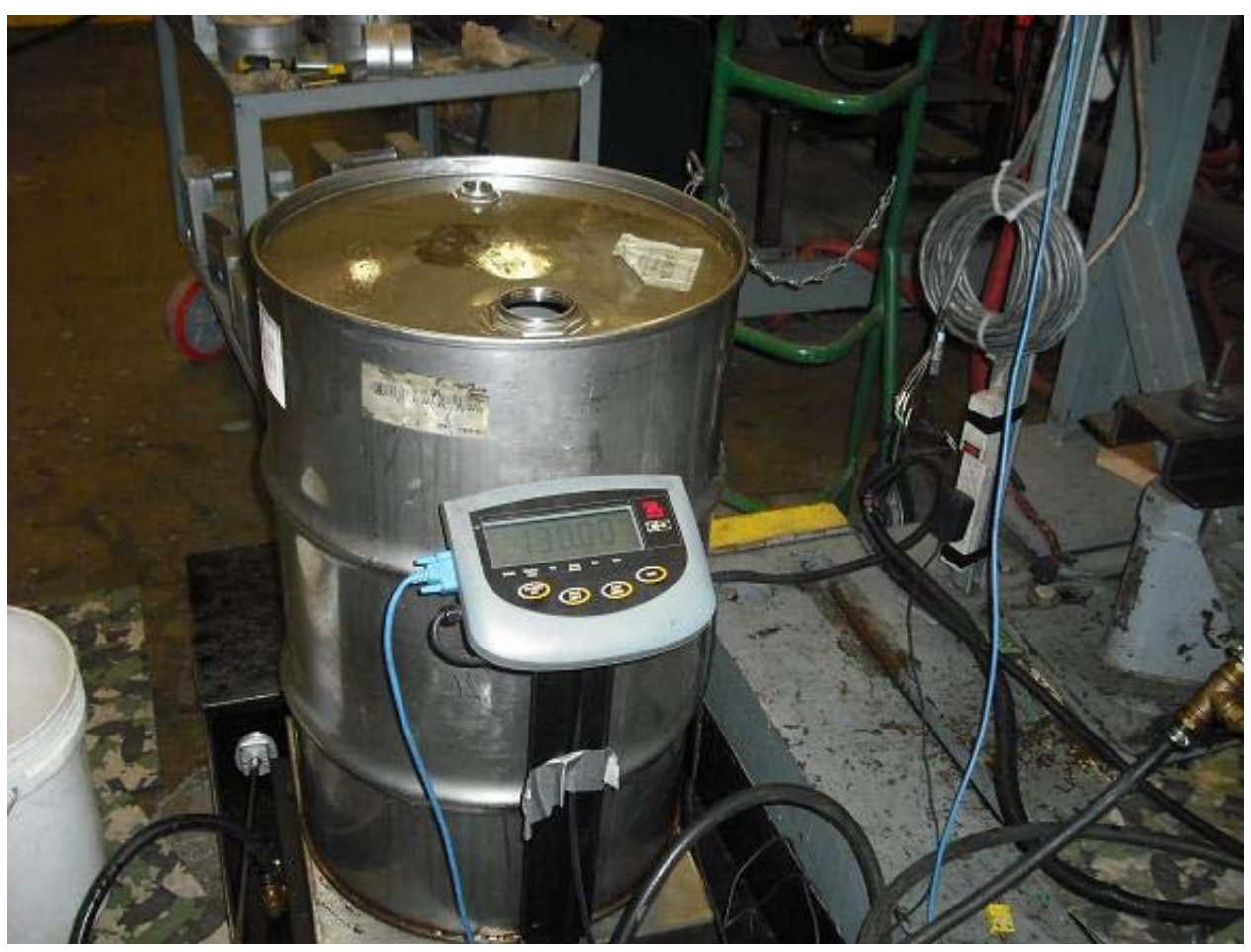

Figure 27. Fuel barrel and scale 


\section{Chapter 5: Aftertreatment System Installation}

The urea-SCR system was connected to the 1992 Detroit Diesel Series 60 engine exhaust in the test cell. The measurement/injection section, mixer, and SCR catalyst were installed along a straight section of pipe located approximately 6 feet from the turbocharger outlet. Prior to the straight section of pipe were two $90^{\circ}$ elbows and a section of flex-pipe to isolate the exhaust transfer pipe from engine vibrations. To ensure fully developed flow at the pitot-tubes, a 40 inch ( 8 diameters) length of straight pipe preceded the aftertreatment system. The measurement/injection section can be seen below in Figure 28. The exhaust pipe was mostly supported with existing hardware; however additional support was required for the SCR catalyst because of its weight, which can be seen in Figure 29.

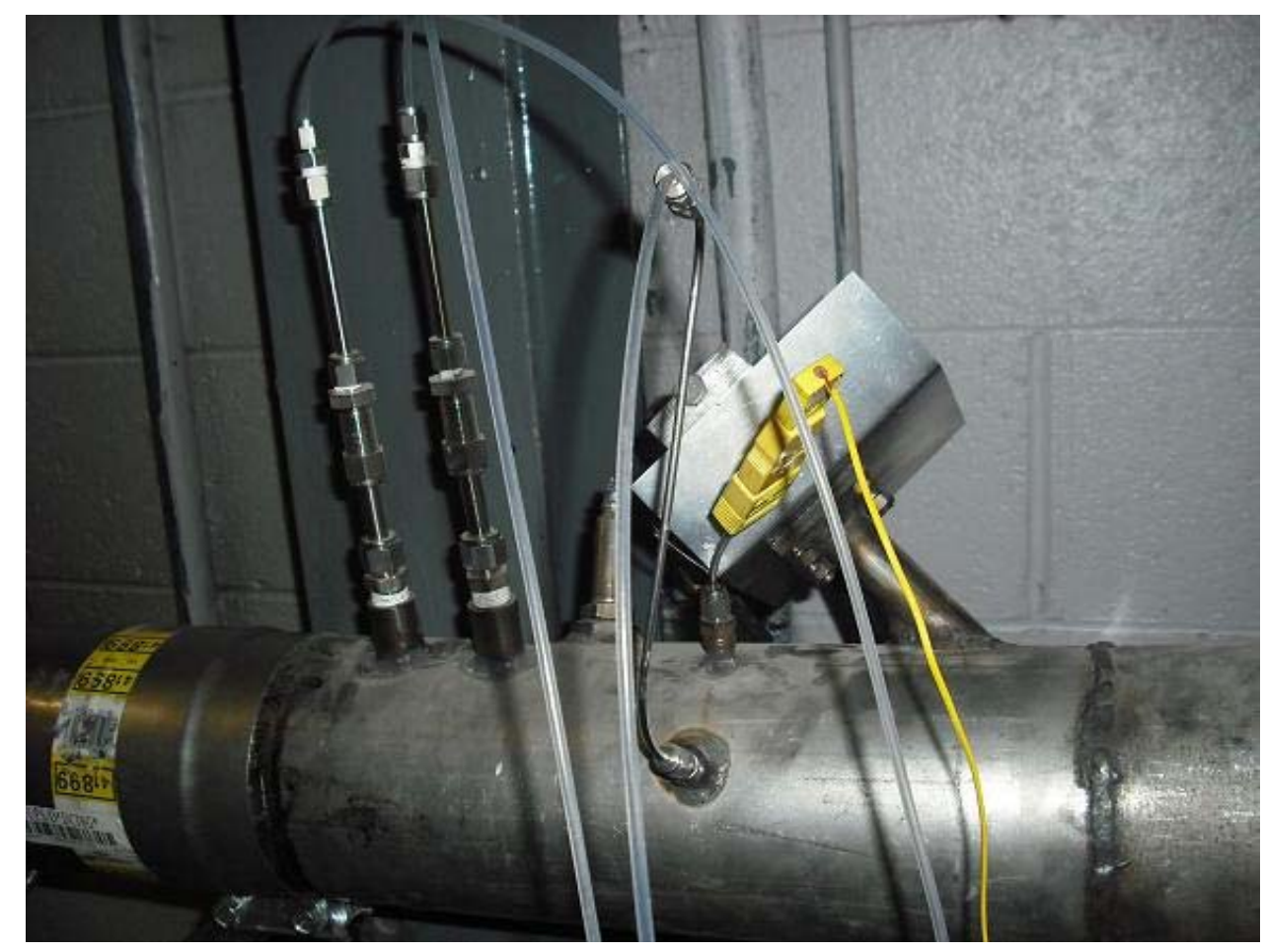

Figure 28. Urea-SCR system installed at WVU 


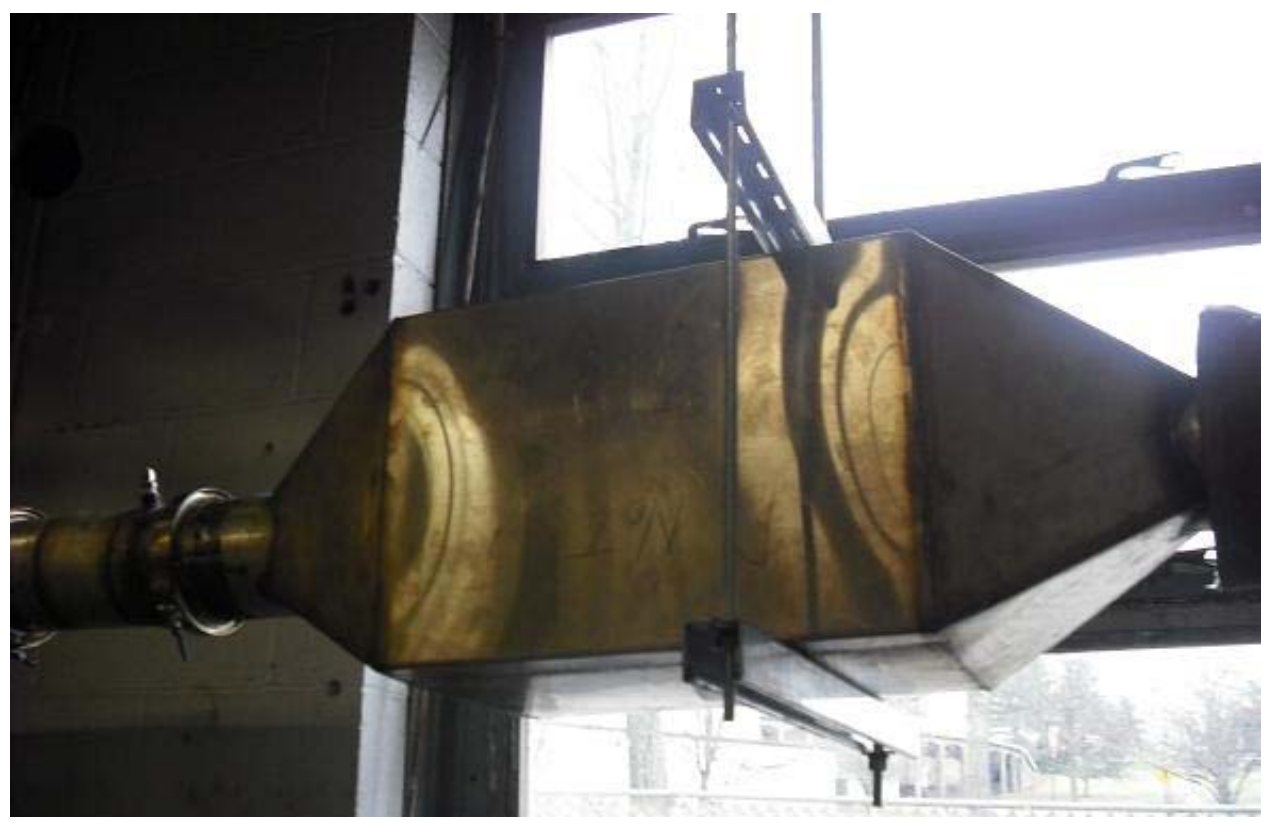

Figure 29. SCR catalyst installed at WVU

After exiting the SCR catalyst, the exhaust was routed out of the test cell, through a backpressure control valve, and into the dilution tunnel. All bare exhaust pipe not associated with the aftertreatment system was wrapped with standard fiberglass insulation to reduce heat loss. A diagram of the exhaust routing can be seen in Figure 30.

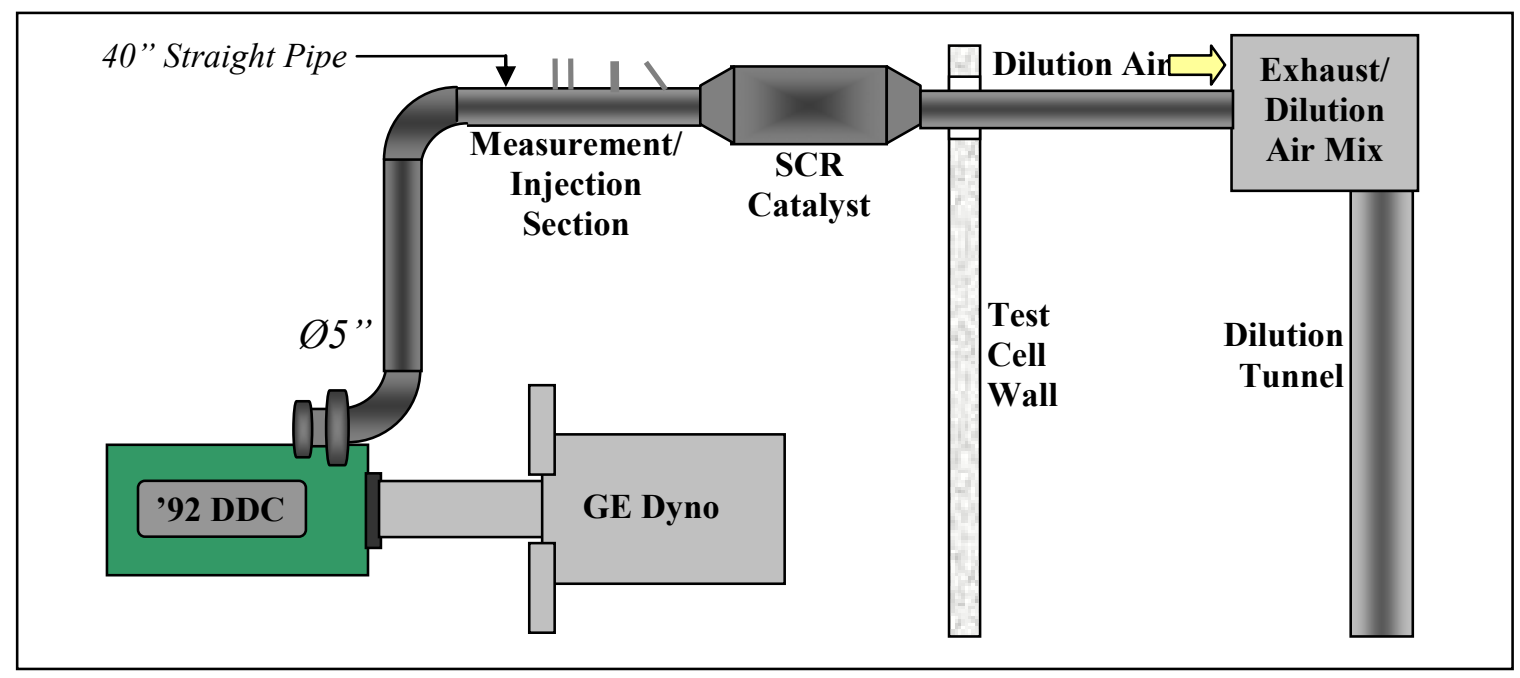

Figure 30. Urea-SCR system install diagram

All instrumentation for the urea-SCR system, urea tank, pump, and Motohawk controller were located on a cart placed under the exhaust inside the test cell. Communication between the Motohawk controller and a laptop computer outside the test cell was possible using an extended CAN cable. This allowed data- 
logging, calibration, and continuous real-time data viewing from the EERL control center (see Figure 24) using a laptop and Mototune software.

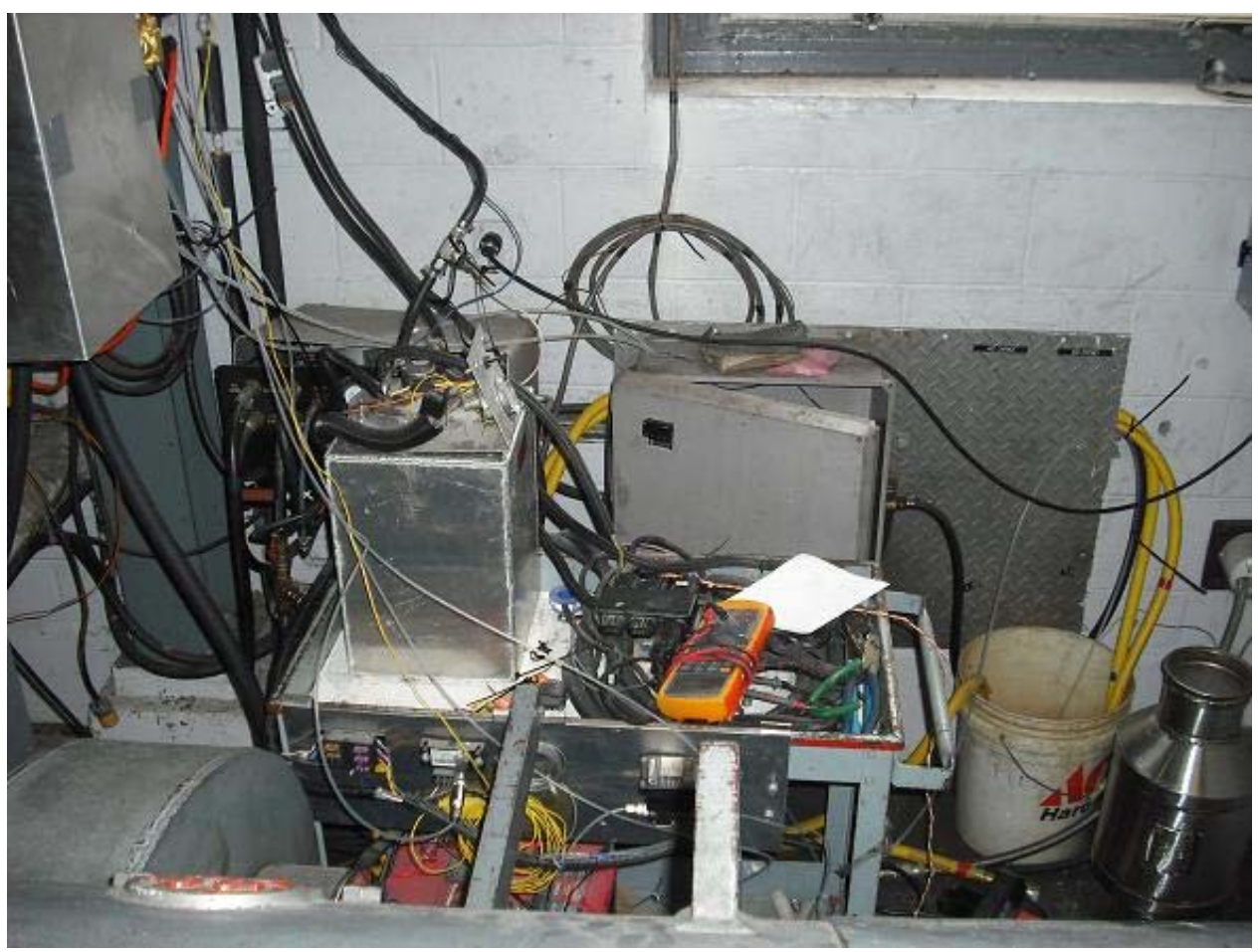

Figure 31. Urea-SCR system instrumentation cart 


\section{Chapter 6: Test Cycles}

During testing, several engine cycles were implemented. The urea-SCR system was designed to operate completely independent of engine communication. As a result, the system is versatile, capable of being retrofit on various engines and applications. This primarily includes on-road, off-road, and marine engines.

\subsection{ICOMIA E5}

The urea-SCR aftertreatment system originally targeted marine applications. As a result, a steady-state marine cycle was implemented during testing of the system. The ICOMIA specify two cycles for marine diesel engines (E3 and E5) and one for marine gasoline engines (E4) [78]. The ICOMIA E5 test cycle is a five point steady-state marine diesel engine test cycle using the specifications given in ISO 8178 as its test method [78]. It consists of five differently weighted points on a propeller curve, which describe a second order speed-torque relationship. The ICOMIA E3 test cycle was exactly the same as the E5, except for the omission of the final idle mode. The E3 cycle may be optionally chosen for determining exhaust gas emissions for engines above $174 \mathrm{hp} \mathrm{[78].} \mathrm{The} \mathrm{test} \mathrm{points} \mathrm{for} \mathrm{both} \mathrm{cycles} \mathrm{were} \mathrm{originally} \mathrm{specified} \mathrm{in} \mathrm{terms}$ of dimensionless speed (\%speed) and power (\%power) (see Appendix A). Prior to testing, the E5 test points were converted to engineering units for the 1992 Detroit Diesel engine based on a recent engine map. The final E5 test points, corresponding weighting factors (time weighted), and gas/PM sample times can be seen in Table 19. During testing, a stabilization period was included before each stage to ensure engine operating parameters were stabilized. The shortest mode length was chosen to have sufficient length for meaningful PM data to be collected. A single PM filter was utilized over the entire ICOMIA E5 test cycle, in a manner similar to the steady-state test procedure dictated in CFR 40 §86.1360-2007 [30].

Table 19. ICOMIA E5 steady-state cycle specifications

\begin{tabular}{|c|c|c|c|c|c|}
\hline \multirow{2}{*}{ Mode } & Engine Speed & Engine Torque & Time Weighting & $\begin{array}{c}\text { Gas Sampling } \\
\text { Time }\end{array}$ & $\begin{array}{c}\text { PM Sampling } \\
\text { Time }\end{array}$ \\
\cline { 2 - 6 } & {$[$ [RPM] } & [ft-lb] & -- & [sec] & [sec] \\
\hline 1 & 1800 & 1071 & 0.08 & 450 & 180 \\
\hline 2 & 1692 & 852 & 0.13 & 120 & 48 \\
\hline 3 & 1560 & 610 & 0.17 & 195 & 78 \\
\hline 4 & 1356 & 320 & 0.32 & 255 & 102 \\
\hline 5 & 600 & 0 & 0.3 & 480 & 192 \\
\hline
\end{tabular}

While the urea-SCR system was originally developed for marine use, it shows great promise in on-road applications. Many on-road vehicles still utilize older model year engines, making them candidates for aftertreatment retrofit. Because it of this broad applicability, several on-road transient test cycles were also implemented. 


\subsection{FTP}

The most prevalent on-road test cycle in the US for HHDDEs is the heavy-duty FTP. The FTP cycle is a transient test cycle used for emissions testing of new heavy-duty on-road engines in the US. The heavyduty FTP was based on the UDDS chassis dynamometer test schedule and created by US regulatory agencies using Monte-Carlo simulation. The FTP has four phases, each representing where the vehicle behavior was derived from. This includes the New York Non-Freeway, Los Angeles Non-Freeway, Los Angeles Freeway, and a repetition of the Los Angeles Non-Freeway.

The heavy-duty FTP includes "motoring" segments where negative torque is to be applied to the engine. These segments represent a time when the vehicle is coasting and the engine is driven by the wheels due to momentum or gravity. During this type of operation, the throttle is completely closed and no fuel is delivered to the engine. Motoring points were designated in the setpoint file by a symbol ${ }^{1}$ and a footnote stating, “1 Indicates closed throttle motoring” (CFR 40 Pt. 86, App. I) [30]. According to CFR 40 §86.133390 , motoring points are simulated in the test cell by adding $-40 \%$ (of maximum positive torque at a given engine speed) points to the setpoint file [30]. Inclusion of large negative torque values causes the dynamometer to motor the engine, cutting fueling and causing closed throttle operation. The motoring torque values (negative) do not affect regression performance because if the setpoint torque was much lower than the measured torque, the point was eliminated from regression analysis as defined in the CFR 40 $\S 86.1341-90$ [30]. The permitted point deletions are summarized below in Table 20.

Table 20. Permitted point deletions from regression analysis [30]

\begin{tabular}{|c|c|}
\hline Condition & Points to be deleted \\
\hline $\begin{array}{l}\text { 1. Wide Open Throttle and Torque Feedback < Torque Reference } \ldots \ldots \ldots \ldots \ldots \ldots \ldots \ldots \ldots \ldots \\
\text { 2. Closed Throttle, Not an Idle Point, Torque Feedback }>\text { Torque Reference } \ldots \ldots \ldots \ldots \ldots \ldots \ldots \ldots \ldots \ldots \ldots \ldots \ldots \ldots \ldots\end{array}$ & $\begin{array}{l}\text { Torque, and/or BHP. } \\
\text { Torque, and/or BHP. } \\
\text { Speed, and/or BHP. }\end{array}$ \\
\hline \multicolumn{2}{|l|}{ For the purposes of this discussion: } \\
\hline \multicolumn{2}{|c|}{$\begin{array}{l}\text { An Idle Point is defined as a point having a Normalized Reference Torque of } 0 \text { and a Normalized Reference } \\
\text { Speed of } 0 \text { and an engine tested as having a manual transmission has a curb idle transmission torque (CITT) } \\
\text { of } 0 \text {. Point deletion may be applied either to the whole or to any part of the cycle. EXPSTB='00' }\end{array}$} \\
\hline
\end{tabular}

Additionally, there are well defined engine speed, torque, and power regression criteria for acceptability of a run. This allows one to be sure that the setpoint values are sufficiently followed and more repeatable results may be obtained. The heavy-duty FTP cycle and its regression standards are designated such that nearly all heavy-duty diesel engines may follow the cycle and pass regression.

\subsection{ACES}

In addition to the heavy-duty FTP cycle, the ACES test schedule was implemented during testing of the urea-SCR system. The ACES engine test schedule was created by WVU engineers, including this author, in 2007 as part of the Advanced Collaborative Emissions Study, a program designed to study the health 
effects of diesel emissions produced by 2007-2010 model year engines. In order to appropriately examine the emissions, engine test cycles had to be developed which accurately capture the type of behavior actually seen during operation. These test cycles helped to demonstrate how the aftertreatment system would respond to different types of on-road behavior not captured by the FTP alone. In order to illustrate how the ACES test schedule was directly derived from in-use truck behavior and is truly representative of HHDDT operation, a brief summary of its creation process is presented.

Prior to the ACES program, a five mode chassis schedule (vehicle speed vs. time) was developed by the CARB based directly on 1,600 hours of real-world truck data from 84 heavy heavy-duty trucks (HHDDT) operating in the state of California [79,80,81]. The chassis schedule includes Idle, Creep, Transient, Cruise, and High-Speed Cruise (HHDDT_S) modes. Seven trucks were exercised on the chassis schedule as part of the Coordinating Research Council (CRC) E-55/59 study [79,80,81]. Engine control unit (ECU) broadcast data and chassis dynamometer data were recorded. These trucks were exercised at three gross vehicle weights $(30,000 \mathrm{lb}, 56,000 \mathrm{lb}$, and 66,000 lb) through the four active chassis modes (Creep, Transient, Cruise, HHDDT_S). The trucks were equipped with heavy-duty engines made by three major US engine manufacturers with a range of model year from 1998 to 2003.

First, all engine data were converted from engineering units to dimensionless quantities of \%speed (engine speed) and \%torque as defined in CFR $40 \$ 86.1333-90$ [30]. Next, each chassis mode was divided into four segments, termed microtrips. A computer program calculated statistics of average speed, average speed squared, average torque, and average torque squared for every microtrip in the database. Based on these results, average database statistics were calculated for each mode, representative of overall fleet behavior.

For each of the four modes, it was desired to assemble the microtrips to create a candidate mode which best represented overall fleet behavior. Each microtrip remained within their original time segment and every possible combination of microtrips (candidate modes) was composed for each mode using a computer program. Additionally, the following pre-selection criteria were applied to the candidate mode creation process to ensure diversity in test weights and engine technologies.

- A candidate mode must not have more than one microtrip from the same chassis test run, nor from the same truck at the same test weight.

- A candidate mode must not have one test weight for more than two microtrips.

- A candidate mode must not have all microtrips from one engine technology (i.e. at least two different engine manufacturers or two different engine types from one engine manufacturer will be selected). 
The method of least square errors was used to identify the candidate modes which best represented the center and spread properties of the database (\%speed, \%torque). For each mode, the candidate modes were arranged according to least squares error. Based on this ranking, the final arrangement of microtrips was chosen for each mode to best represent the database behavior and provide diversity in test weight and engine technology, based on the pre-selection criteria.

Finally, modifications to the setpoint torque of each final ACES mode were required to achieve close compliance of measured and setpoint speed and torque on the engine dynamometer, specifically during gearshifts. This was accomplished by including motoring points in a manner similar to the FTP cycle. The inclusion of motoring points during gearshift troughs resulted in the engine producing no positive torque and more closely following the setpoint torque. Motoring points were designated in the setpoint file and simulated in the test cell as described above for the FTP. Additionally, the permitted point deletions in Table 20 remain applicable for the ACES modes.

As stated above, there were four ACES engine modes including Transient, Creep, Cruise, and HHDDT_S. The Transient mode simulates low to medium speed, stop and go operation. The Creep mode simulates very low speed $(<9 \mathrm{mph})$ stop and go operation, and has low reference work, causing the brake-specific emissions to appear high. The Cruise mode simulates $60 \mathrm{mph}$ freeway operation and the HHDDT_S mode simulates $65 \mathrm{mph}$ freeway operation, both including acceleration and deceleration periods and the beginning and end of the cycles. While the HHDDT_S mode has more high-load operation, the Cruise mode is more than double its length, causing it to have higher reference work. The engine speed and engine torque plots for each ACES mode and the FTP can be seen in Appendix B, converted to engineering units for the 1992 Detroit Diesel engine.

In order to show how the ACES modes compare to the FTP, statistics were computed for each test cycle. These statistics were computed for engine speed and engine torque, and can be seen in Table 21 and Table 22 below. Here, time derivatives of engine speed and torque were calculated for each cycle. By showing the maximum and minimum values, the maximum acceleration and deceleration may be compared between cycles, showing the effect of gear changes and clutch operation for the ACES modes. 
Table 21. Transient test cycle statistics, engine speed (rpm)

\begin{tabular}{|c|c|c|c|c|c|c|c|c|}
\hline \multirow{3}{*}{\multicolumn{2}{|c|}{ Test Cycle }} & \multicolumn{6}{|c|}{ Engine Speed (N) } & \multirow{3}{*}{$\begin{array}{c}\text { Cycle Length } \\
\text { [sec] }\end{array}$} \\
\hline & & \multicolumn{6}{|c|}{ [RPM] } & \\
\hline & & Ave. & $\operatorname{Max}$ & Min & Std. Dev. & Max dN/dt & Min dN/dt & \\
\hline & FTP & 1098 & 1943 & 575 & 494 & 446 & -378 & 1199 \\
\hline \multirow{4}{*}{ ACES } & Transient & 1134 & 1800 & 600 & 360 & 648 & -528 & 687 \\
\hline & Creep & 720 & 1800 & 600 & 215 & 876 & -504 & 1031 \\
\hline & Cruise & 1286 & 1800 & 600 & 311 & 852 & -516 & 2082 \\
\hline & HHDDTS & 1278 & 1800 & 600 & 251 & 408 & -468 & 759 \\
\hline
\end{tabular}

Table 22. Transient test cycle statistics, engine torque (ft-lb)

\begin{tabular}{|c|c|c|c|c|c|c|c|c|c|}
\hline \multirow{3}{*}{\multicolumn{2}{|c|}{ Test Cycle }} & \multicolumn{6}{|c|}{ Engine Torque $(\mathrm{T})$} & \multirow{3}{*}{$\begin{array}{c}\text { Motoring } \\
\text { Percent }\end{array}$} & \multirow{3}{*}{$\begin{array}{c}\begin{array}{c}\text { Ref. } \\
\text { Work }\end{array} \\
\text { [bhp-hr] }\end{array}$} \\
\hline & & \multicolumn{6}{|c|}{ [ft-lb] } & & \\
\hline & & Ave. & $\operatorname{Max}$ & Min & Std. Dev. & Max dT/dt & Min dT/dt & & \\
\hline \multicolumn{2}{|c|}{ FTP } & 263 & 1265 & 0 & 372 & 875 & -832 & $15 \%$ & 24.65 \\
\hline \multirow{4}{*}{ ACES } & Transient & 150 & 1273 & -126 & 284 & 1169 & -1004 & $28 \%$ & 7.62 \\
\hline & Creep & 22 & 581 & -105 & 63 & 581 & -343 & $8 \%$ & 1.18 \\
\hline & Cruise & 348 & 1270 & -139 & 310 & 1264 & -1258 & $8 \%$ & 54.8 \\
\hline & HHDDTS & 548 & 1320 & -113 & 420 & 1225 & -797 & $11 \%$ & 29.37 \\
\hline
\end{tabular}




\section{Chapter 7: Test Results}

During testing, complete emissions, regression, and fueling data were collected from WVU EERL devices. In addition, aftertreatment system parameters were logged separately using Mototune software and a dedicated laptop computer. These data were used for urea injection calculations and to verify the accuracy of values measured by the aftertreatment system. A detailed list of all runs completed during testing can be seen in Appendix C.

\subsection{Day-to-Day Variability}

Testing was conducted over several days (1/6/2009 to 1/14/2009). As a result, variability in measurements may have existed as a result of changing environmental and laboratory conditions. To demonstrate the variability over several test days, the same test cycle and conditions were compared. Each test day except for the first (1/6/2009) and last (1/14/2009) had one FTP run for comparison. All of the runs compared were hot starts except for EO2546-01 (1/9/2009). To show variability, emissions and engine conditions were compared for five days, and can be seen in Table 23.

Table 23. Day-to-day laboratory measurement variability, FTP

\begin{tabular}{|c|c|c|c|c|c|c|c|c|c|c|}
\hline \multirow{3}{*}{ Day } & \multirow{3}{*}{ Run } & \multirow{2}{*}{$\begin{array}{c}\text { Barometric } \\
\text { Pressure }\end{array}$} & \multirow{2}{*}{$\begin{array}{c}\text { Average } \\
\text { Humidity } \\
\text { Factor }\end{array}$} & \multirow[b]{2}{*}{ Work } & \multirow[b]{2}{*}{ BSFC } & \multirow[b]{2}{*}{$\mathrm{CO}_{2}$} & \multicolumn{4}{|c|}{ Background } \\
\hline & & & & & & & $\mathrm{HC}$ & CO & $\mathrm{CO}_{2}$ & NOx \\
\hline & & [in $\mathrm{Hg}]$ & {$[--]$} & [bhp-hr] & {$[\mathrm{lb} / \mathrm{bhp}-\mathrm{hr}$} & [g/bhp-hr] & \multicolumn{4}{|c|}{ [ppm] } \\
\hline $1 / 7 / 2009$ & EO2543-02 & 28.13 & 0.998 & 23.94 & 0.382 & 531.3 & 2.9 & 4.1 & 446.4 & 0.2 \\
\hline $1 / 8 / 2009$ & EO2545-02 & 28.63 & 0.994 & 24.00 & 0.384 & 532.7 & 2.2 & 4.1 & 429.6 & 0.1 \\
\hline $1 / 9 / 2009$ & EO2546-01 ${ }^{1}$ & 29.03 & 0.995 & 24.04 & 0.382 & 535.4 & 2.1 & 3.4 & 432.0 & -0.4 \\
\hline $1 / 12 / 2009$ & EO2547-02 & 29.06 & 0.996 & 24.05 & 0.380 & 536.0 & 3.0 & 3.7 & 445.5 & -0.5 \\
\hline $1 / 13 / 2009$ & EO2548-03 & 28.73 & 1.015 & 24.03 & 0.380 & 536.0 & 2.0 & 3.4 & 437.4 & 0.1 \\
\hline \multicolumn{2}{|c|}{ Average } & 28.72 & 1.000 & 24.01 & 0.381 & 534.3 & 2.45 & 3.744 & 438.2 & -0.10 \\
\hline \multicolumn{2}{|c|}{ Coefficient of Variation } & 0.013 & 0.009 & 0.002 & 0.004 & 0.004 & 0.186 & 0.095 & 0.018 & -3.1 \\
\hline
\end{tabular}

The above table shows that work and fuel consumption were consistent throughout all testing days. The main variations can be seen in barometric pressure and background emissions levels. These differences in environmental conditions may have an affect on the emissions results. Testing of the same cycle with the same engine and conditions should produce equivalent $\mathrm{CO}_{2}$ emissions. Although the differences are small, $\mathrm{CO}_{2}$ emissions were lower for the days with lower barometric pressure (1/7/2009 and 1/8/2009 in particular). The variation in average humidity factor helped to correct NOx emissions due to differences in environmental conditions. Corrected total NOx emissions for dates January 7-12, 2009 were 5.1, 5.1, 5.0, and $5.0 \mathrm{~g} / \mathrm{bhp}$-hr, respectively. NOx emissions for 1/13/2009 cannot be compared because the run included urea injection. 


\subsection{Correlation with Laboratory Measurements}

The FTP cycle alone was chosen to verify the accuracy of aftertreatment system measurements and compare measured exhaust temperatures between the urea-SCR system and WVU EERL. The laboratory and aftertreatment measurements were recorded by completely independent systems. As a result, the logged values were time aligned so that a comparison could be made. To accomplish this, exhaust flow was crosscorrelated, and the time shift which yielded the highest correlation coefficient was used to shift the aftertreatment data. The same time shift was used for all variables logged by the aftertreatment system.

During all testing, a sample frequency of $5 \mathrm{~Hz}$ was used for EERL data acquisition and $1 \mathrm{~Hz}$ for the aftertreatment system (Motohawk) data acquisition. During the data reduction process, laboratory data were averaged and converted from $5 \mathrm{~Hz}$ to $1 \mathrm{~Hz}$ by WVU EERL computers and software. The sampling frequency was of particular importance in emissions measurement because of pulsation in the exhaust. Pulsations are created by the combustion event and subsequent blowdown occurring as the exhaust valve opens and products-of-combustion flow out of the cylinder. There were a number of frequencies produced by the 1992 Detroit Diesel. The frequency of pulsations was dependent on engine speed. Engine speeds ranged from $588 \mathrm{rpm}$ to $1953 \mathrm{rpm}$. The main frequency responsible for producing pulsations in the exhaust is the cyclic frequency of exhaust strokes. This value varied from $29 \mathrm{~Hz}$ to $98 \mathrm{~Hz}$ (exhaust strokes/sec). By using a sampling frequency of $1 \mathrm{~Hz}$ (or even $5 \mathrm{~Hz}$ ), average values were measured rather than catching each peak and trough of the exhaust pulsations, which could cause measured values to appear erroneously high or low.

A correlation was performed between aftertreatment system and EERL measurements for exhaust flow rate and NOx concentration. The NOx values measured by the laboratory analyzer (Rosemount 955) were background and dilute corrected by the WVU data reduction software according to CFR 40 \$86.1342-90, using bagged samples of ambient and dilution tunnel air collected during each test. Measurements made by the Siemens SmartNOx sensor were not background corrected because the exhaust sample was not in contact with the dilution air at point of measurement. This may affect the comparison slightly, however this comparison was only meant to demonstrate that the Siemens sensor could accurately measure NOx emissions. All subsequent total and continuous laboratory emissions presented were background corrected. The following laboratory and aftertreatment system values were compared.

- Engine intake flow by laboratory laminar flow element vs. exhaust flow measured by aftertreatment system pitot-tubes (scfm)

- Laboratory NOx analyzer (Rosemount 955) vs. aftertreatment-mounted NOx analyzer (Siemens SmartNOx) $(g / s)$ 
To increase the accuracy in the comparison, fuel flow rate was included. Additionally, blowby was considered, taken to be $1 \%$ of fuel flow according to Pulkrabek [11]. Blowby flow was subtracted from the total flow because in the laboratory, the crankcase was ventilated rather than being redirected into the engine intake. This correction was required because the fuel flow represented a maximum of $21 \%$ and an average of $1.8 \%$ of intake air flow, by mass. Flow rate correlated well between the engine intake and the aftertreatment system pitot-tubes. This resulted in a coefficient of determination of 0.96 . Continuous and parity plots comparing flow rates measured by the aftertreatment system and laboratory can be seen in Figure 32 (a) and (b), respectively.

The aftertreatment flow tended to be noisier than laboratory flow, which affected error over the entire measurement range. This noise was observed in the differential pressure sensor signal, and may have been caused by turbulence or exhaust pulsation. Error was observed at low flow because the differential pressure sensor error became large compared to the measured value at the low end of the measurement range. However, error at low flow was acceptable in a retrofit urea-SCR application because low exhaust flows typically correspond to low NOx and temperature situations, when urea was not injected. Error was also found at high flow peaks. The laboratory measured intake air flow without the addition of fuel and the aftertreatment system flow calculations assumed a constant velocity profile. This caused the aftertreatment flow measurement to be slightly high compared to laboratory measurements. Even with error and noise, the flow measurement accuracy was more than sufficient for proper urea dosing to achieve the desired reductions. 


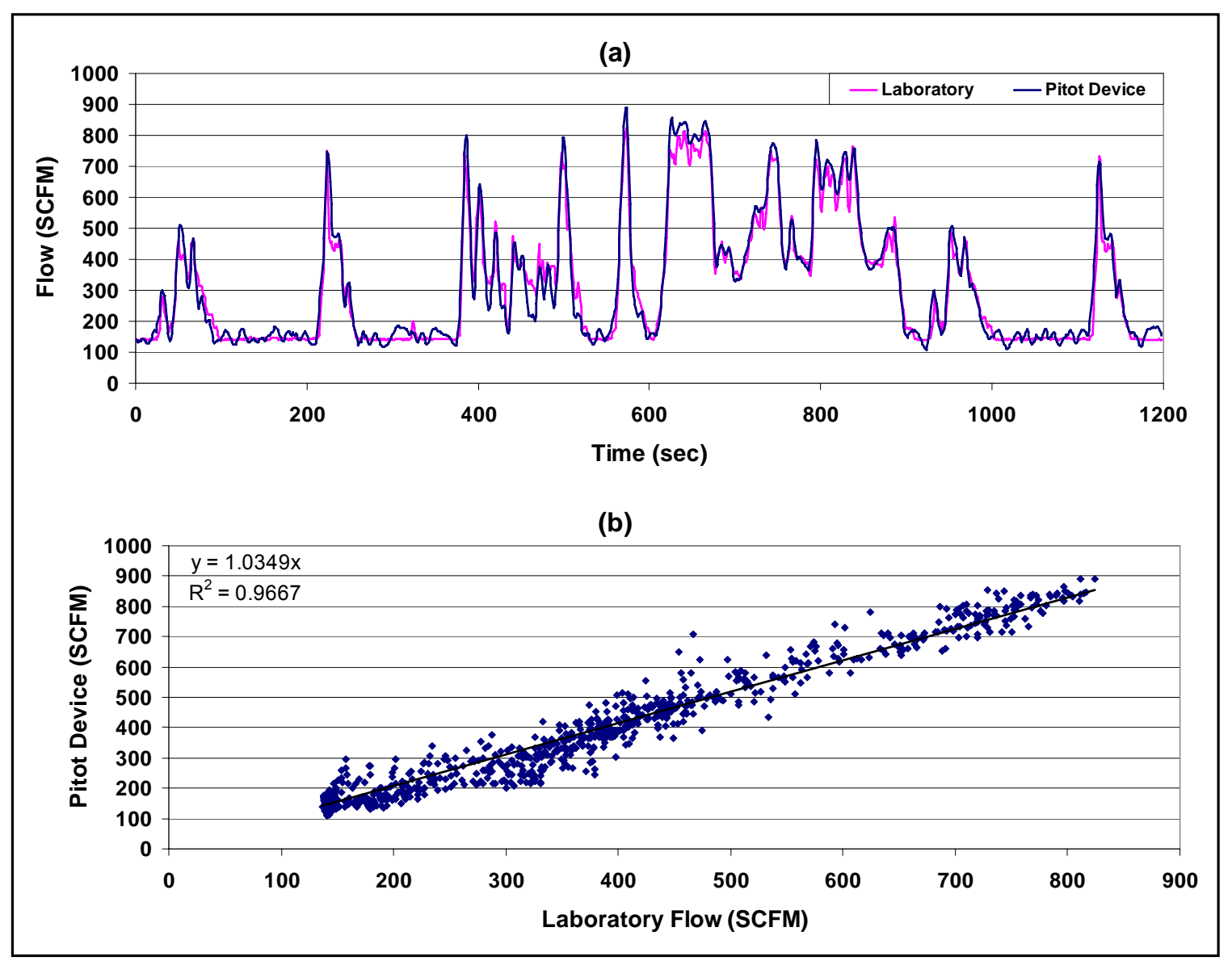

Figure 32. (a) Continuous flow comparison (scfm), (b) flow correlation (scfm), FTP

In a similar manner, NOx was compared between laboratory analyzers and the aftertreatment system sensor. The laboratory and aftertreatment NOx measurements were performed in terms of concentration, in units of ppm. However, NOx was measured by the laboratory analyzers in diluted exhaust, while the aftertreatment system sensor measured in raw exhaust. This caused a difference in NOx concentrations.

In order to compare the raw and dilute NOx measurements, they had to be compared on a mass flow basis. NOx mass flow was calculated using the NOx concentration, in ppm, and volumetric flow rate, in scfm. An expression similar to that specified for NOx in CFR $40 \$ 86.1342-90$ was utilized, shown in Equation 16. For laboratory measurements, the total flow of dilution air and exhaust gas was used $\left(\mathrm{V}_{\text {mix }}\right)$. For aftertreatment measurements, exhaust flow alone was used. The following equation was implemented, where the density of NOx was specified in CFR $40 \$ 86.1342-90\left(54.16 \mathrm{~g} / \mathrm{ft}^{3}\right)$ [30]. When calculating mass flow of NOx from values measured by the WVU laboratory, a variable NOx correction factor $\left(\mathrm{k}_{\mathrm{NOx}}\right)$ was also implemented. For the case of aftertreatment measurements, a constant NOx correction factor of 1.0 was utilized. 
$\dot{m}_{N O x}=k_{N O x}\left[\left(\frac{p p m_{N O x}}{10^{6}}\right) \cdot \dot{V} \cdot \rho_{N O x}\right]$

Because flow rate was used to convert the NOx measurements from a concentration to mass flow rate, any error in flow was translated to NOx. This means that the NOx accuracy could not be any greater than for the flow correlation $\left(\mathrm{R}^{2}\right.$ of 0.96$)$. In general, the Siemens SmartNOx sensor had very high accuracy $( \pm 10 \%$ [73]). Most NOx measurement error arose from flow measurement and the conversion from a concentration to mass flow.

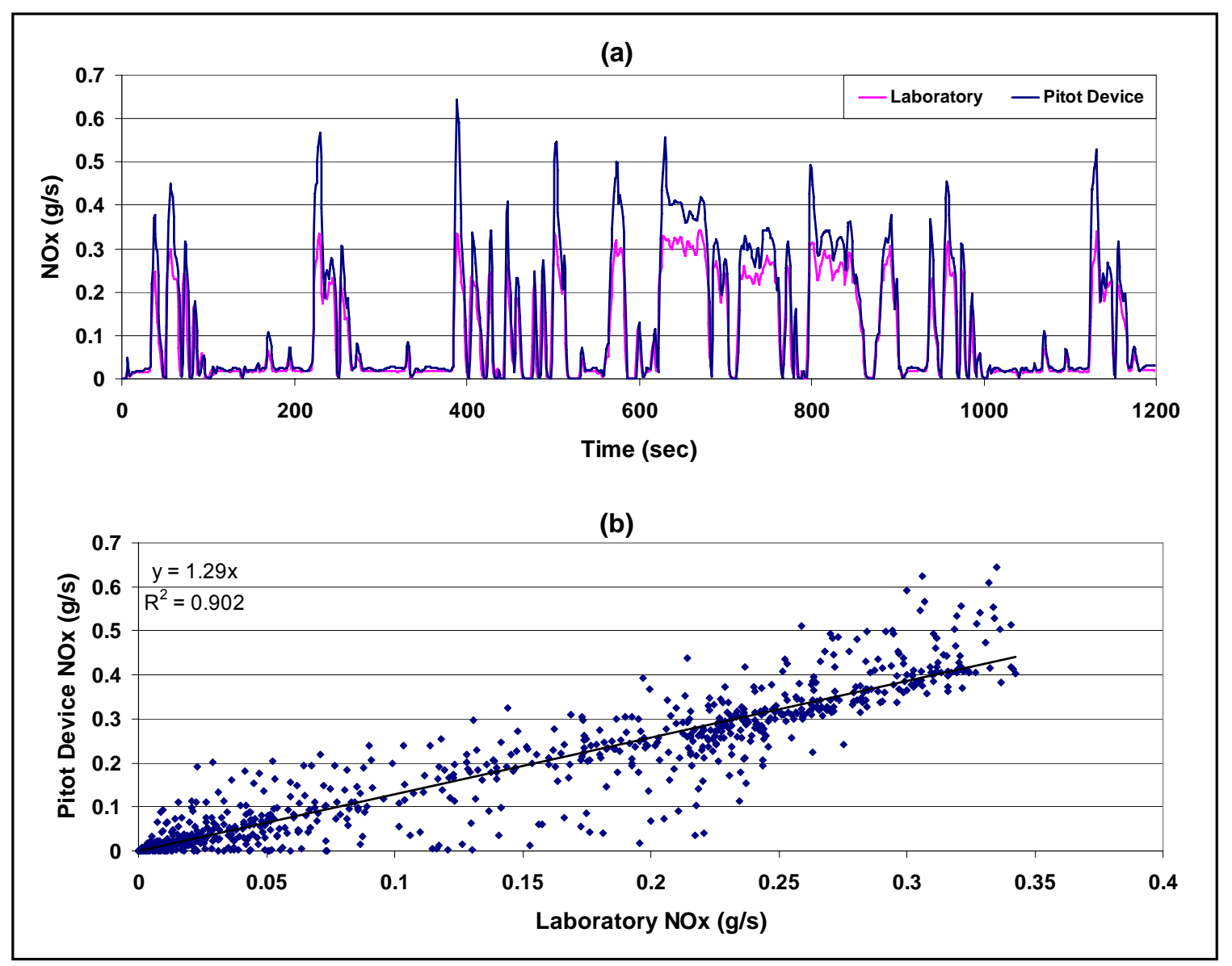

Figure 33. (a) Continuous NOx Comparison (g/s), (b) NOx Correlation (g/s), FTP

Exhaust temperature was measured by the laboratory directly after the turbocharger outlet and by the ureaSCR system prior to the urea injection plane. The length (approx. $8 \mathrm{ft}$.) between the two measurement locations allowed the exhaust gases to cool, resulting in a difference in temperature measurements. The exhaust temperature measured by the aftertreatment system was used in the control strategy to determine if urea injection should occur. As a result, it was used for all calculations and comparisons here. The exhaust 
temperature measured by the WVU EERL and measured by the urea-SCR aftertreatment system can both be seen in Figure 34 below.

It can be seen that the length of pipe between the two measurement locations resulted in significant temperature differences. This caused the aftertreatment system temperature to be lower at the hightemperature peaks due to heat loss from the pipe as the exhaust traveled further down the pipe. During cooler operation, heat may have been transferred back from the hot exhaust pipe to the exhaust gases, causing higher pre-SCR exhaust temperatures. The post-turbocharger and SCR inlet temperatures were plotted for the FTP and can be seen in Figure 34.

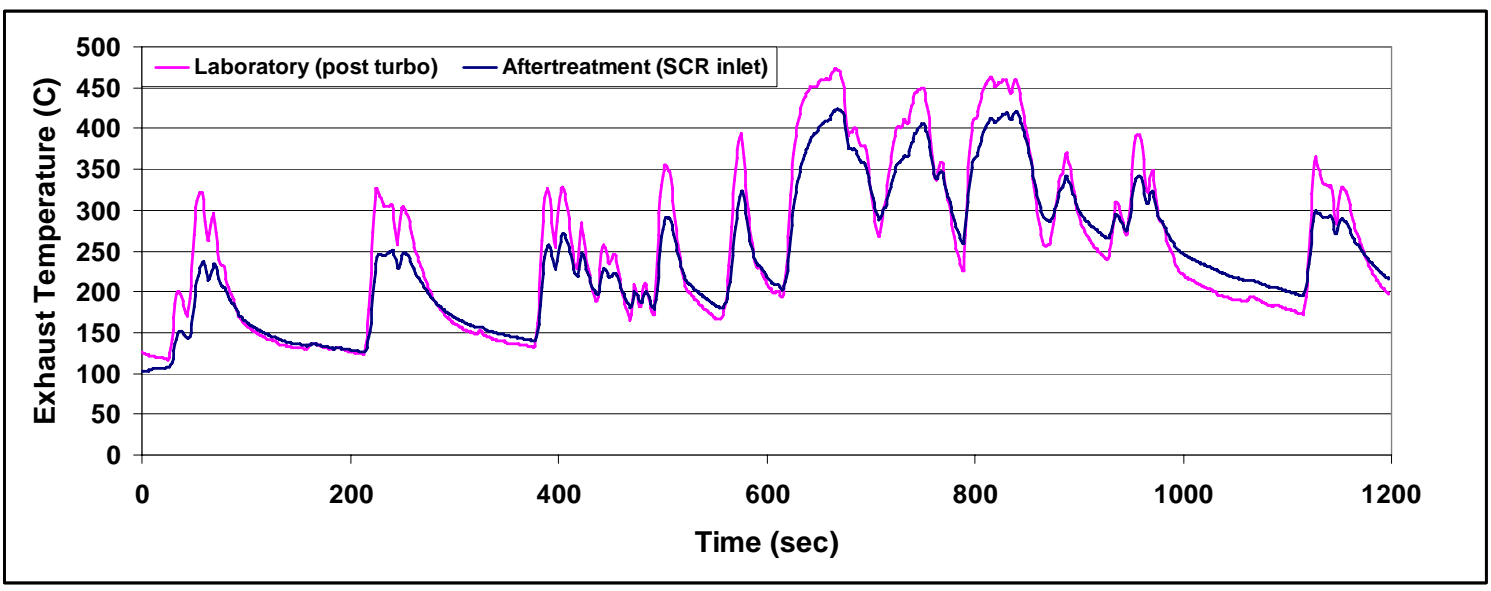

Figure 34. Exhaust temperature comparison $\left({ }^{\circ} \mathrm{C}\right)$, FTP

\subsection{Regression Performance}

Regression criteria were established to verify completion of a valid test run, quantify setpoint compliance, and ensure repeatable results. Measured continuous torque, engine speed, and brake horsepower (BHP) were compared to the reference values and calculation results included the slope and y-intercept of the first order linear trend line, standard error, and coefficient of regression. Additionally, the integrated BHP was required to fall within a given range. Regression criteria are applicable to transient tests, and currently there are federally mandated regression standards only for the FTP cycle, defined in CFR 40 §86.1341-90 [30]. Regression standards have also been proposed for the ACES modes; however because the ACES modes are not universally recognized, there are no formally-defined standards. Regression standards for the ACES modes were determined according to test results from several engines, results of which can be seen in [64] and [76].

For a given FTP run to be considered valid, all regression criteria had to fall within the range specified by the CFR. The ACES modes were not necessarily required to pass their regression criteria in order to be considered a valid run, because they were only proposed standards. The proposed standards were included 
to compare setpoint compliance between modes, and observe which modes had trouble meeting regression. This may in turn reveal where the proposed standards need revision.

The regression performance for the FTP and each of the ACES modes can be seen below along with the appropriate regression standards. The standards for the ACES modes are accompanied by a note indicating proposed standards. The regression performance for engine speed, torque, and BHP, can be seen in Table 24, Table 25, and Table 26, respectively. In each table, a blue highlighted box corresponds to a given criterion being too low with respect to the proposed ACES standard, while a yellow highlighted box corresponds to a given criterion being too high with respect to the proposed ACES standard. All runs compared were baseline, without urea injection. The introduction of urea had no effect on regression performance, making a single comparison for each transient test sufficient.

Table 24. Engine speed regression performance (rpm)

\begin{tabular}{|c|c|c|c|c|c|c|c|c|c|c|c|c|}
\hline & \multicolumn{3}{|c|}{ Standard Error (rpm) } & \multicolumn{3}{|c|}{ Slope of Regression } & \multicolumn{3}{|c|}{ Y-Intercept (rpm) } & \multicolumn{3}{|c|}{$\begin{array}{l}\text { Coefficient of } \\
\text { Regression }\end{array}$} \\
\hline & Test & Min & Max & Test & Min & Max & Test & Min & Max & Test & Min & $\operatorname{Max}$ \\
\hline FTP & 12.41 & 0.00 & 100.00 & 1.00 & 0.97 & 1.03 & 9.35 & -50.00 & 50.00 & 1.00 & 0.97 & 1.00 \\
\hline Transient $^{1}$ & 21.35 & 0.00 & 100.00 & 0.97 & 0.96 & 1.03 & 44.81 & -69.52 & 69.52 & 0.99 & 0.97 & 1.00 \\
\hline Creep $^{1}$ & 59.35 & 0.00 & 100.00 & 0.95 & 0.97 & 1.03 & 53.48 & -61.62 & 61.62 & 0.94 & 0.97 & 1.00 \\
\hline Cruise $^{1}$ & 18.42 & 0.00 & 100.00 & 0.99 & 0.97 & 1.03 & 26.00 & -50.00 & 50.00 & 0.99 & 0.97 & 1.00 \\
\hline HHDDTS $^{1}$ & 10.15 & 0.00 & 100.00 & 0.99 & 0.96 & 1.03 & 23.49 & -62.22 & 62.22 & 1.00 & 0.97 & 1.00 \\
\hline
\end{tabular}

Table 25. Engine torque regression performance (ft-lb)

\begin{tabular}{|c|c|c|c|c|c|c|c|c|c|c|c|c|}
\hline & \multicolumn{3}{|c|}{ Standard Error (ft-lb) } & \multicolumn{3}{|c|}{ Slope of Regression } & \multicolumn{3}{|c|}{ Y-Intercept (ft-lb) } & \multicolumn{3}{|c|}{$\begin{array}{l}\text { Coefficient of } \\
\text { Regression }\end{array}$} \\
\hline & Test & Min & Max & Test & Min & Max & Test & Min & Max & Test & Min & Max \\
\hline FTP & 65.21 & 0.00 & 174.94 & 0.96 & 0.83 & 1.03 & -4.580 & -15.00 & 15.00 & 0.969 & 0.88 & 1.00 \\
\hline Transient $^{1}$ & 92.98 & 0.00 & 174.94 & 0.83 & 0.77 & 1.03 & -15.11 & -15.00 & 15.00 & 0.89 & 0.85 & 1.00 \\
\hline Creep $^{1}$ & 25.57 & 0.00 & 174.94 & 0.64 & 0.81 & 1.03 & -3.69 & -15.00 & 15.00 & 0.72 & 0.88 & 1.00 \\
\hline Cruise $^{1}$ & 72.96 & 0.00 & 174.94 & 0.97 & 0.81 & 1.03 & -5.05 & -15.00 & 15.00 & 0.94 & 0.88 & 1.00 \\
\hline HHDDTS $^{1}$ & 66.02 & 0.00 & 174.94 & 0.97 & 0.59 & 1.03 & -1.17 & -15.00 & 15.00 & 0.97 & 0.60 & 1.00 \\
\hline
\end{tabular}


Table 26. Brake-horsepower regression performance (bhp)

\begin{tabular}{|l|c|c|c|c|c|c|c|c|c|c|c|c|c|}
\hline & \multicolumn{1}{|c|}{ Standard Error (bhp) } & \multicolumn{3}{c|}{ Slope of Regression } & \multicolumn{3}{c|}{ Y-Intercept (bhp) } & \multicolumn{3}{c|}{$\begin{array}{c}\text { Coefficient of } \\
\text { Regression }\end{array}$} \\
\hline FTP & 22.84 & 0.00 & 29.36 & 0.97 & 0.89 & 1.03 & -2.20 & -5.00 & 5.00 & 0.96 & 0.91 & 1.00 \\
\hline Transient $^{1}$ & 31.72 & 0.00 & 31.32 & 0.86 & 0.85 & 1.03 & -8.03 & -5.00 & 5.00 & 0.87 & 0.87 & 1.00 \\
\hline Creep $^{1}$ & 9.20 & 0.00 & 29.36 & 0.53 & 0.89 & 1.03 & 0.49 & -5.00 & 5.00 & 0.60 & 0.89 & 1.00 \\
\hline Cruise $^{1}$ & 22.60 & 0.00 & 29.36 & 0.97 & 0.88 & 1.03 & -0.28 & -5.00 & 5.00 & 0.92 & 0.91 & 1.00 \\
\hline HHDDTS $^{\mathbf{1}}$ & 17.35 & 0.00 & 29.36 & 0.97 & 0.62 & 1.03 & 0.46 & -5.00 & 5.00 & 0.96 & 0.52 & 1.00 \\
\hline
\end{tabular}

It was specified for the FTP that the integrated BHP be between $+5 \%$ and $-15 \%$ of the calculated value based on the setpoint engine speed and torque in CFR 40 \$86.1341-90 [30]. The proposed standards for the ACES modes adopted the same standard for integrated BHP. A comparison of integrated BHP and the acceptable range for each transient test can be seen in Table 27.

Table 27. Integrated brake-horsepower performance (bhp-hr)

\begin{tabular}{|l|c|c|c|c|}
\hline & $\begin{array}{c}\text { Actual Work } \\
\text { (bhp-hr) }\end{array}$ & $\begin{array}{c}\text { +5\% Ref. Work } \\
\text { (bhp-hr) }\end{array}$ & $\begin{array}{c}\text {-15\% Ref. Work } \\
\text { (bhp-hr) }\end{array}$ & $\begin{array}{c}\text { Reference Work } \\
\text { (bhp-hr) }\end{array}$ \\
\hline FTP & 23.94 & 25.88 & 20.95 & 24.65 \\
\hline Transient $^{1}$ & 6.58 & 8.00 & 6.48 & 7.62 \\
\hline Creep $^{1}$ & 1.01 & 1.24 & 1.00 & 1.18 \\
\hline Cruise $^{1}$ & 54.50 & 57.54 & 46.58 & 54.80 \\
\hline HHDDTS $^{1}$ & 28.77 & 30.84 & 24.96 & 29.37 \\
\hline \multicolumn{4}{|r|r|}{} \\
\hline
\end{tabular}

Despite the fact that several select points did not meet regression, the 1992 Detroit Diesel Series 60 engine had acceptable engine speed and torque setpoint compliance throughout all test cycles. The Creep mode had the highest number of proposed regression criteria to not be met, followed by the Transient mode. These modes had a relatively high amount of low-speed transient behavior, much of which is caused by clutch operation. The proposed regression standards may require broadening of the failed criteria for future use.

\subsection{Emissions Results}

As discussed above, emissions of $\mathrm{CO}_{2}, \mathrm{CO}, \mathrm{NOx}, \mathrm{THC}$, and $\mathrm{PM}$ were measured during testing. In addition, $\mathrm{NH}_{3}$ was measured during urea injection runs in order to determine ammonia slip. Ammonia slip is highly variable, dependent upon engine behavior, $\mathrm{NOx}$ concentration, urea dosing, and the amount of $\mathrm{NH}_{3}$ currently stored in the SCR catalyst. Because ammonia slip is dependent upon so many variables, it is particularly hard to predict. As a result, urea injection must be carefully metered. 
Total and continuous emissions were compared for each of the final test runs, with and without urea injection. Total emissions and fueling data were calculated by the EERL data reduction software according to CFR $40 \S 86.1342-90$, which includes humidity correction for NOx emissions [30]. Additionally, $\mathrm{NH}_{3}$ mass flow was determined using the following equation. To maintain consistency with CFR-based NOx mass flow calculations, the density of $\mathrm{NH}_{3}$ was taken at the same standard temperature and pressure conditions $\left(20.017 \mathrm{~g} / \mathrm{ft}^{3}\right)$.

$\dot{m}_{N H 3}=\left[\left(\frac{p p m_{N H 3}}{10^{6}}\right) \cdot \dot{V} \cdot \rho_{N H 3}\right]$

Equation 17

Inclusion of the SCR catalyst in the engine exhaust showed a reduction in emissions, even without urea injection. During testing, catalyst space velocity $\left(\dot{V}_{\text {exhaust }} / V_{\text {catalyst }}, 1 / \mathrm{s}\right)$ ranged from $1.60 \mathrm{~Hz}$ to $9.61 \mathrm{~Hz}$ over the FTP. Reductions were mainly seen in THC emissions, but a difference in PM was also observed. The THC and PM emissions with and without the SCR catalyst installed, along with the corresponding reduction percentage, can be seen in Table 28. The 1992 Detroit Diesel engine had very low THC emissions in general. The reduction percentages below are differences of two very small numbers and compared between a single run, implying that the reductions below may include some inaccuracies, and should not be generally expected. All subsequent emissions comparisons were performed for runs with the SCR catalyst installed.

Table 28. THC, PM emissions performance (g/bhp-hr), with and without SCR catalyst

\begin{tabular}{|l|c|c|c|}
\hline & Without SCR & With SCR & Reduction \\
\hline \multicolumn{4}{|c|}{} \\
\hline THC [ [g/bhp-hr] & 0.08 & 0.01 & $84 \%$ \\
\hline \multicolumn{4}{|c|}{} \\
\hline PM [ [g/bhp-hr] & 0.20 & 0.19 & $5 \%$ \\
\hline
\end{tabular}

A comparison of $\mathrm{CO}_{2}, \mathrm{CO}$, THC, and PM emissions was performed for each of the final test runs, with and without urea injection. A percentage reduction of each emission was calculated for each of the test runs. These emission values and percent reductions can be seen in Table 29. A urea-SCR aftertreatment system is designed to reduce NOx emissions. However a slight reduction in CO, THC, and PM was seen during testing as well. These reductions varied greatly with test cycle. In the case of THC emissions, an increase in emissions was actually observed for the FTP and Creep cycles. The chemistry responsible for these reductions is not well documented, and may depend on many variables, including catalyst formulation. As a result, reductions in non-NOx species may or may not occur for a given aftertreatment system and test cycle. Additionally, the reductions presented are calculated based on a single run with and a single run without urea injection. 
Table 29. Total $\mathrm{CO}_{2}, \mathrm{CO}, \mathrm{THC}, \mathrm{PM}$ emissions comparison (g/bhp-hr)

\begin{tabular}{|c|c|c|c|c|c|c|c|c|c|c|c|c|c|}
\hline \multirow{3}{*}{\multicolumn{2}{|c|}{ Test Cycle }} & \multicolumn{2}{|c|}{$\mathrm{CO}_{2}$} & \multirow{3}{*}{$\begin{array}{l}\mathrm{CO}_{2} \\
\text { Red. } \\
{[\%]}\end{array}$} & \multicolumn{2}{|c|}{$\mathrm{CO}$} & \multirow{3}{*}{$\begin{array}{c}\text { CO } \\
\text { Red. } \\
{[\%]}\end{array}$} & \multicolumn{2}{|c|}{ THC } & \multirow{3}{*}{$\begin{array}{c}\text { HC } \\
\text { Red. } \\
{[\%]}\end{array}$} & \multicolumn{2}{|c|}{ PM } & \multirow{3}{*}{$\begin{array}{r}\text { PM } \\
\text { Red. } \\
{[\%]}\end{array}$} \\
\hline & & Base & Urea & & Base & Urea & & Base & Urea & & Base & Urea & \\
\hline & & \multicolumn{2}{|c|}{ [g/bhp-hr] } & & \multicolumn{2}{|c|}{ [g/bhp-hr] } & & \multicolumn{2}{|c|}{ [g/bhp-hr] } & & \multicolumn{2}{|c|}{ [g/bhp-hr] } & \\
\hline \multicolumn{2}{|c|}{ FTP } & 531.3 & 534.5 & -1 & 2.9 & 2.6 & 10 & 0.014 & 0.015 & -9 & 0.19 & 0.18 & 7 \\
\hline \multirow{4}{*}{ ACES } & Transient & 586.7 & 588.3 & 0 & 6.4 & 5.8 & 9 & 0.068 & 0.066 & 3 & 0.23 & 0.21 & 8 \\
\hline & Creep & 1324.5 & 1339.4 & -1 & 16.1 & 14.7 & 9 & 0.390 & 0.455 & -17 & 0.08 & 0.03 & 69 \\
\hline & Cruise & 490.9 & 496.0 & -1 & 1.8 & 1.6 & 11 & 0.020 & 0.017 & 12 & 0.07 & 0.06 & 8 \\
\hline & HHDDTS & 481.1 & 485.5 & -1 & 3.0 & 2.7 & 11 & 0.012 & 0.011 & 6 & 0.23 & 0.16 & 29 \\
\hline \multicolumn{2}{|c|}{ ICOMIA } & 487.8 & 473.9 & 3 & 0.96 & 0.835 & 13 & 0.022 & 0.009 & 58 & 0.11 & 0.04 & 60 \\
\hline
\end{tabular}

A comparison of the three fuel measurement methods was performed for each run. This fueling comparison can be seen in Table 30. The fuel weight was taken to be the reference method, as it was believed that gravimetric measurement was the most reliable and accurate method of determining total fuel consumption. Additionally, the actual work done by the engine, with and without urea injection, was included along with the reference work for each test cycle. Here reference work was defined as the total calculated work done by the engine according to the setpoint engine speed and torque. The fuel consumption and work results here show no definitive trend and little difference between runs with and without urea injection. This was to be expected, as urea injection does not affect engine fueling, $\mathrm{CO}_{2}$, emissions or engine work.

Table 30. Work and fuel consumption comparison (bhp-hr, lb)

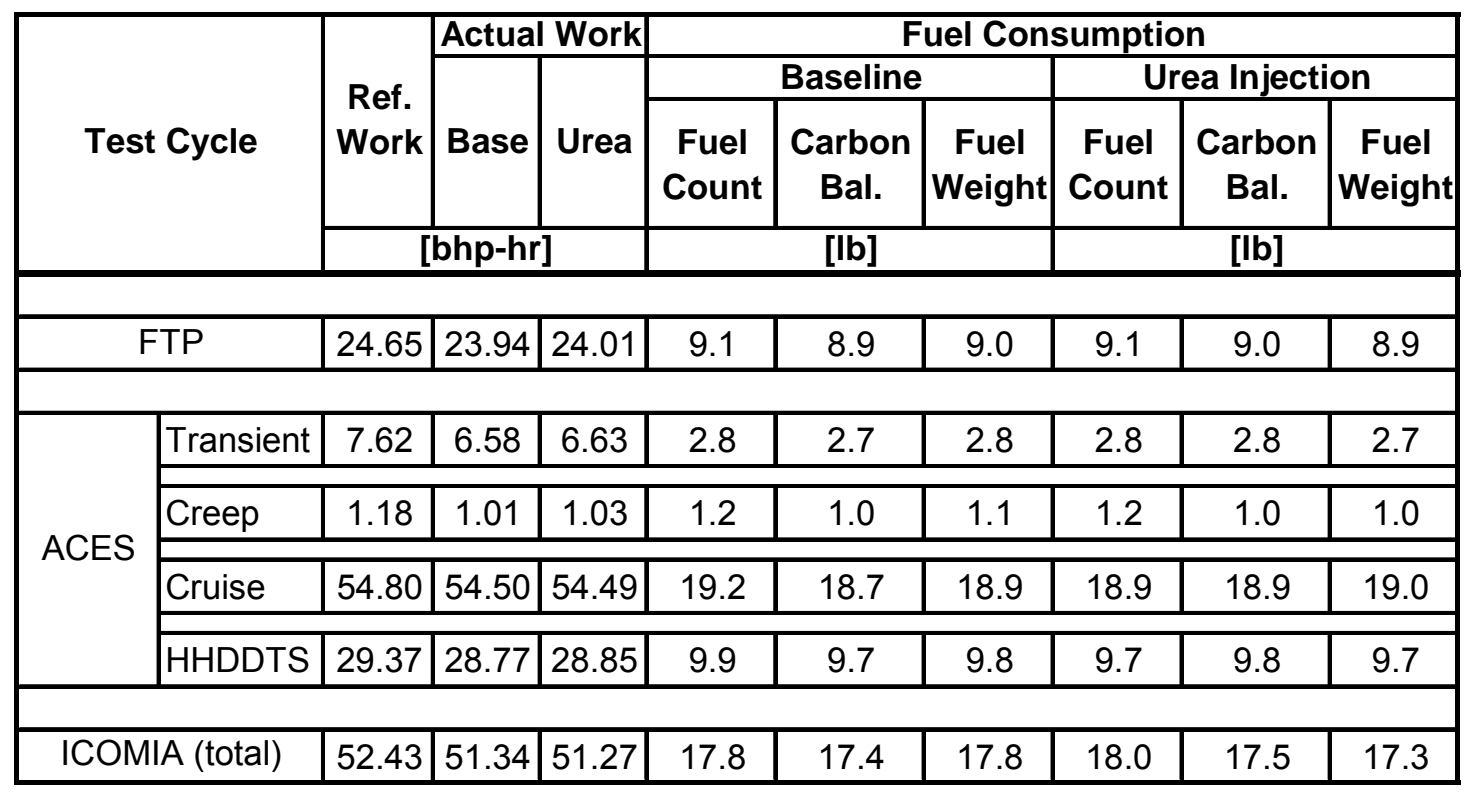


During development of the urea-SCR system, a 50\% reduction in total NOx was targeted with minimal ammonia slip. In order to demonstrate the NOx reduction capabilities of the system, continuous and total NOx for baseline and urea injection were compared for each test run. The continuous NOx was plotted for each run with and without urea injection, and included ammonia slip for the urea run. These results can be seen in Figure 35, parts (a) through (f). The ammonia slip presented here was measured by the ABB Advanced Optima NDUV analyzer because it was thought to be the more reliable method of $\mathrm{NH}_{3}$ measurement compared to the differencing techniques employed by the Ecophysics CDL $822 \mathrm{CMh}$.

For the ICOMIA run, it should be noted that urea dosing had to be decreased to circumvent high ammonia slip. This was accomplished from within the control software by reducing a urea dosing factor from 0.5 (corresponding to an ideal 50\% NOx reduction) to 0.25 . This reduction was required because most of the ICOMIA modes produced sustained high exhaust temperatures $\left(>400^{\circ} \mathrm{C}\right)$, which were not typically seen in transient operation. Based on results from testing, it was clear that the SCR catalyst has a distinctive temperature band where it is most efficient. 


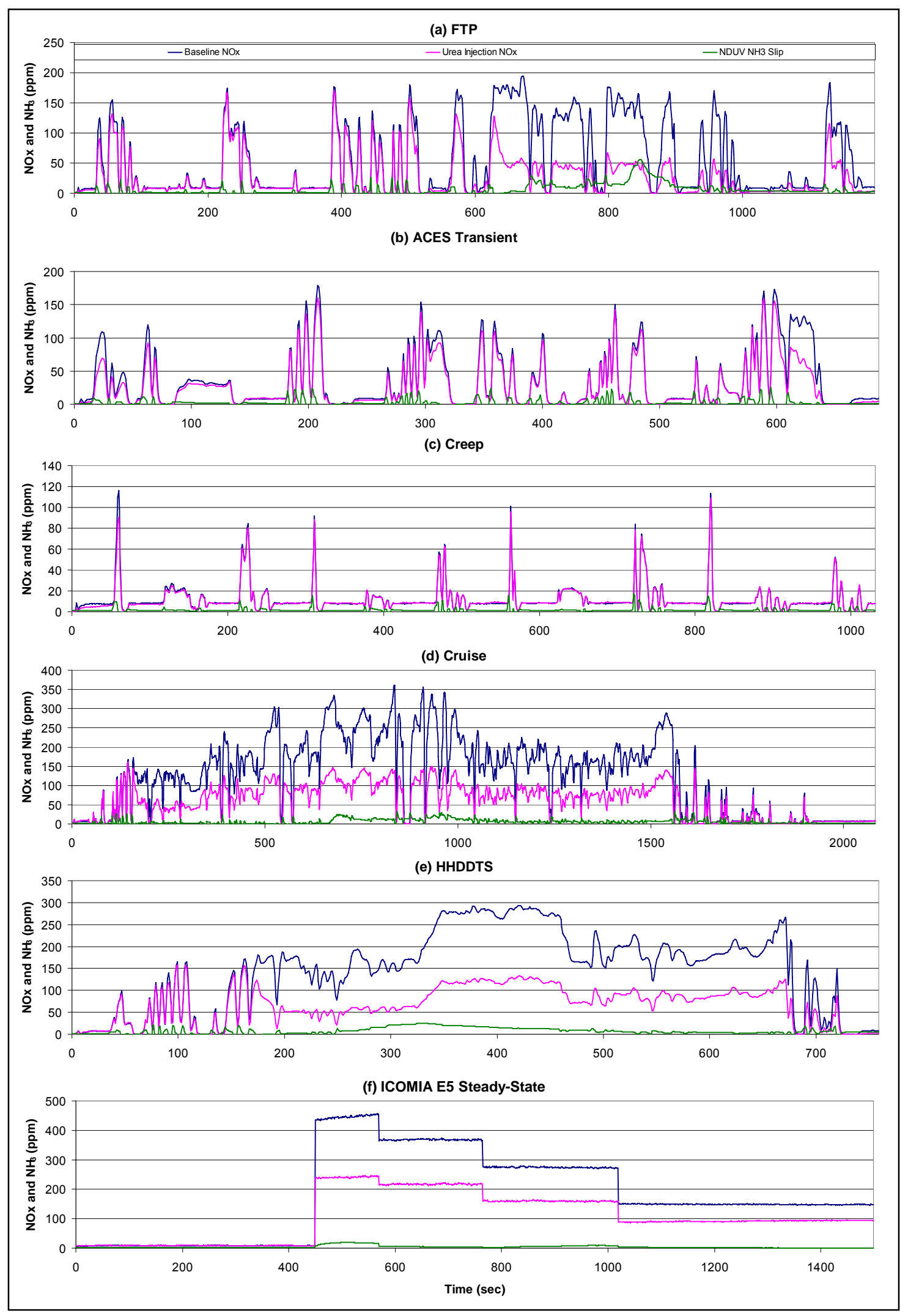

Figure 35. Continuous $\mathrm{NOx}$ and $\mathrm{NH}_{3}$ 
The total NOx emissions and corresponding reduction percentage for each run can be seen in Table 31 . In addition, the maximum ammonia slip concentration (dilute) observed over each cycle was included. From these results, it was clear that a 50\% NOx reduction can be achieved by the system, depending on cycle. Reasonably low ammonia slip was achieved over most cycles; however some higher peaks occurred, in particular over the FTP.

Table 31. Total NOx emissions (g/bhp-hr), NOx reduction (\%), and $\mathrm{NH}_{3}$ slip (ppm)

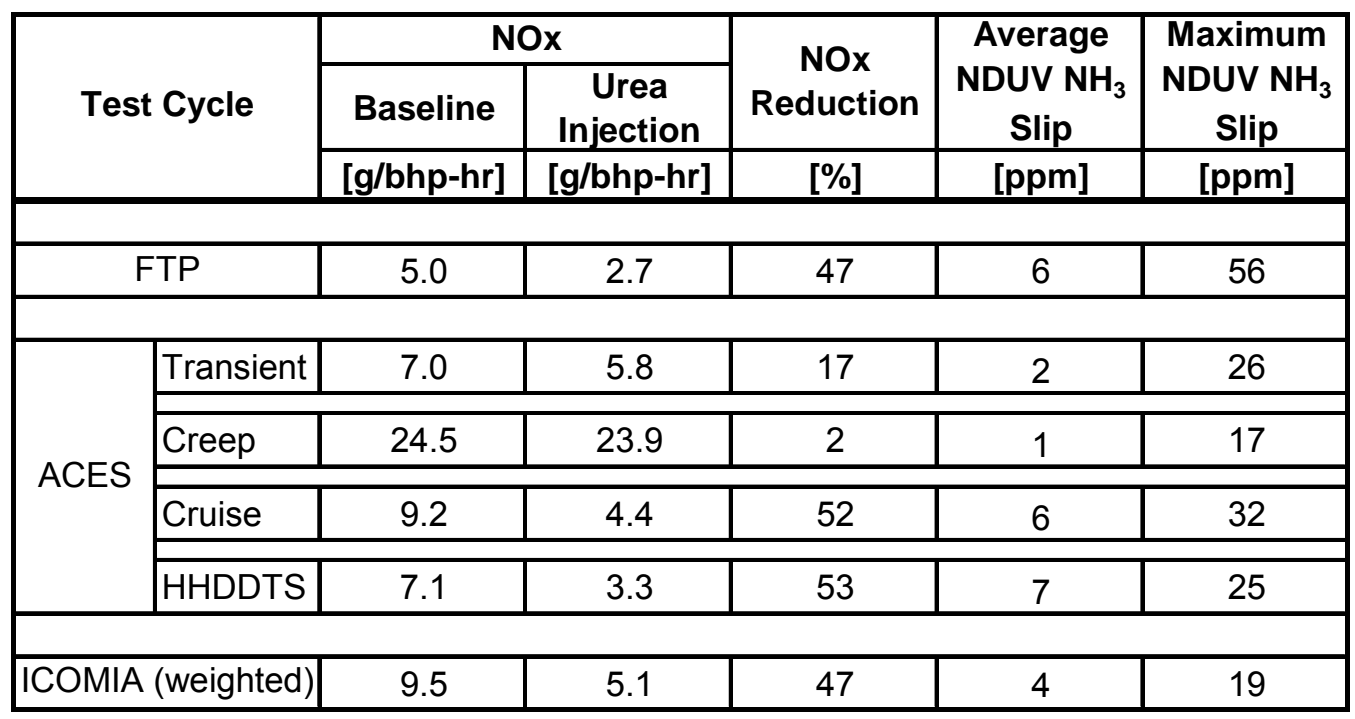

Data show that ammonia slip occurred in particular when the exhaust temperature was outside of the catalyst's efficiency band $\left(\approx 300-400^{\circ} \mathrm{C}\right)$ or when sudden large temperature spikes caused $\mathrm{NH}_{3}$ desorption. In order to demonstrate this, exhaust temperature was plotted in Figure 36 along with ammonia slip and NOx reduction percentage for the FTP cycle. Additionally, the overall low exhaust temperatures of the FTP can be seen, particularly over the first 600 seconds, where little urea injection took place. 


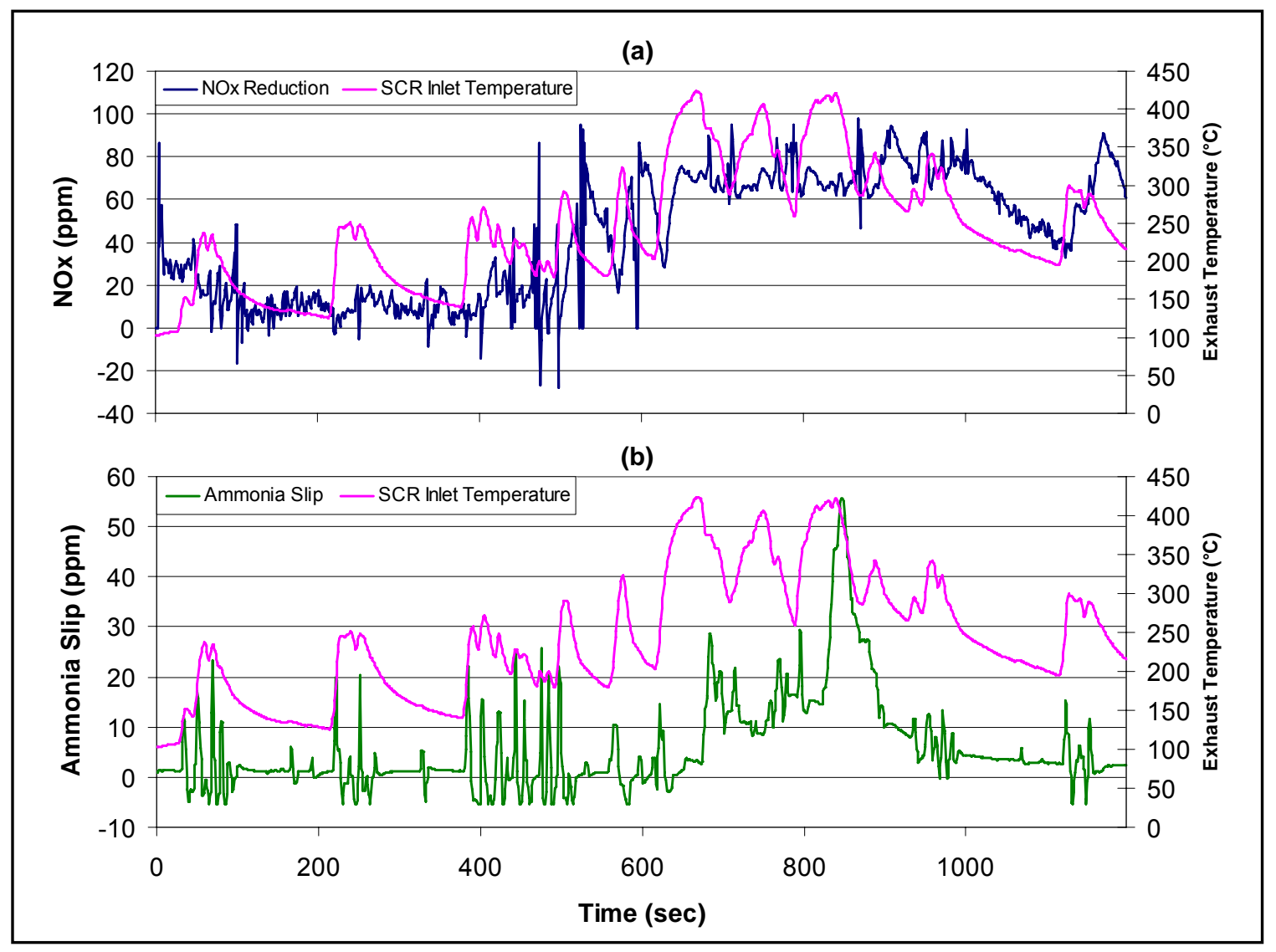

Figure 36. (a) NOx reduction (\%), (b) ammonia slip (ppm), exhaust temperature $\left({ }^{\circ} \mathrm{C}\right)$, FTP

A final run was performed to demonstrate the $\mathrm{NH}_{3}$ storage and release behavior of the SCR catalyst at different steady-state exhaust temperatures. This was accomplished by first running the engine without urea injection until all $\mathrm{NH}_{3}$ was desorbed, and the $\mathrm{NOx}$ level increased to a constant, baseline value. Then, urea was injected at a urea dosing factor of 0.75 , until ammonia slip was observed. During this time, the NOx emissions dropped to a constant, reduced NOx value. The point of ammonia slip was easily determined through visual observation of the NDUV analyzer readout. When ammonia slip began to occur, the $\mathrm{NH}_{3}$ concentration rose quickly above 3-5 ppm. At the point of ammonia slip, urea injection was instantly halted through the control software, the $\mathrm{NH}_{3}$ absorbed on the SCR catalyst began to desorb, and the NOx emissions rose back to the baseline value.

The whole process was completed at a constant engine speed of $1700 \mathrm{rpm}$ for three load points, $355 \mathrm{ft}-\mathrm{lb}$, $492 \mathrm{ft}-\mathrm{lb}$, and $690 \mathrm{ft}-\mathrm{lb}$. These load points corresponded to post-turbocharger exhaust temperatures of $321^{\circ} \mathrm{C}, 373^{\circ} \mathrm{C}$, and $429^{\circ} \mathrm{C}$, respectively. The NOx emissions, $\mathrm{NH}_{3}$ slip, and urea mass flow were plotted for each exhaust temperature in Figure 37. 


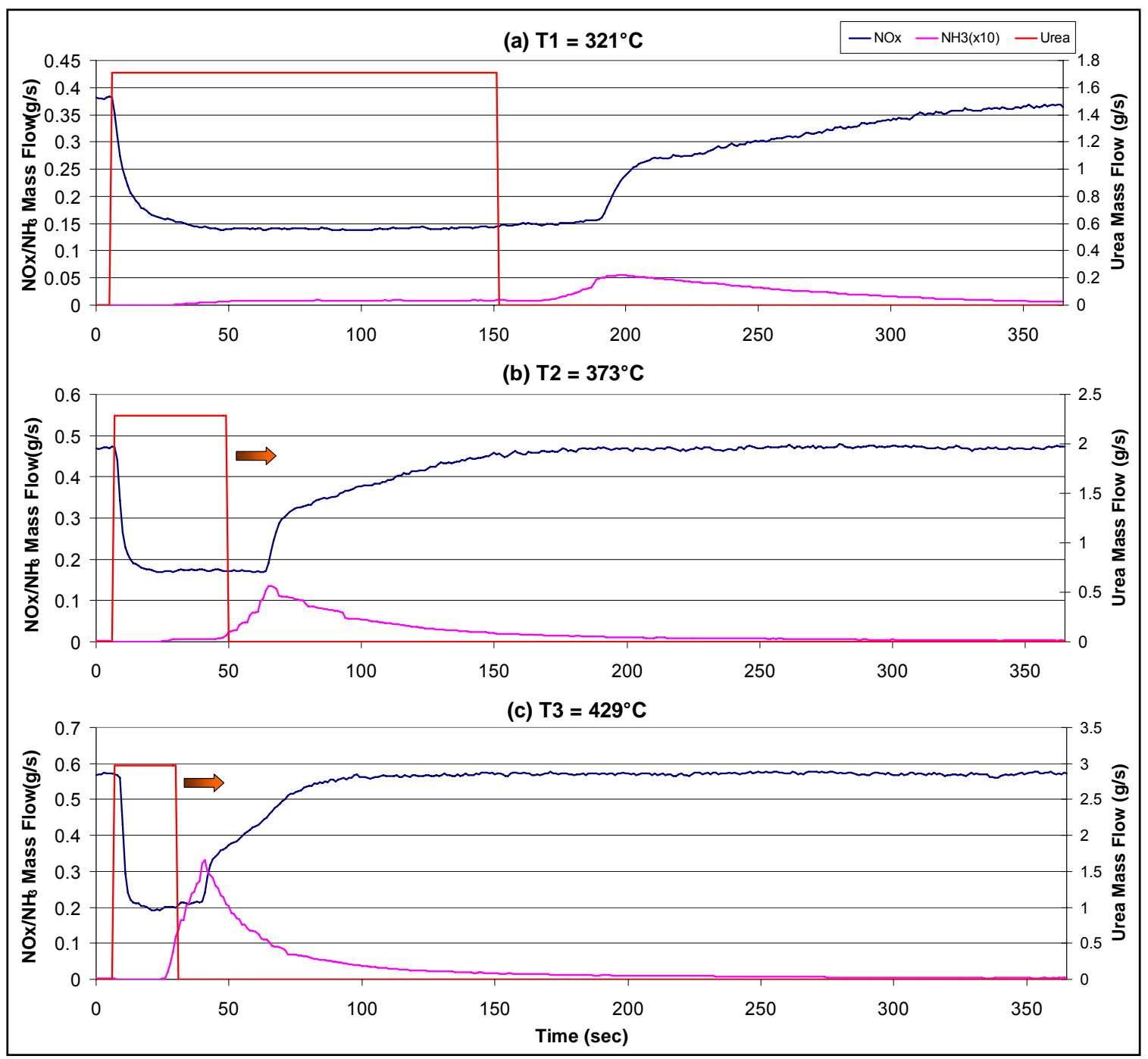

Figure 37. SCR catalyst storage, (a) $321^{\circ} \mathrm{C}$, (b) $373^{\circ} \mathrm{C}$, (c) $429^{\circ} \mathrm{C}$

Additionally, a continuous mass balance was performed for each exhaust temperature to determine the rate of adsorption and desorption of $\mathrm{NH}_{3}$ on the SCR catalyst substrate. The mass balance considered the mass of $\mathrm{NH}_{3}$ injected as urea, the mass of ammonia slip, and the mass of $\mathrm{NH}_{3}$ consumed by NOx. The following mass balance equation was utilized, assuming the molecular weight of NOx was equal to that of NO.

$$
\frac{d m}{d t}{ }_{\text {storage }}=\frac{1}{2} \frac{M_{N H 3}}{M_{\text {urea }}} \dot{m}_{\text {urea }}-\dot{m}_{\text {slip }}-\left[\frac{M_{N H 3}}{M_{N O x}}\right]\left(N O x_{\text {base }}-N O x\right) \quad \text { Equation } 18
$$

The instantaneous mass balance was plotted for each of the three exhaust temperatures, and can be seen in Figure 38. The adsorption and desorption rates were distinctly different, and varied with exhaust temperature. 


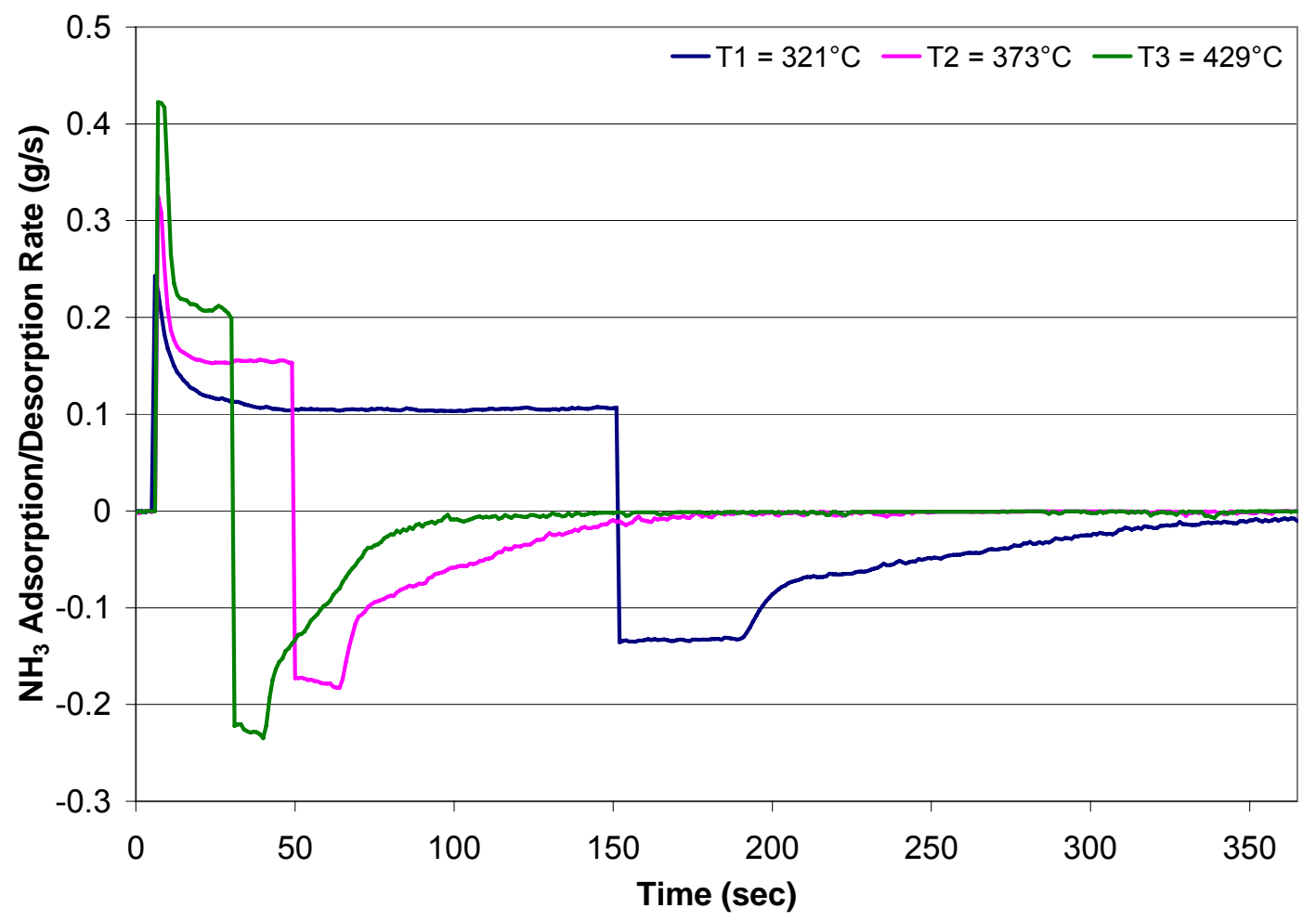

Figure 38. $\mathrm{NH}_{3}$ adsorption/desorption rates $(\mathrm{g} / \mathrm{s}), 321^{\circ} \mathrm{C}, 373^{\circ} \mathrm{C}, 429^{\circ} \mathrm{C}$

The instantaneous adsorption and desorption rates were integrated over time to determine the total mass of $\mathrm{NH}_{3}$ that was adsorbed and desorbed on the SCR catalyst. The total mass adsorbed and desorbed varied with exhaust temperature. There was a $10-25 \%$ difference between the mass of $\mathrm{NH}_{3}$ adsorbed and desorbed, depending on exhaust temperature. These differences may have been a result of other reactions or temperature dependences not considered in the simplified mass balance, or NDUV analyzer measurement inaccuracies.

Table 32. Total $\mathrm{NH}_{3}$ mass adsorbed and desorbed

\begin{tabular}{|c|c|c|}
\hline \multirow{2}{*}{$\begin{array}{c}\text { Exhaust } \\
\text { Temperature }\end{array}$} & \multicolumn{2}{|c|}{$\mathbf{N H}_{3}$ Totals } \\
\cline { 2 - 3 } & Adsorbed & Desorbed \\
\hline$[\mathrm{C}]$ & {$[\mathrm{g}]$} & {$[\mathrm{g}]$} \\
\hline 321 & 16.3 & 12.2 \\
\hline 373 & 7.2 & 8.0 \\
\hline 429 & 5.9 & 6.9 \\
\hline
\end{tabular}




\section{Chapter 8: System Model Development}

In order to evaluate the performance of each proposed control scenario computationally and determine an optimal control configuration, a model of the urea-SCR aftertreatment system was developed. The model included separate modules, which were integrated together into an overall system model. The main components of the system model included a heavy-duty diesel engine model, SCR catalyst model, NOx sharpening model, pipe heat loss model, thermocouple response correction, and urea injection control strategy. A diagram of the overall system model can be seen below in Figure 39. Here, the stoichiometric, feed-forward control strategy is represented (implemented during testing), which does not include feedback NOx. Each of the separate components are discussed in detail below.

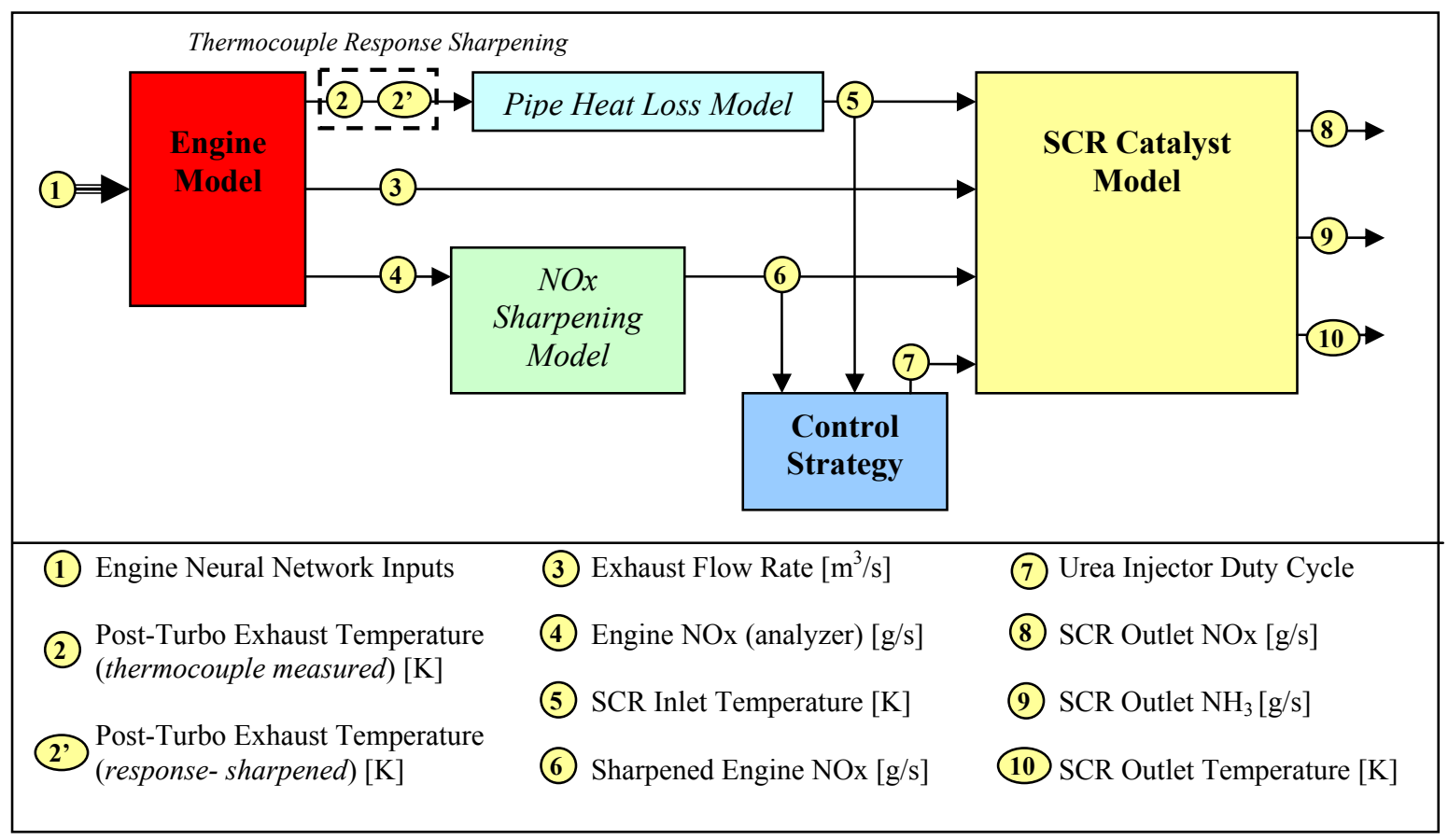

Figure 39. Overall system model diagram 


\subsection{Heavy-Duty Diesel Engine Model}

In order to develop a system model representing a comprehensive view of the urea-SCR aftertreatment process, a diesel engine model was included. In addition, by developing an engine model, experimental aftertreatment system data were not required as an input. A diesel engine model was developed implementing an ANN approach. This approach to modeling HHDDEs has been proven in literature and by WVU researchers [61-66], allowing continuous and accurate prediction of emissions, temperature, flow rate, and other engine outputs in response to input engine parameters. The modeling approach here utilized the Matlab/Simulink environment and neural network toolbox. A Matlab program (m-file) was written to train the model, while the final HHDDE model was established in Simulink. The ANN model predicted NOx emissions $(\mathrm{g} / \mathrm{s})$, exhaust temperature $(\mathrm{K})$, and exhaust volumetric flow rate $\left(\mathrm{m}^{3} / \mathrm{s}\right)$.

\section{$\underline{\text { 8.1.1 Model Structure }}$}

The HHDDE ANN model utilized single-hidden-layer feed-forward architecture. A diagram representing this type of arrangement can be seen in Figure 40. Weights and connections are only shown for select neurons to simplify the diagram; however they exist in a similar manner for each summation node and neuron. Hidden layer neurons and inputs continue from 1 to $j$ and 1 to $k$, respectively.

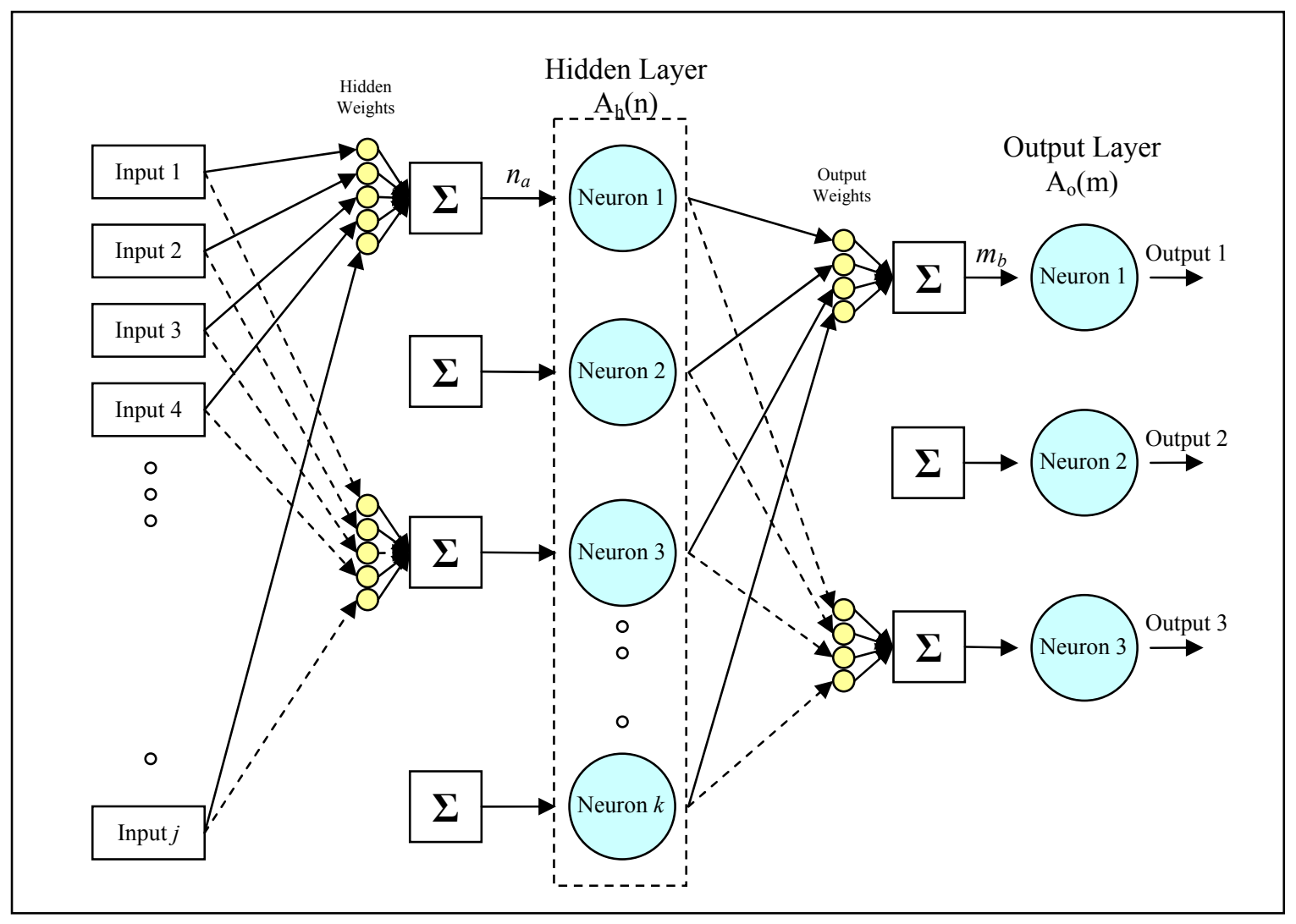

Figure 40. Single hidden layer feed-forward ANN architecture 
Activation functions were selected for the hidden and output layers to achieve the best predictions in response to input values. A logsig activation function was implemented in the hidden layer. This function is similar to the sigmoid activation function, which is a commonly used hidden layer activation function $[56,62]$. The hidden layer activation function can be seen in Equation 19, where $n_{a}$ is the summation of inputs and their corresponding weights for each hidden neuron, $a$.

$\log \operatorname{sig}(n)=A_{h}\left(n_{a}\right)=\frac{1}{1+e^{-n_{a}}}$

Equation 19

A simple linear activation function was implemented in the output layer. This is the simplest activation function available, as the summed input is passed directly through without modification. A linear activation function is often used in the output layer of a single hidden layer network arrangement [56] and was sufficient for accurate predictions in this application. The output layer activation function can be seen in Equation 20, where $m_{b}$ is the summation of hidden neuron outputs and their correcponding weights for each output neuron, $b$.

$\operatorname{lin}(m)=A_{o}\left(m_{b}\right)=m_{b}$

Equation 20

The number of neurons in the hidden layer was varied during model development, with 28 providing the best match with target data, while still achieving reasonable computational time. The output layer had three neurons, corresponding to each of the model outputs. It should be noted that the arrangement and training data presented here are very general and the ANN is not considered to be in a fully optimized form. However the model provides predictions which are sufficiently accurate for this optimization application and allows low computational effort.

\subsubsection{Input Parameter Selection}

A number of engine parameters were considered as ANN inputs. Engine parameters which affected model outputs the most were chosen. Historically, HHDDE ANN models have implemented engine speed, engine torque, and their time derivatives as inputs [61]. Engine boost was chosen because of its relationship to engine load, emissions (NOx), and exhaust flow rate, as well as being a good transient indicator. It was believed that oil and coolant temperatures may aid in the prediction of exhaust temperatures and provide additional information for the prediction of NOx emissions, which have a thermal dependence. Ambient temperature was not included in the neural network model because of a lack of experimental training data and to maintain focus on the SCR catalyst model and optimization of the control configuration.

Derivatives of boost, oil temperature, and coolant temperature were included in a manner similar to engine speed and torque. The inclusion of derivative inputs attempted to provide the model with rate of change 
information during transient operating conditions. All derivatives were calculated as backward numerical derivatives. By taking some derivatives over larger intervals, additional behavior may be captured according to previous (time history) or average values [66]. This may be particularly helpful in predicting NOx, which included some delay and may be dependent on engine behavior over the previous 10 seconds. In the case of engine oil and coolant temperature, variations occurred very slowly compared to other input variables. Therefore, only by taking derivatives over a longer time period would significant variations be captured. All time history derivative lengths were chosen to be 10 seconds. The complete list of inputs, outputs, and their corresponding normalization ranges for the engine model are shown in Table 33.

Table 33. Engine model inputs, outputs, and normalization ranges

\begin{tabular}{|c|c|c|c|c|c|c|}
\hline \multirow{2}{*}{ Engine Parameter } & \multirow{2}{*}{$\begin{array}{l}\text { ANN Input } \\
\text { Variable }\end{array}$} & \multirow{2}{*}{ Units } & \multicolumn{4}{|c|}{ Data Normalization } \\
\hline & & & \multicolumn{2}{|c|}{ Dimensional Range } & \multicolumn{2}{|c|}{ Normalized Range } \\
\hline \multicolumn{7}{|l|}{ Inputs } \\
\hline \multirow{3}{*}{ Engine Speed } & $N$ & $R P M$ & 0 & 2300 & 0 & 1 \\
\hline & $\mathrm{dN} / \mathrm{dt}_{1}$ & $R P M / s$ & -2300 & 2300 & -1 & 1 \\
\hline & $\mathrm{dN} / \mathrm{dt}_{10}$ & $R P M / s$ & -230 & 230 & -1 & 1 \\
\hline \multirow{3}{*}{ Engine Torque } & $\mathrm{T}$ & $N-m$ & -500 & 1000 & -1 & 1 \\
\hline & $\mathrm{dT} / \mathrm{dt}$ & $N-m / s$ & -1500 & 1500 & -1 & 1 \\
\hline & $\mathrm{dT} / \mathrm{dt}_{10}$ & $N-m / s$ & -150 & 150 & -1 & 1 \\
\hline \multirow{2}{*}{ Engine Oil Temperature } & $T_{\text {oil }}$ & $K$ & 0 & 250 & 0 & 1 \\
\hline & $\mathrm{dT}_{\text {oil }} / \mathrm{dt}_{10}$ & $K / s$ & -25 & 25 & -1 & 1 \\
\hline \multirow{2}{*}{ Engine Coolant Temperature } & $T_{\text {cool }}$ & $K$ & 0 & 250 & 0 & 1 \\
\hline & $\mathrm{dT}_{\text {cool }} / \mathrm{dt}_{10}$ & $K / s$ & -25 & 25 & -1 & 1 \\
\hline \multirow{2}{*}{ Engine Boost } & $B$ & $k P a_{a b s}$ & 100 & 300 & 0 & 1 \\
\hline & $\mathrm{dB} / \mathrm{dt}$ & $k P a_{a b s} / s$ & -200 & 200 & -1 & 1 \\
\hline \multicolumn{7}{|l|}{ Outputs } \\
\hline Engine-Out NOx & NOx & $g / s$ & 0 & 0.5 & 0 & 1 \\
\hline Exhaust Temperature & $T_{\text {exh }}$ & K & 0 & 500 & 0 & 1 \\
\hline Exhaust Volumetric Flow & $\mathrm{V}$ & $m^{3} / s$ & 0 & 0.4 & 0 & 1 \\
\hline
\end{tabular}

\subsubsection{Training Program and Model Development}

All input, training target, and validation data were compiled into a single spreadsheet in engineering units. Using a Matlab routine, input and training target data were read into the program. Corresponding input derivatives were computed, where backward numerical derivatives were utilized. Input and training target data were normalized over pre-defined ranges prior to being introduced into the neural network. Consequently, the network outputs were normalized, and had to be de-normalized for conversion to engineering units. The normalization ranges (Table 33) were chosen such that they were applicable to all 
test cycles considered. Depending on the variable, the normalized range may be between 0 and 1 or -1 and 1. The tightest possible normalization ranges were utilized to achieve high resolution of all variables.

Training of the model consisted of exposing the network to input data and adjusting the hidden and output layer weights to best match training target data. Here, training was accomplished using a Matlab training algorithm, trainlm. The trainlm function implemented the Levenberg-Marquardt backpropagation algorithm to adjust the weighting factors [82]. During the development process, several other algorithms were considered, however trainlm provided the best match ( $\mathrm{R}$ and total error) with target data for all output variables. The training algorithm included a learning rate parameter which varied the rate at which the ANN's synaptic weights were changed as training data are applied. A higher learning rate caused the weights to be varied more quickly, while a lower learning rate caused changes to occur more slowly. The learning rate was varied during development, with 0.1 providing the best match with target data. Finally, the training program called a pre-defined Matlab function, which converted the trained ANN into a Simulink block, which was inserted into the final HHDDE Simulink model. The Simulink neural network block can be seen in Figure 41.

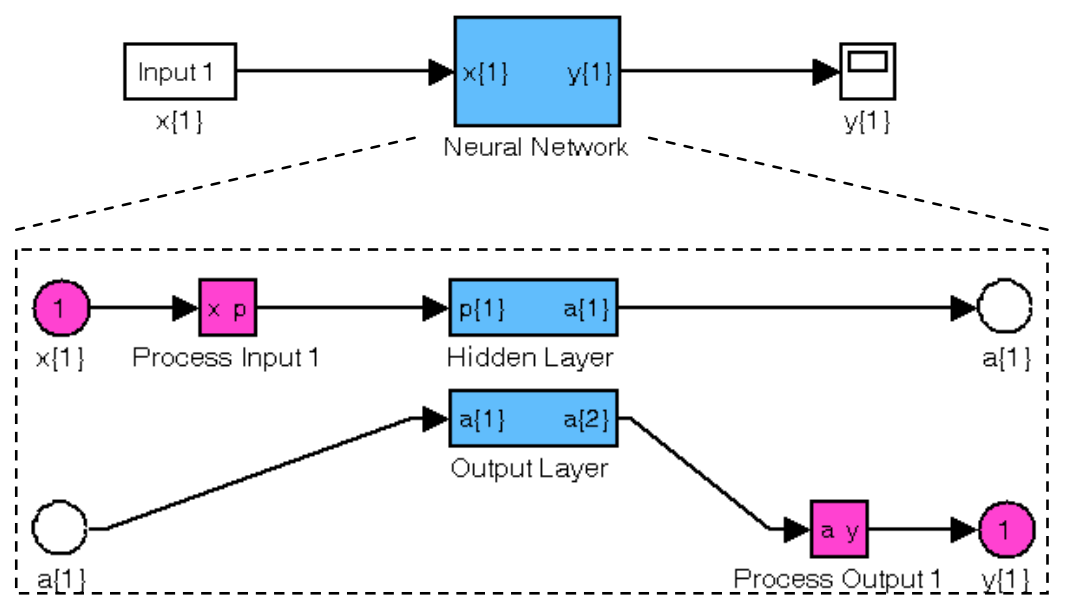

Figure 41. Simulink neutral network block

By developing the final model in Simulink, real-time adjustments could be made by the control scheme (example: feedback NOx) to continuously alter the dosing of urea in the SCR catalyst model. The HHDDE Simulink model performed many of the same data processing calculations as the training program, yet in the Simulink environment. This included calculating input derivatives, normalizing input data, and denormalizing output data. Prior to accepting the training and validation results, it was ensured that all calculated input data were identical between the Matlab training program and Simulink HHDDE model, and that the same normalization ranges were implemented. The final Simulink HHDDE model read input 
data from Matlab .mat files, calculated input derivatives, normalized all input data, and sent the input data matrix to the trained Simulink neural network block. The neural network outputs of NOx, exhaust temperature, and exhaust volumetric flow rate were then de-normalized, resulting in final predictions in appropriate engineering units.

\subsubsection{Training Cycle Creation}

In order to train the ANN so that accurate predictions could be made during different types of engine behavior, a representative composite training cycle was created. Initially, the FTP alone was considered as a training cycle. However this resulted in poor predictions over portions of the ACES cycles and especially over the steady-state points of the ICOMIA cycle. By combining segments of multiple cycles into a single composite training cycle, a wide variety of engine behavior was captured, resulting in a more robust model.

The composite training cycle was generated using data from the FTP, ACES Transient, HHDDT_S, and Creep modes, and the ICOMIA cycle. In order to avoid over-training the network, only the most representative portions of each cycle were included. Over-training can occur when a neural network is exposed to too much training data. This can cause the network to only have the ability to predict the training data and can result in small deviations causing large changes in output values [56]. Also, because the model would be exposed to the training data over multiple iterations, repetitive behavior could be eliminated in the training cycle. The ACES Cruise cycle was not included here because the behavior it exhibited was nearly identical to the HHDDT_S and FTP cycles, but it was nearly double the length (see Appendix B). Additional details regarding the data used in the composite training cycle can be seen in Table 34. The input engine speed and torque traces can be seen in Figure 42 (a) and (b), respectively.

Table 34. Composite training cycle data

\begin{tabular}{|c|c|c|c|c|c|}
\hline \multicolumn{2}{|c|}{ Segment } & \multicolumn{2}{|c|}{ Original Test Cycle } & Original Time Segment & $\begin{array}{c}\text { Duration } \\
\text { (sec) }\end{array}$ \\
\hline \multicolumn{2}{|c|}{1} & \multirow{2}{*}{\multicolumn{2}{|c|}{ FTP }} & $0-150 \mathrm{sec}$ & 150 \\
\hline \multicolumn{2}{|c|}{2} & & & $550-915 \mathrm{sec}$ & 365 \\
\hline \multicolumn{2}{|c|}{3} & \multirow{4}{*}{ ACES } & Transient & $150-250 \mathrm{sec}$ & 100 \\
\hline \multicolumn{2}{|c|}{4} & & Transient & $510-680 \mathrm{sec}$ & 170 \\
\hline \multicolumn{2}{|c|}{5} & & Creep & $0-320 \mathrm{sec}$ & 320 \\
\hline \multicolumn{2}{|c|}{6} & & HHDDTS & $137-667 \mathrm{sec}$ & 530 \\
\hline \multirow{5}{*}{7} & $a$ & \multirow{5}{*}{ ICOMIA } & Idle & [Mode 1] $0-60 \mathrm{sec}$ & 60 \\
\hline & $\mathrm{b}$ & & High & [Mode 2] $0-60 \mathrm{sec}$ & 60 \\
\hline & c & & Mid & [Mode 3] $0-60 \mathrm{sec}$ & 60 \\
\hline & $\mathrm{d}$ & & \begin{tabular}{|l} 
Mid-High \\
\end{tabular} & [Mode 4] $0-60 \mathrm{sec}$ & 60 \\
\hline & $\mathrm{e}$ & & Low & [Mode 5] $0-60 \mathrm{sec}$ & 60 \\
\hline
\end{tabular}




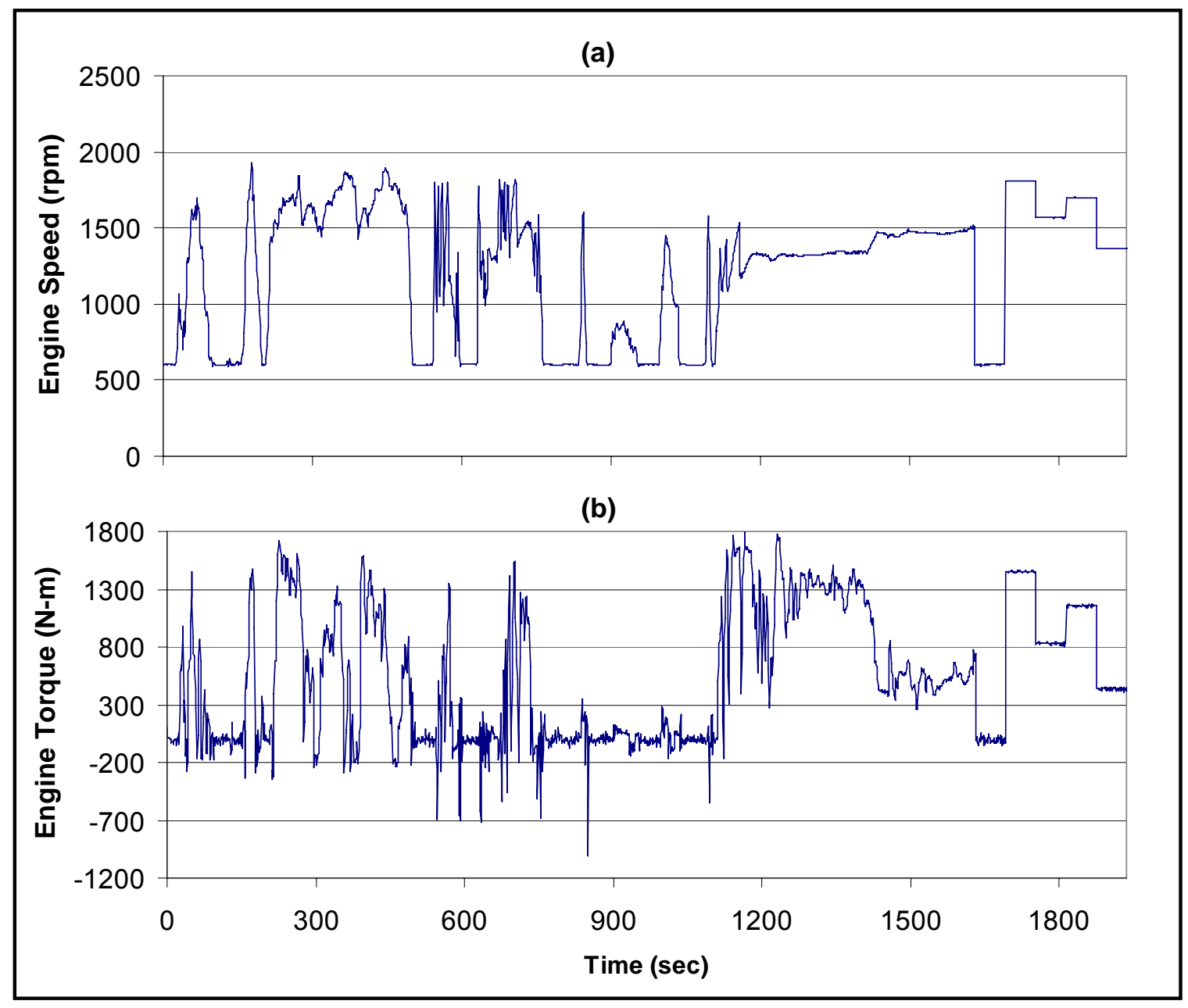

Figure 42. Composite training cycle (a) engine speed (rpm), (b) engine torque (N-m)

\subsection{SCR Catalyst Model}

The main focus of the system model was the SCR catalyst. Two main approaches to developing an SCR catalyst model were identified: higher-order models and reduced-order models. Either approach includes separate (but coupled) thermal and chemical modules.

Higher-order SCR models attempt to represent the system as accurately as possible. The urea decomposition process can be modeled by a four-step mechanism [83], which includes urea $\left(\left(\mathrm{NH}_{2}\right)_{2} \mathrm{CO}\right)$, ammonia $\left(\mathrm{NH}_{3}\right)$, and isocyanic acid (HNCO). The thermal component of the SCR model includes gas and solid phase energy balances. The solid phase energy balance considers longitudinal heat conduction and the thermal energy of surface reactions [83-85]. The chemical component of the SCR model includes both gas and solid phase species balances for $\mathrm{NO}, \mathrm{NO}_{2}$, and $\mathrm{NH}_{3}$. It is assumed that mass transfer occurs from the gas phase to the solid phase, where all SCR reactions take place on the catalyst surface. The storage of $\mathrm{NH}_{3}$ within the catalyst is modeled, considering adsorption, desorption, and the cumulative reaction of $\mathrm{NH}_{3}$ $[83,84,85]$. Finally, some approaches [83] also model species diffusion in the radial direction. Higher-order 
models offer the highest accuracy and are the most physically relevant. However these models can be very computationally intensive and require substantial knowledge of specific chemical and thermodynamic parameters.

For this control optimization application, model accuracy and computational effort were both considered. To allow forms of model-based control to be implemented, the chosen approach could not be too computationally intensive. Therefore, two reduced order chemical modeling approaches were considered. It has been shown that reduced-order models can have accuracies which approach that of higher-order models. Both reduced-order approaches neglect the urea decomposition process and gaseous to solid mass transfer (other than storage of $\mathrm{NH}_{3}$ ). A three-state model, which considers gaseous $\mathrm{NO}$, gaseous $\mathrm{NH}_{3}$, and stored $\mathrm{NH}_{3}$ has shown poor performance when compared to higher-order models [85]. This is likely due to the fact that when considering NO alone, only a single SCR reaction (Equation 22) is used. This single reaction is not adequate to describe the chemical kinetics within the SCR catalyst [85]. However, when utilizing a four-state model and considering gaseous $\mathrm{NO}$, gaseous $\mathrm{NO}_{2}$, gaseous $\mathrm{NH}_{3}$, and stored $\mathrm{NH}_{3}$, performance similar to a higher-order model is achieved. Devarakonda et al. [85] demonstrated that when compared to a higher-order model, the four-state model maximum and minimum percent absolute error was $5.5-10 \%$ and $0.3-1.3 \%$, respectively. The variation in error here was dependent on the reaction rate parameters used. As a result of this comparison, the four-state chemical modeling approach was chosen to provide a compromise between model accuracy and computational effort. Additionally, a simplified form of the higher-order thermal modeling approach was utilized. The chosen modeling approach is detailed below, with separate sections for the thermal and chemical components.

\subsubsection{Four-State Chemical Reaction Sub-Model Description}

The four-state modeling approach utilized was similar to that outlined by Devarakonda et al. in $[84,85]$.

This approach considered gaseous $\mathrm{NO}$, gaseous $\mathrm{NO}_{2}$, gaseous $\mathrm{NH}_{3}$, and stored $\mathrm{NH}_{3}$. The major assumptions made in the model were as follows.

1. The SCR channels are square, and mass balances for a single channel are used to represent the entire catalyst.

2. Radial profiles of species concentrations and temperature are uniform within the channel and over the catalyst cross-section.

3. Each SCR channel is divided into $n$ ideal partitions in the longitudinal direction, with each partition having constant gas and solid phase species concentrations, temperatures, and pressure.

4. Ideal gas properties are assumed.

5. Urea evaporation, decomposition, and hydrolysis are assumed to be complete in the exhaust pipe upstream of the SCR catalyst. It is assumed that two moles of $\mathrm{NH}_{3}$ are produced for every one mole of urea injected $[84,85]$. 
6. Only $\mathrm{NO}, \mathrm{NO}_{2}$, and $\mathrm{NH}_{3}$ species concentrations are modeled. All other species are considered constant.

7. The NO/NOx ratio is considered constant at 0.90 . (see $\$ 2.1 .3$ and Figure 1)

8. Axial dispersion is neglected as a result of the high exhaust velocities.

9. Mass transfer is neglected, meaning that the chemical kinetics within the SCR catalyst are reaction controlled [85].

10. Surface phase concentrations are neglected (not including $\mathrm{NH}_{3}$ storage).

11. Reaction rates are defined solely as a function of temperature, $\mathrm{NH}_{3}$ storage, and gas phase concentrations of $\mathrm{NO}$ and $\mathrm{NO}_{2}$.

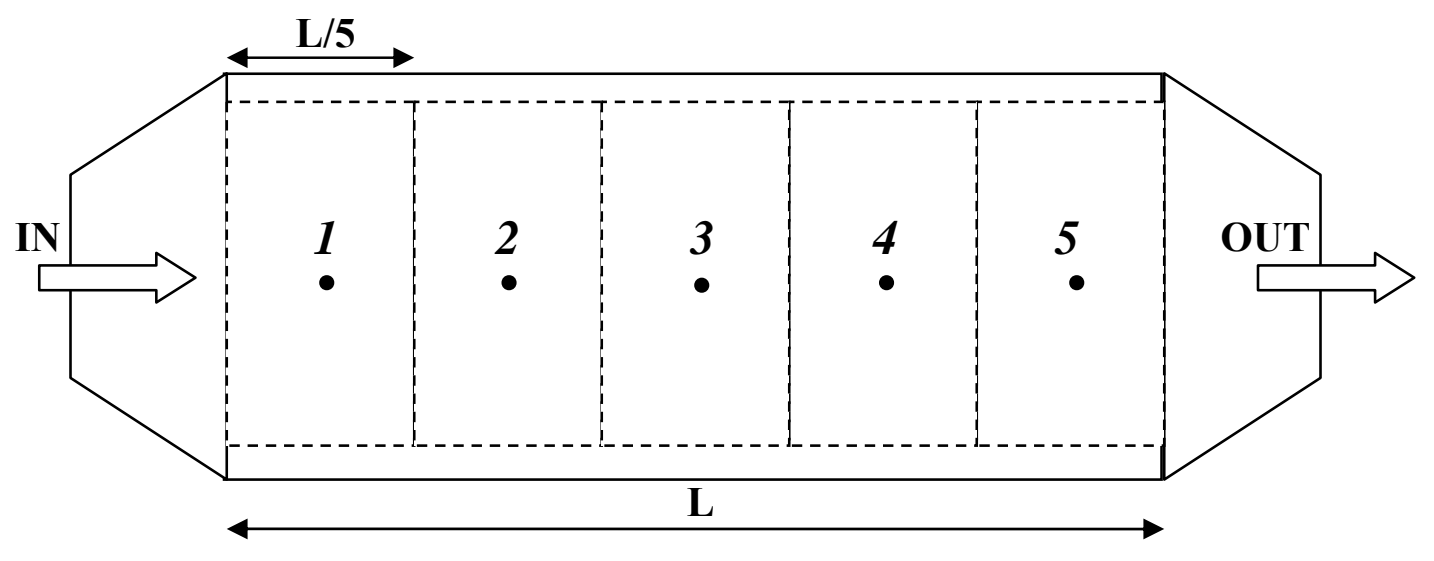

Figure 43. SCR catalyst model physical layout $(n=5)$

The four-state model considered a total of 6 chemical reactions, detailed below. These are the same six reactions considered for the higher-order modeling approach. Here, Equation 21 was denoted as the 'Fast SCR' reaction, Equation 22 was the 'Standard SCR' reaction, and Equation 23 was the 'Slow SCR' reaction. Equation 25 and Equation 26 represented the adsorption and desorption of $\mathrm{NH}_{3}$ on the catalyst substrate. In accordance with approaches in literature [84,85], the oxidation of $\mathrm{NH}_{3}$ to $\mathrm{NO}$ and $\mathrm{NO}$ oxidation to $\mathrm{NO}_{2}$ could be associated with very high exhaust temperatures $\left(>500^{\circ} \mathrm{C}\right)$, and were neglected. In Equation 25 and Equation 26, $\varphi$ represents available surface reaction sites.

$$
\begin{array}{lr}
4 \mathrm{NH}_{3}+2 \mathrm{NO}+2 \mathrm{NO}_{2} \rightarrow 4 \mathrm{~N}_{2}+6 \mathrm{H}_{2} \mathrm{O}(\mathbf{R} 1) & \text { Equation } 21 \\
4 \mathrm{NH}_{3}+4 \mathrm{NO}+\mathrm{O}_{2} \rightarrow 4 \mathrm{~N}_{2}+6 \mathrm{H}_{2} \mathrm{O}(\mathbf{R} 2) & \text { Equation 22 } \\
4 \mathrm{NH}_{3}+3 \mathrm{NO}_{2} \rightarrow \frac{7}{2} \mathrm{~N}_{2}+6 \mathrm{H}_{2} \mathrm{O}(\mathrm{R} 3) & \text { Equation } 23 \\
4 \mathrm{NH}_{3}+3 \mathrm{O}_{2} \rightarrow 2 \mathrm{~N}_{2}+3 \mathrm{H}_{2} \mathrm{O}(\mathbf{R} 4) & \text { Equation } 24
\end{array}
$$


As stated in the assumptions, the reactions rates for each equation were defined purely as a function of ammonia storage $(\theta)$, gaseous $\mathrm{NO}$, and gaseous $\mathrm{NO}_{2}$. The reaction rate expressions used for each reaction 1 through 6 (Equation 21-26) can be seen below.

$R_{1}=k_{1} C_{N O} C_{N_{2}} \theta \Omega$

$R_{2}=k_{2} C_{\mathrm{NO}_{\mathrm{O}}} n_{\mathrm{O}_{2}} \theta \Omega$

$R_{3}=k_{3} C_{\mathrm{NO}_{2}} \theta \Omega$

$R_{4}=k_{4} \theta \Omega$

$R_{5}=k_{5} C_{N_{3}}(1-\theta) \Omega$

$R_{6}=k_{6} \theta \Omega$
Equation 27 [84,85]

Equation 28 [84,85]

Equation 29 [84,85]

Equation 30 [84,85]

Equation $31[84,85]$

Equation 32 [84,85]

In the above reaction rate expressions, $\Omega$ denotes the catalyst storage capacity, in moles of $\mathrm{NH}_{3}$ per $\mathrm{m}^{3}$ of exhaust gas volume [85]. During experimental testing of the aftertreatment system, an $\mathrm{NH}_{3}$ mass balance was performed, which approximated the total $\mathrm{NH}_{3}$ mass adsorbed and desorbed within the catalyst brick at three exhaust temperatures (see Table 35). Here $\mathrm{NH}_{3}$ storage was modeled as a function of exhaust temperature, where linear interpolation and extrapolation were used to determine storage at additional temperatures. Additional details of the $\mathrm{NH}_{3}$ mass balance can be seen in the above experimental results section.

Table 35. SCR catalyst model $\mathrm{NH}_{3}$ storage $\left(\mathrm{moles} / \mathrm{m}^{3}\right)$

\begin{tabular}{|c|c|}
\hline $\begin{array}{c}\text { Exhaust } \\
\text { Temperature }\end{array}$ & $\mathrm{NH}_{3}$ Storage \\
\hline$[\mathrm{K}]$ & {$\left[\mathrm{moles} / \mathrm{m}^{3}\right]$} \\
\hline 594 & 23.7 \\
\hline 646 & 11.7 \\
\hline 702 & 10.1 \\
\hline
\end{tabular}

Reaction rate constants were defined using the standard Arrhenius expression below.

$k_{i}=A_{i} e^{\frac{-E_{i}}{R T}}(i=1 \ldots 6)$

Equation 33 
Here, $E_{i}$ is the activation energy for each reaction, $A_{i}$ is a pre-exponential constant, $R$ is the universal gas constant, and $T$ is the relevant temperature. The values of $E_{i}$ and $A_{i}$ used for each reaction 1 through 6 can be seen in Table 36 .

Table 36. Model reaction rate parameters

\begin{tabular}{|c|c|c|c|c|}
\hline \multirow{2}{*}{\multicolumn{2}{|c|}{ Reaction (i) }} & \multirow{2}{*}{\multicolumn{2}{|c|}{$\begin{array}{l}\text { Pre-Exponential Constant } \\
\qquad\left(A_{i}\right)\end{array}$}} & \multirow{2}{*}{$\begin{array}{c}\text { Activation } \\
\text { Energy }\left(E_{i}\right) \\
{[\mathrm{kJ} / \mathrm{mol}]}\end{array}$} \\
\hline & & & & \\
\hline 1 & Fast SCR & $4.50 \mathrm{E}+14$ & {$\left[\mathrm{~m}^{6} / \mathrm{mol}^{2}-\mathrm{s}\right]$} & 100 \\
\hline 2 & Standard SCR & $6.00 \mathrm{E}+06$ & {$\left[\mathrm{~m}^{3} / \mathrm{mol}-\mathrm{s}\right]$} & 70 \\
\hline 3 & $\mathrm{NO}_{2} \mathrm{SCR}$ & $2.82 E+08$ & {$\left[\mathrm{~m}^{3} / \mathrm{mol}-\mathrm{s}\right]$} & 85 \\
\hline 4 & $\mathrm{NH}_{3}$ Oxidation & $4.44 \mathrm{E}+06$ & {$[1 / \mathrm{s}]$} & 106 \\
\hline 5 & $\mathrm{NH}_{3}$ Adsorption & $5.24 \mathrm{E}+06$ & {$\left[\mathrm{~m}^{3} / \mathrm{mol}-\mathrm{s}\right]$} & 47 \\
\hline 6 & $\mathrm{NH}_{3}$ Desorption & $3.26 E+09$ & {$[1 / \mathrm{s}]$} & 114 \\
\hline
\end{tabular}

A gas phase species mass balance was performed for $\mathrm{NO}, \mathrm{NO}_{2}$, and $\mathrm{NH}_{3}$, and a solid phase species mass balance was performed for the stored $\mathrm{NH}_{3}(\theta)$. Mass flows were converted to molar flows by dividing by the corresponding molecular weight. Molar flow rates were divided by the total volumetric flow rate of exhaust gas, so that species were represented as concentrations $\left(\mathrm{moles} / \mathrm{m}^{3}\right) . \mathrm{NH}_{3}$ storage was a nondimensional parameter ranging from zero to one. Implementing the above reaction rate expressions, the final gaseous species mass balances for $\mathrm{NO}, \mathrm{NO}_{2}$, and $\mathrm{NH}_{3}$, as well as $\mathrm{NH}_{3}$ storage can be seen below in Equation 34 through 37.

$$
\begin{array}{lr}
\dot{C}_{N O}=\bar{Q}\left(N O_{I N}-N O\right)-k_{1} C_{N O} C_{N_{2}} \theta \Omega-k_{2} C_{N O} n_{O_{2}} \theta \Omega & \text { Equation 34 } \\
\dot{C}_{\mathrm{NO}_{2}}=\bar{Q}\left(N O_{2 I N}-N O_{2}\right)-k_{1} C_{N O} C_{N_{2}} \theta \Omega-k_{3} C_{N_{2}} \theta \Omega & \text { Equation 35 } \\
\dot{C}_{N_{3}}=\bar{Q}\left(N H_{3 I N}-N H_{3}\right)-k_{5} C_{N_{3}}(1-\theta) \Omega+k_{6} \theta \Omega & \text { Equation 36 } \\
\dot{\theta}=k_{5} C_{N_{3}}(1-\theta)-k_{1} C_{N O} C_{N_{2}} \theta-k_{2} C_{N O} n_{O_{2}} \theta-k_{3} C_{N_{2}} \theta-\left(k_{4}+k_{6}\right) \theta & \text { Equation 37 }
\end{array}
$$

Here, $\bar{Q}$ is a normalized flow, defined as the exhaust volumetric flow divided by the total exhaust gas volume within the SCR catalyst. By using normalized parameters, it enabled the equations to be the same regardless of whether a single SCR channel (or partition) or the whole catalyst brick was considered.

Equation 34 through 37 were solved simultaneously for each partition of the SCR catalyst. The number of partitions was chosen carefully to maintain manageable computational effort while accurately modeling SCR behavior. Schar et al. [50] chose to utilize as little as three SCR partitions, while others used as many as 15 [83]. The model developed here utilized 5 SCR partitions, which provided the best match with 
experimental validation data. The final SCR catalyst model was developed using Matlab/Simulink. This enabled it to be linked to other modules to create the overall system model.

\subsubsection{Thermal Sub-Model Description}

A thermal model was developed to determine the SCR outlet exhaust gas temperature and SCR brick temperature in response to the SCR inlet exhaust gas temperature. The following assumptions were applied in addition to the major assumptions made above.

1. Longitudinal heat conduction is neglected.

2. Energy released or consumed by chemical reactions is neglected.

Using the first law of thermodynamics and Newton's law of cooling, coupled energy equations were developed for the SCR catalyst brick (wall) and flowing exhaust gas.

$$
\begin{aligned}
& \frac{d T_{w}}{d t}=\frac{A_{i} h_{i}}{\left(V \rho c_{p}\right)_{w}}\left(T_{g}-T_{w}\right)-\frac{A_{o} h_{o}}{\left(V \rho c_{p}\right)_{w}}\left(T_{w}-T_{\infty}\right) \\
& \frac{d T_{g}}{d t}=\bar{Q}\left(T_{i n}-T_{g}\right)-\frac{A_{i} h_{i}}{\left(V \rho c_{p}\right)_{g}}\left(T_{g}-T_{w}\right)
\end{aligned}
$$

Similar to the chemical reaction model, equations were solved for each of the five SCR partitions, assuming constant properties and temperatures within each. In order to solve the above equations, heat transfer coefficients were required for the internal forced convection and external free convection. To determine these values, correlations for Nusselt number (defined below) were used. Here, $h$ is the convective heat transfer coefficient, $k$ is the thermal conductivity, and $D$ is the characteristic length.

$$
N u_{D}=\frac{h D}{k}
$$

Equation 40

For the correlations below $D$ represented the SCR passage hydraulic diameter, defined in Equation 41. Here $A$ is the cross-sectional area and $P$ is the wetted perimeter.

$$
D_{h}=\frac{4 A}{P}
$$

The inner heat transfer coefficient was determined using an empirical correlation for forced convection for laminar heat transfer in tubes $[83,86]$. The Nusselt number here was a function of Reynolds number and 
Prandtl number in the SCR passage. As an example, the Reynolds number varied between 94 and 675 over the FTP. This correlation considered non-fully developed flow, as dictated by literature [83]. According to an entrance length correlation for laminar pipe flow with constant wall temperature [86], the maximum length required for the flow to become fully developed was $0.08 \mathrm{~m}$ over the FTP. Each SCR partition is $0.09 \mathrm{~m}$ long, which is very close to calculated entrance length. This implied that the Nusselt number correlation below was valid over the length of each SCR partition.

$$
N u_{D}=1.86\left(\operatorname{Re}_{D} \operatorname{Pr}\right)^{\frac{1}{3}}\left(\frac{D}{L}\right)^{\frac{1}{3}}\left(\frac{\mu}{\mu_{w}}\right)^{0.14}
$$

Here, $\mathrm{L}$ is the length of each SCR partition, $\mu$ is the dynamic viscosity of the exhaust gas, and $\mu_{\mathrm{w}}$ is the dynamic viscosity of the exhaust gas evaluated at the wall (SCR brick) temperature. The Reynolds number and Prandtl number are defined below, where $v$ is the exhaust gas velocity, $\rho$ is the exhaust gas density, and $c_{p}$ is the exhaust gas specific heat capacity.

$$
\begin{aligned}
& \operatorname{Re}_{D}=\frac{\rho v D}{\mu} \\
& \operatorname{Pr}=\frac{\mu c_{p}}{k}
\end{aligned}
$$

Equation 44

The outer convective heat transfer coefficient was determined as a function of the Grashof number and Prandtl number using an empirical correlation for free convection from a horizontal cylinder $[83,86]$. Even though the SCR catalyst shape is really that of a rectangular block, this correlation has been suggested by authors in [83] and is far simpler than one considering separate horizontal and vertical surfaces.

$$
N u^{1 / 2}=0.60+0.387\left[\frac{G r \operatorname{Pr}}{\left[1+(0.559 / \operatorname{Pr})^{9 / 16}\right]^{16 / 9}}\right]^{1 / 6}
$$

Equation 45 [83]

Here the Prandtl number of ambient air was considered constant, equal to 0.712 . The Grashof number was defined according to the relation below, where $g$ is the acceleration due to gravity $\left(9.81 \mathrm{~m} / \mathrm{s}^{2}\right), T_{w}$ is the wall (SCR brick) temperature, and $T_{\infty}$ is the environment temperature (constant, $305 \mathrm{~K}$ ). The Grashof number varied between 100 and 324 over the FTP.

$$
G r=\frac{g \beta\left(T_{w}-T_{\infty}\right) D^{3} \rho^{2}}{\mu^{2}}
$$


The parameter $\beta$ is defined as $1 / T_{\text {film }}$, where $T_{\text {film }}$ is defined below.

$T_{\text {film }}=\frac{T_{w}+T_{\infty}}{2}$

Equation 47

The SCR catalyst model does not thermally or chemically consider the front or back edges of the brick. This practice was shared with approaches in literature $[50,83,84,85]$. When considering a single SCR channel, the wall comprised a maximum of $17 \%$ of the total frontal area. The wall thickness was small $(0.0001 \mathrm{~m})$, and it was assumed that a fairly sharp leading edge was maintained. Additionally, the front and rear areas of the brick would likely not contain any catalytic material, meaning that they would not contribute to any reactions.

\subsection{NOx Sharpening Model}

In order to model the SCR chemistry accurately, the actual instantaneous NOx being produced from the engine must be used as an input. It should be noted that there is a distinct difference between the NOx actually being produced by the engine and the NOx measured by the laboratory analyzer (Rosemount 955) or exhaust-mounted Siemens SmartNOx sensor.

Emissions measured by modern analyzers are both diffused and delayed (see Figure 44). There is a significant delay between the time point when an engine experiences an operating condition and the time point when the emissions related to that operating condition are measured by the analyzer [87]. This can be as a result of the delay in time for the exhaust gases to flow from the engine to the analyzer and analyzer measurement delay $[87,88]$. Additionally, the engine emissions can be diffused over time. This means that even if the operating condition is instantaneous, the measured emissions may be dispersed in time. This can be caused as a result of the emissions being diffused axially (along the flow direction) while being measured [88]. This behavior can cause the measured peaks and troughs to be higher or lower than the actual emissions [87]. 


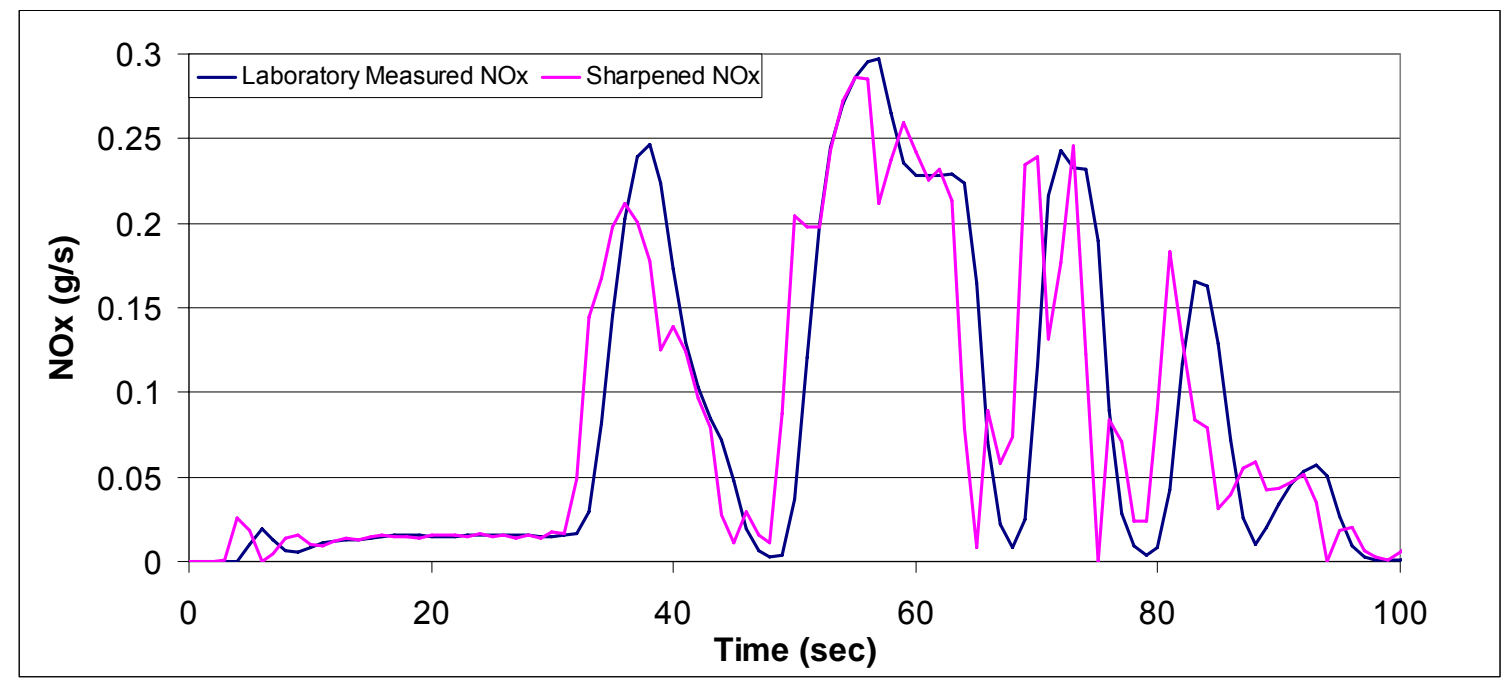

Figure 44. Diffusion and delay of NOx emissions $(\mathrm{g} / \mathrm{s})$, FTP

In order to reconstruct the true emissions from measured values, the differential coefficients method of instantaneous emissions reconstruction [87] was implemented. This technique, which has a mathematical and theoretical basis, was discussed in detail by Ajtay and Weilenmann [89]. The reconstruction procedure assumed that the true emissions, $U(t)$, may be reconstructed using the output, $Y(t)$ (measured emissions), and a linear combination of the first and second derivatives of the output [87]. The reconstruction expression can be seen below.

$U(t)=Y(t)+a_{1} \frac{d Y(t)}{d t}+a_{2} \frac{d^{2} Y(t)}{d t^{2}}$

Equation 48 [86]

It has been established that high levels of NOx correspond to periods of high engine power and NOx varies positively with power [88]. As a result, the reconstructed emissions were cross-correlated with engine power to determine the constants $\mathrm{a}_{1}$ and $\mathrm{a}_{2}$. Performing cross-correlation over different cycles resulted in different constant values. Because the FTP is used for regulatory research and it includes many different types of engine operation, its correlation coefficients were utilized in the final NOx sharpening model. The final coefficients $a_{1}$ and $a_{2}$ were determined to be $1.08 \mathrm{sec}$ and $2.60 \mathrm{sec}^{2}$, respectively.

One condition that had to be maintained when reconstructing emissions was that the total integrated emissions must be the same for the measured and reconstructed values. During the reconstruction process, negative values could be produced as a result of sharpening troughs that occur near zero. These negative values clearly do not correspond to any physically relevant emissions. As a result, they were set equal to zero. Total integrated NOx for the measured and sharpened emissions were $120.75 \mathrm{~g}$ and $120.72 \mathrm{~g}$, 
respectively. To satisfy the integrated emissions condition, the instantaneous emissions were shifted by a $0.00013 \mathrm{~g}$ at each time point. This is only $0.04 \%$ of the maximum value in Figure 44 .

\subsection{Pipe Heat Loss Model}

The experimental setup of the heavy-duty diesel engine and urea-SCR aftertreatment system resulted in an 8-foot length of pipe between the turbocharger outlet and SCR inlet. The WVU laboratory devices measured exhaust temperature at the turbocharger outlet, while the independent urea-SCR controller measured at the SCR inlet. As stated above, the engine model predicted the post-turbocharger exhaust temperature. However the SCR model required the exhaust temperature at the inlet of the catalyst. In order to avoid using measured aftertreatment system data as an input, a pipe heat loss model was developed to predict the SCR inlet temperature as a function of the post-turbocharger exhaust temperature.

The same equations used to determine the SCR brick temperature (Equation 38) and exhaust gas temperature (Equation 39) were implemented here to model heat loss from the 8-foot length of 5-inch diameter exhaust pipe. Equation 38 was implemented here to solve for the pipe wall temperature, assuming a wall thickness of $1 / 8$ inch. The correlations used for the inner and outer heat transfer coefficients varied slightly due to differences in Reynolds and Grashof numbers as a result of considering whole pipe flow compared to SCR passage flow. The Reynolds number varied from 17,600 to 110,000 over the FTP, implying turbulent flow. The Grashof number varied from $1.83 \times 10^{7}$ to $5 \times 10^{7}$ over the FTP. The Prandtl number varied from 0.6 to 0.75 over the FTP. The empirical correlation for forced convection for turbulent heat transfer in tubes can be seen in Equation 49.

$$
N u_{D}=0.023 \operatorname{Re}_{D}^{0.8} \operatorname{Pr}^{0.4}
$$

Equation 49 [86]

The correlation for free convection of a horizontal tube (for $\mathrm{Gr}<10^{9}[86]$ ) can be seen in Equation 50 .

$$
N u^{1 / 2}=0.36+0.518\left[\frac{(G r \operatorname{Pr})^{1 / 4}}{\left[1+(0.559 / \operatorname{Pr})^{9 / 16}\right]^{4 / 9}}\right]
$$

Equation 50 [86]

Again, the pipe heat loss model considered five identical partitions in the longitudinal direction. Equation 38 and Equation 39 were solved for each pipe partition, in a similar manner to the SCR catalyst.

\subsection{Thermocouple Response Sharpening}

In addition, the thermocouple response time was considered. Prior to entering the heat loss model described above, the true exhaust gas temperature was determined as a function of the measured exhaust gas temperature. This response sharpening was performed here because the diesel engine neural network model 
training was based on exhaust temperature measured by the thermocouple. The thermocouples used to measure the exhaust temperature at both locations were 1/8" diameter, Type-K Chromel-Alumel.

The transient response of the thermocouple can be described by a first-order expression. An energy balance was performed for the thermocouple probe, neglecting conduction and radiation (which are negligible [90]). This type of a lumped mass approximation differs from the classical pin-shaped cooling fin heat conduction problem, which assumes steady-state and focuses on determining the longitudinal temperature profile. These assumptions were justified because the Biot number of the largest diameter thermocouple probe was 0.003 , which is much less than 0.1 and implies less than a $5 \%$ temperature difference within the thermocouple probe [90]. The following equation was implemented.

$$
m c \frac{d T}{d t}=h A\left(T_{\infty}-T\right)
$$

Equation 51

The above equation can be expressed in the following manner, which incorporates the instantaneous time constant, defined as $m c / h A$. Here $m$ is the thermocouple probe mass, $c$ is the specific heat capacity of the thermocouple probe, $h$ is the convective heat transfer coefficient, and $A$ is the surface area of the probe.

$$
\tau \frac{d T}{d t}+T=T_{\infty}
$$

Equation 52 [90]

Here, the actual temperature of the exhaust gas $\left(T_{\infty}\right)$ was solved for in response to the measured, thermocouple temperature $(\mathrm{T})$.

A generic thermocouple time constant can be defined as the time it takes for the thermocouple voltage to reach $63.2 \%$ of the value it will reach as $\mathrm{t} \rightarrow \infty$ in response to a temperature step change. According to [91], the thermocouple time constant is on the order of 18 seconds for a $1 / 8$ " thermocouple probe. Through experimentation, this time constant value is clearly not applicable to the above equation in response to transient exhaust temperature measurement. Therefore, an instantaneous time constant was determined using the expression below. Clearly, based on Equation 53, moving from a $1 / 8$ " to a $1 / 16$ " thermocouple would cause the instantaneous time constant to be decreased by a factor of two, implying faster response times.

$$
\tau=\frac{(\rho c D)_{\text {probe }}}{4 h}
$$


In this expression, $\rho$ is the density of the probe material and $D$ is the probe diameter $\left(1 / 8^{\prime \prime}\right)$. The heat transfer coefficient was determined using a correlation by Gnielinski for forced convection flow across a circular cylinder $[92,93]$. The correlation includes laminar and turbulent components, implying validity for $10<\operatorname{Re}_{1}<10^{7}$ and $0.6<\operatorname{Pr}<1000$. In this correlation, the length parameter was defined as $\pi \mathrm{D}_{\text {probe }} / 2$.

$$
\begin{aligned}
& N u_{\text {lam }}=0.664\left(\operatorname{Re}_{l}\right)^{1 / 2}(\operatorname{Pr})^{1 / 3} \\
& N u_{\text {turb }}=\frac{0.037 \operatorname{Re}_{l}^{0.8} \operatorname{Pr}}{1+2.443 \operatorname{Re}_{l}^{-0.1}\left(\operatorname{Pr}^{2 / 3}-1\right)} \\
& N u_{l}=0.3+\sqrt{N u_{\text {lam }}^{2}+N u_{\text {turb }}^{2}}
\end{aligned}
$$

Equation 56 [92,93]

\subsection{Control Strategy}

The simple control strategy implemented during all previous experimental testing of the urea-SCR system was integrated into the overall system model. By initially utilizing the current control strategy, the system model could be validated with experimental data prior to considering control optimization. Additionally, it eliminated the use of experimental aftertreatment system data (injector duty cycle) as a model input.

Realistic measurement of the control inputs was considered. The NOx mass flow signal input to the control strategy during experimental testing of the system incorporated pitot-tube flow and Siemens SmartNOx signals. By comparing the sharpened NOx signal to the Siemens SmartNOx measurement, it was clear that the response time of the SmartNOx sensor was faster compared to the laboratory analyzers. This was to be expected since the sample was directly measured, eliminating most of the diffusion and delay associated with the laboratory analyzer setup. As such, it was assumed that the sharpened NOx was a good estimate of what the Siemens SmartNOx sensor would measure. A comparison of NOx measured by the aftertreatment system, sharpened NOx, and laboratory analyzer NOx can be seen below in Figure 45. Some measurement differences may be attributed to the accuracy of Siemens SmartNOx sensor measurements $( \pm 10 \%$ maximum [73]). 


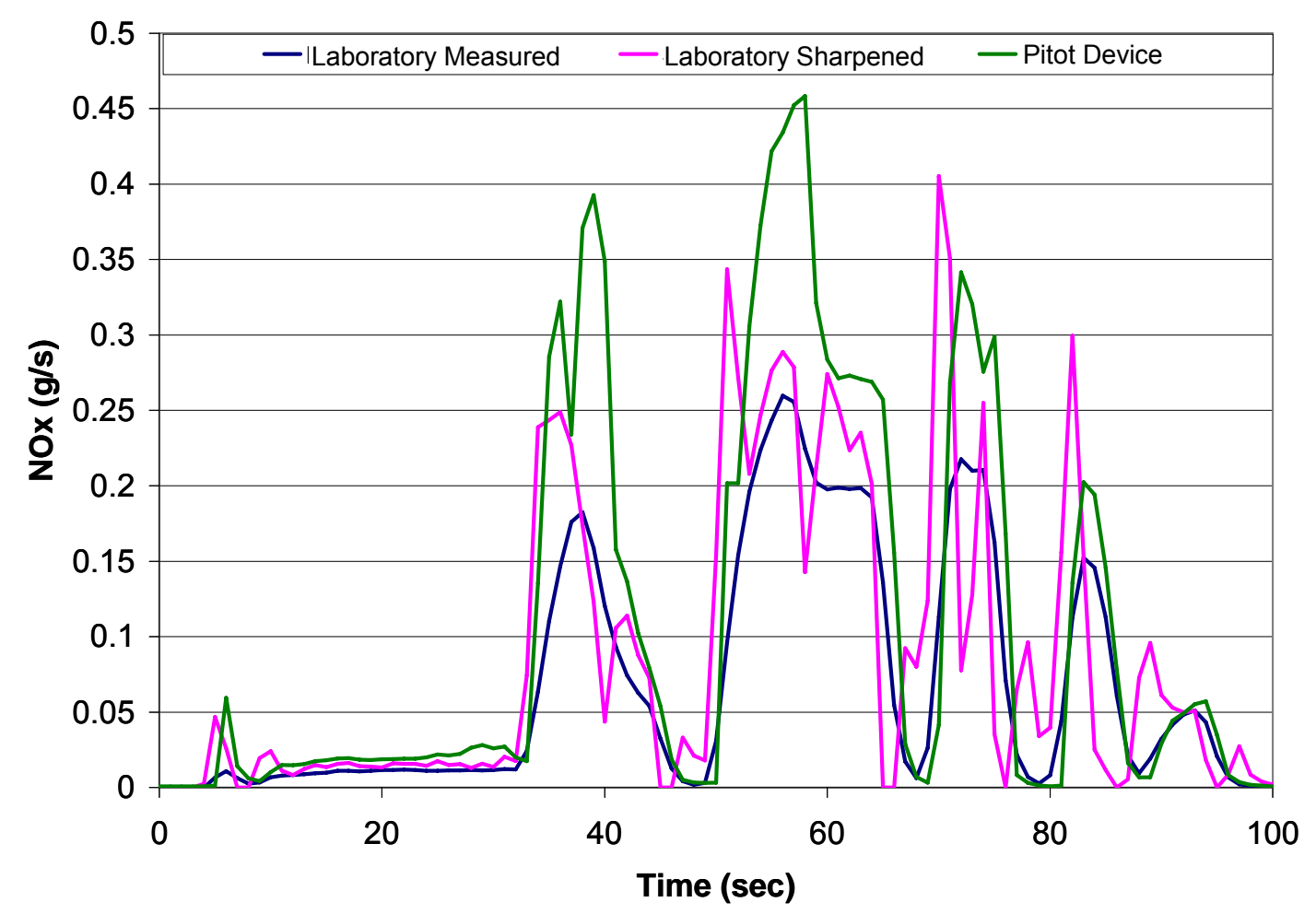

Figure 45. Siemens SmartNOx sensor response $(\mathrm{g} / \mathrm{s})$

The pitot-tube signal tended to read high compared to the engine intake flow as measured by a laminar flow element, including corrections for fuel flow and blowby. The over-reading tended to be higher at high flow and lower at low flow, and may have been a result of (1) considering only centerline velocity measurement in flow calculations, (2) using symmetrical pitot-tubes increased the differential pressure measurement as a result of vacuum on the static tube, (3) non-linearities in the external flow coefficient (example: $\mathrm{C}=\mathrm{f}(\mathrm{Re})$ ). The NOx mass flow was corrected for the pitot-tube flow over-reading by calibrating with data from the ICOMIA steady-state cycle. A lookup table, implementing linear interpolation between values, was used for correction of the sharpened NOx signal. The corrected, uncorrected, and experimental validation NOx for each point in the ICOMIA cycle can be seen in Figure 46. 


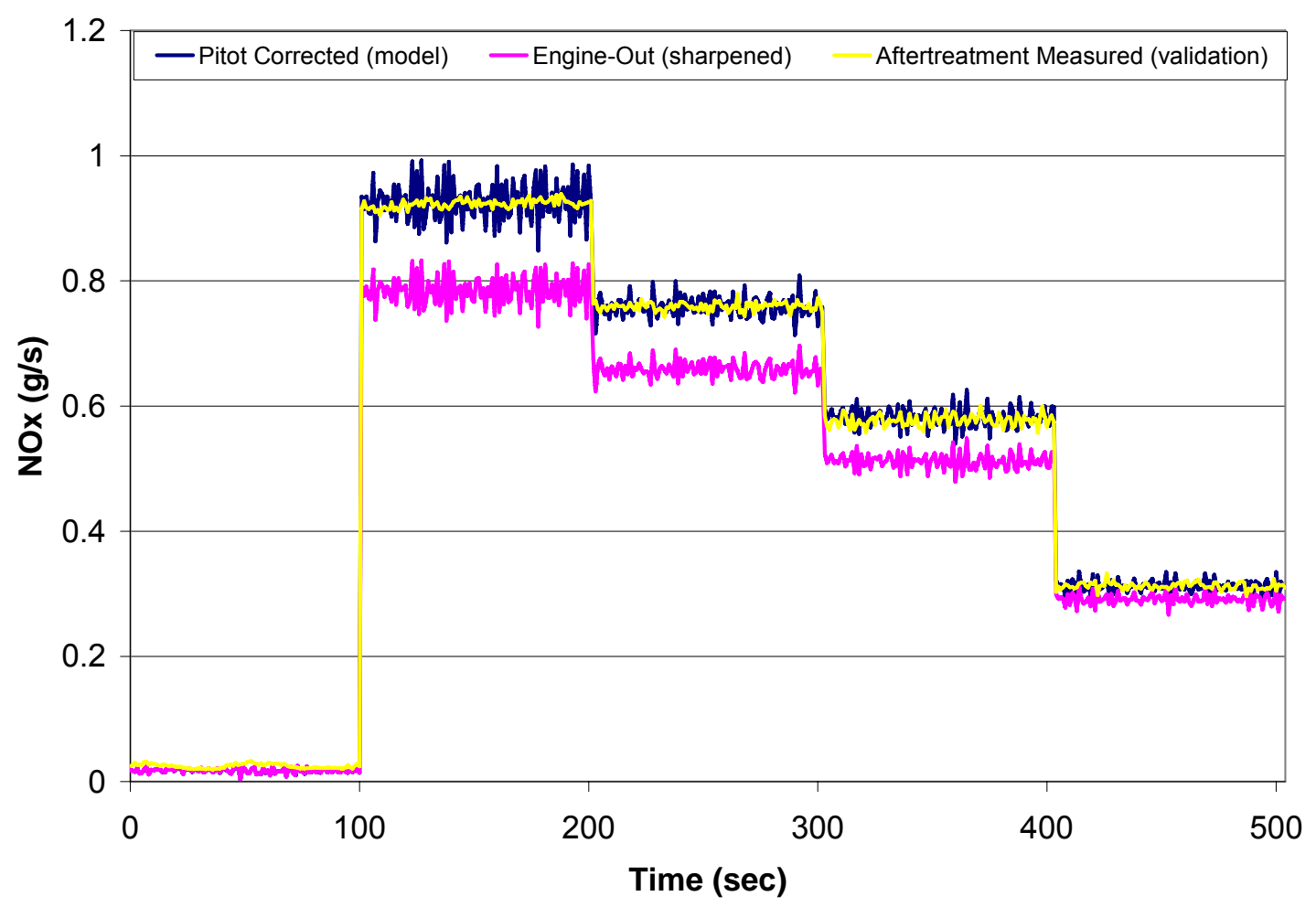

Figure 46. Pitot-tube NOx correction $(\mathrm{g} / \mathrm{s})$

\subsubsection{Control Logic}

The simple control logic determined appropriate urea dosing according to idealized urea decomposition and stoichiometric reaction of $\mathrm{NOx}$ and $\mathrm{NH}_{3}$. The injector duty cycle was determined according to the instantaneous measured NOx and exhaust temperature. As stated above, for modeling purposes, the NOx signal measured by laboratory analyzers was sharpened and corrected for pitot-tube measurement (to mimic the Siemens SmartNOx measurement). The un-corrected thermocouple measurement was used because this was the signal actually seen by the control hardware.

First, the instantaneous NOx was converted from grams per second to moles per second to facilitate stoichiometric calculations (see Equation 16). According to a single SCR reaction (Equation 9), the stoichiometric reaction of one mole of $\mathrm{NO}$ consumes one mole of $\mathrm{NH}_{3}$. Urea decomposition was considered in a manner similar to the catalyst model. This was described by Equation 15, where two moles of $\mathrm{NH}_{3}$ are produced for every one mole of urea. According to literature $[83,84]$, this approximation of urea decomposition represents the physical process well.

The molar flow rate of urea was then converted back to a mass flow rate using the molecular weight of urea $(60 \mathrm{~g} / \mathrm{mol})$. This mass flow represented the flow of pure urea. Since urea was delivered in solution form 
(32.5\% by mass), the urea mass flow was converted to solution mass flow. Finally, the urea solution mass flow was converted to an injector duty cycle. In the fully open position, the injector delivered $28 \mathrm{lb} / \mathrm{hr}$ of flow (manufacturer specified). The solution mass flow was divided by the maximum injector flow to determine the instantaneous injector duty cycle. In actual implementation of the control logic on the Motohawk controller, this duty cycle was also converted to a pulse width by multiplying by the maximum pulse width, 4095 .

These calculations were performed continuously within the control logic. Additionally, a temperature block was included so that injection only took place within the appropriate range of exhaust temperatures. Here, urea was injected above $250^{\circ} \mathrm{C}$ only, according to the logic below.

if $\left(T_{\text {exhaust }} \geq 250^{\circ} \mathrm{C}\right) \rightarrow$ then $($ inject_urea $=$ TRUE $)$

else $\rightarrow$ then(inject_urea $=$ FALSE)

The control logic also included a urea dosing multiplier. When set to one, the control logic performed stoichiometric calculations. When decreased to a value less than one, urea dosing was decreased accordingly. This multiplier was fixed during operation of the aftertreatment system and for model runs. It was normally set to 0.5 (determined by previous testing of the urea-SCR system [69] and ideally corresponding to a $50 \%$ NOx reduction) for all transient test runs. However, it was reduced further to 0.25 for the ICOMIA steady-state test to circumvent high ammonia slip. 


\section{Chapter 9: System Model Validation and Results}

Prior to beginning the control optimization procedure, the predictive ability of the system model was validated with experimental data. Model results are presented over multiple test cycles for each of the major modules.

\subsection{Heavy-Duty Diesel Engine Model}

\subsubsection{Input Parameter Reduction}

One goal in development of the engine model was to compare the predictive performance as the number of input variables was reduced. Ultimately, the most convenient model would be one that only utilized engine speed and torque as inputs. This would allow only the target speed and torque for a given test cycle to be input to the model, completely eliminating the use of experimental data as an input.

A parameter denoted as standard error was defined to allow an error comparison to be performed for network training and validation with experimental data. The standard error definition considers the final network outputs in engineering units (de-normalized) and can be seen in Equation 58. Here, target refers to the training or validation data trying to be matched by the model. This definition sums the total error over a given test cycle and normalizes against maximum values. In this manner, prediction accuracy may be compared between different output variables on a similar scale. This definition was also implemented in subsequent sections for total error comparisons in other model components.

error $_{\text {std }}=\sum_{i}\left|\left[\frac{\left(Y_{\text {output }}\right)_{i}}{\left(Y_{\text {output }}\right)_{\max }}\right]-\left[\frac{\left(Y_{t \arg e t}\right)_{i}}{\left(Y_{t \arg e t}\right)_{\max }}\right]\right|$

Equation 58

Three groups of independent ANN inputs were considered to determine if a reduction in the number of input parameters was warranted. For each group of independent inputs, the corresponding derivative values (see Table 37) were also included. The predictive performance of the ANN was good when considering all input parameters. Correlation coefficients of $0.99,1.00$, and 1.00 were achieved for NOx, exhaust temperature, and exhaust volumetric flow, respectively. A total error was computed as the sum of the standard error for NOx, exhaust temperature, and exhaust volumetric flow. When considering all input variables, the total error (sum of standard error (Equation 58) for NOx, exhaust temperature, and exhaust volumetric flow, see Table 37) was 101.70, with NOx having the highest individual standard error.

Subsequently, input variables were removed to compare the predictive performance of the ANN to the case when all inputs were considered. The input variable cases considered are summarized in Table 37. It can be seen that when reducing the inputs to solely engine speed and torque, the correlation coefficients decreased 
and standard error of NOx and exhaust temperature became unacceptably high. In the SCR catalyst model, accurate engine-out NOx predictions are essential. As a result, the utmost importance was placed on NOx predictions in the engine model. In Table 37, it can be seen that NOx predictions were generally reduced for any case that did not include boost pressure. Additionally, exhaust volumetric flow accuracy was increased when including boost pressure, however these predictions were still good even without its inclusion, with correlation coefficients of 1.00 for all cases.

Originally, coolant temperature and oil temperature were both considered. However, both of these variables essentially capture behavior from the same phenomena (engine heat and load). Including both variables may have caused a reduction in ANN performance because of contradictory information. In general, it was believed that oil temperature may be a better predictive variable for engine temperature because fewer variables may be involved. Coolant temperature may be dependent upon radiator size, thermostat operation, and environmental temperature (less important in a laboratory setting). Oil temperature was also dependent upon environmental temperature; although its dependence may be reduced if an external oil cooler was not used. Additionally, because engine oil is often routed through the turbocharger, it may capture behavior related to boost level.

Some cases are also shown without the inclusion of derivative inputs. Eliminating derivative inputs almost always negatively impacted predictions. They provided important rate-of-change information that aided in all predictions. Also, because derivative inputs were dependent upon other variables and did not require the use of additional input data, there was no reason not to include them.

The final list of input variables was chosen primarily considering the performance of NOx predictions. From Table 37, it was evident that NOx was most difficult variable to predict of the variables selected in this workt. The final list of input variables included engine speed, the derivative of engine speed over one and ten seconds, engine torque, the derivative of engine torque over one and ten seconds, boost pressure, the derivative of boost pressure over one second, oil temperature, and the derivative of oil temperature over ten seconds. This combination of input variables was able to improve the predictive ability of all output variables compared to the complete list of inputs. As a result, the total error was decreased by $17 \%$. This configuration does not totally eliminate the use of experimental input data. If future applications of the engine model do not have oil temperature and boost data available, additional models could be implemented to determine these values as a function engine speed and torque. 
Table 37. ANN input comparison, correlation coefficient and standard error

\begin{tabular}{|c|c|c|c|c|c|c|c|c|}
\hline \multirow{2}{*}{ Independent ANN Inputs } & \multicolumn{3}{|c|}{ Correlation Coeffient [R] } & \multicolumn{3}{|c|}{ Standard Error } & \multirow{2}{*}{$\begin{array}{l}\text { Total } \\
\text { Error }\end{array}$} & \multirow{2}{*}{$\begin{array}{c}\text { Error } \\
\text { Increase }\end{array}$} \\
\hline & NOx & Temp. & Flow & NOx & Temp. & Flow & & \\
\hline $\begin{array}{r}\text { Engine Speed }\left(d_{1}, d_{10}\right) \\
\text { Engine Torque }\left(d_{1}, d_{10}\right) \\
\text { Coolant Temperature }\left(d_{10}\right) \\
\text { Oil Temperature }\left(d_{10}\right) \\
\text { Boost Pressure }\left(d_{1}\right)\end{array}$ & 0.99 & 1.00 & 1.00 & 43.1 & 33.8 & 24.8 & 101.70 & $0 \%$ \\
\hline $\begin{array}{r}\text { Engine Speed }\left(d_{1}, d_{10}\right) \\
\text { Engine Torque }\left(d_{1}, d_{10}\right) \\
\text { Boost Pressure }\end{array}$ & 0.99 & 0.98 & 1.00 & 56.2 & 47.3 & 21.4 & 124.90 & $22.81 \%$ \\
\hline $\begin{array}{l}\text { Engine Speed }\left(d_{1}, d_{10}\right) \\
\text { Engine Torque }\left(d_{1}, d_{10}\right)\end{array}$ & 0.97 & 0.98 & 1.00 & 86.2 & 55.6 & 20.5 & 162.30 & $59.59 \%$ \\
\hline $\begin{array}{l}\text { Engine Speed }\left(d_{1}, d_{10}\right) \\
\text { Engine Torque }\left(d_{1}, d_{10}\right) \\
\text { Coolant Temperature }\end{array}$ & 0.97 & 0.99 & 1.00 & 81.0 & 40.7 & 51.3 & 173.00 & $70 \%$ \\
\hline $\begin{array}{r}\text { Engine Speed }\left(d_{1}, d_{10}\right) \\
\text { Engine Torque }\left(d_{1}, d_{10}\right) \\
\text { Coolant Temperature }\left(d_{10}\right) \\
\text { Boost Pressure }\left(d_{1}\right)\end{array}$ & 0.99 & 0.99 & 1.00 & 50.4 & 31.8 & 15.9 & 98.10 & $-4 \%$ \\
\hline $\begin{array}{r}\text { Engine Speed }\left(d_{1}, d_{10}\right) \\
\text { Engine Torque }\left(d_{1}, d_{10}\right) \\
\text { Oil Temperature }\left(d_{10}\right) \\
\text { Boost Pressure }\left(d_{1}\right)\end{array}$ & 0.99 & 0.99 & 1.00 & 42.6 & 29.0 & 13.0 & 84.60 & $-17 \%$ \\
\hline $\begin{array}{r}\text { Engine Speed }\left(d_{1}, d_{10}\right) \\
\text { Engine Torque }\left(d_{1}, d_{10}\right) \\
\text { Oil Temperature }\left(d_{10}\right) \\
\text { Boost Pressure }\end{array}$ & 0.99 & 0.99 & 1.00 & 45.4 & 43.2 & 17.1 & 105.70 & $4 \%$ \\
\hline $\begin{array}{r}\text { Engine Speed }\left(d_{1}, d_{10}\right) \\
\text { Engine Torque }\left(d_{1}, d_{10}\right) \\
\text { Oil Temperature } \\
\text { Boost Pressure }\left(d_{1}\right)\end{array}$ & 0.99 & 0.99 & 1.00 & 50.0 & 31.4 & 13.7 & 95.10 & $-6 \%$ \\
\hline $\begin{array}{l}\text { Engine Speed }\left(d_{1}, d_{10}\right) \\
\text { Engine Torque }\left(d_{1}, d_{10}\right) \\
\text { Oil Temperature }\left(d_{10}\right)\end{array}$ & 0.99 & 0.99 & 1.00 & 56.7 & 31.3 & 19.4 & 107.40 & $6 \%$ \\
\hline $\begin{array}{l}d_{1} \text { Indicates a derivative over a } 1 \\
d_{10} \text { Indicates a derivative over a }\end{array}$ & $\begin{array}{l}\text { cond ti } \\
\text { second }\end{array}$ & interval & & & $\begin{array}{l}\text { ndicates } \\
\text { ndicates }\end{array}$ & $\begin{array}{l}\text { erence } \\
\text { al selec }\end{array}$ & inputs & \\
\hline
\end{tabular}




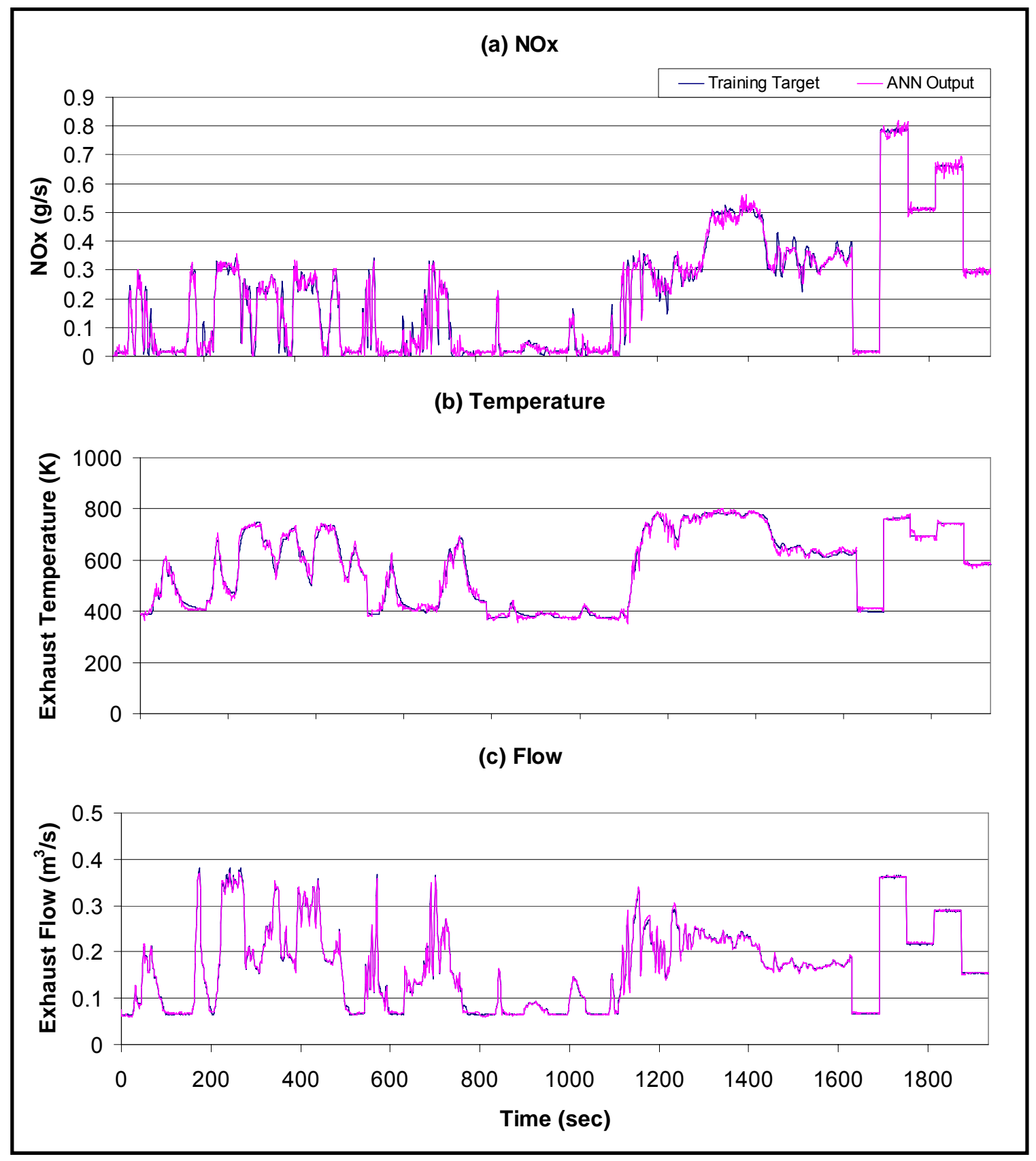

Figure 47. ANN engine model training results, all inputs: (a) NOx (g/s), (b) exhaust temperature (K), (c) exhaust flow $\left(\mathrm{m}^{3} / \mathrm{s}\right)$ 


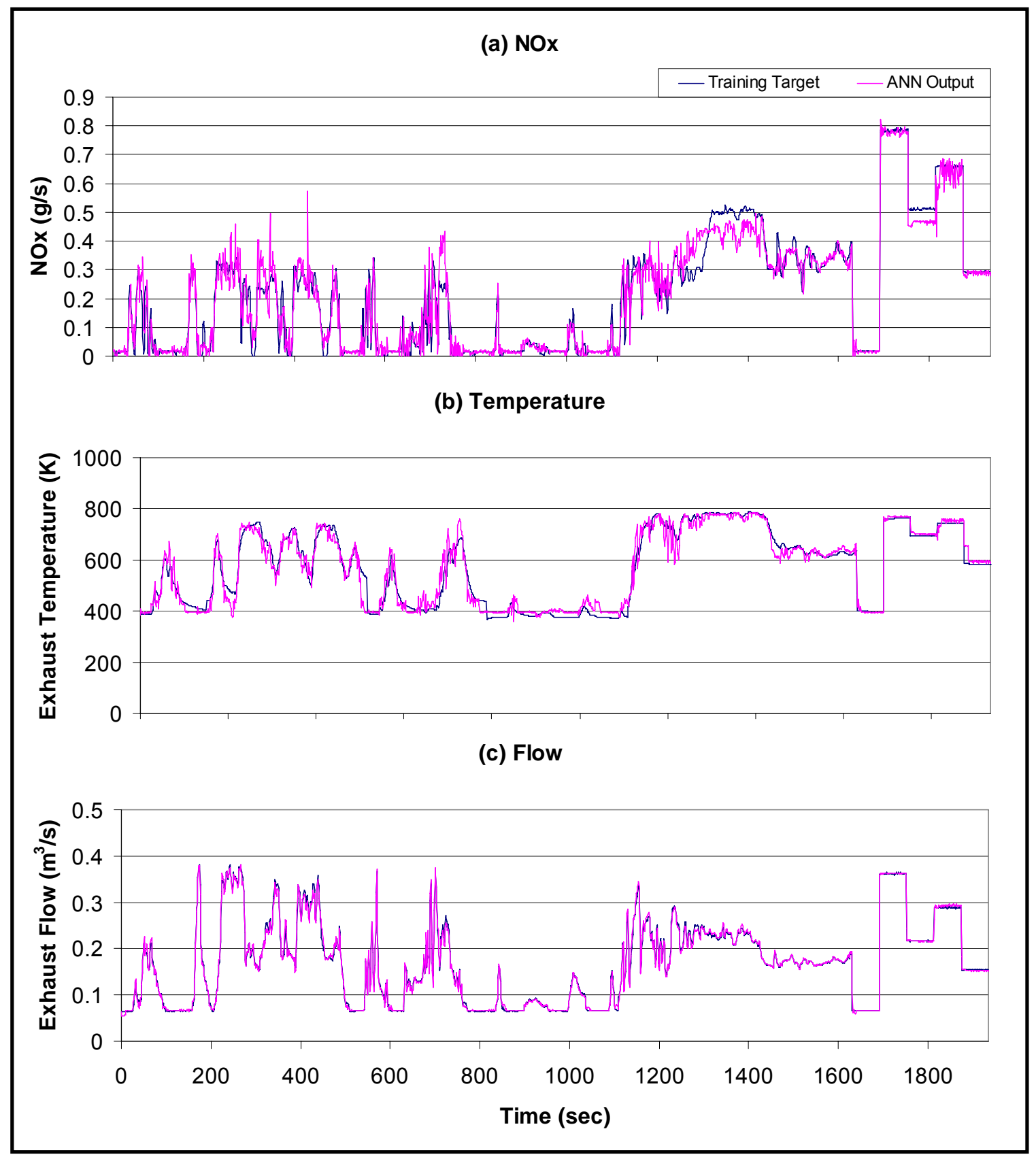

Figure 48. ANN engine model training results, engine speed and torque inputs: (a) NOx (g/s), (b) exhaust temperature (K), (c) exhaust flow $\left(\mathrm{m}^{3} / \mathrm{s}\right)$ 


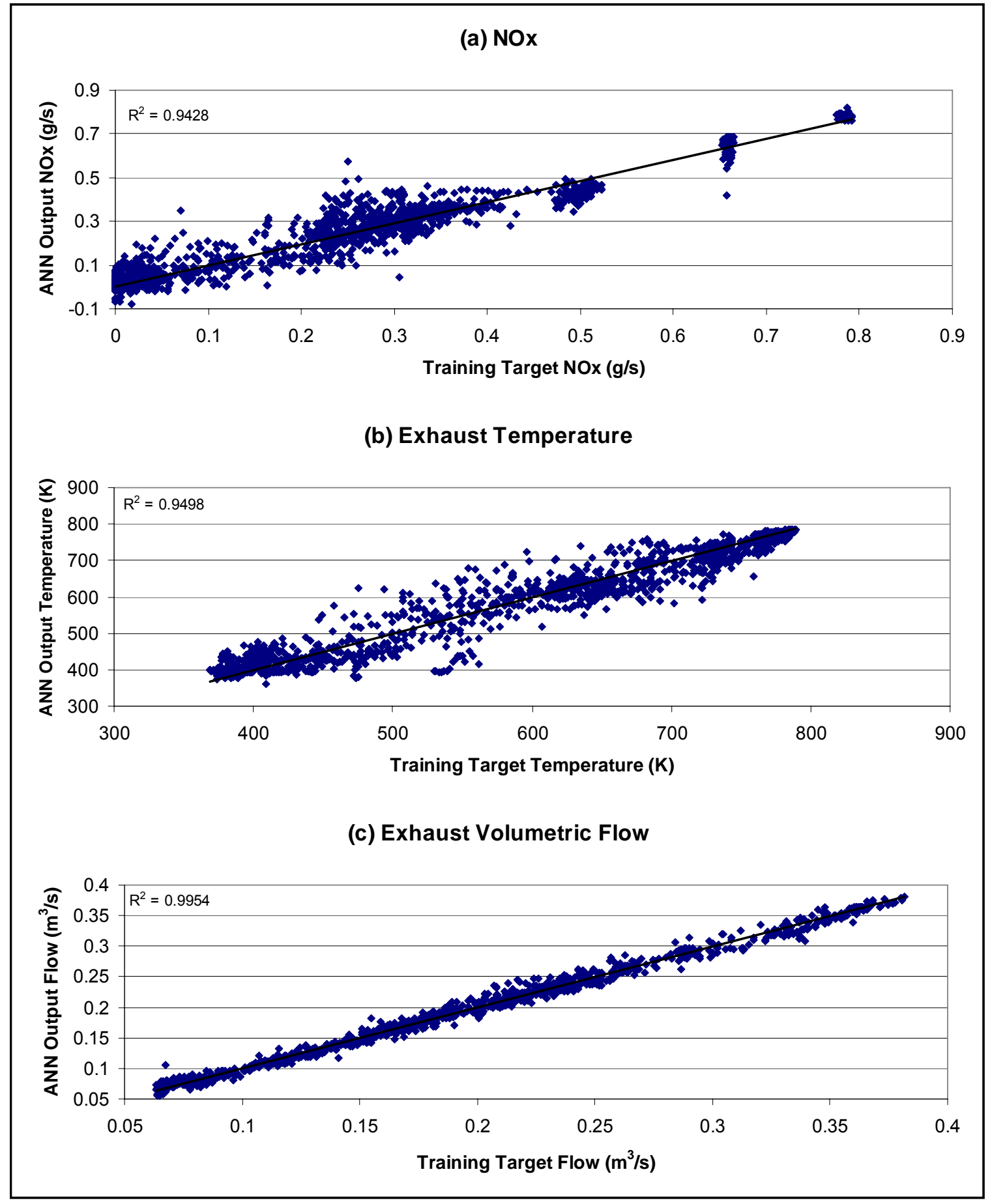

Figure 49. ANN engine model training parity plot, engine speed and torque inputs: (a) NOx (g/s), (b) exhaust temperature $(\mathrm{K})$, (c) exhaust flow $\left(\mathrm{m}^{3} / \mathrm{s}\right)$ 


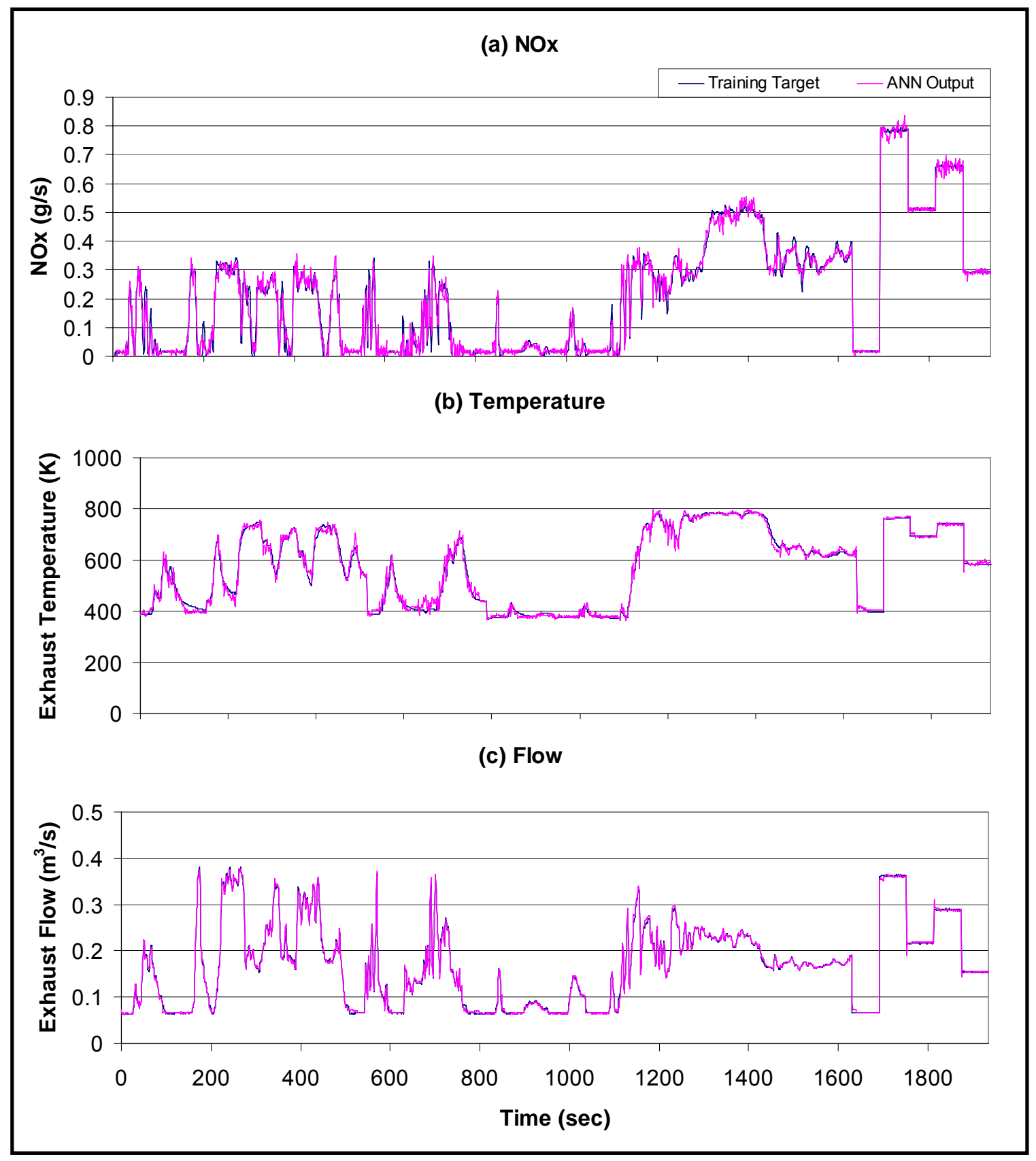

Figure 50. ANN engine model training results, engine speed, torque, oil temperature, boost inputs (final inputs): (a) NOx (g/s), (b) exhaust temperature (K), (c) exhaust flow $\left(\mathrm{m}^{3} / \mathrm{s}\right)$ 


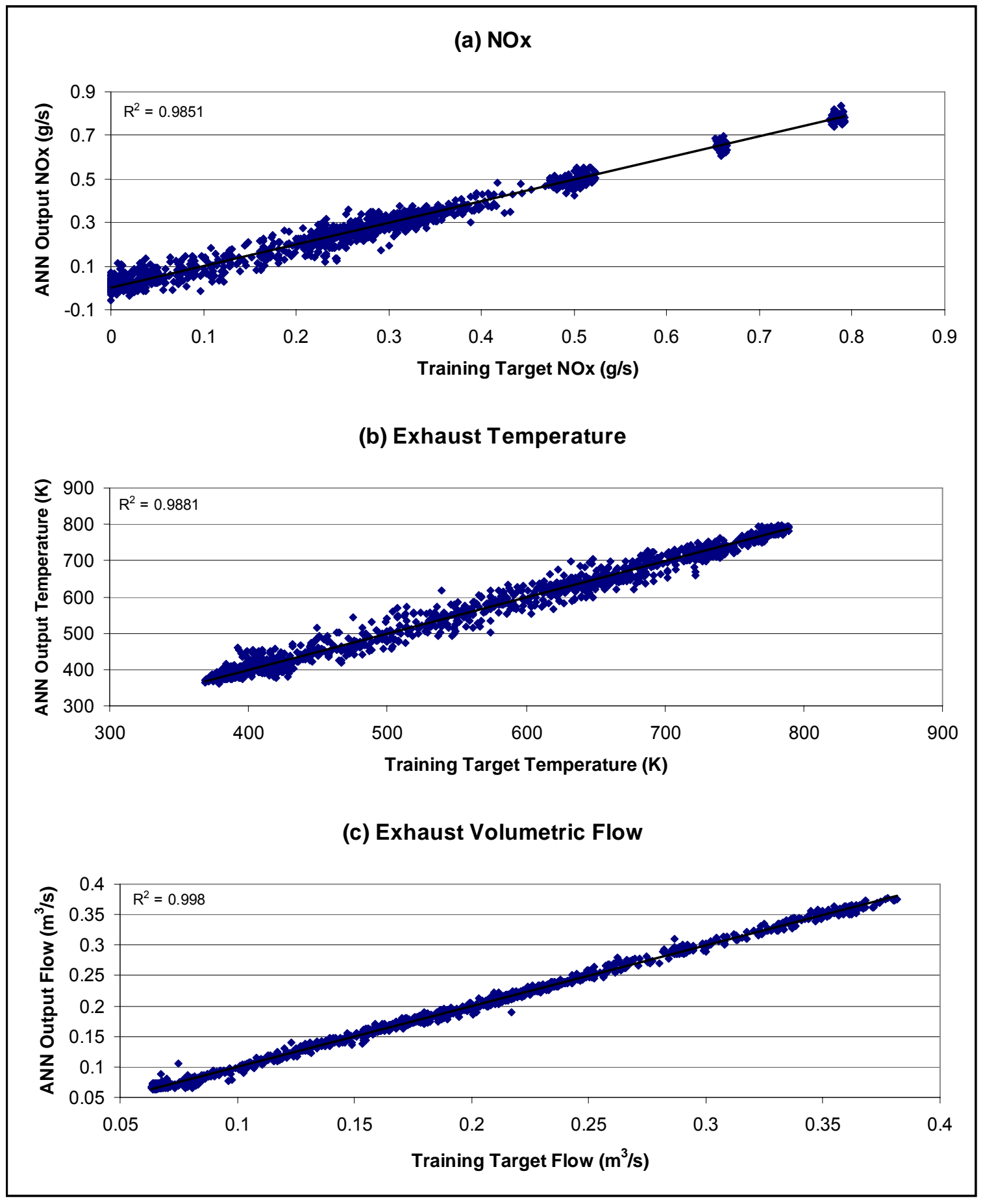

Figure 51. ANN engine model training parity plot, engine speed, torque, oil temperature, boost inputs (final inputs): (a) NOx (g/s), (b) exhaust temperature (K), (c) exhaust flow $\left(\mathrm{m}^{3} / \mathrm{s}\right)$ 


\subsubsection{Demonstration of Model Predictions}

The final trained ANN engine model was demonstrated over the ICOMIA E5 marine steady-state cycle, heavy-duty FTP, ACES Transient, Creep, and HHDDT_S. Again, the ACES Cruise cycle was not included here because the behavior it exhibited was very similar to the HHDDT_S cycle. Validation of model predictions for NOx, exhaust temperature, and exhaust flow can be seen for each test cycle in Figure 52, Figure 53, and Figure 54, respectively. Additionally, correlation coefficient and standard error values over each test cycle are presented in Table 38. For this comparison, correlation coefficients were utilized as opposed to coefficients of determination because that was the convention used by a pre-defined Matlab neural network toolbox regression function which was implemented.

As expected, NOx was the most difficult output variable to predict, especially during times of highly transient behavior. This can be seen in portions of the FTP and ACES Transient cycles in particular (Figure 52 (a) and (b)), although predictions during smoother portions were very good. Overall, NOx mass flow predictions during the HHDDT_S and ICOMIA test cycles were good, with correlation coefficients of 0.93 and 1.00, respectively. During the second mode of the ICOMIA cycle, some deviation from steady operation was seen, which may be attributed to the severe step change from idle to rated operation. The Creep mode predictions were not as accurate, exhibiting a correlation coefficient of 0.63 . This may be attributed to the very low NOx emissions over the cycle and the fact that training emphasized such a wide range of engine behavior and NOx levels. Even though some accuracy may be lost at these low NOx levels, higher accuracy was gained over cycles such as the HHDDT_S and ICOMIA.

Exhaust temperature predictions can be seen in Figure 53, and were very good over all test cycles except Creep. The best correlation coefficient was achieved over the ICOMIA cycle, at 1.00. However the ICOMIA cycle exhibited a higher standard error of 29 compared to that of the HHDDT_S cycle, which was 20. The Creep mode exhibited a correlation coefficient of 0.39 and standard error of 132 . This large error was a result of the cooling effect that had been observed over the ACES Creep cycle during multiple testing periods at WVU. Prior to running a Creep cycle, high-power cycles such as the FTP, ACES Cruise, or HHDDT_S were often run, causing high exhaust exhaust, oil, and coolant temperatures. Even with the typical CFR $\$ 86.1330$-90-dictated 20 minute hot soak prior to running a Creep cycle, the engine continued to cool over the cycle as a result of the large amount of idle operation and low exhaust temperatures. This behavior can be seen in Figure 53 (d), as the target temperature curve decreases and the model prediction error increases over the Creep cycle.

Exhaust volumetric flow predictions were excellent over all cycles (Figure 54), showing a minimum correlation coefficient of 0.99 over the Creep cycle. The ANN engine model was easily able to predict exhaust flow as a function of the input variables during any type of engine operation. 


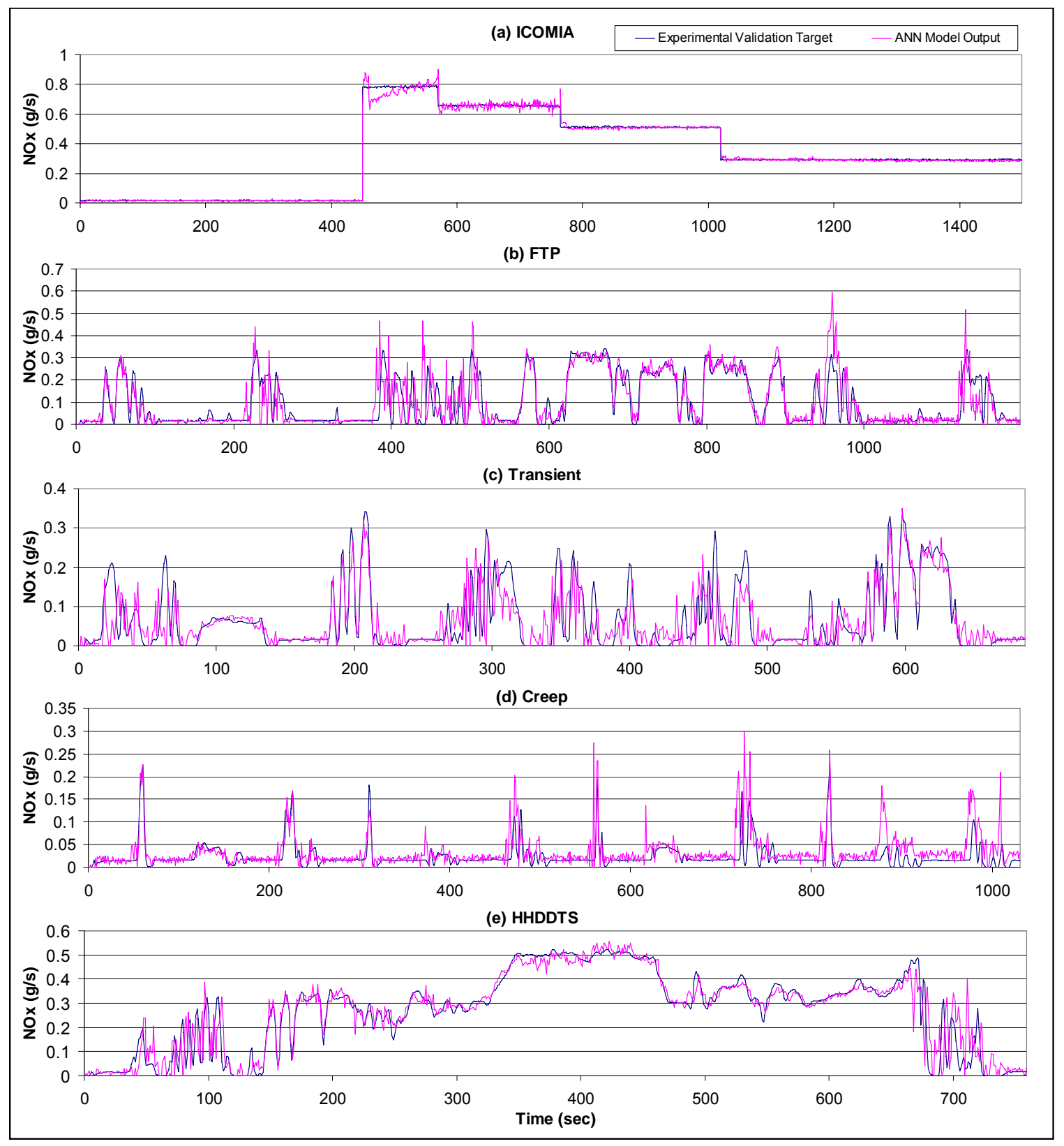

Figure 52. ANN engine model validation, continuous NOx (g/s), (a) ICOMIA, (b) FTP, (c) ACES Transient, (d) ACES Creep, (e) ACES HHDDT_S 


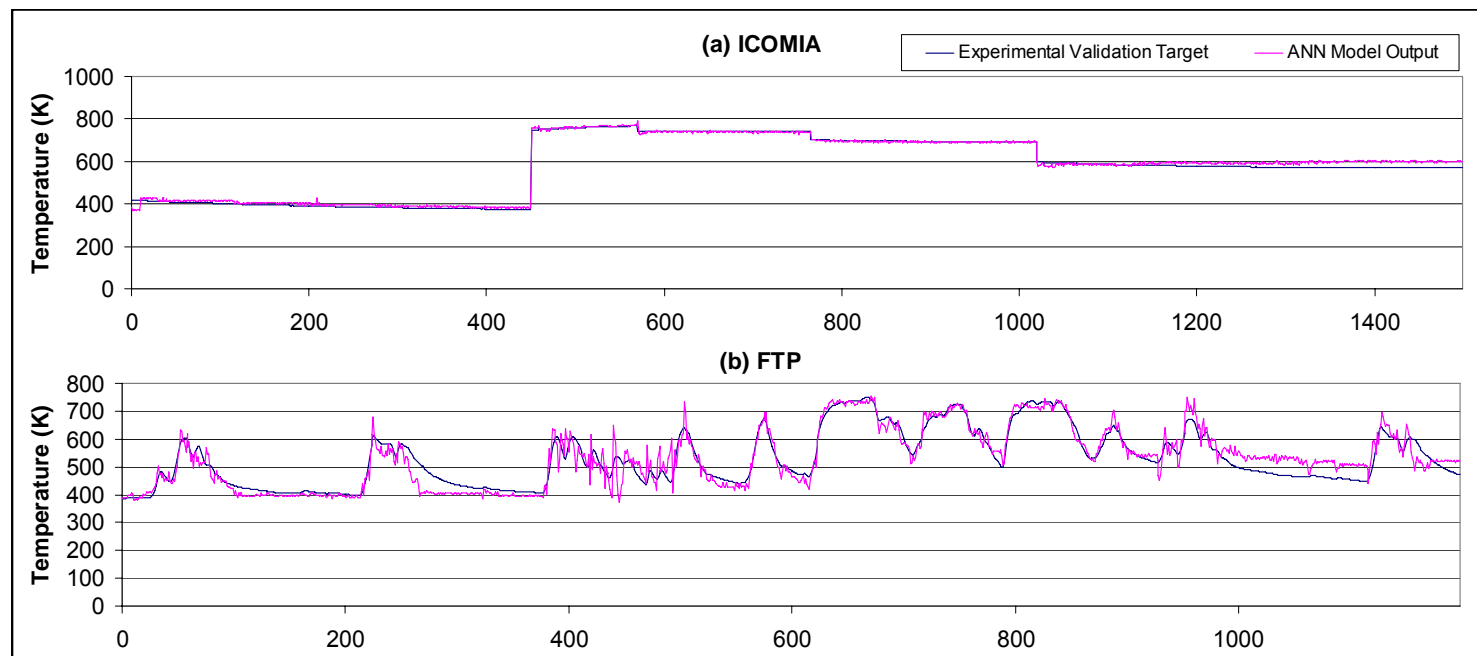

(c) Transient
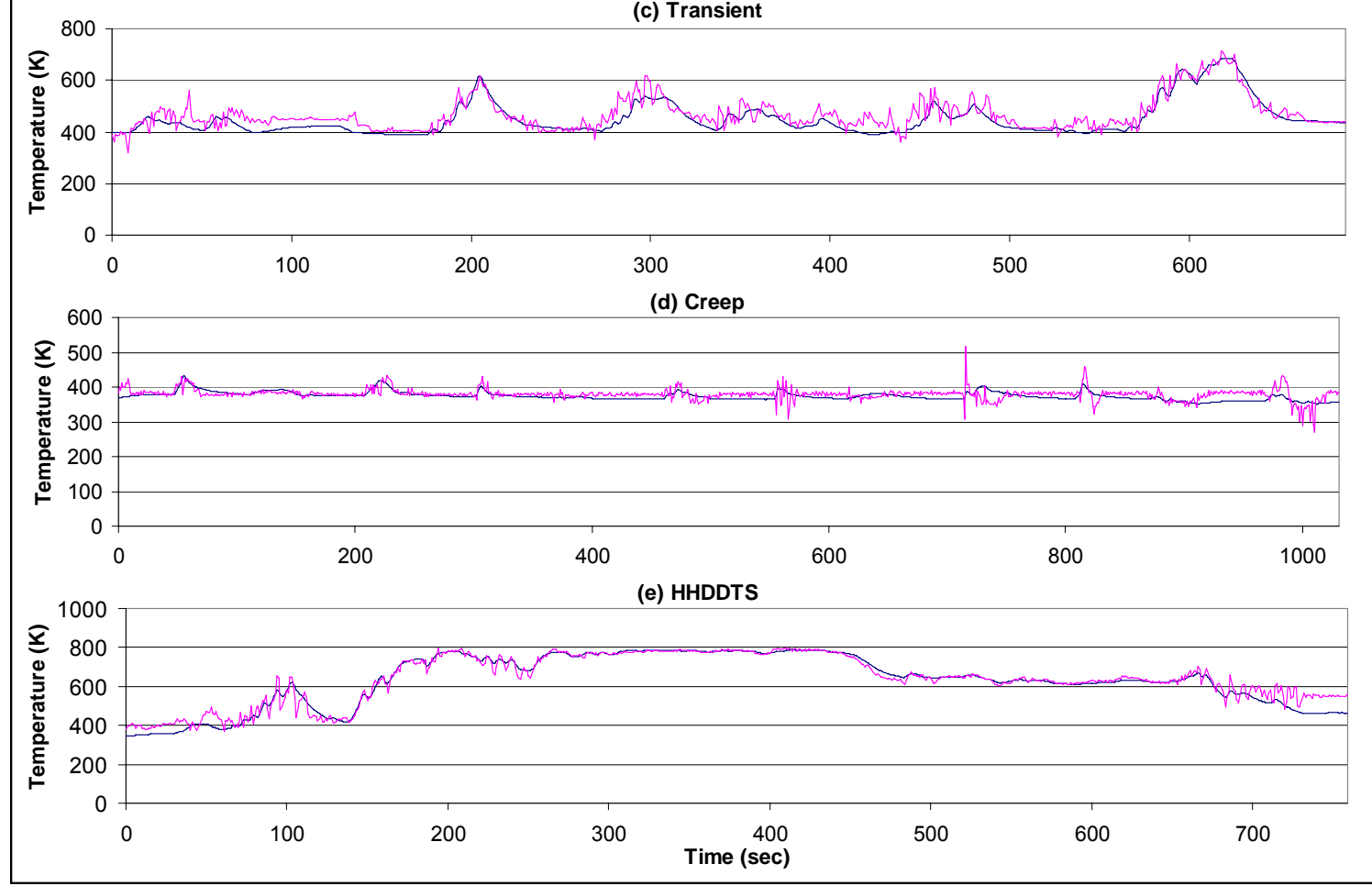

Figure 53. ANN engine model validation, continuous exhaust temperature (K), (a) ICOMIA, (b) FTP, (c) ACES Transient, (d) ACES Creep, (e) ACES HHDDT_S 


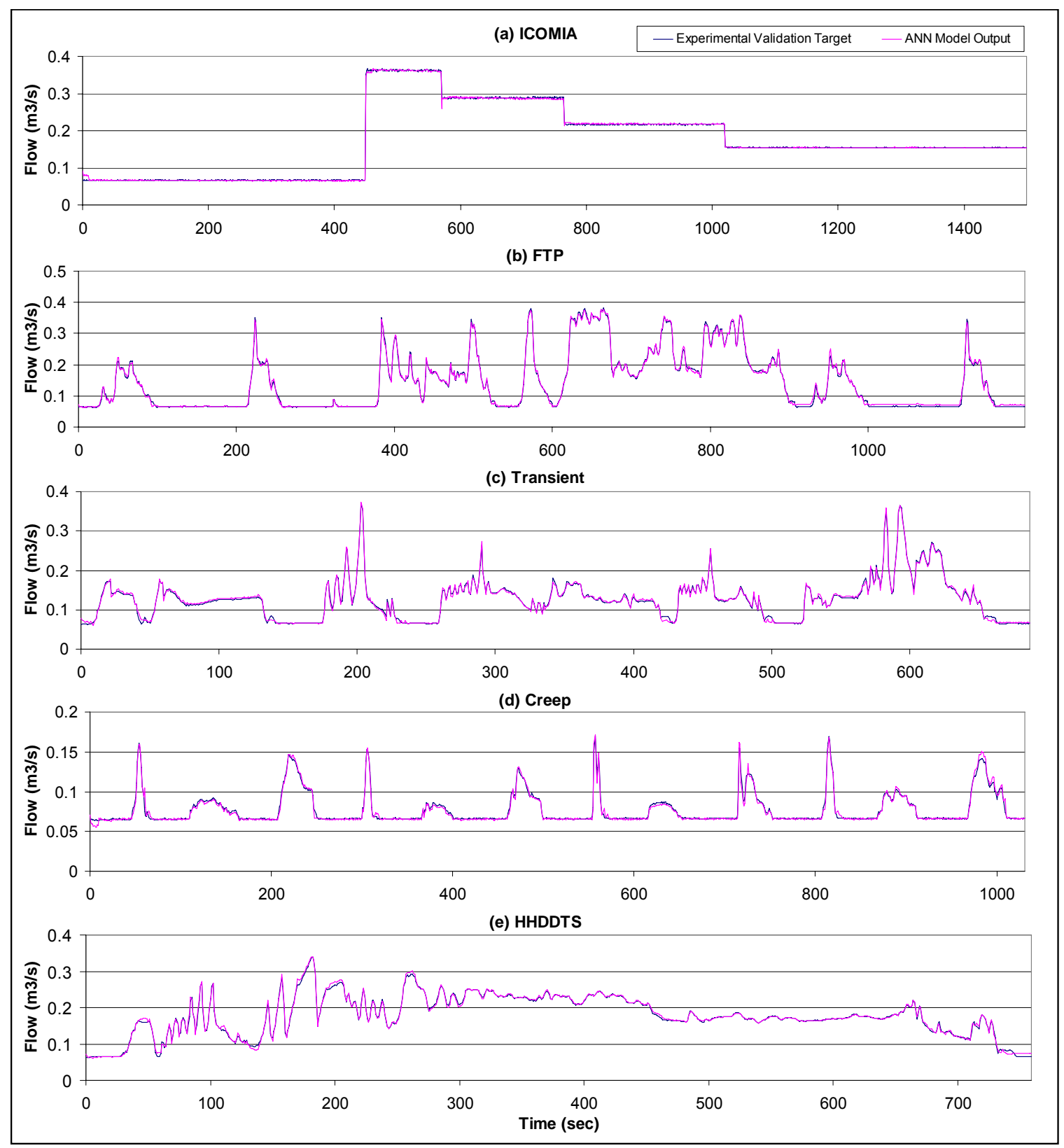

Figure 54. ANN engine model validation, continuous exhaust flow $\left(\mathrm{m}^{3} / \mathrm{s}\right)$, (a) ICOMIA, (b) FTP, (c) ACES Transient, (d) ACES Creep, (e) ACES HHDDT_S 


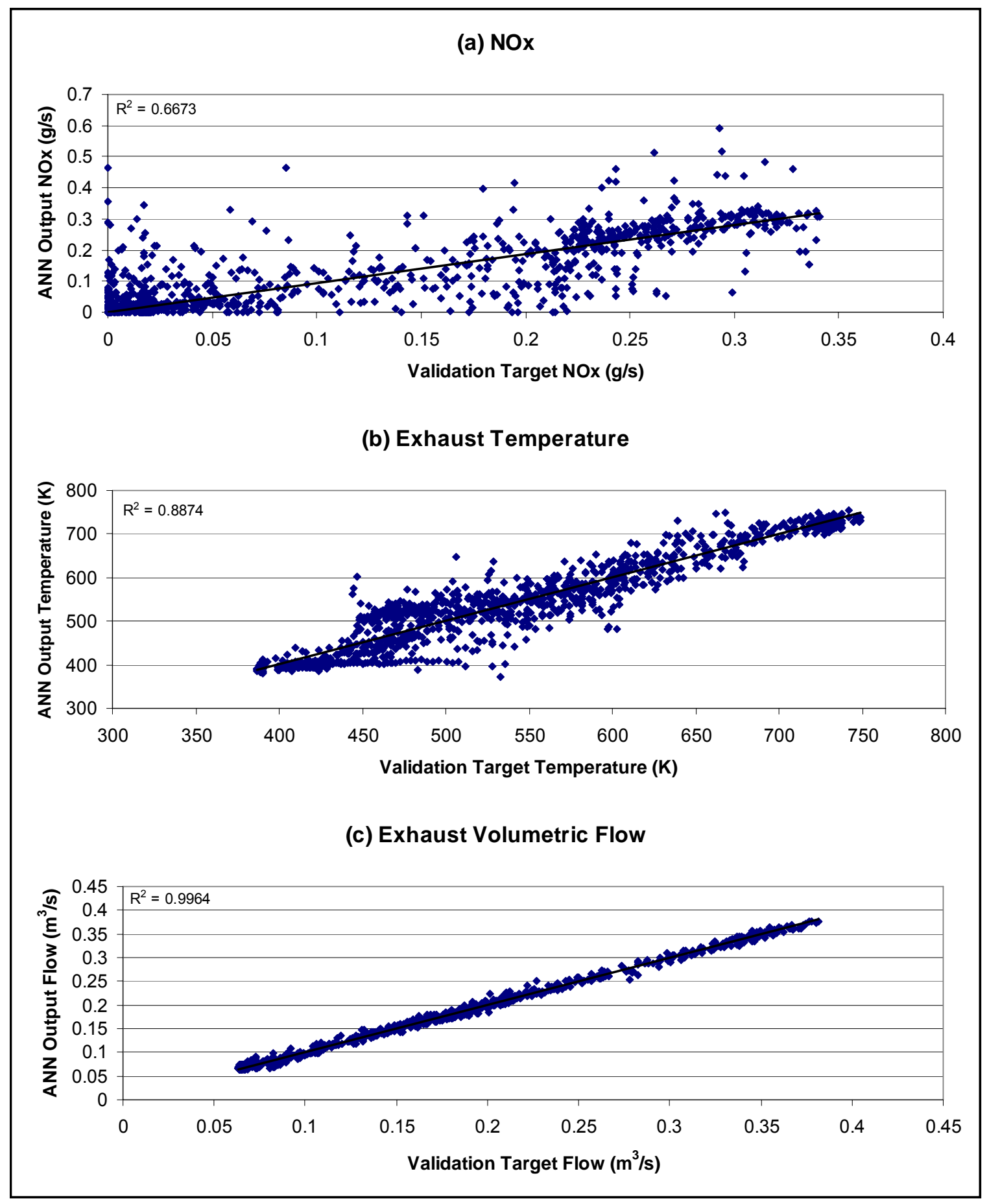

Figure 55. ANN engine model validation parity plot, FTP, (a) NOx (g/s), (b) exhaust temperature (K), (c) exhaust flow $\left(\mathrm{m}^{3} / \mathrm{s}\right)$ 


\section{(a) NOx}

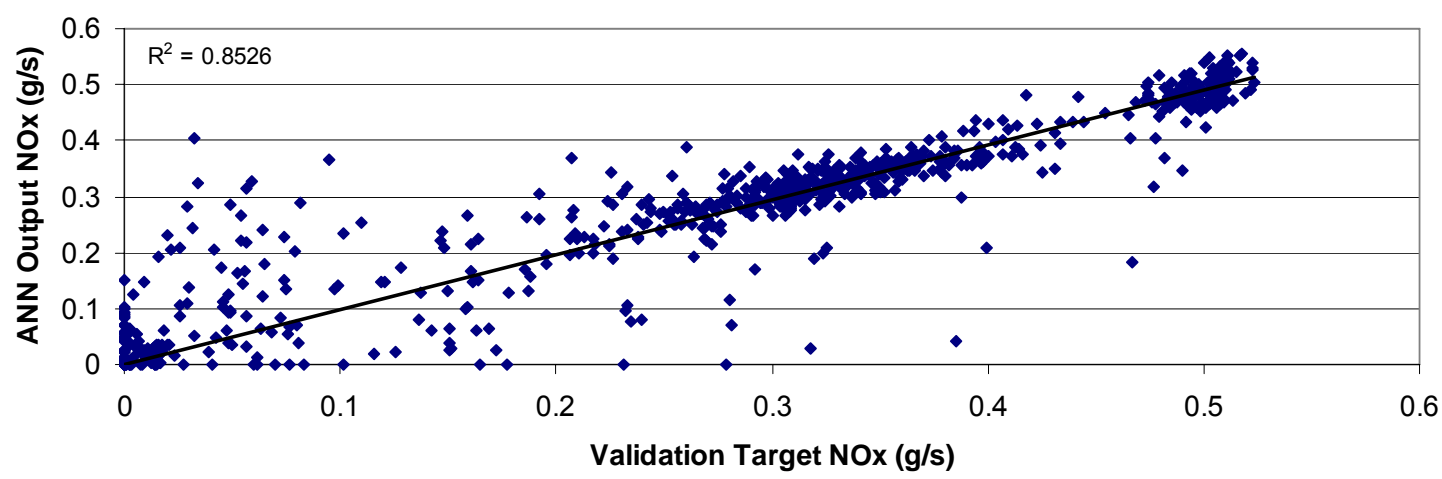

(b) Exhaust Temperature

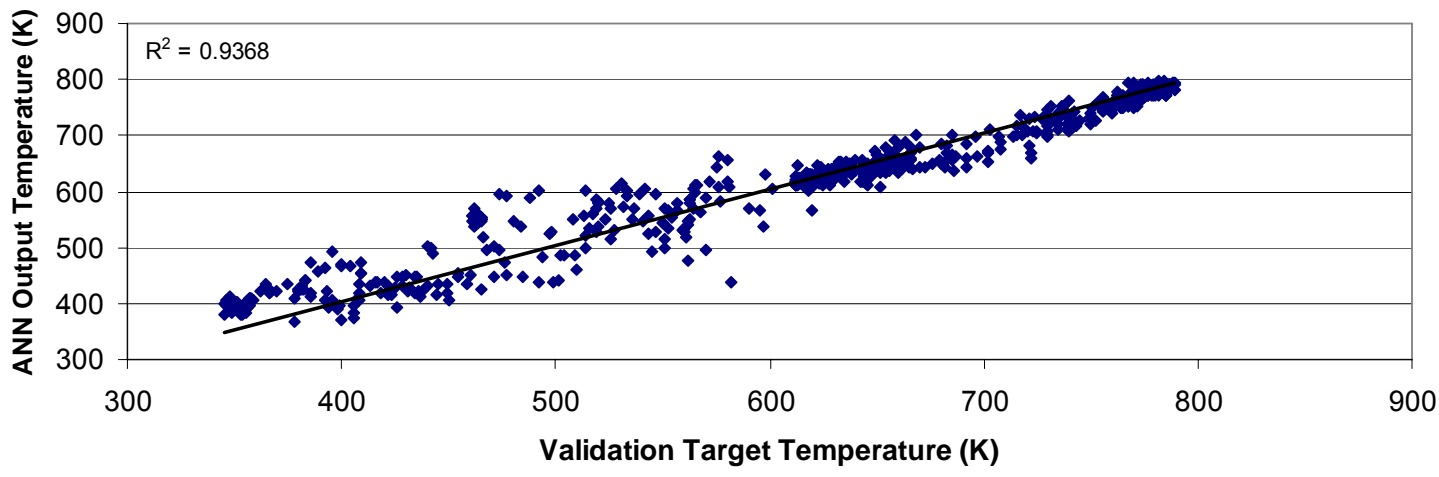

(c) Exhaust Volumetric Flow

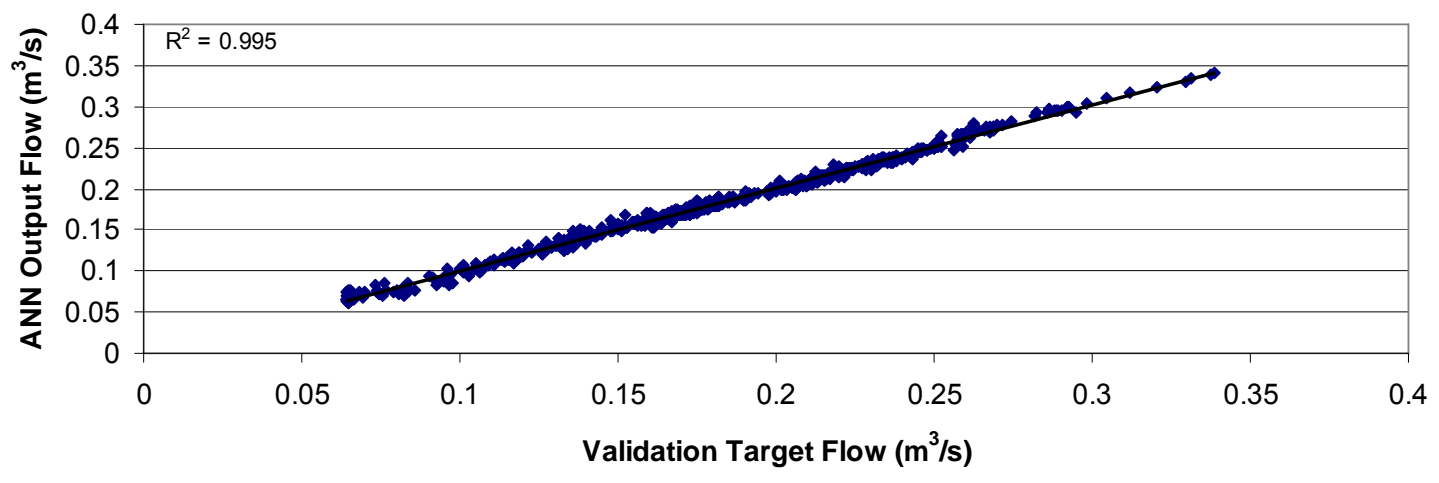

Figure 56. ANN engine model validation parity plot, HHDDTS, (a) NOx (g/s), (b) exhaust temperature (K), (c) exhaust flow $\left(\mathrm{m}^{3} / \mathrm{s}\right)$ 
Table 38. ANN engine model validation, correlation coefficient and standard error

\begin{tabular}{|c|c|c|c|}
\hline \multirow{3}{*}{ ICOMIA } & NOx & 1.00 & 82 \\
\hline & Temperature & 1.00 & 29 \\
\hline & Flow & 1.00 & 6 \\
\hline \multirow{3}{*}{ FTP } & NOx & 0.82 & 191 \\
\hline & Temperature & 0.94 & 43 \\
\hline & Flow & 1.00 & 15 \\
\hline \multirow{3}{*}{ Transient } & $\mathrm{NOx}$ & $\overline{0.74}$ & 69 \\
\hline & Temperature & 0.90 & 22 \\
\hline & Flow & 1.00 & 6 \\
\hline \multirow{3}{*}{ Creep } & NOx & 0.63 & 61 \\
\hline & Temperature & 0.39 & 132 \\
\hline & Flow & 0.99 & 11 \\
\hline \multirow{3}{*}{ HHDDTS } & $\mathrm{NOx}$ & 0.93 & 56 \\
\hline & Temperature & 0.98 & 20 \\
\hline & Flow & 1.00 & 6 \\
\hline
\end{tabular}

\subsection{NOx Sharpening Model}

The NOx sharpening model described above was applied to SCR catalyst input and output validation data, both of which were experimentally measured by laboratory analyzers. The sharpening procedure relied on the differential coefficients method of instantaneous NOx reconstruction. By correcting the input NOx for diffusion and delay, a good approximation of the NOx which was truly flowing into the SCR catalyst was obtained. Results from the NOx sharpening procedure are presented in Figure 57 for engine-out NOx during the FTP. It can be seen that the procedure shifted the data backward in time, correcting for measurement delay. Additionally, the transient response was sharpened, and in some cases the magnitude of peaks and troughs were increased and decreased, respectively. This behavior is shown in particular in Figure 57, part (b). 

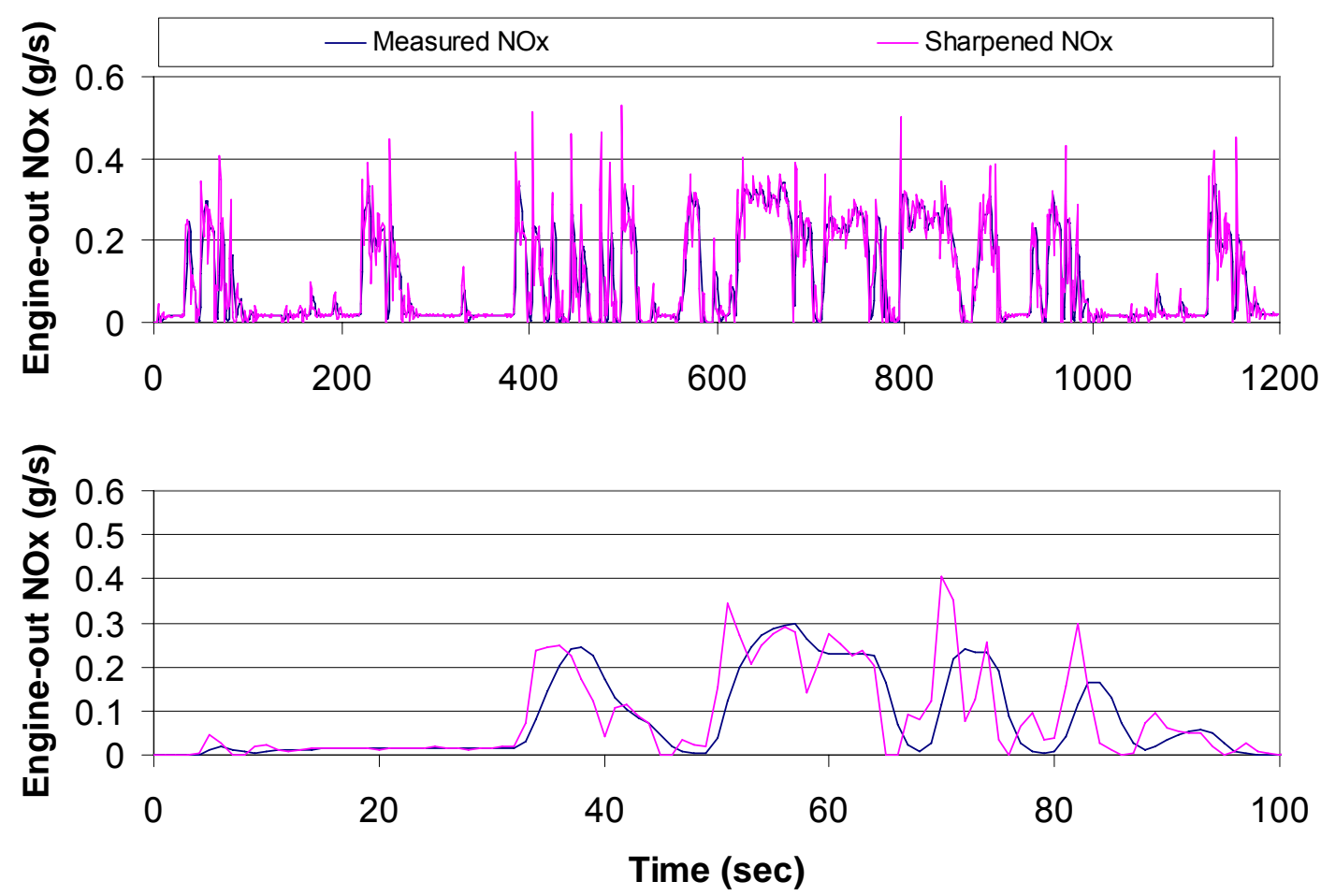

Figure 57. NOx sharpening results $(\mathrm{g} / \mathrm{s})$, FTP

\subsection{Pipe Heat Loss Model}

In order to eliminate the use of aftertreatment system data (SCR inlet temperature) as an input to the SCR catalyst model, it was desired to obtain the SCR inlet temperature as a function of engine post-turbocharger exhaust temperature. Results from the pipe heat loss model are presented below in Figure 58 for the FTP. It can be seen that the pipe heat loss model, which included the thermal mass of the 8-foot length of exhaust pipe, was able to accurately predict the SCR inlet exhaust temperature. The model predictions remained accurate even during the most transient periods of the FTP. As a result of accurately matching the measured SCR inlet temperature, the model was considered to be valid and acceptable for integration into the final system model. 


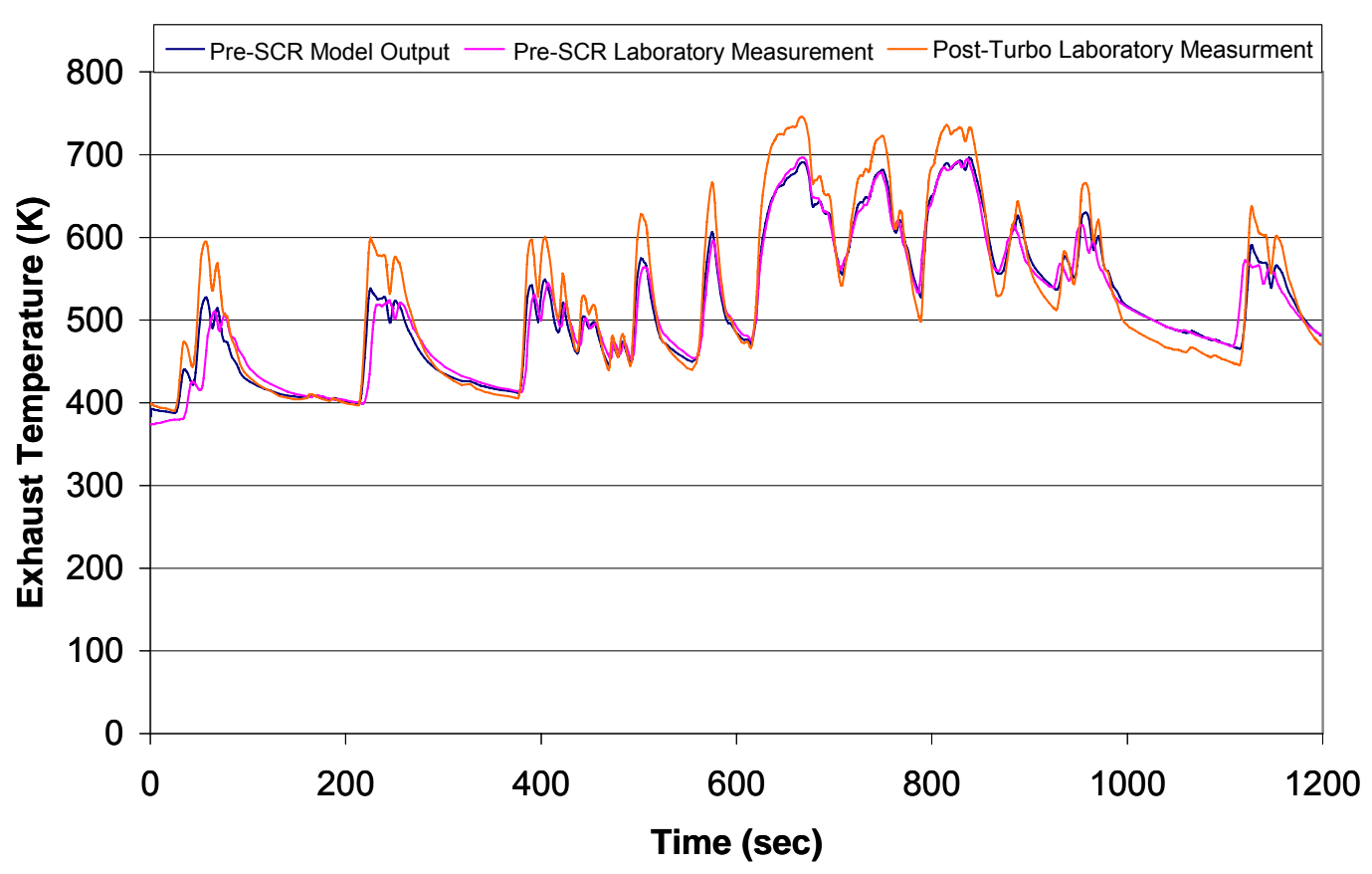

Figure 58. Pipe heat loss model validation (K), FTP

\subsection{Thermocouple Response Correction}

The measured exhaust temperature was corrected for thermocouple response time in order to highlight any differences between 'true' and 'measured' values within the system model. The thermocouple model response time tended to be fast. For example, to cause a one second thermocouple response time from $570^{\circ} \mathrm{C}$ to $700^{\circ} \mathrm{C}$, the exhaust temperature must spike to almost $950^{\circ} \mathrm{C}$ over the same interval. The continuously measured post-turbocharger exhaust temperature and corrected exhaust temperature were plotted together over the FTP. This comparison can be seen in Figure 59. Here, it can be seen that the exhaust temperature changes more quickly than the thermocouple can actually measure, although the magnitude of this low-level transient behavior is small compared to transients captured by the thermocouple. This type of low-level, high-frequency reconstruction is similar to data presented in [90]. 


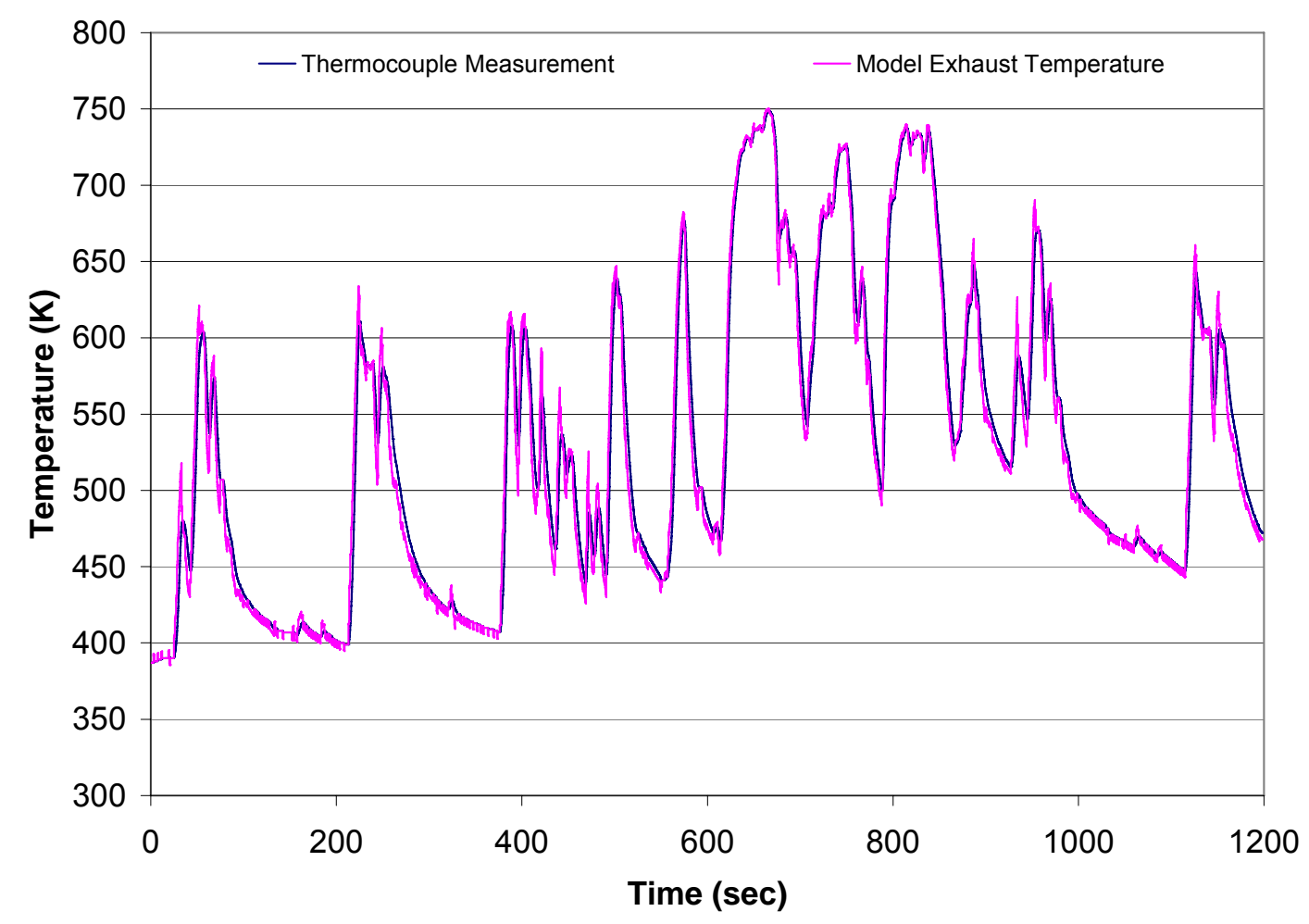

Figure 59. Thermocouple response correction (K), FTP

\subsection{SCR Catalyst Model}

Results and validation comparisons were performed separately for the two SCR catalyst sub-models. During most recent experimental testing of the aftertreatment system, post-SCR exhaust temperature was not measured due to lack of an immediately available thermocouple probe mount and datalogging channel and testing time constraints. As a result, the thermal sub-model was validated using temperature data from a previous testing period with the retrofit urea-SCR system at the WVU EERL. More detail regarding this testing period can be found in [69]. All other portions of the system model were validated using only data from the most recent experimental testing period.

\subsubsection{Four-State Chemical Reaction Sub-Model}

In order to independently validate the chemical reaction sub-model, experimental data were used for input and validation. NOx emissions measured by laboratory analyzers during non-urea injection runs were used as the pre-SCR input NOx. Prior to entering the model, the input NOx was sharpened using the differential coefficients method, as described above. Similarly, engine intake flow and exhaust temperature, as measured by laboratory devices, were used as inputs. Intake flow was corrected for fuel flow and blowby in a manner similar to that which was performed for the engine model training data and during the pitot-tube flow correlation. 
$\mathrm{NOx}$ and $\mathrm{NH}_{3}$ measured by the laboratory during urea injection runs were compared to SCR model outputs for validation. The validation NOx was sharpened in the same way as the input NOx. Validation $\mathrm{NH}_{3}$ was not corrected or sharpened in any way. Measurement of $\mathrm{NH}_{3}$ emissions is an imprecise process. As a result, the model output $\mathrm{NH}_{3}$ was compared to validation $\mathrm{NH}_{3}$ only to ensure the location, shape, and approximate magnitude of ammonia slip. There was some delay between the two curves, however this delay cannot be easily corrected since $\mathrm{NH}_{3}$ does not necessarily correlate well with any engine parameter.

The SCR catalyst model was run for three different test cycles: FTP, ICOMIA steady-state, and ACES HHDDT_S. As a result of cool exhaust temperatures, the possible NOx reductions over the ACES Transient and Creep cycles were low (demonstrated by the experimental results above). For this reason, they were not implemented during model validation and control optimization. For each test cycle, continuous model $\mathrm{NOx}$ and $\mathrm{NH}_{3}$ at the SCR outlet were compared to experimental validation SCR outlet emissions and model SCR inlet emissions. This comparison can be seen below in Figure 60 and Figure 61, parts (a) through (c). By examining the results in Figure 60, it was clear that the model could predict NOx over a variety of test cycles. In particular, the model had excellent steady-state predictive ability. The ICOMIA experimental validation data presented here included stabilization periods before data collection at each point. The model results, however, do not have stabilization periods and include the step changes between each point. This can particularly be seen in the second mode, where the model NOx decreases to the validation value. The large spikes at each transition point are a result of differentiation during the NOx sharpening process.

NOx results over the FTP and HHDDT_S test cycles were not as accurate as for the steady-state ICOMIA cycle; however the essential emissions behavior of the urea-SCR system was captured. As a result of the highly transient nature of these test cycles, NOx and temperature change very rapidly. It can be seen that at the beginning of the FTP and HHDDT_S cycles, the inlet NOx flow matched the outlet, indicating that no urea was being injected as a result of low exhaust temperatures $\left(<250^{\circ} \mathrm{C}\right)$. During quick transients in the FTP, the model was able to match the experimental data well (Figure 62). Later in the cycle, during the more steady portions (with respect to inlet NOx), the model could not exactly match the experimental data. This may have been a result of temperature dependence or storage and release of $\mathrm{NH}_{3}$ in the SCR catalyst. The HHDDT_S cycle included a large cruise portion, which was even less transient than for the FTP. During this portion $(200-650 \mathrm{sec})$, the model matched the experimental data well, although it was shifted down slightly.

The ammonia slip data were more difficult to compare as a result of inaccurate $\mathrm{NH}_{3}$ measurement. By examining the experimental $\mathrm{NH}_{3}$ data, it could be seen that even when no urea was being injected, there were large spikes present. These spikes may have been a result of analyzer noise or $\mathrm{NO}_{2}$ crosscontamination, which can occur in NDUV analyzers. The experimental data do show where periods of 
significant ammonia slip occur. These measurements were delayed and diffused, in a manner similar to other analyzers. As a result, the validation of $\mathrm{NH}_{3}$ predictions was primarily limited to the shape and location of periods of significant slip. The best match with experimental data was for the FTP. During the other two test cycles, the shape and location of ammonia slip spikes matched reasonably with experimental data, even though the magnitudes differed.

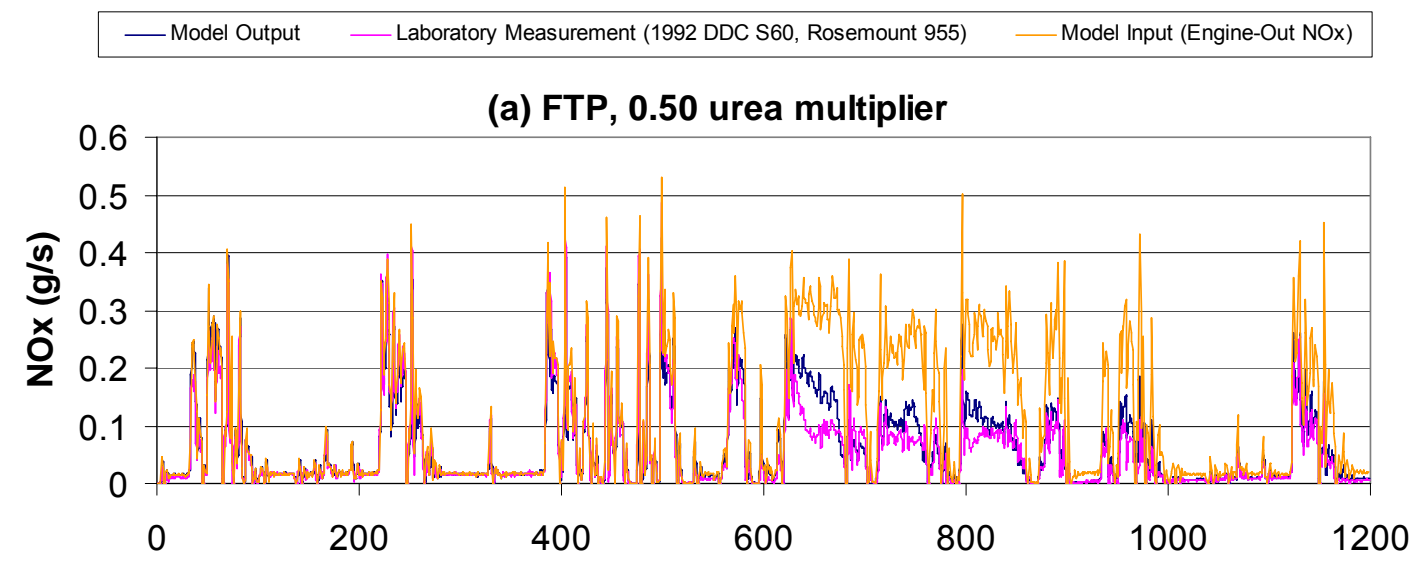

(b) HHDDTS, 0.50 urea multiplier

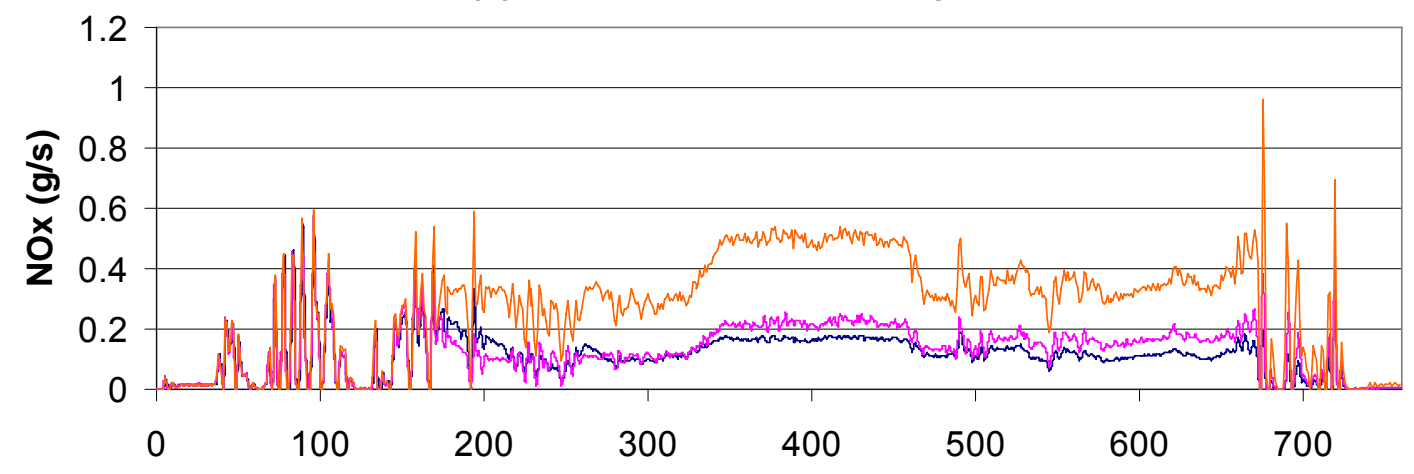

(c) ICOMIA, 0.25 urea multiplier

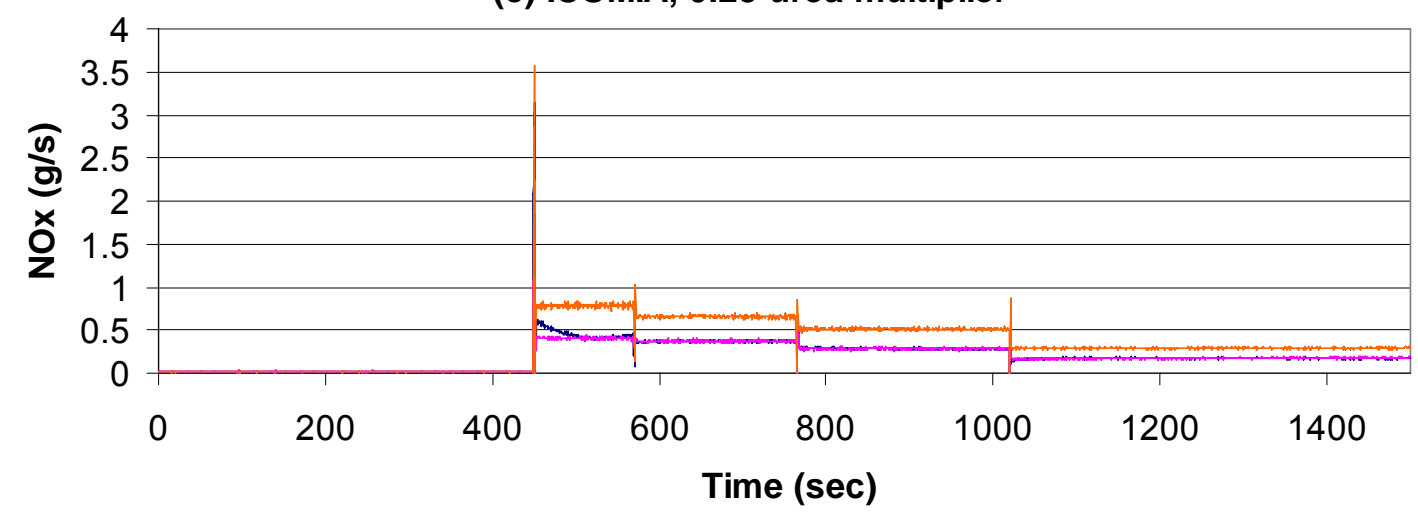

Figure 60. SCR catalyst model NOx validation (g/s): (a) FTP, (b) ACES HHDDT_S, (c) ICOMIA 


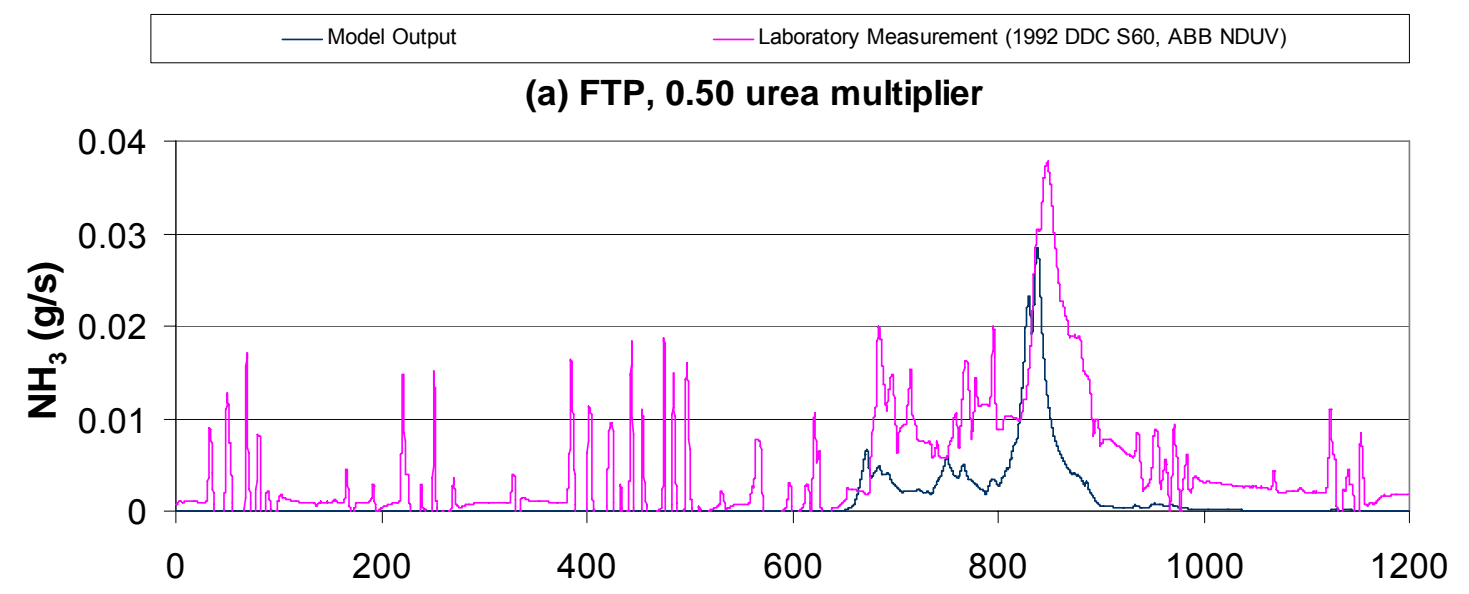

(b) HHDDTS, 0.50 urea multiplier

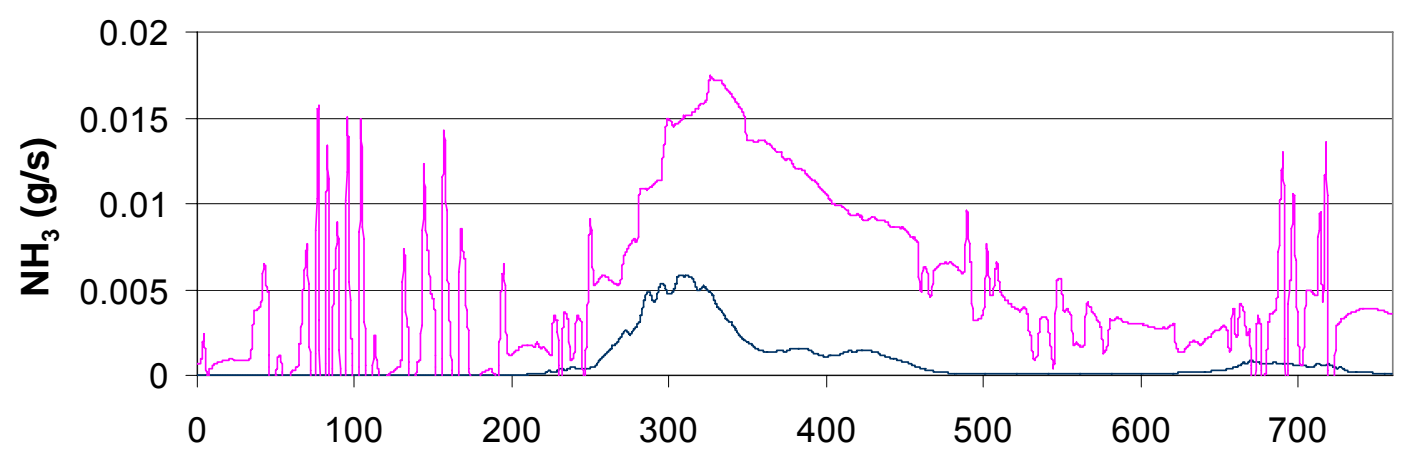

(c) ICOMIA, 0.25 urea multiplier

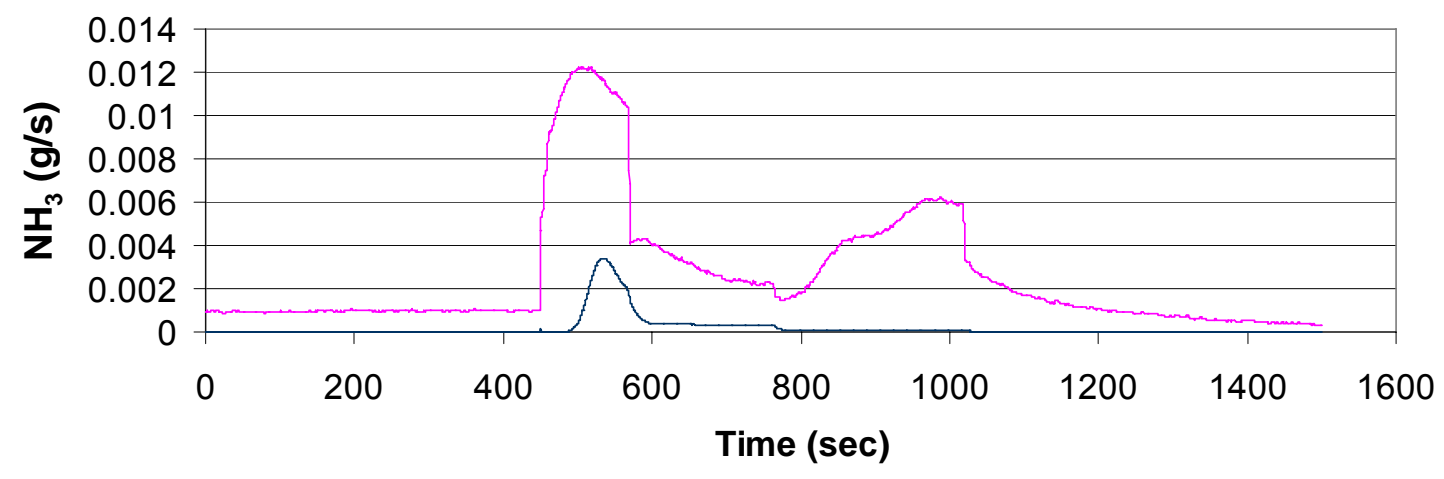




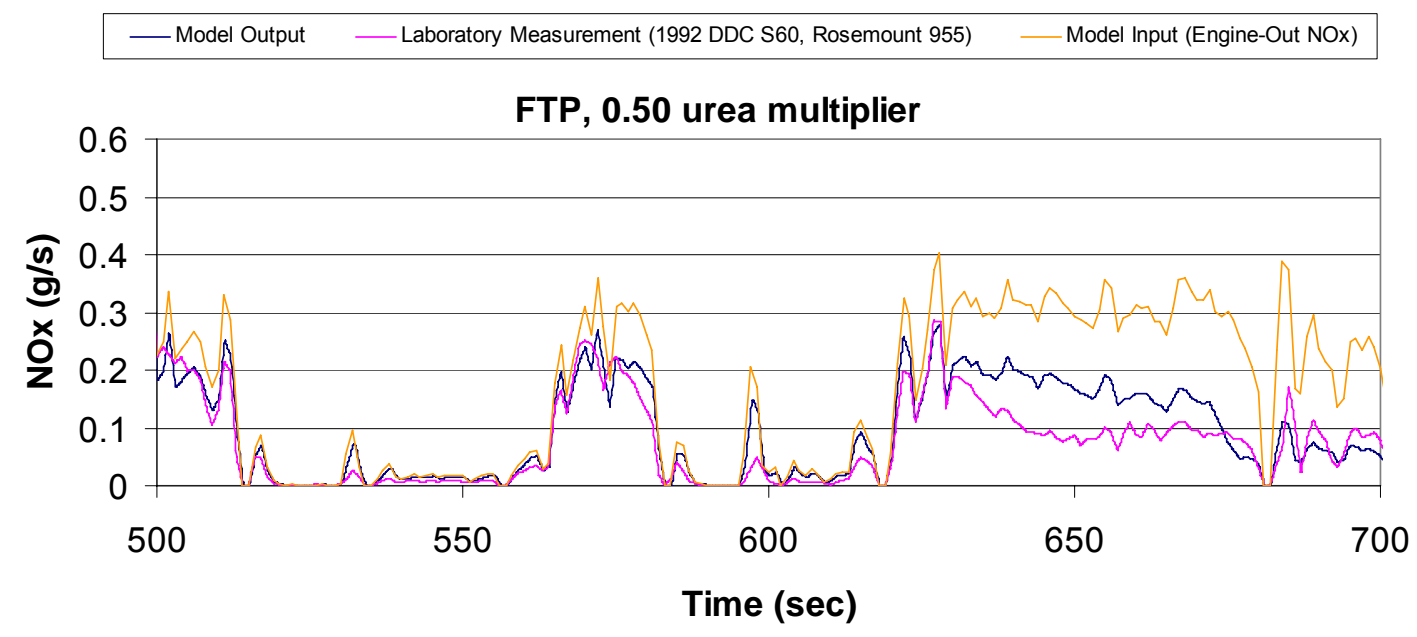

Figure 62. SCR catalyst model NOx validation $(\mathrm{g} / \mathrm{s})$, enlarged

Additionally, total $\mathrm{NOx}$ and $\mathrm{NH}_{3}$ were compared to measured totals, including the corresponding percent NOx reduction. A percent difference between the total $\mathrm{NOx}$ and $\mathrm{NH}_{3}$ and the coefficient of determination $\left(\mathrm{R}^{2}\right)$ were calculated for each test cycle. As previously stated, the NDUV analyzer tended to exhibit erroneous behavior during times when no $\mathrm{NH}_{3}$ was present. In order to allow comparison between model and measured total $\mathrm{NH}_{3}$ results, good engineering judgment was used to visually determine an appropriate time shift and integration interval. This allowed the $\mathrm{NH}_{3}$ measurement fluctuations during times of zero $\mathrm{NH}_{3}$ to be eliminated in the comparison.

The total results for NOx and $\mathrm{NH}_{3}$ can be seen below in Table 39 and Table 40, respectively. The total NOx compared well between the SCR catalyst model and experimental data, showing a maximum of $12 \%$ difference, over the HHDDT_S cycle. The best match with experimental data was observed over the ICOMIA cycle, which should be expected from the continuous results above. Moreover, the small difference (1\%) was likely the result of not including stabilization periods and from the NOx sharpening process. It should be noted that the ICOMIA NOx results presented here were for unweighted totals, which accounted for the small decrease in percent reduction compared to the experimental results previously presented (43\% vs. $47 \%$ ). Utilizing unweighted totals allowed much simpler calculation of total NOx results in the modeling environment, with the same comparability between control strategies for the optimization process. 
Table 39. SCR catalyst model total NOx (g) validation

\begin{tabular}{|c|c|c|c|c|c|c|c|c|}
\hline \multirow{4}{*}{$\begin{array}{l}\text { Test } \\
\text { Cycle }\end{array}$} & \multirow{3}{*}{$\begin{array}{c}\text { Baseline } \\
\text { Measured } \\
\text { NOx }\end{array}$} & \multicolumn{7}{|c|}{ Urea Injection } \\
\hline & & \multirow{2}{*}{$\begin{array}{c}\text { Measured } \\
\text { NOx }\end{array}$} & \multirow{2}{*}{ Reduction } & \multirow{2}{*}{ Model NOx } & \multirow{2}{*}{ Reduction } & \multicolumn{2}{|c|}{ Model vs. Measured } & \multirow{2}{*}{$\begin{array}{c}\text { Urea } \\
\text { Multiplier }\end{array}$} \\
\hline & & & & & & Diff. & $\mathbf{R}^{2}$ & \\
\hline & [g] & [g] & [\%] & [g] & [\%] & [\%] & {$[--]$} & {$[--]$} \\
\hline FTP & 124.3 & 65.9 & $47 \%$ & 71.5 & $42 \%$ & $9 \%$ & 0.91 & 0.50 \\
\hline ICOMIA & 502.7 & 286.3 & $43 \%$ & 288.5 & $43 \%$ & $1 \%$ & 0.83 & 0.25 \\
\hline HHDDTS & 208.3 & 99.0 & $52 \%$ & 87.3 & $58 \%$ & $12 \%$ & 0.83 & 0.50 \\
\hline
\end{tabular}

The total $\mathrm{NH}_{3}$ comparison here was included for completeness and to allow comparison between test cycles. The experimental $\mathrm{NH}_{3}$ data included periods of apparent erroneous measurement (when no urea was being injected) and tended to be much higher than model predictions. As a result, the total $\mathrm{NH}_{3}$ differed greatly between model and experimental data. This resulted in up to a $92 \%$ difference and $0.04 \mathrm{R}^{2}$ value over the ICOMIA cycle. Even with large differences in total $\mathrm{NH}_{3}$, the model predictions showed the location and duration of significant periods of ammonia slip and were useful in control optimization. The percent difference and $\mathrm{R}^{2}$ values were presented to quantify the model accuracy with respect to measured results. Average and maximum concentrations were presented because they were metrics used to quantify ammonia slip.

Table 40. SCR catalyst model total $\mathrm{NH}_{3}(\mathrm{~g})$ validation

\begin{tabular}{|c|c|c|c|c|c|c|}
\hline \multirow{4}{*}{$\begin{array}{l}\text { Test } \\
\text { Cycle }\end{array}$} & \multicolumn{6}{|c|}{ Urea Injection } \\
\hline & \multirow{2}{*}{$\begin{array}{c}\text { Measured } \\
\mathrm{NH}_{3}\end{array}$} & \multirow[b]{2}{*}{ Model $\mathrm{NH}_{3}$} & \multicolumn{2}{|c|}{ Model vs. Measured } & \multicolumn{2}{|c|}{$\mathrm{NH}_{3}$ Concentrations } \\
\hline & & & Diff. & $\mathbf{R}^{2}$ & Maximum & Average \\
\hline & [g] & [g] & [\%] & {$[--]$} & [ppm] & [ppm] \\
\hline FTP & 4.21 & 1.41 & $67 \%$ & 0.59 & 158 & 7 \\
\hline ICOMIA & 3.14 & 0.26 & $92 \%$ & 0.04 & 16 & 1 \\
\hline HHDDTS & 3.55 & 0.58 & $84 \%$ & 0.39 & 21 & 4 \\
\hline
\end{tabular}

Typical results found in literature were for simple steady-state points, step changes, or ramps $[50,83,84,85]$. It was novel to present model results over entire transient test cycles, but would not be realistic to hope for an exact match with experimental data over such cycles. This is particularly true for ammonia slip emissions, which proved difficult to measure experimentally. By matching experimental NOx data at each 
steady-state point exactly and matching important behavior over transient test cycles, the four-state chemical reaction portion of the SCR catalyst model was considered to be valid and acceptable for use in the subsequent control optimization process.

Additional results are shown below for the FTP cycle. Figure 63 shows $\mathrm{NH}_{3}$ storage in each partition of the SCR catalyst (denoted as P1 through P5), which is non-dimensional and ranges from zero to one. It can be seen that most of the storage occurred in the first SCR partition, which was to be expected since the $\mathrm{NH}_{3}$ inlet concentration was highest. Also, $\mathrm{NH}_{3}$ storage did not begin until urea injection began, once sufficient exhaust temperatures were achieved.

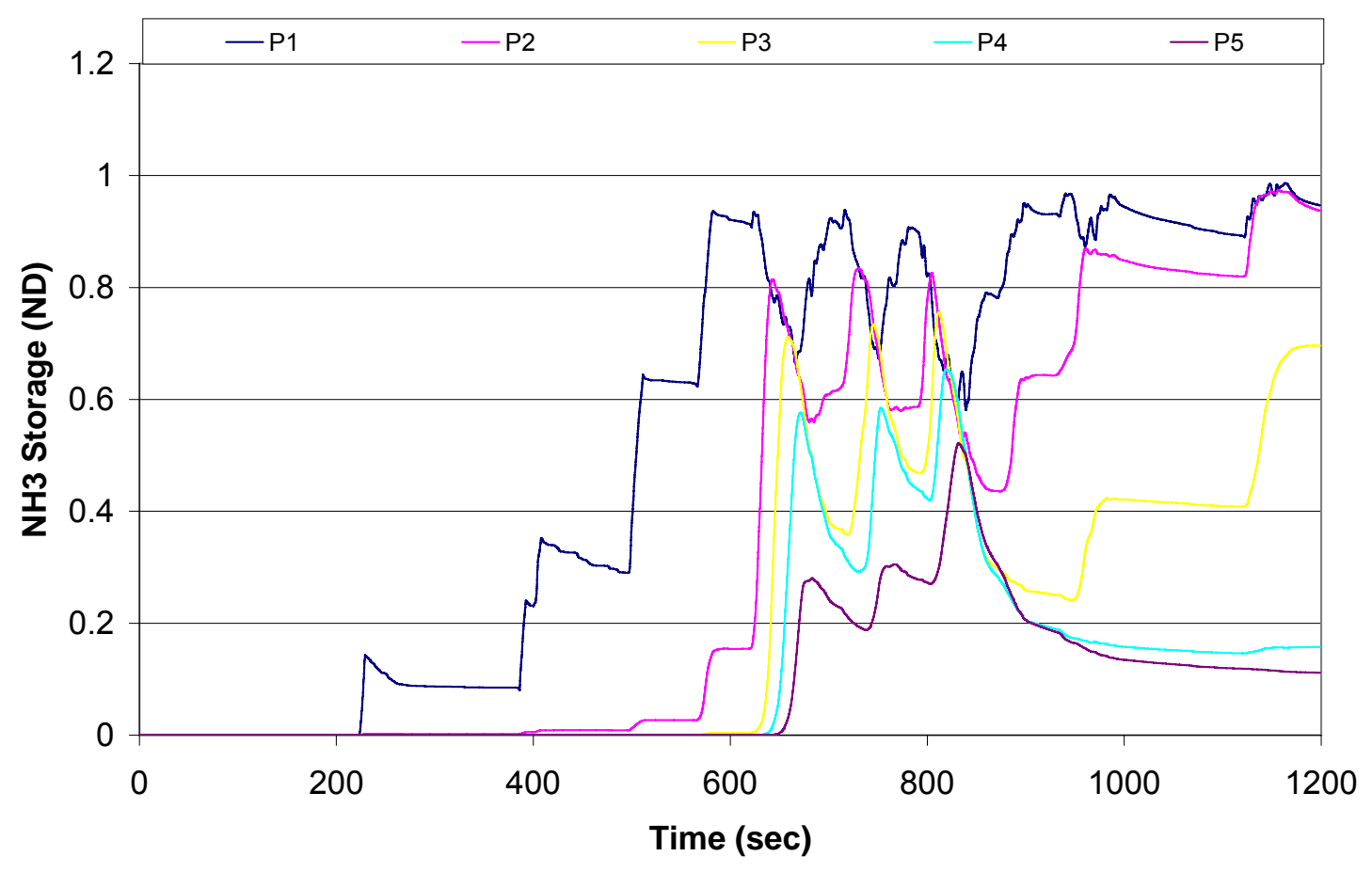

Figure 63. SCR catalyst model $\mathrm{NH}_{3}$ storage, FTP 
Figure 64 parts (a) through (c) show how $\mathrm{NO}, \mathrm{NO}_{2}$, and $\mathrm{NH}_{3}$ were reduced in each partition of the SCR. The results here are presented in terms of concentrations, in units of moles per $\mathrm{m}^{3}$ of exhaust gas. It was desired to compare emissions reductions, $\mathrm{NH}_{3}$ consumption, and $\mathrm{NH}_{3}$ storage as a function of SCR catalyst position to data in literature. However, as of the date of writing suitable comparison data were not available.

— SCR Inlet —P1 Outlet —P2 Outlet $\quad \mathrm{P} 3$ Outlet $-\mathrm{P} 4$ Outlet $-\mathrm{P} 5$ Outlet

(a) NO

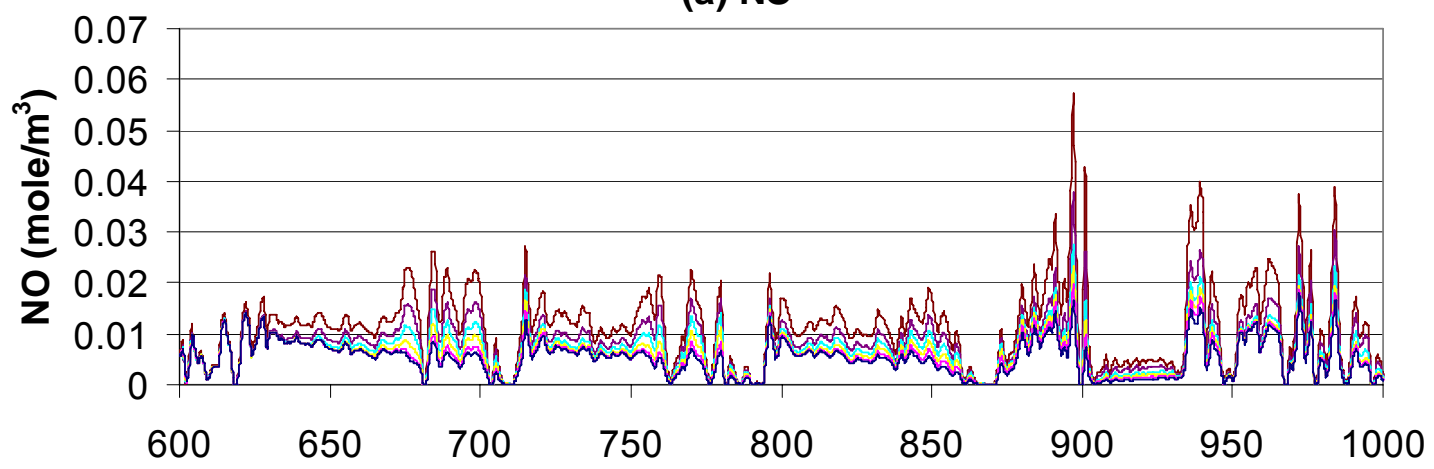

(b) $\mathrm{NO}_{2}$

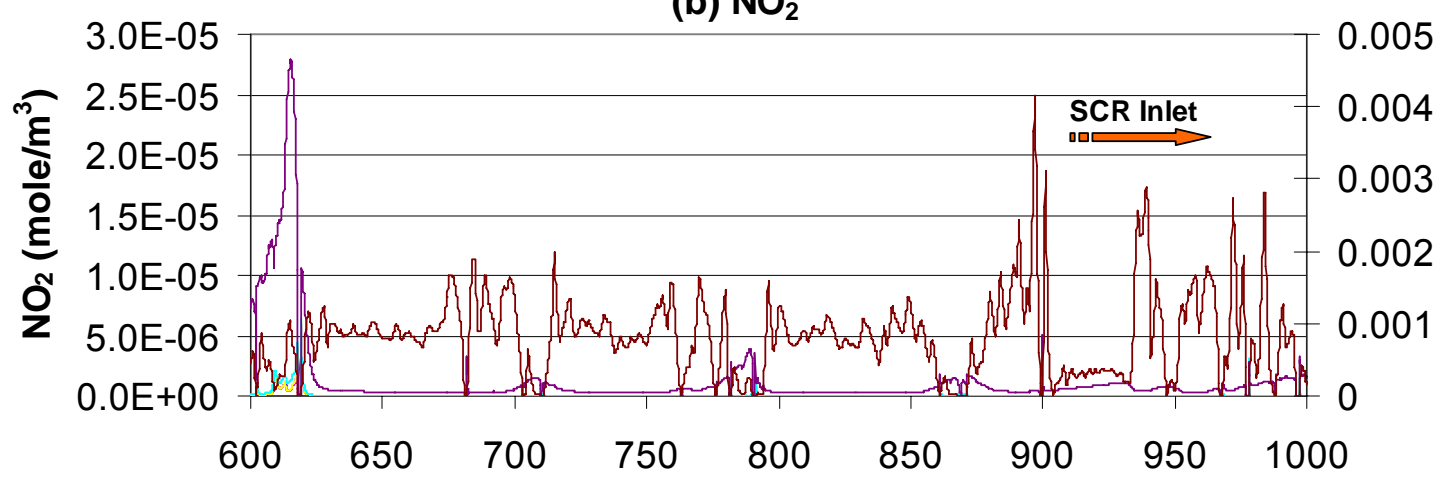

(c) $\mathrm{NH}_{3}$

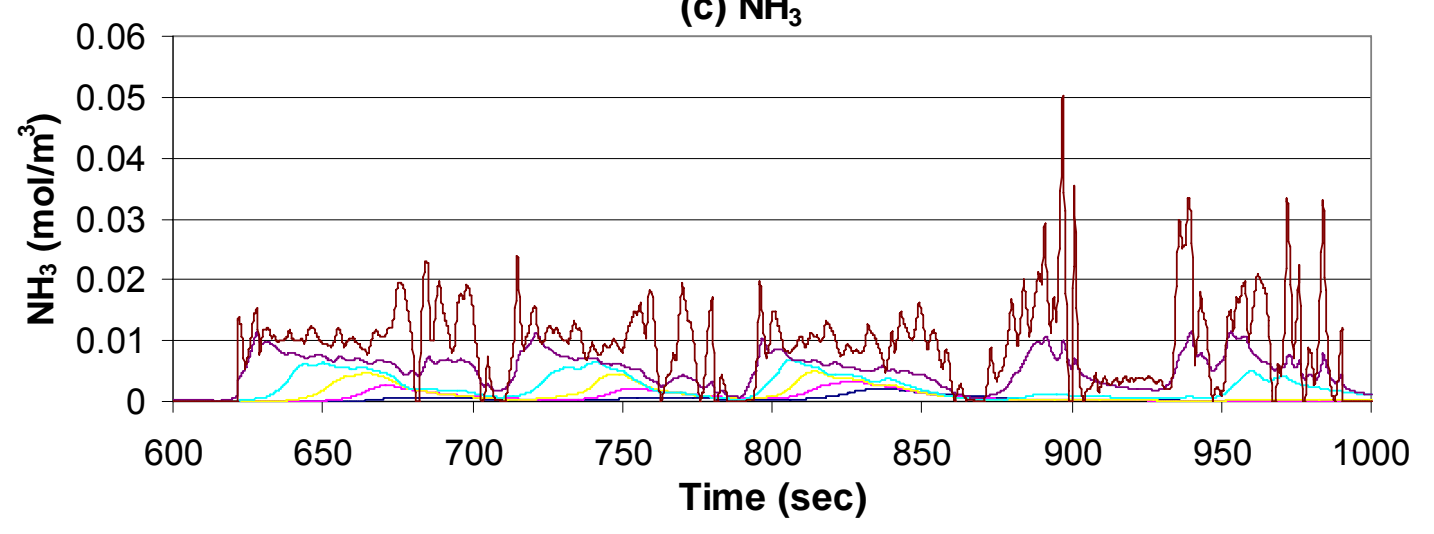

Figure 64. Reduction of (a) NO, (b) $\mathrm{NO}_{2}$, (c) $\mathrm{NH}_{3}$, FTP (600-1000 sec) 
In order to demonstrate rates of adsorption and desorption of $\mathrm{NH}_{3}$, the timescales associated with $\mathrm{NH}_{3}$ storage were compared to the timescales associated with the flow of $\mathrm{NH}_{3}$ through the SCR. A comparison was performed considering $\mathrm{NH}_{3}$ mass flow rates at the inlet of the SCR catalyst and rates of adsorption and/or desorption of $\mathrm{NH}_{3}$ on the SCR catalyst. The rate of adsorption and/or desorption was determined by differentiating the instantaneous $\mathrm{NH}_{3}$ storage, determined by the product of the non-dimensional storage parameter $(\theta)$ and the instantaneous total storage capacity. The two rates, both having units of moles per second, were compared over the FTP (Figure 65).

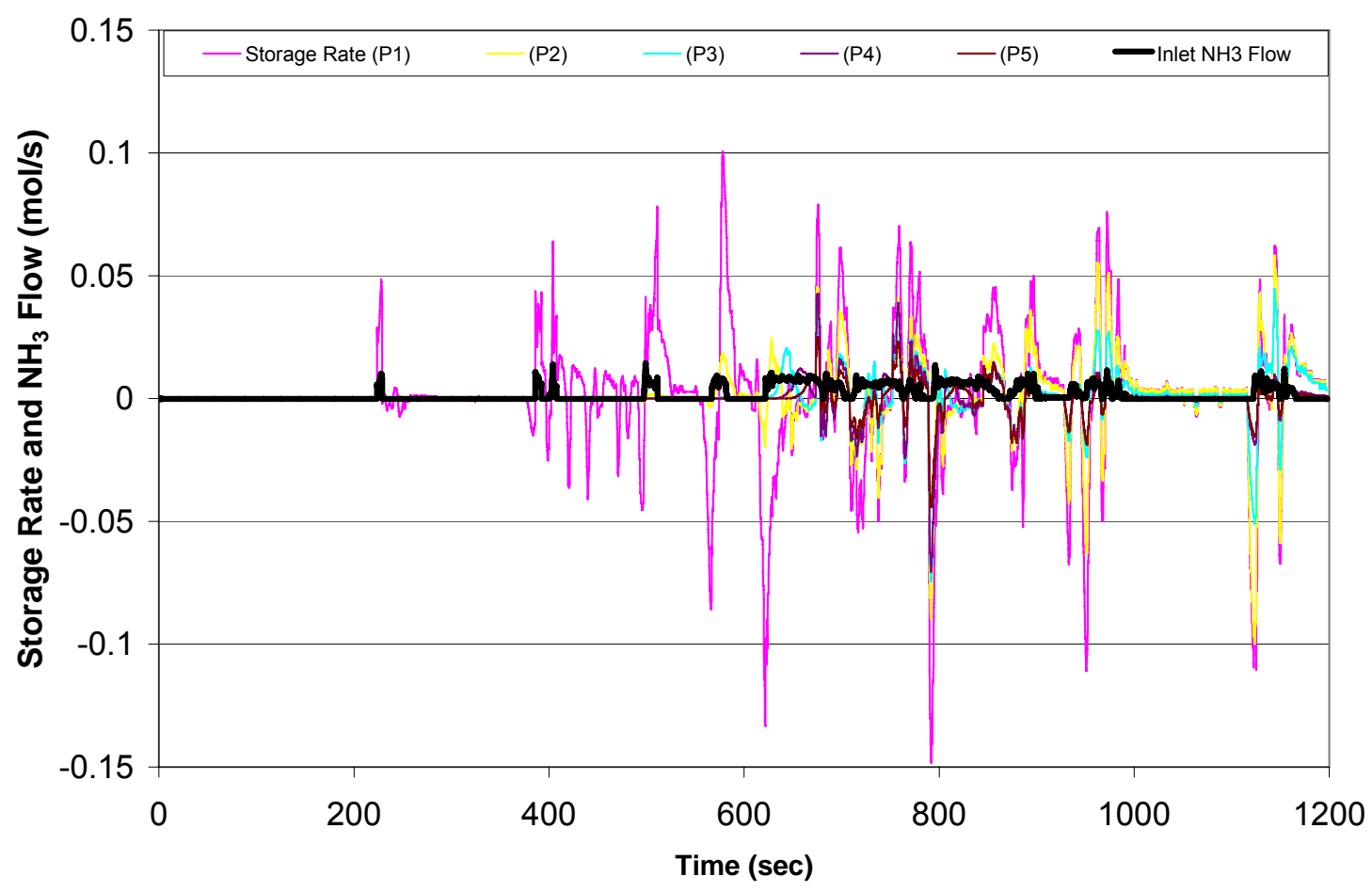

Figure 65. $\mathrm{NH}_{3}$ storage vs. flow timescale comparison $(\mathrm{mol} / \mathrm{s})$

This comparison showed that the rate of adsorption and desorption in the SCR catalyst decreased along the length of the SCR catalyst. The ratio of the maximum $\mathrm{NH}_{3}$ adsorption rate to the maximum inlet $\mathrm{NH}_{3}$ flow for partitions 1 through 5 was 6.96, 4.03, 3.10, 2.96, and 1.73, respectively. By examining the above plot, it was clear that the timescales associated with the storage of $\mathrm{NH}_{3}$ were much faster compared to flow entering the catalyst. This difference was nearly an order of magnitude during some periods. 


\subsubsection{Thermal Sub-Model}

As with the chemical component of the SCR catalyst model, experimental data were used as inputs and for validation. The measured post-turbocharger exhaust temperature was input to the pipe heat loss model, and the resulting SCR inlet temperature was used as input for the thermal sub-model. The measured exhaust flow rate, corrected for fuel flow and blowby, was converted to exhaust flow velocity (assuming a constant velocity profile) to be used in Reynolds number calculations required by the heat transfer coefficient correlations.

First, the SCR outlet temperature was validated with experimental data. During the testing period described in Chapters 4 through 7, the post-SCR exhaust temperature was not measured due to hardware and time constraints. As a result, the post-SCR exhaust temperature was validated using data collected during the previous testing period [69]. During this testing period, an extra thermocouple channel was used to measure the post-SCR temperature. A John Deere non-road heavy-duty diesel engine (Tier 3, reconfigured to Tier 4) was utilized at the WVU EERL and exercised over the Non-Road Transient Cycle (NRTC). Figure 66 shows the measured SCR outlet temperature and model prediction over the first half of the NRTC. It can be seen that the model was able to accurately predict the SCR outlet temperature as a function of SCR inlet temperature. Figure 66 shows some discrepancies between model and measured values in the first 150 seconds of the cycle. This was a result of differences in initial brick temperature between the model and physical system. The initial brick temperature used in the model was $305 \mathrm{~K}$.

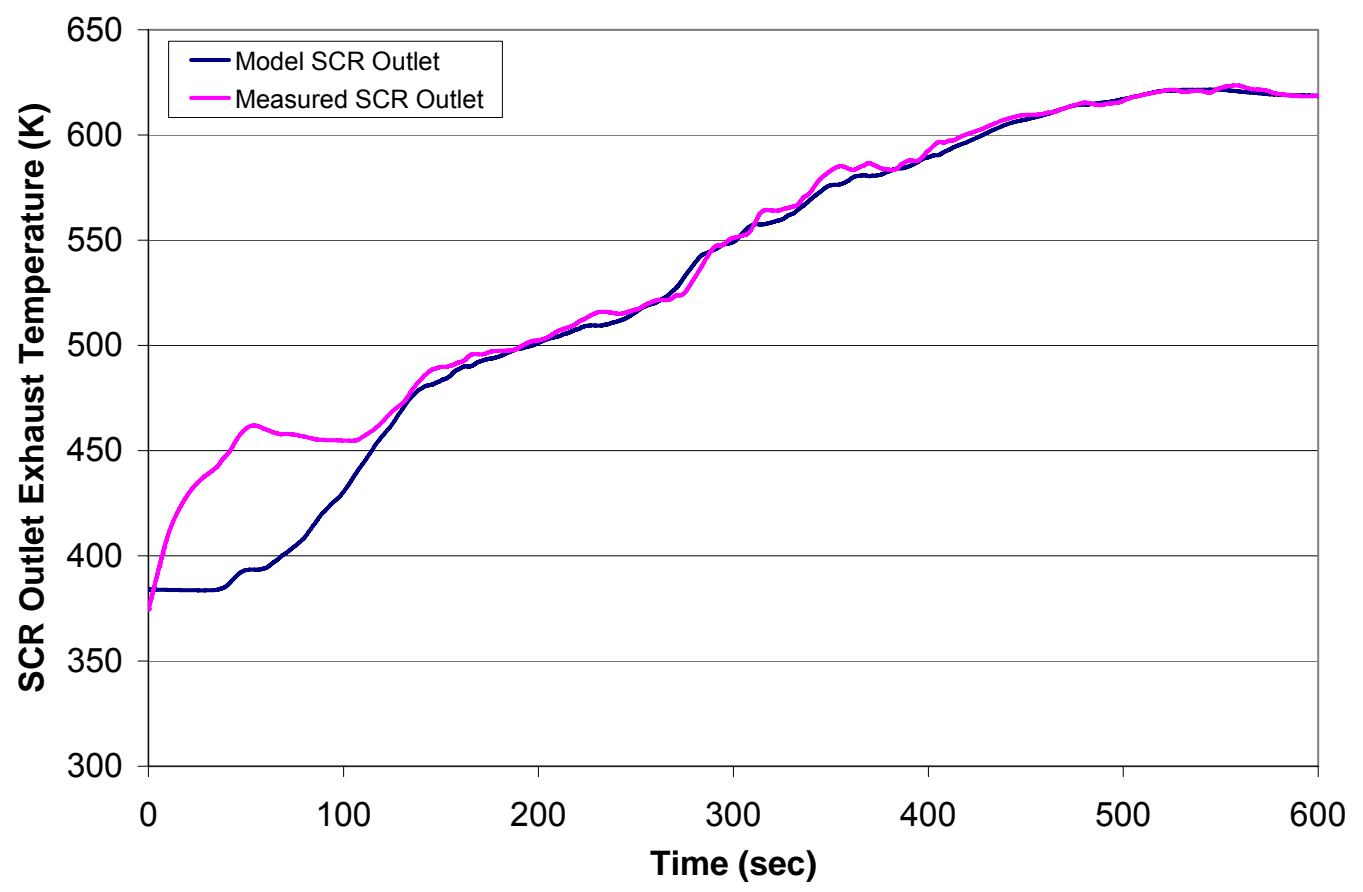

Figure 66. SCR thermal model outlet temperature (K) validation, NRTC (John Deere HHDDE) [69] 
In addition to validating the predictive ability of the thermal sub-model, further results are presented below. Figure 67 shows differences in model exhaust temperatures from the turbocharger outlet, SCR inlet, and SCR outlet. It can be seen that the length of pipe and SCR catalyst heat loss and thermal storage damp and decrease the exhaust temperature considerably.

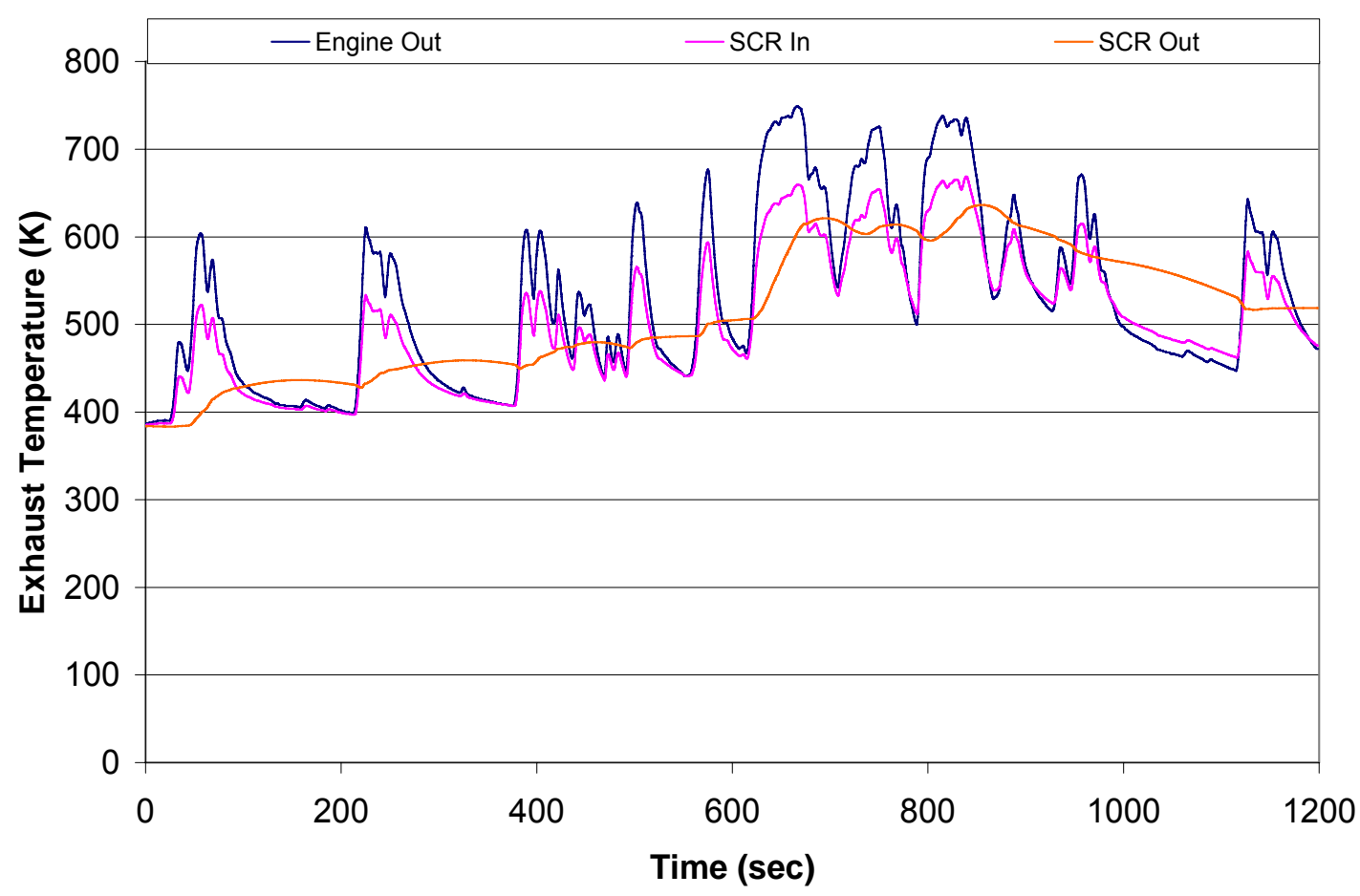

Figure 67. SCR catalyst model exhaust temperature comparison (K), FTP

Below, detail regarding the thermal behavior of the SCR catalyst can be seen. Figure 68 shows the corresponding SCR catalyst brick temperatures for each partition 1 through 5. Figure 69 shows additional detail compared to Figure 67, illustrating the decrease in exhaust temperature between the SCR inlet and outlet. 


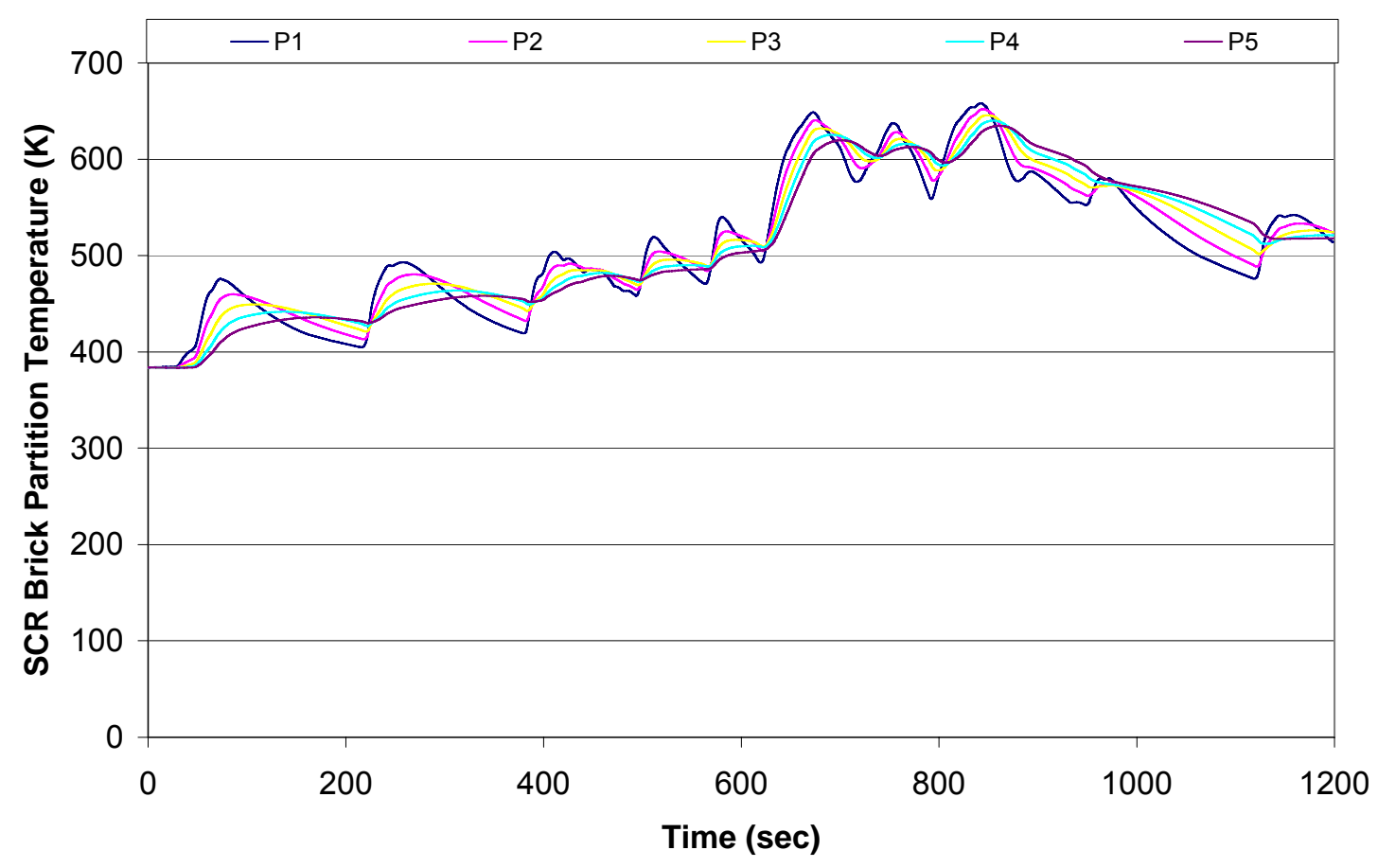

Figure 68. SCR catalyst model brick temperature comparison (K), FTP

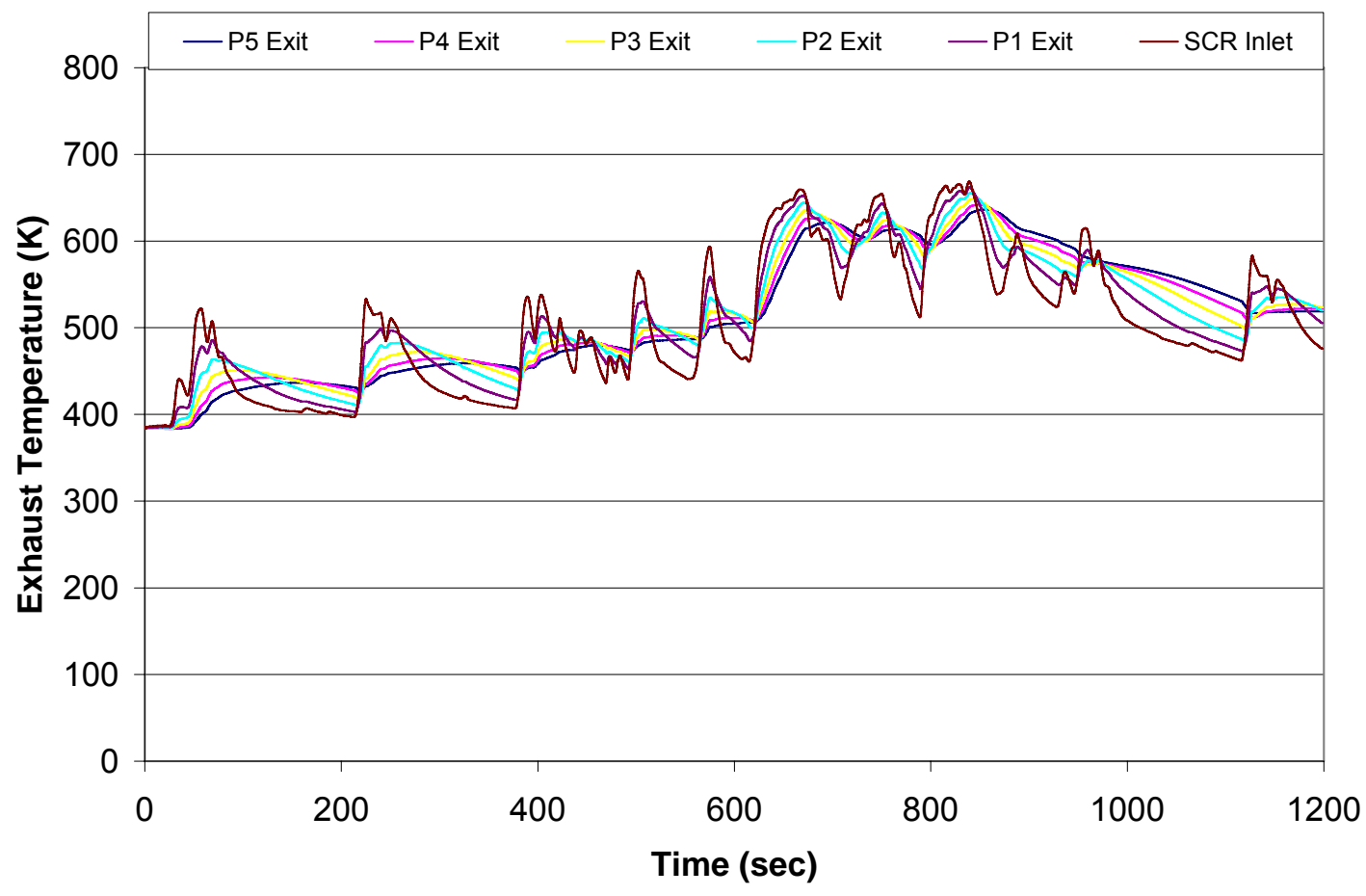

Figure 69. SCR catalyst model gas temperature comparison (K), FTP

Finally, detail of inlet, outlet, and brick temperatures were examined for partition 2 of the SCR catalyst. It can be seen that compared to the inlet temperature, the outlet and brick temperatures were further damped 
and smoothed. Additionally, it should be noted that the outlet temperature was nearly equivalent to that of the SCR brick, implying the SCR partition acted as a nearly perfect heat exchanger.

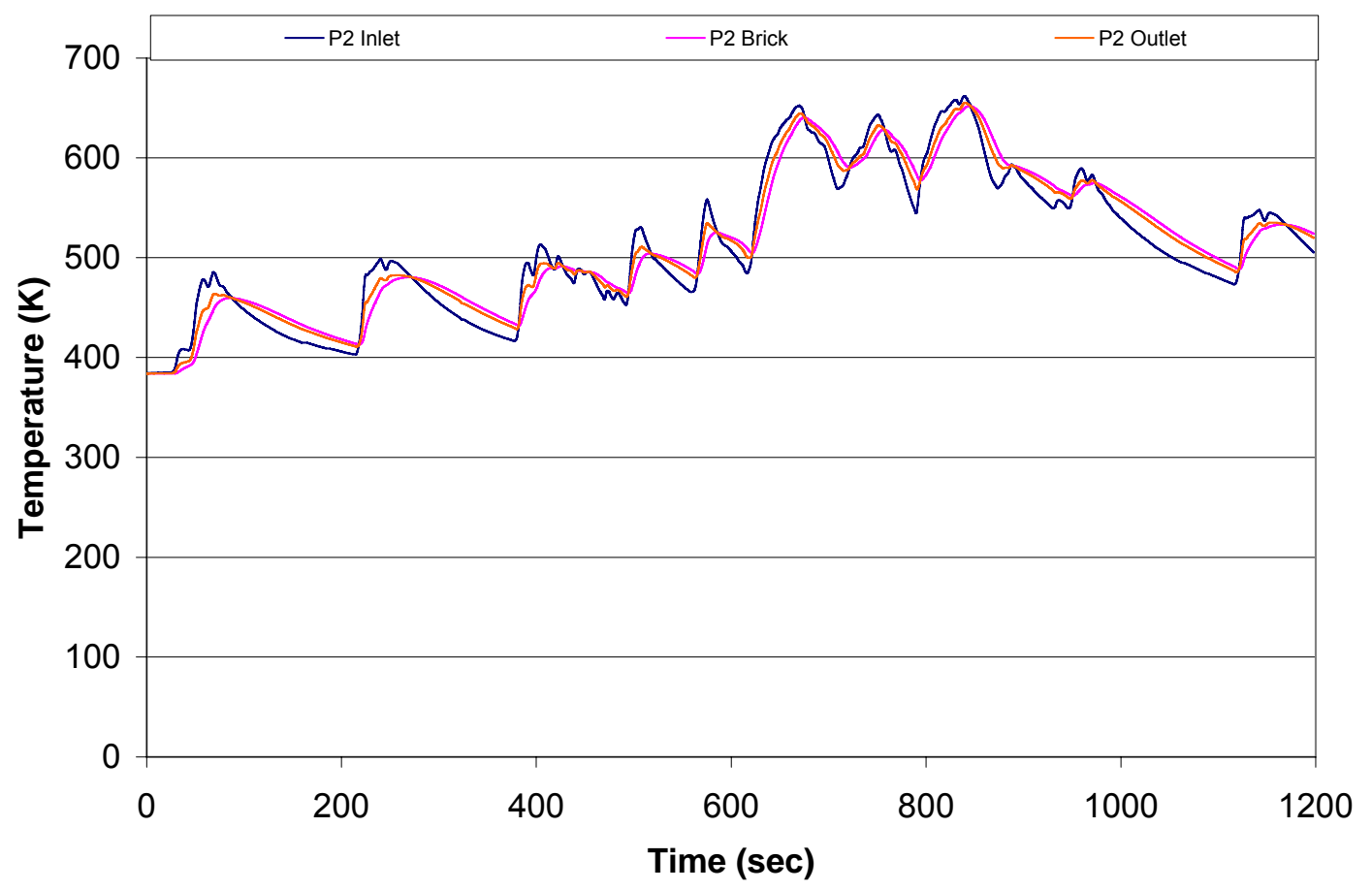

Figure 70. SCR catalyst model partition 2 temperatures (K), FTP 


\section{Chapter 10: Control Optimization}

The original control strategy determined urea dosing according to the ideal decomposition of urea to $\mathrm{NH}_{3}$ and the subsequent stoichiometric reaction with NOx in the SCR catalyst. This control strategy approach, shown in Figure 74, was developed for simplicity, considering ideal processes and an open-loop, feedforward architecture. An open-loop and/or map-based control strategy has been most often implemented in urea-SCR systems to date, proven sufficient to meet Euro-4 and Euro-5 NOx emissions standards [51] or achieve a 2 g/bhp-hr NOx level (US FTP cycle) [67]. Closed-loop and/or model-based control may prove beneficial in two separate application segments. This includes the development of very accurate urea dosing strategies to allow the impending US 2010 NOx standards to be met and creating robust urea-SCR systems that can be universally installed in retrofit applications to control NOx emissions from older engines. As previously stated, the urea-SCR system being considered in this dissertation specifically targets retrofit applications. In either application segment, there still exist difficulties in determining accurate calibration parameters since regulatory agencies have not definitively stated allowable levels of ammonia slip.

The emissions performance of four control and hardware configurations was evaluated over on-road and marine cycles using the urea-SCR system model. Emissions performance was characterized by NOx reduction and ammonia slip. These results were considered along with complexity, robustness, and overall cost to suggest an optimal control and hardware configuration. It should be noted that the control strategy development and optimization specifically target retrofit applications and the results were not meant to satisfy impending US on-road emissions standards for new engines.

\subsection{Model Configurations}

In order to evaluate emissions performance, model runs were performed considering two levels of measurement idealization. The level of idealization was meant to correspond to the accuracy of sensor measurements. By considering emissions performance for exact and ideal measurements, the way in which each control configuration responded to realistic measurement inaccuracy could be evaluated.

The most accurate and exact SCR model represented a case in which true values of exhaust temperature, flow rate, and NOx were exactly and instantaneously known. In other words, no delay, diffusion, or error in measurement existed in the values input to the control strategy. Additionally, more accurate experimental exhaust temperature, flow rate, and NOx data were used as inputs instead of the neural network engine model predictions. This was the configuration used to validate the SCR model with experimental data (see above model validation section). Generally, the exact model configuration included much more rapid and sharp transients. As a result, more urea was dosed, which increased the likelihood of ammonia slip. 
To represent the ideal case, less exact sensor measurements were approximated. First, this was accomplished by utilizing the neural network engine model outputs as SCR model inputs. The NOx, temperature, and exhaust flow rate values here were a good approximation of what was measured by the laboratory equipment (used for training data), which included some inherent inaccuracy, time delay, and/or diffusion. Because the ANN predictions were not exact, some additional error was also introduced. To additionally mimic realistic sensor inputs, the NOx emissions were not sharpened, thermocouple response was not corrected, and the flow rate was not adjusted for pitot-tube measurement offset.

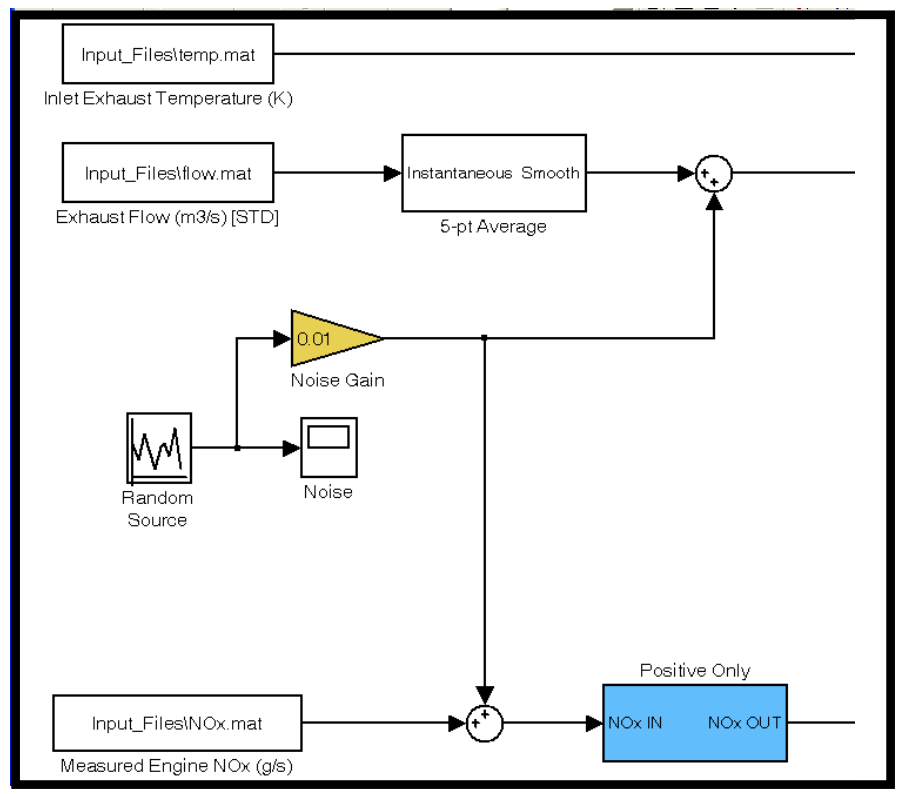

Figure 71. Ideal model NOx and flow rate noise application

The Meriam Instruments 50MC2-6 laminar flow element utilized for flow measurement in the laboratory setting generally had high accuracy $( \pm 0.86 \%$ of reading). To create a more ideal exhaust flow measurement input, a five-point average was added to decrease the sharpness of measurement and low-level noise was added to the signal to simulate measurement noise and flow pulsations. Noise was added to the NOx $(\mathrm{g} / \mathrm{s})$ and exhaust flow rate $\left(\mathrm{m}^{3} / \mathrm{s}\right)$ signals using a random noise block in Simulink. To simulate the typical exhaust pulsation frequency that may be seen in diesel exhaust, a noise sample time of 0.1 seconds was used. This was not quite as high frequency as the actual exhaust pulsations, but was as high as feasibly possible while still maintaining acceptable model run time. The model run time was increased due to a requirement that the simulation time step be less than the random noise frequency. In actual implementation, $10 \mathrm{~Hz}$ noise may not be entirely observed by the controller depending on the sample frequency, which was $1 \mathrm{~Hz}$ for the Motohawk controller and $5 \mathrm{~Hz}$ for the laboratory systems.

As an example, input NOx, SCR inlet exhaust temperature, and exhaust flow rate for the exact and ideal model configurations for the FTP cycle are shown in Figure 72 below. It should be noted that the exhaust 
temperature for the exact case was corrected for thermocouple response time. The additional transience seen in the ideal SCR inlet temperature was a result of predictive inaccuracies of the neural network engine model.

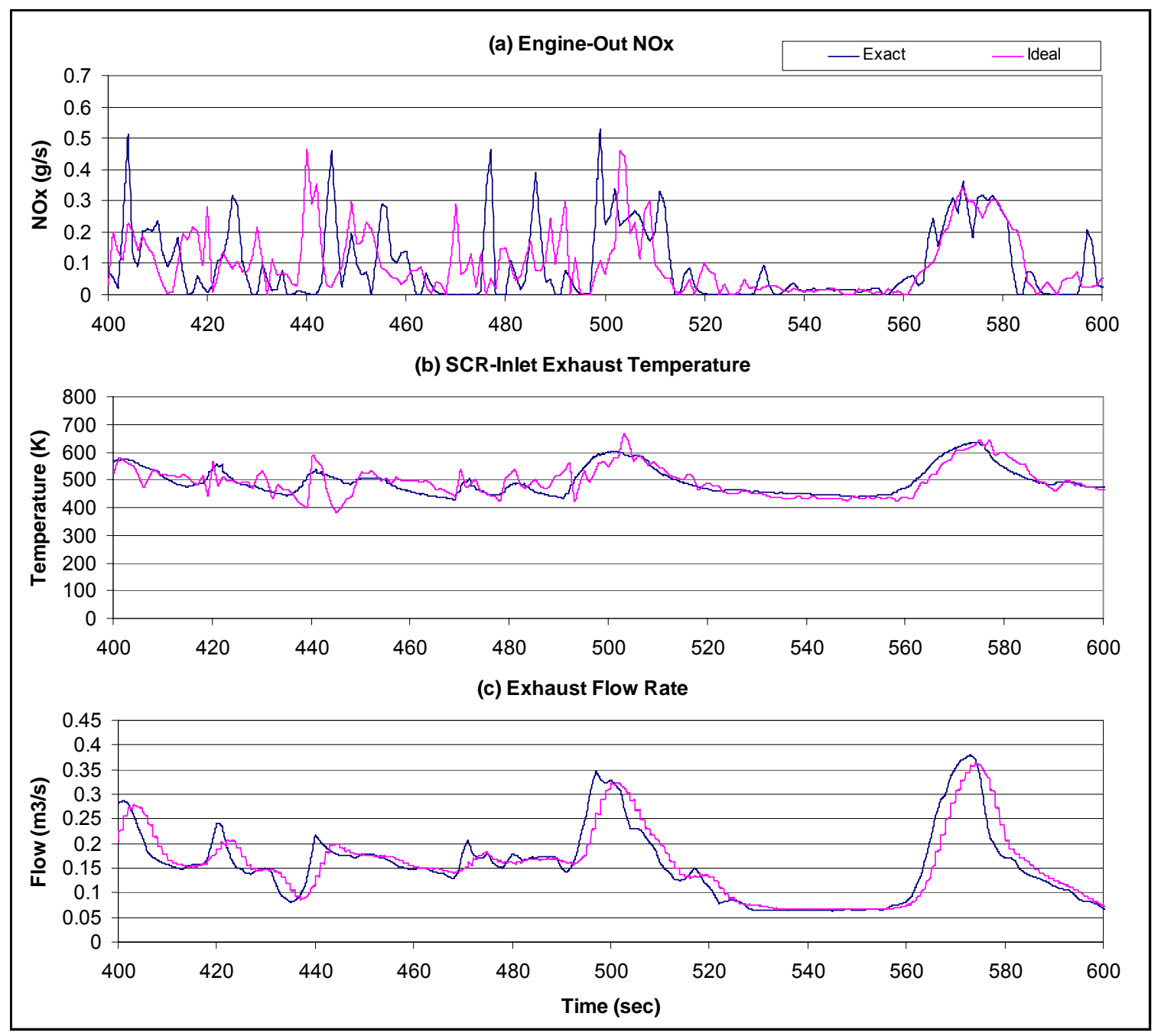

Figure 72. Ideal and exact (a) NOx (g/s), (b) exhaust temperature (K), (c) flow (m³/s), FTP

\subsection{Relevant Urea Injection Temperature}

In order to achieve maximum NOx reduction and stay within the defined temperature band for the SCR catalyst, the use of two different exhaust temperatures were considered. This temperature comparison was performed using the most exact SCR model and the original feed-forward control configuration. The $250^{\circ} \mathrm{C}$ urea injection temperature threshold was determined during original system development [69], based on information found in literature. It was believed that when the catalyst operated above this temperature, the reaction, adsorption, and desorption rates would be sufficient for high NOx conversion efficiency. From the model results, a clear distinction could be made between SCR catalyst brick temperature and the SCR inlet gas temperature measured by the aftertreatment system. As a result of the thermal mass of the SCR brick, it 
may take some time for it to heat to a higher exhaust gas temperature or cool to a lower exhaust gas temperature. The thermal storage effect could be seen most clearly during the FTP, which produced highly transient exhaust temperatures. The SCR inlet gas temperature and SCR brick temperature were plotted continuously in Figure 73.

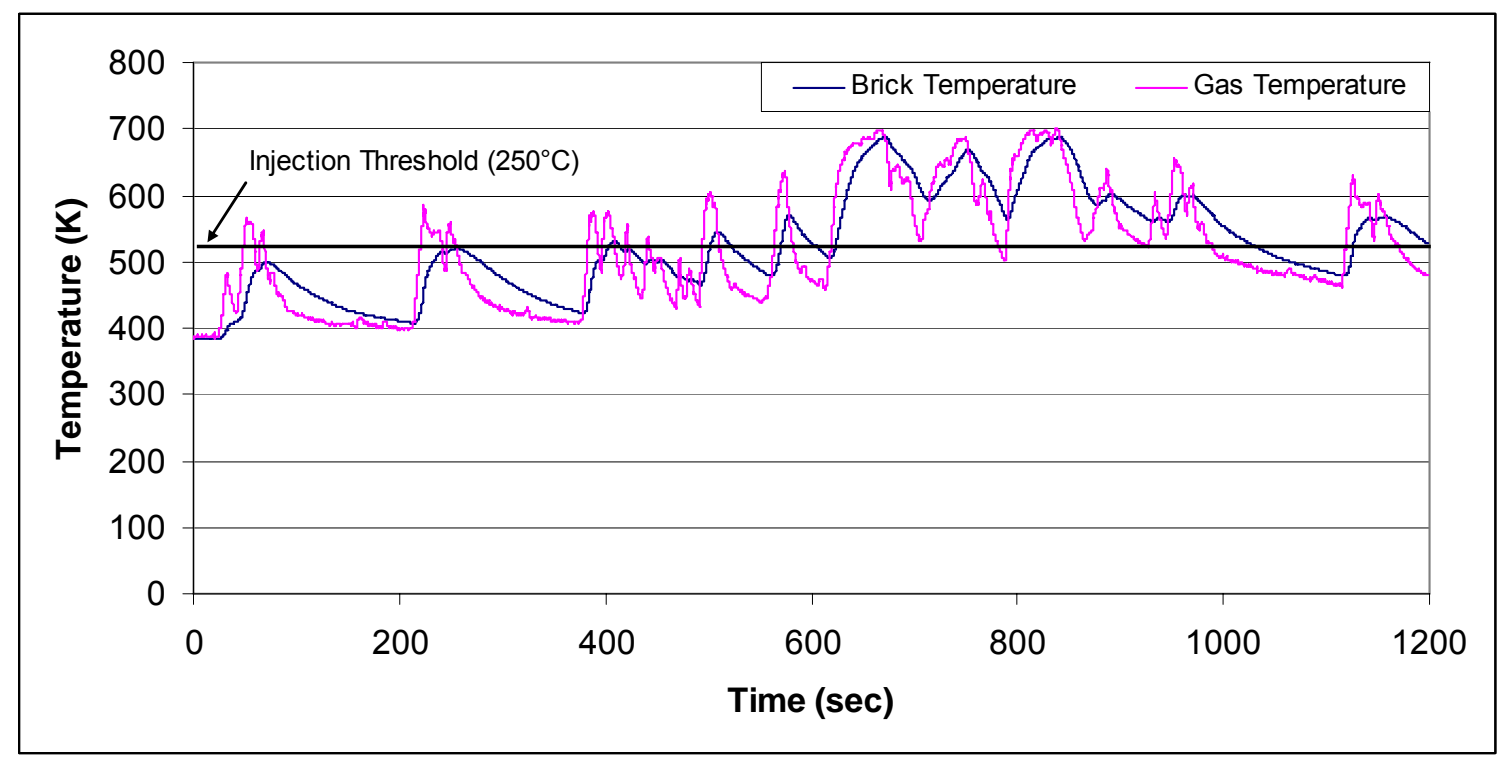

Figure 73. SCR Inlet Gas and Brick Temperature (K), FTP

Originally, it was thought that the thermal mass of the SCR catalyst brick would be beneficial to the system's NOx reduction ability. However, when implementing a model-based SCR brick temperature as opposed to the measured SCR inlet gas temperature, total NOx reductions dropped by $2 \%, 6 \%$, and $1 \%$ for the ICOMIA, FTP, and ACES HHDDT_S cycles, respectively. By examining Figure 73, it can be seen that when utilizing the SCR brick temperature, there were times when urea could be injected, but was not. This caused a greater loss of performance at temperature peaks compared to the gains at temperature troughs. The only times during the FTP when utilizing SCR brick temperature was beneficial were around 600, 800, and 1000 seconds. Based on these results, SCR gas inlet temperature was exclusively used to determine urea dosing in subsequent control strategy comparisons and evaluations. The possibility of utilizing a lower urea injection threshold temperature should be separately investigated. 


\subsection{Configuration 1: Pre-SCR NOx Sensor, Open-Loop Feed-Forward Control}

As stated above, an open-loop, feed-forward strategy was originally developed to control the urea-SCR system. This strategy relied on a pre-SCR NOx sensor and was implemented during experimental testing, detailed in the above sections. A diagram of the current feed-forward control strategy can be seen in Figure 74. The strategy relied on the SCR inlet NOx mass flow (based on measured concentration and volumetric flow rate) and exhaust temperature, as well as a urea dosing factor, which was used for tuning and reduction of ammonia slip.

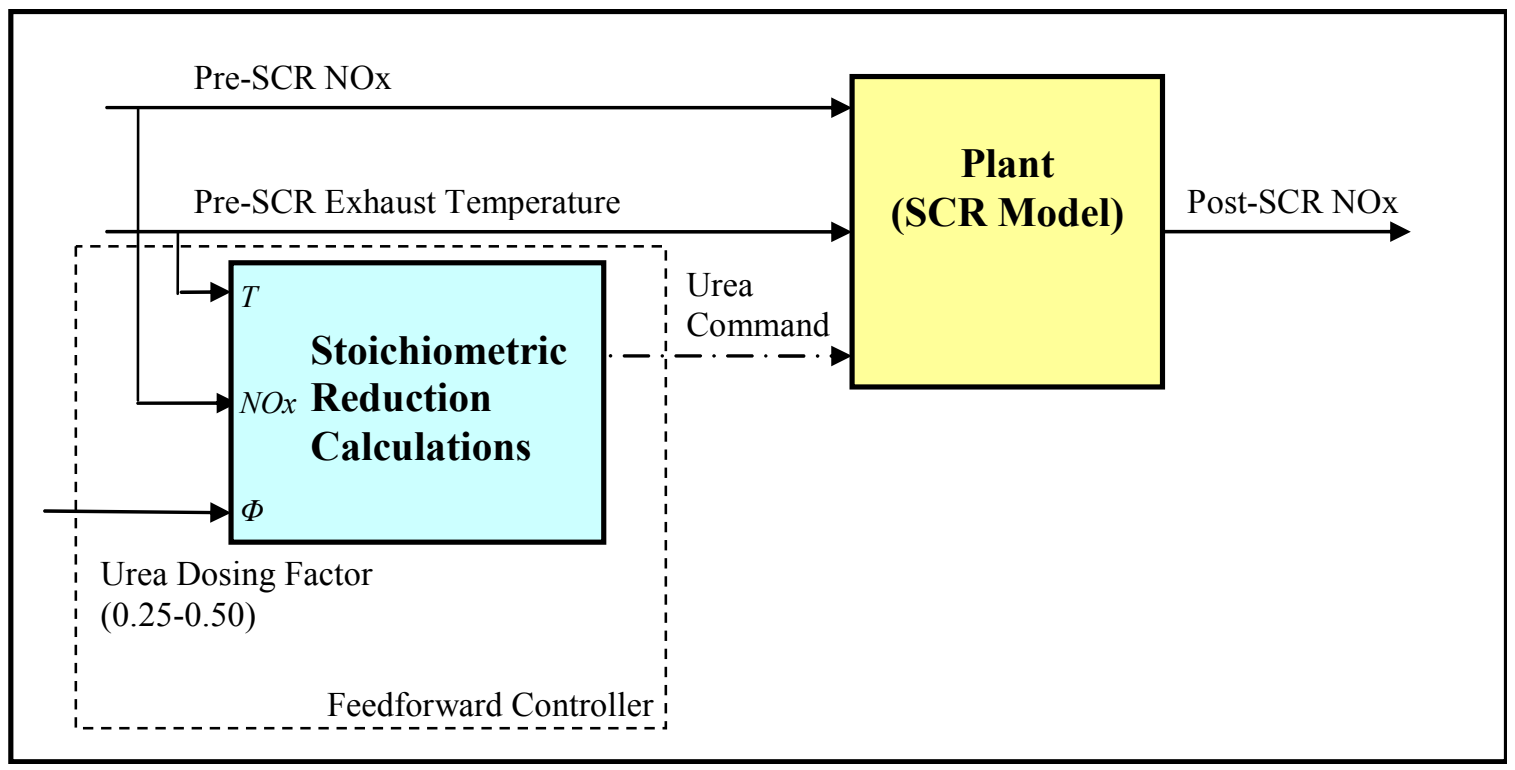

Figure 74. Pre-SCR NOx sensor, open-loop, feed-forward control diagram

A basic overview of the control logic employed in the open-loop feed-forward control configuration was presented in preceding sections. This included implementation of Equation 16 to convert measured NOx from concentration (ppm) to mass rate $(\mathrm{g} / \mathrm{s})$, Equation 15 to determine $\mathrm{NH}_{3}$ production, and Equation 9 to describe the NOx reaction chemistry. Little calibration effort was required. The only tuning parameter available was the urea dosing factor, which was varied to achieve different levels of NOx reduction and control ammonia slip. Originally, the control strategy targeted a 50\% NOx reduction, constrained by ammonia slip. Typically the potential for ammonia slip increased with NOx reduction, both of which could vary greatly with test cycle. As a result, the urea dosing factor had to be set depending on the application. In the experimental results section above, it was demonstrated that a urea dosing factor of 0.50 could be implemented with acceptable ammonia slip over the FTP and ACES test cycles. But a reduction to 0.25 was required over the steady-state ICOMIA cycle to circumvent unacceptable ( $\sim 400 \mathrm{ppm}$ peak, model) ammonia slip during the high load (and exhaust temperature) mode. 
Performance of the pre-SCR NOx sensor configuration with open-loop feed-forward control was detailed extensively in the SCR model validation section above. The validation results were presented considering the most accurate SCR catalyst model. Total NOx reductions of $43 \%, 42 \%$, and $58 \%$ were achieved by the open-loop feed-forward control strategy for the exact model case over the ICOMIA, FTP, and ACES HHDDT_S cycles, respectively. Total NOx reductions dropped to $38 \%, 41 \%$, and $55 \%$ for the ICOMIA, FTP, and ACES HHDDT_S cycles when utilizing an ideal model configuration. Additionally, large reductions in maximum and average ammonia slip were observed for the ideal model. Continuous NOx and $\mathrm{NH}_{3}$ slip for each test cycle using the exact model configuration are presented in Figure 75. It can be seen that ammonia slip occurred over the FTP during the cruise portions as a result of a sudden exhaust temperature increase. This proved to be the largest ammonia slip observed at $158 \mathrm{ppm}$; however a urea dosing factor of 0.5 was implemented over the FTP. Over the ACES HHDDT_S cycle, maximum ammonia slip of $21 \mathrm{ppm}$ occurred during a transient cruise portion of the cycle $(\approx 225 \mathrm{sec})$. Finally, maximum ammonia slip of $16 \mathrm{ppm}$ was observed over the ICOMIA test cycle during the high-load mode (mode 2). This level of ammonia slip still occurred, even with a urea dosing factor of 0.25 . As a result of the high exhaust temperature and instantaneous step change, the overall storage capacity of the SCR brick decreased as well as the conversion efficiency in general. In order to circumvent such ammonia slip, some method of temperature compensation or feed-back information should be included.

Mass flow rates were specified in the model validation section in order to compare raw model results with dilute experimental results. It was more appropriate to present all modeled ammonia slip values in terms of raw concentrations from here on, because of how the ammonia slip performance metrics were defined. Continuous results for the ideal model configuration can be seen in Figure 76.

In general, the open-loop feed-forward control strategy offered a reasonable NOx reduction over each test cycle. However, its biggest downfall was the inability to achieve such a reduction with acceptable ammonia slip and without modifying the urea dosing factor with test cycle. This type of an arrangement was clearly not feasible in a universal retrofit application; and if a constant urea dosing factor of 0.25 was utilized, meager reductions would be achieved over the FTP and ACES HHDDT_S cycles. As such, each subsequent control strategy strived to eliminate a cycle dependent calibration. 


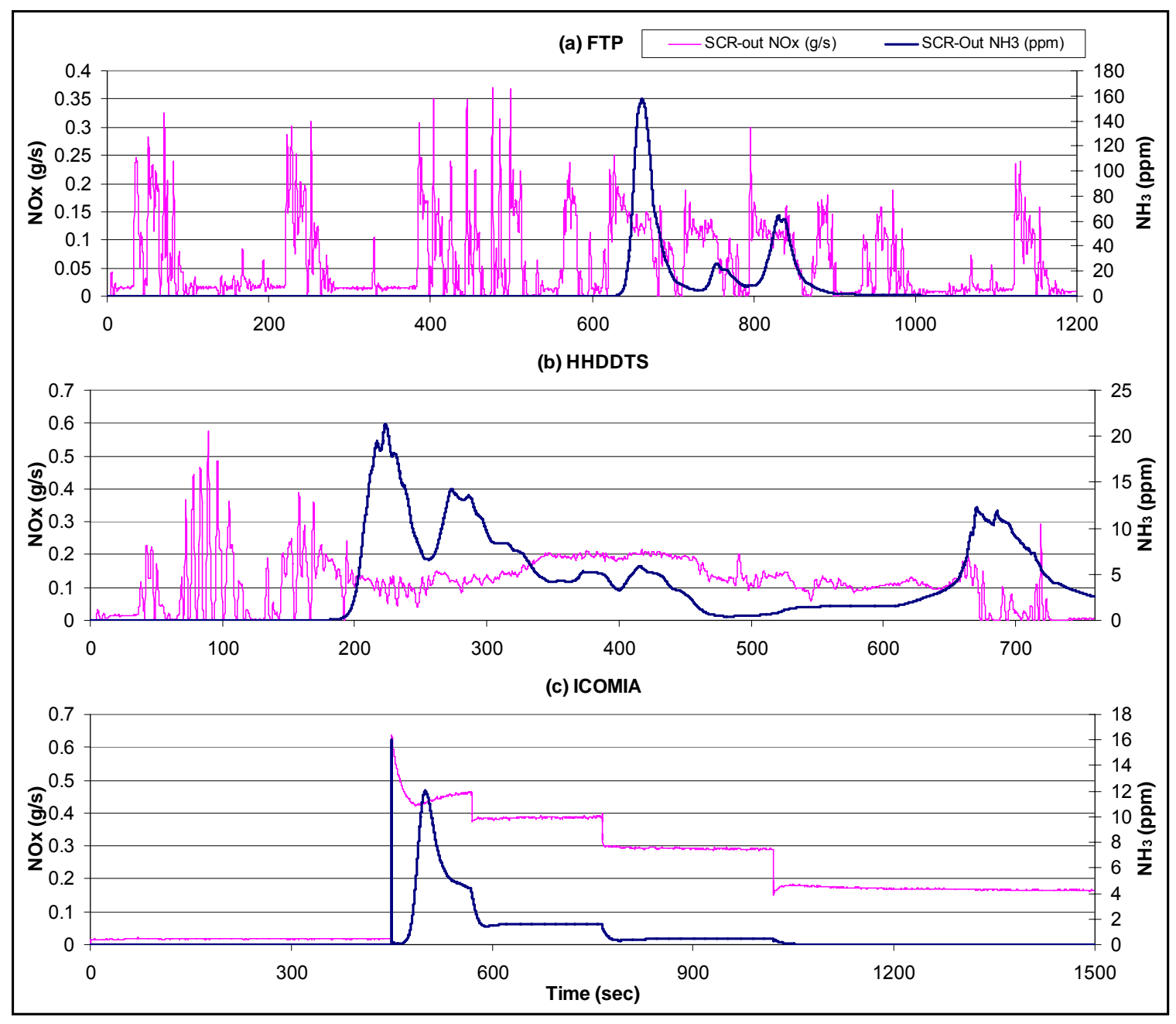

Figure 75. Configuration 1 exact, continuous $\mathrm{NOx}(\mathrm{g} / \mathrm{s})$ and $\mathrm{NH}_{3}$ (ppm): (a) FTP, (b) ACES HHDDT_S, (c) ICOMIA 


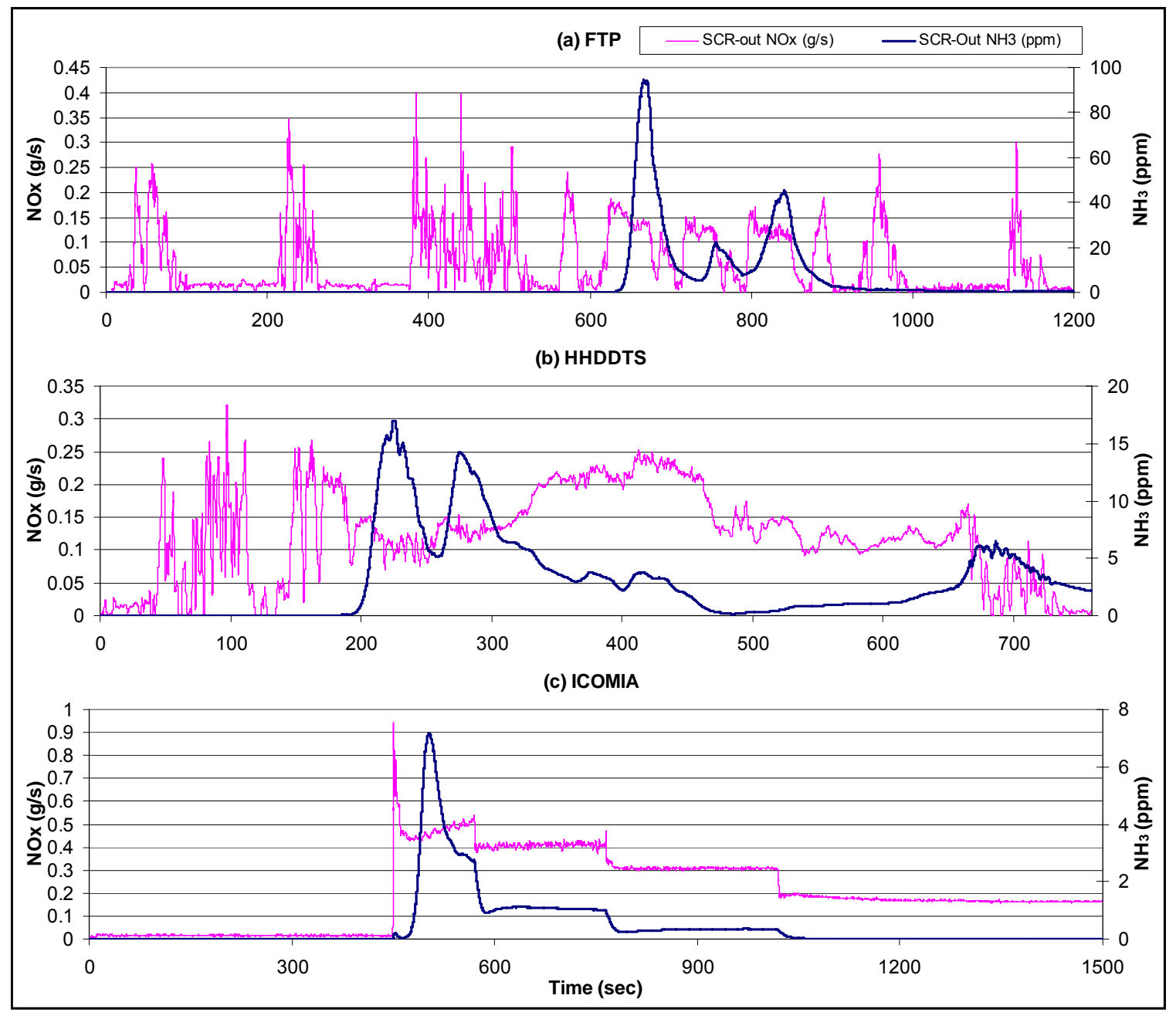

Figure 76. Configuration $1 \underline{\text { ideal }}$, continuous $\mathrm{NOx}(\mathrm{g} / \mathrm{s})$ and $\mathrm{NH}_{3}$ (ppm): (a) FTP, (b) ACES HHDDT_S, (c) ICOMIA

Willems et al. [51] make note that an open-loop, feed-forward strategy may be combined with model-based dynamic compensation, which considers the adsorption, desorption, and storage of $\mathrm{NH}_{3}$, in order to improve control, particularly during transient operation. This type of compensation is included below in Configuration 4.

\subsection{Control Strategy Targets: NOx Reduction and Ammonia Slip}

The emissions performance of each control strategy was evaluated using two criteria: NOx reduction and ammonia slip. In the modeling environment, total NOx emitted by the engine and exiting the SCR were calculated on an integrated mass basis over each test cycle (FTP, ICOMIA, ACES HHDDT_S). The overall NOx reduction was calculated as a percent difference between the engine-out and SCR-out total NOx (Equation 59). In subsequent discussions, this may be abbreviated as \%deNOx. 
$\%$ deNOx $=\left[\frac{N O x_{\text {engine }}-N O x_{S C R}}{N O x_{\text {engine }}}\right]$

Equation 59

Ammonia slip was quantified over a given test cycle according to the maximum and average concentrations emitted from the SCR catalyst. These values were specified in terms of concentrations, in units of ppm, and used as metrics to evaluate the overall ammonia slip performance of a given control configuration.

A major objective of the research was to determine an optimal control configuration to achieve a high level of NOx reduction with minimal ammonia slip. Because the original open-loop feed-forward strategy was simple and inexpensive, in order for any of the other configurations to be chosen as optimal, it would likely need to achieve a greater NOx reduction and/or lower ammonia slip. As a result, each control configuration was evaluated considering the NOx reduction and ammonia slip model results of the open-loop feedforward strategy (Table 41). Here, raw ammonia slip was presented and the total NOx reduction over the ICOMIA test cycle included unweighted totals.

Table 41. Original open-loop feed-forward model NOx reduction (\%) and ammonia slip (ppm) results

\begin{tabular}{|c|l|c|c|c|}
\hline \multicolumn{2}{|c|}{} & FTP & ACES HHDDTS & ICOMIA E5 \\
\hline \multicolumn{2}{|c|}{ Overall NOx Reduction [\%] } & 42 & 58 & 43 \\
\hline \multirow{2}{*}{$\begin{array}{c}\text { Ammonia Slip } \\
\text { [ppm }_{\text {raw }}\end{array}$} & Maximum & 158 & 21 & 16 \\
\cline { 2 - 5 } & Average & 7 & 4 & 1 \\
\hline
\end{tabular}

While the above ammonia slip values were considered as targets, a more universal 'acceptable' ammonia slip concentration can be defined in a number of ways. Currently, the EPA does not designate allowable ammonia slip; however estimates for allowable maximum and/or average raw ammonia slip concentration can be made from data provided in literature. Using a model-based feed-forward controller Schar et al. [50] achieved mean ammonia slip of 18-35 ppm over the so-called "warm-up test," an instantaneous low-to-high load step change. With open-loop, closed-loop, and model-based control strategies, Willems et al. [51] achieved ammonia slip performance of 3-9 ppm average and 15-91 ppm maximum over the ESC, and 1-3 ppm average and 33-48 ppm maximum over the ETC. Chi et al. [83] utilized a model-based controller to achieve ammonia slip of $<55 \mathrm{ppm}$ maximum and $<7 \mathrm{ppm}$ average over the FTP cycle. The material safety data sheet (MSDS) for commercial SCR-grade urea designated a number of exposure limits for ammonia. It was stated that no respiratory protection is required for continuous ammonia exposure to $<25 \mathrm{ppm}$ ammonia (8-hr time weighted average) and for $<50 \mathrm{ppm}$ if exposure time is less than 15 minutes [94]. Greater than $50 \mathrm{ppm}$, some type of filtration or respirator apparatus is required, with $300 \mathrm{ppm}$ being designated as the immediately dangerous to life and health (IDLH) limit [94]. 
It was desired that each control strategy achieve as good or better average and maximum ammonia slip performance compared to the open-loop feed-forward configuration. Additionally, it would be preferred if a given strategy could achieve $<25 \mathrm{ppm}$ average and $<50 \mathrm{ppm}$ maximum in order to avoid any possibility of human health impact (and to more or less match acceptable values in literature). Depending on test cycle, these concentrations may be greater than or less than the model performance of the original open-loop feedforward control strategy. The larger value for maximum and average ammonia slip was chosen as the minimum desired performance. This changed the ammonia slip target to $25 \mathrm{ppm}$ average for all test cycles and $50 \mathrm{ppm}$ maximum for all test cycles except the FTP, which remained at $158 \mathrm{ppm}$. Ammonia slip less than these thresholds were rewarded, while greater values were penalized. It should be noted that these raw ammonia slip targets are conservative. In actual implementation, ammonia slip would mix with ambient air, reducing the exposure concentration and its potential for negative human health impact.

A NOx reduction and ammonia slip reward and penalty procedure was applied to each evaluated control strategy. The overall NOx reduction, maximum ammonia slip, and average ammonia slip were each compared to the targets discussed in the above paragraph. For each test cycle, relative performance indices (RPIs) were determined for NOx reduction and ammonia slip based on the following equations. These expressions are essentially normalized difference equations with respect to the control targets. In this manner, if a given strategy exactly met the control targets, it received a relative performance index of zero. Any negative RPI values were considered worse and any positive RPI values were considered better.

$$
\begin{aligned}
& N O x_{R P I}=\frac{\% N O x_{-} r e d_{\text {strategy }-x}-\% N O x_{-} \text {red }_{\text {control_t } \operatorname{targ} \text { et }}}{\% N O x_{-} r e d_{\text {control_t } \arg e t}} \quad \text { Equation } 60
\end{aligned}
$$

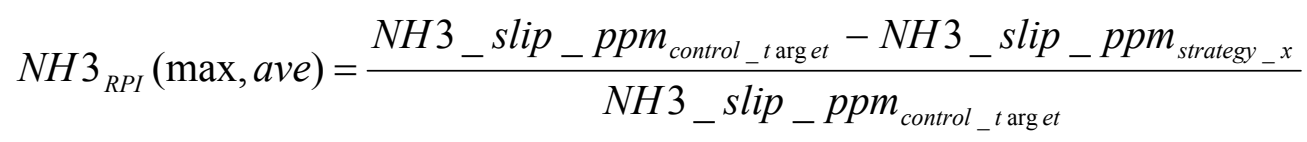

Equation 61

As a result of the distinctly different engine behavior of the FTP, ACES HHDDT_S, and ICOMIA E5, the RPI for each test cycle in each criterion was summed with equal weights. Each criterion (NOx reduction, maximum ammonia slip, average ammonia slip) however was given a separate weighting factor.

In order to determine how $\mathrm{NOx}$ and $\mathrm{NH}_{3}$ slip should be weighted, their impact on the environment and human health must be considered. The EPA designates NOx as a criteria air pollutant and a major pollutant along with $\mathrm{PM}_{10}$ and $\mathrm{PM}_{2.5}$ [95]. Additionally, $\mathrm{NH}_{3}$ has been shown to combine with nitrates and sulfates in the atmosphere to form secondary fine particulate matter (PM2.5) [96]. The National Fire Protection Association (NFPA) designates health (blue), flammability (red) and instability/reactivity (yellow) ratings to $\mathrm{NH}_{3}$ and $\mathrm{NOx}\left(\mathrm{NO}+\mathrm{NO}_{2}\right)$. The health ratings are of primary interest here. These ratings 
range from zero to four and are shown below to aid in determining appropriate weightings for NOx reduction and ammonia slip. Both $\mathrm{NOx}$ and $\mathrm{NH}_{3}$ received health ratings of three out of four [97].

Based on EPA designations, NFPA ratings, and general health and environmental impact information, NOx was considered the more important pollutant and thus given a higher weighting factor. However NOx and $\mathrm{NH}_{3}$ are still both considered to be hazardous, so only a mild NOx bias will be included in the weighting. Overall percent NOx reduction was weighted at 0.6 , while ammonia slip was weighted at 0.4. Average and maximum ammonia slip were further weighted, at 0.65 and 0.35 , respectively. A higher weight was placed on the average ammonia slip, because prolonged exposure would be most likely to cause human health issues rather than an intermittent spike. Additionally, if the spike became too high, its influence would cause a noticeable increase in average $\mathrm{NH}_{3}$. This resulted in final weights of $0.6,0.14$, and 0.26 for total NOx reduction, maximum ammonia slip, and average ammonia slip. Emissions performance evaluations for all control configurations along with their individual and final weighted RPIs can be seen in Table 44 .

\subsection{Confiquration 2: Post-SCR NOx Sensor, Closed-Loop Feed-Back Control}

The second configuration that was investigated involved moving the exhaust-mounted NOx sensor after the SCR catalyst as opposed to before it (see Figure 77). This type of configuration was not typically discussed in literature, except when engine ECU signals or NOx maps were implemented to infer the pre-SCR NOx concentration. However since this urea-SCR system was considered as stand-alone, an appropriate postSCR setpoint NOx concentration (ppm) had to be determined indirectly.

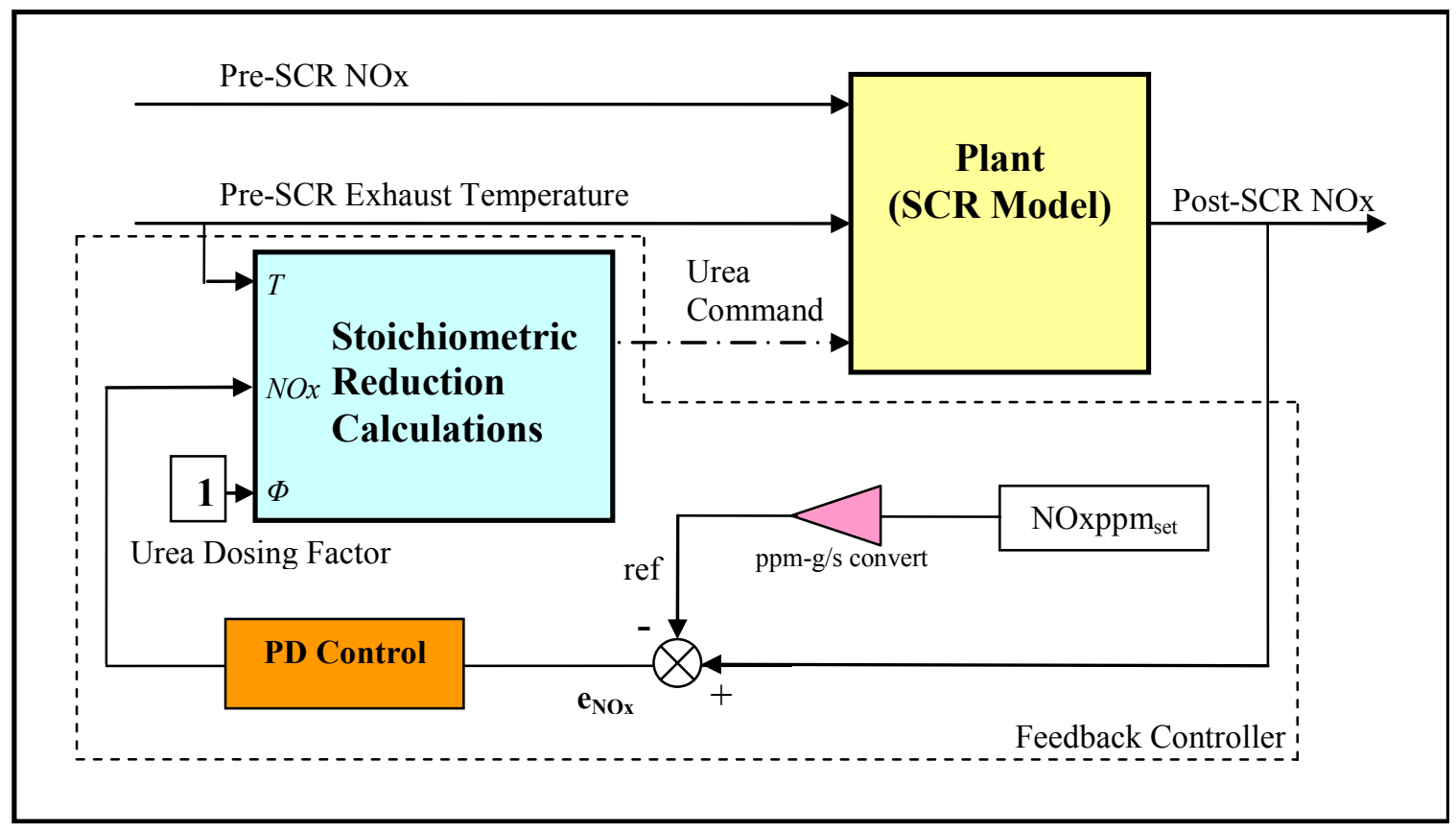

Figure 77. Post-SCR NOx sensor, feed-back PD control diagram 
Original development of the post-SCR control strategy relied on a constant setpoint NOx concentration. Setpoint NOx was specified as a concentration to include exhaust flow dependence. Different setpoint values were investigated for the FTP, ICOMIA, and ACES HHDDT_S cycles using the most accurate SCR model configuration. A constant setpoint of $500 \mathrm{ppm}$ resulted in marginal NOx reduction performance over all test cycles, with some spikes of high ammonia slip. By examining the NOx reduction and ammonia slip performance at $300 \mathrm{ppm}, 500 \mathrm{ppm}$, and $600 \mathrm{ppm}$ NOx setpoints, it was clear that a variable setpoint would be required to achieve an optimal balance of high NOx reduction and low ammonia slip over a variety of test cycles. This was demonstrated over the ICOMIA test cycle in particular. High ammonia slip (382 ppm) was produced only during the first transient step change, and an overall NOx reduction of $50 \%$ was achieved when utilizing a $500 \mathrm{ppm}$ setpoint concentration. When increasing the NOx setpoint to $600 \mathrm{ppm}$, the peak ammonia slip dropped to less than $70 \mathrm{ppm}$, but the overall NOx reduction decreased to $42 \%$ as well. Additionally, since lower load modes produce less NOx, a lower setpoint could easily be implemented without risking ammonia slip.

By implementing a variable setpoint NOx concentration, higher overall NOx reductions were achieved with lower ammonia slip. In the final post-SCR control configuration, setpoint NOx was varied continuously, according to exhaust temperature and degree of transience (DOT), which was determined by exhaust flow. Exhaust temperature was considered to be indicative of engine load, and consequently NOx concentration. Based on results using constant values, the setpoint NOx was varied linearly between 486 ppm and 680 ppm, corresponding to exhaust temperatures between 523 and $800 \mathrm{~K}$. The lower temperature limit of $523 \mathrm{~K}$ $\left(250^{\circ} \mathrm{C}\right)$ corresponded to the lowest temperature at which urea is injected. Any setpoint variation below this temperature had no effect since the urea injection threshold control overrode subsequent calculations, forcing the injector duty cycle to zero.

A transient correction factor was applied to the temperature dependent setpoint NOx concentration. During very steady operation, the setpoint NOx value could be further decreased without the risk of ammonia slip, which may be caused by quick NOx and temperature transients. Additionally, during very transient engine operation, the setpoint NOx could be increased to reduce the risk of ammonia slip. This type of mode switching operation was particularly useful for achieving higher NOx reductions during long periods of steady operation, such as marine, stationary, or on-road cruise cycles.

The DOT was determined by differentiating the exhaust flow rate and performing a 20 point average (smoothing). It should be noted that in the SCR modeling environment, one simulation point did not necessarily correspond to a one second time interval (maximum time step of $0.1 \mathrm{sec}$ ). The smoothing here was included to slow the frequency with which the setpoint NOx concentration varied, which could cause controllability problems. Depending on the DOT, the following correction factors were applied to increase or decrease the setpoint NOx concentration: 0.7 for DOT $<0.00035,0.85$ for $0.00035<\mathrm{DOT}<0.002,1.5$ for 
DOT $>0.002$. When combined with the temperature dependence, this allowed the setpoint NOx concentration to be varied continuously between 340 and $1020 \mathrm{ppm}$.

The corresponding setpoint and baseline NOx (engine-out, unknown to the post-SCR control strategy) over FTP and ICOMIA test cycles are presented in Figure 78, part (a) and (b), respectively. In particular, it can be seen that during the large step changes of the ICOMIA the setpoint NOx was briefly increased, thereby significantly reducing ammonia slip compared to the case of a constant setpoint concentration.

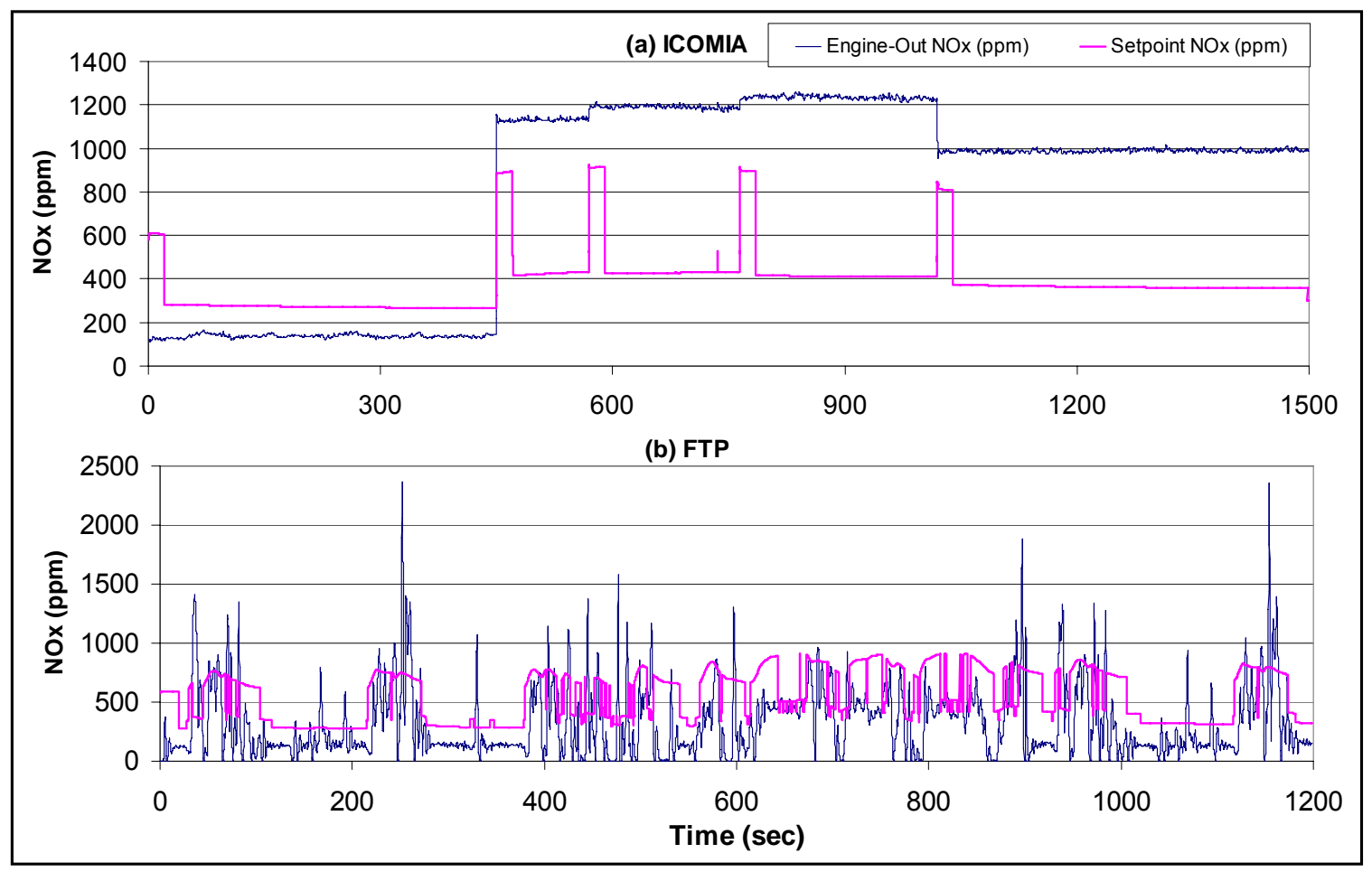

Figure 78. Post-SCR control configuration NOx setpoint (ppm): (a) ICOMIA, (b) FTP

To aid in reaching the desired setpoint post-SCR NOx concentration as quickly and accurately as possible, a PID control block was added to the control strategy. PID controllers are implemented in many engine and aftertreatment control schemes. More than half of all industrial controllers in use today implement some form of PID control [98]. In particular, when a simple mathematical model of the plant is not known, analytical controller design methods cannot be used and PID controls prove to be the most useful [98]. One downside of PID implementation is the tuning effort required, particularly when system behavior is complex and non-linear. This type of a situation existed in the urea-SCR system as a result of highly transient inlet conditions and the storage, adsorption, and desorption of $\mathrm{NH}_{3}$ by the catalyst. Typical PID controller tuning methods, such as Ziegler-Nichols rules [98], could not be easily implemented. For a system that is too complicated to develop a simple mathematical transfer function, experimental approaches must be applied to the PID controller tuning process [98]. Basic control actions and their effect on system 
response were used in this application to determine proportional, derivative, and integral gains. The rules shown in Table 42 were used as a guide throughout the PID tuning process. For example, if $K_{I}$ and $K_{D}$ were fixed, increasing $K_{P}$ alone would decrease rise time, increase overshoot, slightly increase settling time, decrease steady-state error, and decrease stability [99].

Table 42. Effects of independent $\mathrm{P}$, I, and D tuning on closed-loop response [99]

\begin{tabular}{|l|c|c|c|c|c|}
\hline & Rise Time & Overshoot & Settling Time & Steady-State Error & Stability \\
\hline Increasing $K_{\mathrm{P}}$ & Decrease & Increase & Small Increase & Decrease & Degrade \\
\hline Increasing $\mathrm{K}_{\mathrm{I}}$ & Small Decrease & Increase & Increase & Large Decrease & Degrade \\
\hline Increasing $\mathrm{K}_{\mathrm{D}}$ & Small Decrease & Decrease & Decrease & Minor Change & Improve \\
\hline
\end{tabular}

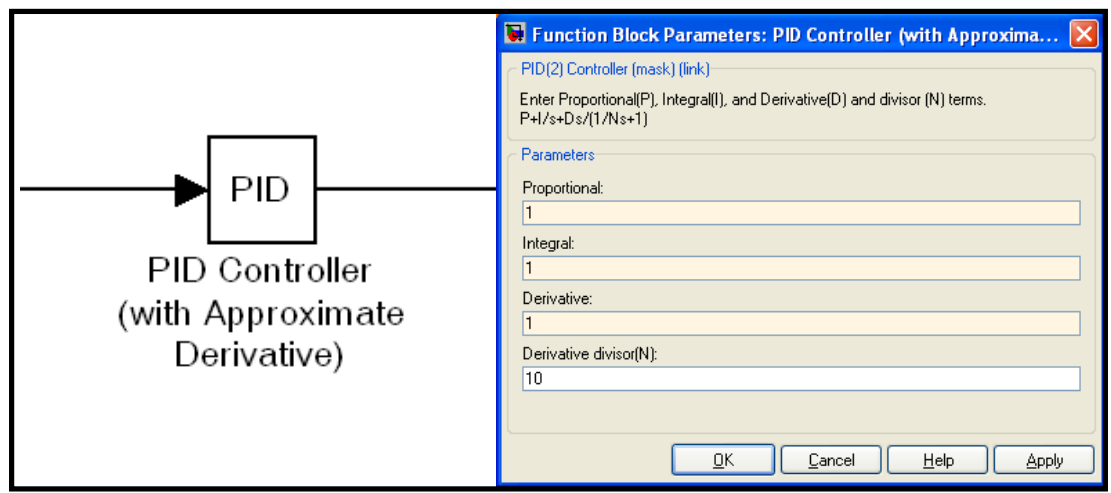

Figure 79. Simulink PID block and parameters

PID control was implemented through Matlab/Simulink using an existing function block (Figure 79). Additionally, a block with an approximate derivative was used in order to avoid singularities during transients. The derivative approximation (shown in the s-domain in Equation 62) allowed computation over a wider interval, where $\mathrm{N}$ dictated the number of points to be used. As $\mathrm{N} \rightarrow 0$, the approximate derivative becomes equal to the exact expression. Here a value of $\mathrm{N}=10$ was used, which avoided singularities at the ICOMIA step changes.

$\frac{K_{D} s}{\left[\frac{1}{N S+1}\right]} \approx K_{D} S$

Equation 62

Within the PID block, separate gains were adjusted for proportional, integral, and derivative components. Initially, all gains were set to one. In order to evaluate how the system responds to different PID control adjustments, a step change input was used. It was desired to have a step change where urea was injected at the low and high load modes so that the catalyst was at least partially loaded with $\mathrm{NH}_{3}$ once the step occurs. 
One problem with observing system response during the PID tuning process involved the sudden adsorption and desorption of urea and its subsequent effect on output NOx. The step change input was created based on the final and second ICOMIA modes, each with increased duration to allow sufficient settling and stabilization time. After initial settings were determined using the step change input, the complete FTP, ACES HHDDT_S, and ICOMIA modes were implemented to determine final PID gains.

Emphasis was placed on minimizing overshoot and steady-state error, while still achieving acceptable settling time. Large overshoot in particular could cause problems with ammonia slip by momentarily overdosing urea. Additionally, steady-state error had to be minimized in order to achieve the desired reduction and avoid ammonia slip (depending on if error was positive or negative). While exact control targets were not specified, NOx reduction and ammonia slip targets was considered over different test cycles, shown in Table 41 above.

Because of the nature of the NOx setpoint when implementing this type of feed-back control, negative error often arose when implementing any significant integral gain. This occurred in particular during idle operation. As a result, when the NOx transitioned above the setpoint and positive error occurred, it caused a delay in time until urea injection. This behavior is demonstrated in Figure 80 below.

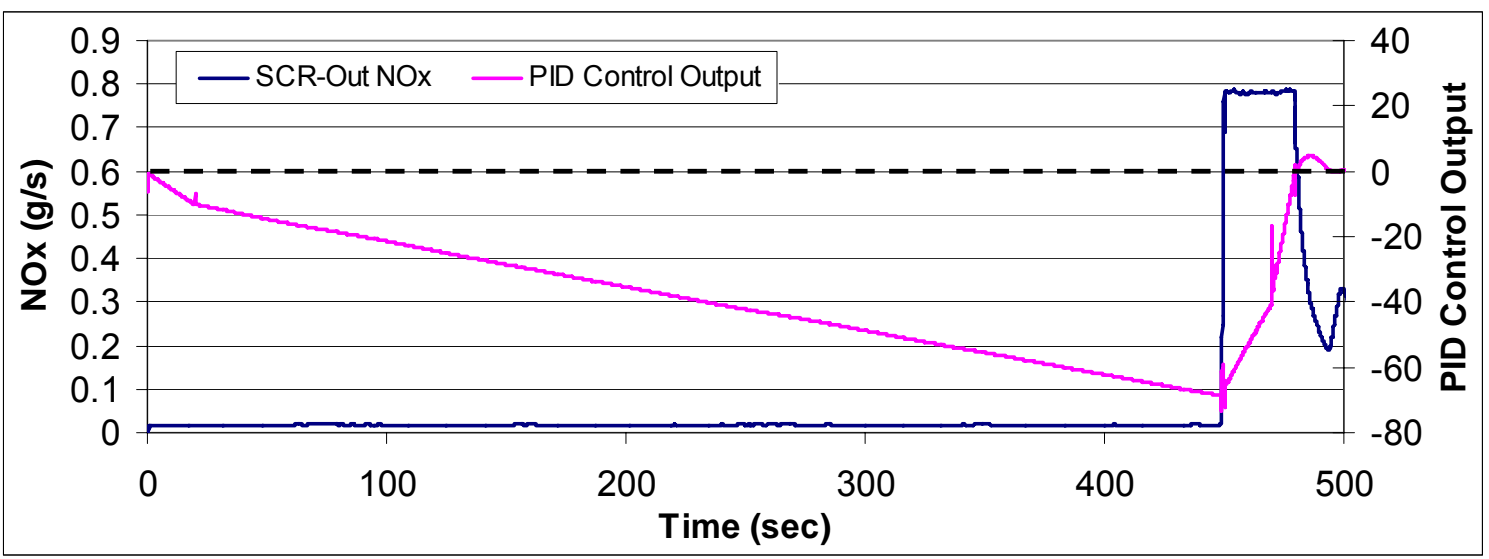

Figure 80. Integral gain injection delay effect

As a result of injection delay, the integral gain here was set to zero. This configuration (PD control) allowed better control of the system for a post-SCR NOx sensor. Subsequently, the derivative and integral gains were adjusted using PID tuning rules and considering NOx and ammonia slip targets. In almost every case, unacceptable maximum ammonia slip was the limiting variable. For all calibration and demonstration of the post-SCR control strategy, the urea dosing factor was set to one and only the PD gains were used for tuning. The continuous $\mathrm{NOx}$ and $\mathrm{NH}_{3}$ results for each test cycle and level of idealization are presented in Figure 81 and Figure 82, respectively. The total $\mathrm{NOx}$, maximum $\mathrm{NH}_{3}$, and average $\mathrm{NH}_{3}$ for each cycle and model configuration are presented in the control strategy evaluation section, Table 44. 
Based on the continuous emissions results below, it was clear that ammonia slip over the steady-state ICOMIA mode limited how the control configuration could be calibrated. The largest amount of slip occurred at the midpoint of the high-load ICOMIA mode. This point of high ammonia slip was caused by very high exhaust temperatures, which diminished the storage capacity and catalyst efficiency. By using a variable setpoint which was varied with flow rate transience, a large ammonia slip spike was avoided at the first step change $(\approx 450 \mathrm{sec})$. As a result of fairly high proportional and derivative gains, the PID controller was able to rapidly bring the NOx to the new desired setpoint after reaching steady operation (see Figure 81). Additionally, the high gains allowed this control strategy to respond to transient operation without creating oscillatory NOx reduction/ammonia slip behavior.

The locations of the ammonia slip spikes, particularly for the exact model case, were nearly equivalent to the results for the open-loop feed-forward control strategy. For the FTP, this included the three cruise portions between 600 and 1000 seconds, for the ACES HHDDT_S it included a transient portion around 225 seconds, and for the ICOMIA included the second high-load mode. While their locations were nearly equal, the magnitude of ammonia slip was generally less for the post-SCR NOx sensor configuration. The exception to this was for the second ICOMIA mode, however it should be noted that much greater than a $50 \%$ NOx reduction was being achieved over the second mode for the post-SCR NOx sensor configuration $(\approx 0.35 \mathrm{~g} / \mathrm{s}$ NOx vs. $\approx 0.5 \mathrm{~g} / \mathrm{s}$ NOx $)$.

The exact model case achieved total NOx reductions of $55 \%, 26 \%$, and $46 \%$ over the ICOMIA, FTP, and ACES HHDDT_S cycles, respectively. The ideal model case achieved total NOx reductions of 54\%, 23\%, and $43 \%$ over the ICOMIA, FTP, and ACES HHDDT_S cycles, respectively. Comparing results between the exact and ideal model cases showed a small decrease in overall NOx reduction over each mode, but a substantial reduction in ammonia slip. This was primarily a result of using diffused, delayed, and/or smoothed sensor inputs, with the largest difference caused by eliminating the NOx sharpening. This technique, while an excellent way of reconstructing true NOx emissions, introduced transients that proved too rapid to follow exactly with urea dosing. The inability to follow such transients was primarily a result of slow catalyst dynamics, $\mathrm{NH}_{3}$ adsorption/desorption and, in actual implementation, urea injection delay. Additionally, the NOx sharpening technique often resulted in larger NOx spike magnitudes, which could cause over-dosing of urea and lead to considerable ammonia slip. 


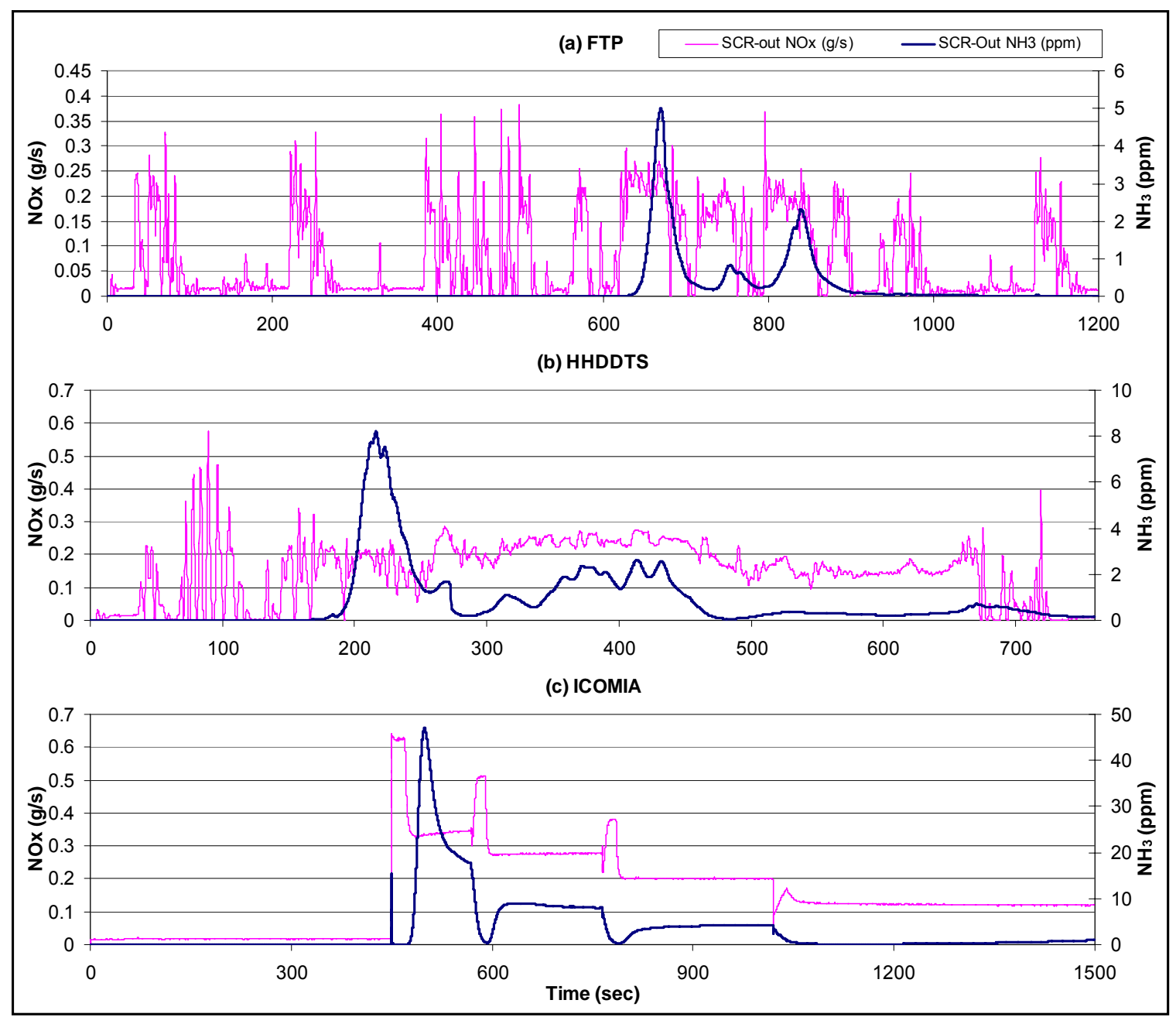

Figure 81. Configuration 2 exact, continuous $\mathrm{NOx}(\mathrm{g} / \mathrm{s})$ and $\mathrm{NH}_{3}$ (ppm): (a) FTP, (b) ACES HHDDT_S, (c) ICOMIA 


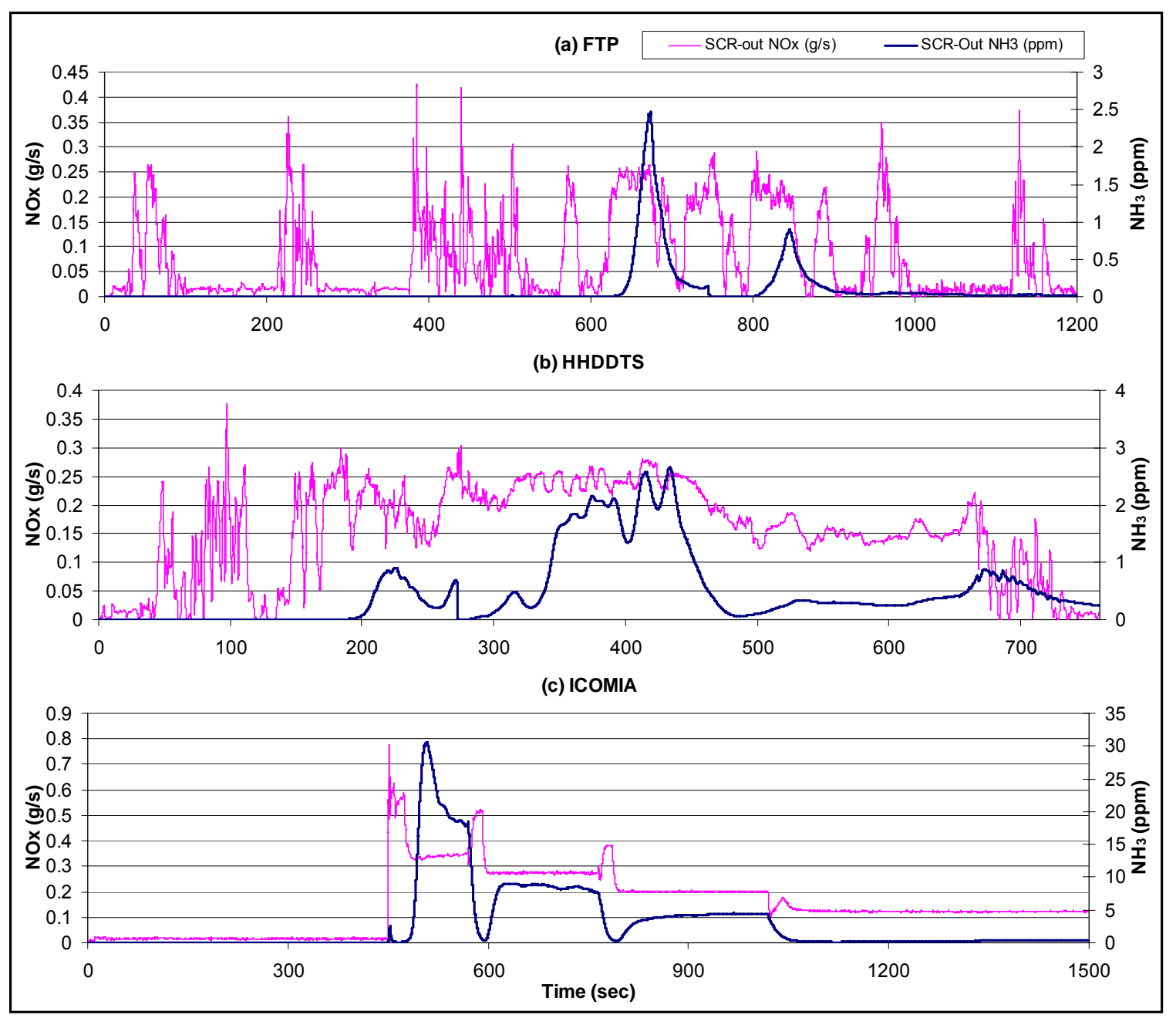

Figure 82. Configuration $2 \underline{\mathrm{ideal}}$ continuous $\mathrm{NOx}$ (g/s) and $\mathrm{NH}_{3}$ (ppm): (a) FTP, (b) ACES HHDDT_S, (c) ICOMIA 


\subsection{Configuration 3: Pre- and Post-SCR NOx Sensors, Closed-Loop Feed-Back Control}

Next, a configuration implementing both pre- and post-SCR NOx sensors was considered. This configuration, shown in Figure 83, included a classical closed-loop PID control strategy. The same stoichiometric reduction calculations from configuration 1 and 2 were implemented here to determine appropriate urea dosing (injector duty cycle) according to NOx error. The urea dosing factor was set to 1 . A desired NOx reduction was specified, typically constrained by ammonia slip.

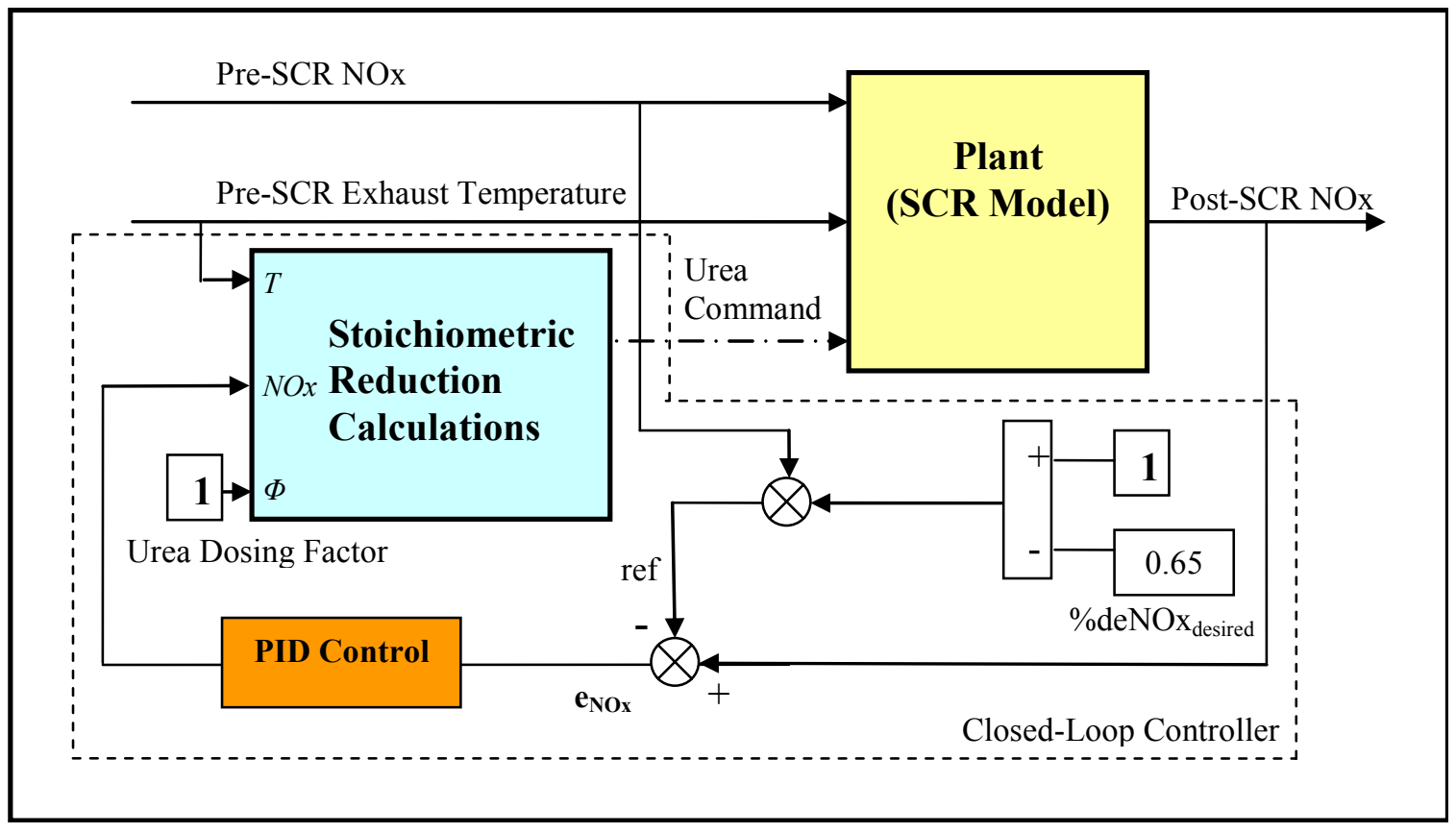

Figure 83. Pre- and post-SCR NOx sensors, closed-loop feed-back control diagram

Based on engine-out and SCR-out NOx (g/s), the NOx error was defined as follows.

$e_{N O x}=N O x_{\text {scr-out }}-\left[N O x_{\text {eng-out }} \cdot\left(1-\%\right.\right.$ deNOx $\left.\left.x_{\text {desired }}\right)\right] \quad$ Equation 63

In this manner, zero error implied that the desired reduction was exactly being achieved; positive error implied that the desired reduction had not been achieved and the injection rate must be increased; negative error implied that greater than the desired reduction had been achieved and the injection rate must be decreased to avoid ammonia slip. Because of the way in which the NOx setpoint and error were defined in this configuration, sustained portions of negative error were not seen as in configuration 2. As a result, the PID controller was able to be tuned considering proportional, derivative, and integral gains. This helped in particular to eliminate steady-state error. 
Again, the PID controller was tuned considering basic response rules (Table 42) and emissions targets. In a manner similar to configuration 2, proportional, integral, and derivative gains were initially all set to 1 , and a step input was applied. The desired NOx reduction was set to $50 \%$ for the PID tuning process. The PID gains were then varied until desired system response characteristics were observed. Again, the storage, adsorption, and desorption of $\mathrm{NH}_{3}$ proved to make the PID tuning process difficult. Once initial gain values were determined using the step input, FTP, ACES HHDDT_S, and ICOMIA test cycles were implemented to tune the controller for desired NOx reduction and ammonia slip targets. Once appropriate proportional, integral, and derivative gains were determined, the desired reduction could be increased to $55 \%$ with acceptable ammonia slip. In this instance in particular, the magnitude of the gains had to be kept small in order to avoid rapid increases in urea injection which lead to significant ammonia slip. During steady-state operation, this often caused an increase in rise time (time for NOx decrease, see ICOMIA Mode 2), but avoided overshoot, which was a contributor to ammonia slip. In actual steady operation, the mode lengths would likely be even greater, eliminating issues with a longer rise time.

In general, the pre- and post-SCR NOx sensor configuration allowed much more consistent NOx reduction and ammonia slip over each test cycle. For the exact model, total NOx reductions of 53\%, 44\%, and $47 \%$ were achieved over ICOMIA, FTP, and ACES HHDDT_S cycles, respectively. Additionally, ammonia slip performance was better than the open-loop feed-forward case for all test cycles. The maximum ammonia slip (113 ppm) was observed over the FTP cycle, which limited calibration of the controller. The maximum peak was one of three which occurred over the cruise portion between 800 and 900 seconds. Again, this was the portion of the FTP which ammonia slip most often occurred, regardless of control strategy. Very low ammonia slip was observed over the ACES HHDDT_S and ICOMIA cycles. Interestingly, the location of maximum ammonia slip during the ICOMIA cycle was during the final mode. Compared to the ammonia slip observed for configuration 1 and 2, nearly zero ammonia slip was observed over the second, high-load mode. One reason for this in particular was that the urea dosing was slowly increased, without overshoot. However because of its short duration, the setpoint was not reached until near the end of the mode. Additionally, only a 55\% reduction was being requested, unlike the higher reduction demanded by configuration 2.

Although the pre- and post-SCR NOx sensor control strategy did not quite achieve the level of reduction seen by the feed-forward case over the ACES HHDDT_S, it achieved more consistent reductions and less ammonia slip. By incorporating two NOx sensors, this control strategy was able to adapt to different types of engine behavior well. This was particularly demonstrated by the consistent reductions for the exact and ideal model cases. In this case, the pre- and post-SCR NOx sensor control strategy actually achieved a higher reduction over each test cycle and lower ammonia slip for the ideal model case. NOx reductions of 53\%, 44\%, and 47\% were achieved over ICOMIA, FTP, and ACES HHDDT_S cycles, respectively. 
Because of the addition of a second expensive NOx sensor, the cost and complexity of configuration 3 must be carefully considered.

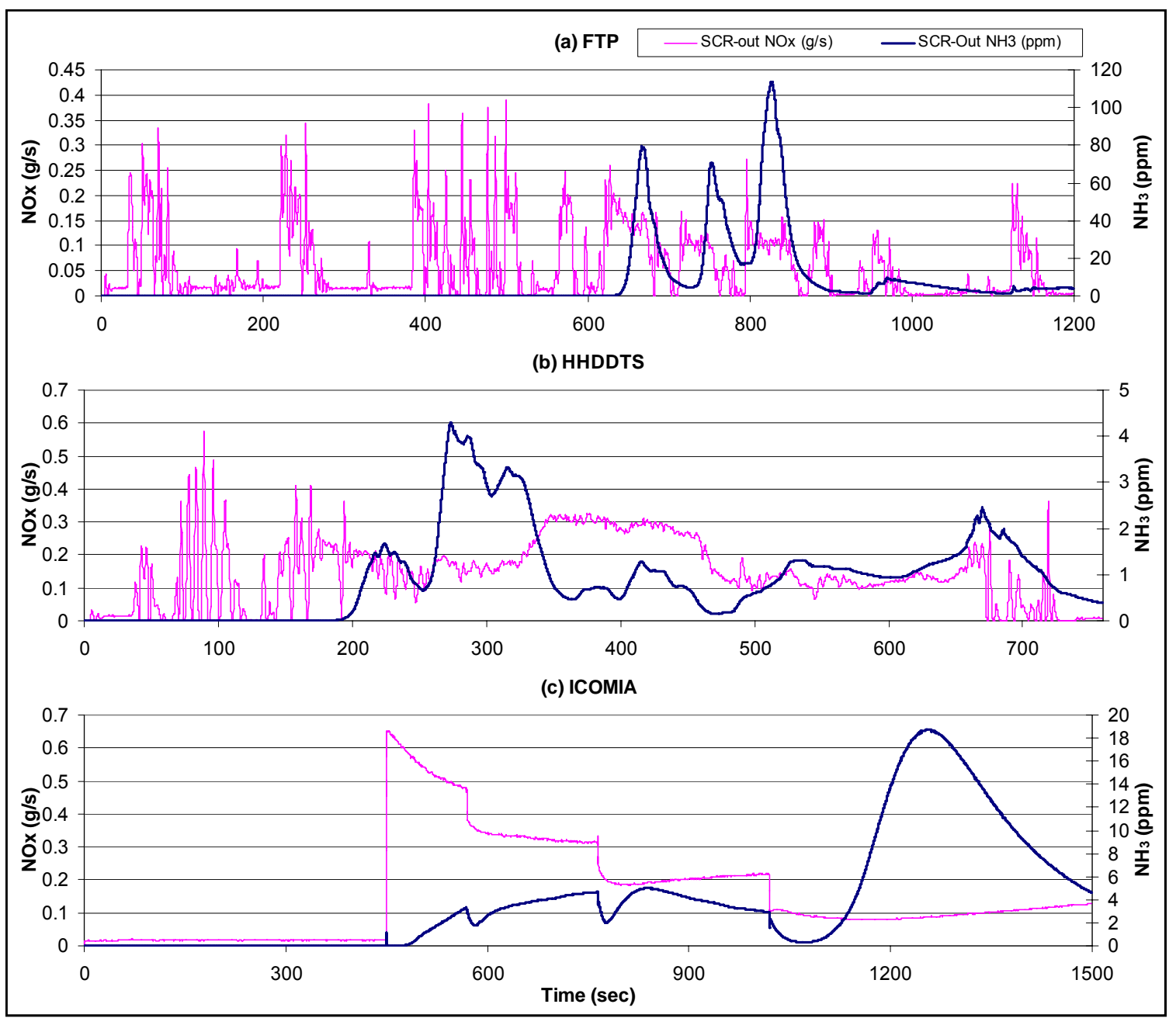

Figure 84. Configuration 3 exact, continuous $\mathrm{NOx}(\mathrm{g} / \mathrm{s})$ and $\mathrm{NH}_{3}$ (ppm): (a) FTP, (b) ACES HHDDT_S, (c) ICOMIA 


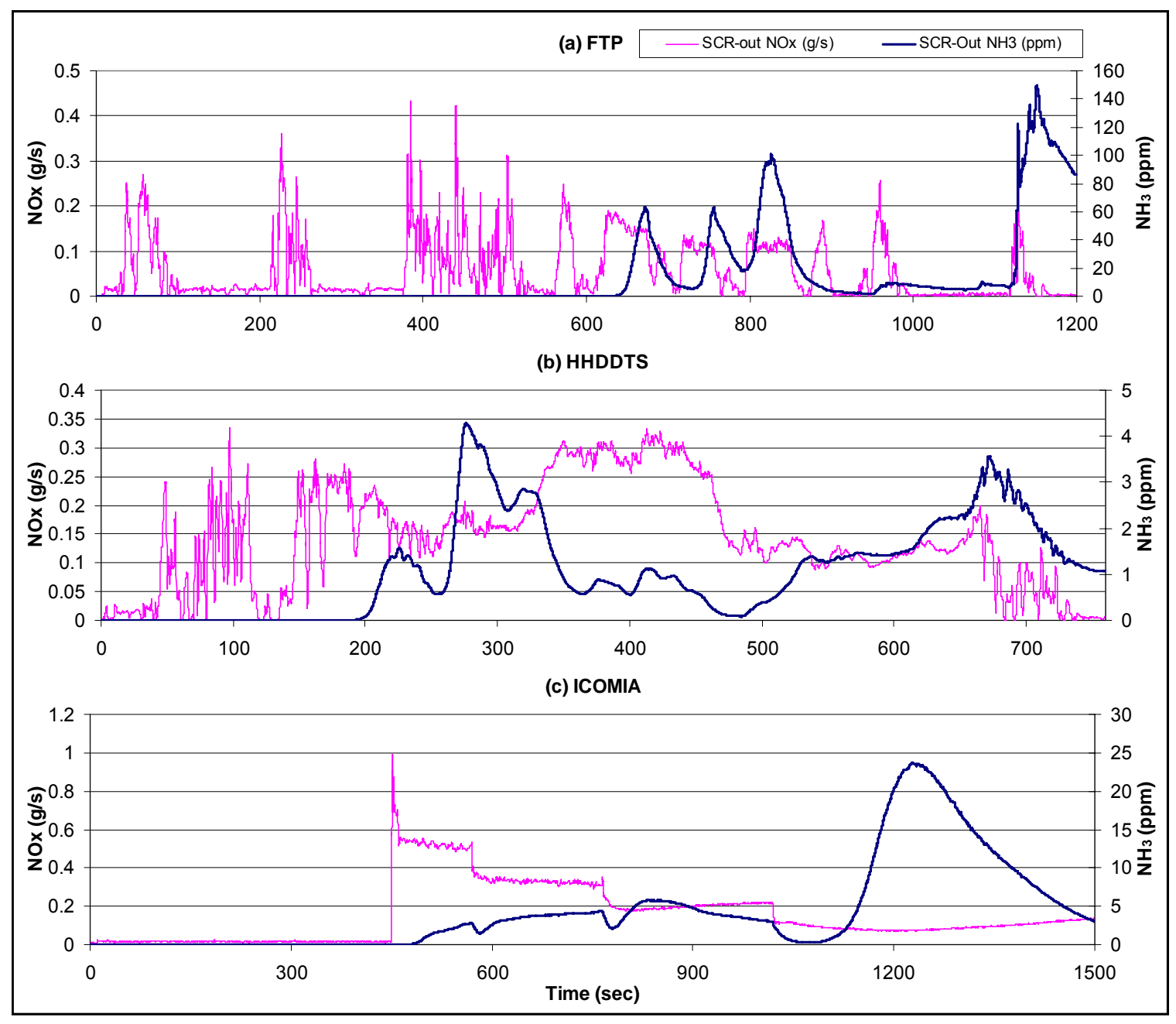

Figure 85. Configuration $3 \underline{\text { ideal }}$, continuous $\mathrm{NOx}(\mathrm{g} / \mathrm{s})$ and $\mathrm{NH}_{3}$ (ppm): (a) FTP, (b) ACES HHDDT_S, (c) ICOMIA 


\subsection{Configuration 4: Pre-SCR NOx Sensor, Open-Loop Model-Based Control}

The final configuration considered a form of model-based control. In literature, it was stated that surface coverage control offered the best solution to preventing ammonia slip spikes [51]. Considering this and other model-based approaches [50-53,67,83-85], a surface coverage-based control strategy was developed. This strategy still implemented the same stoichiometric reduction calculations; however they were augmented by a variable storage dynamic compensation block. This block continuously adjusted the urea dosing factor depending on exhaust temperature and $\mathrm{NH}_{3}$ storage within the SCR brick.

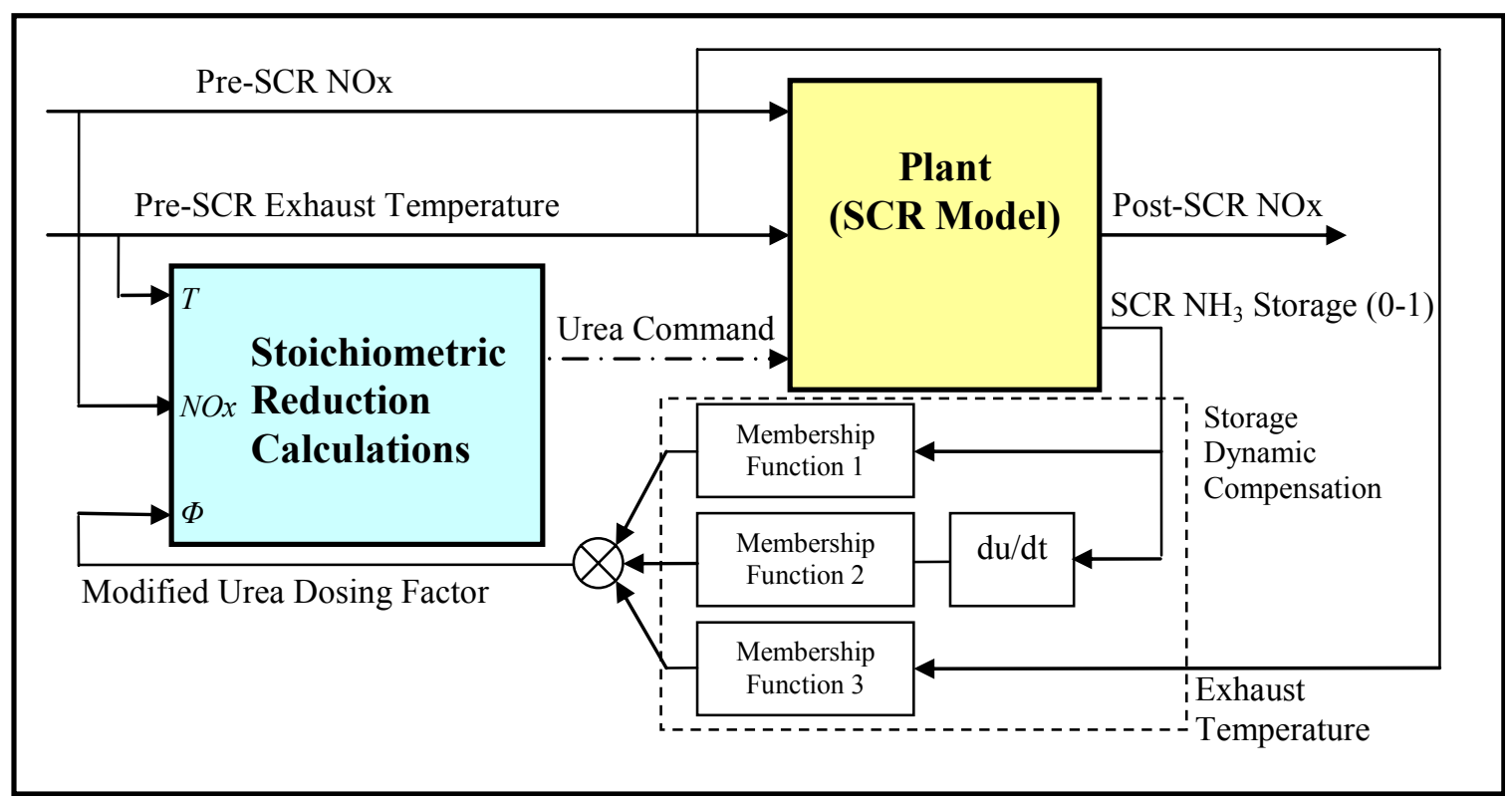

Figure 86. Pre-SCR NOx sensor, model-based control diagram

The storage dynamic compensation block implemented a fuzzy-logic approach with three membership functions. First, urea dosing must be decreased at high exhaust temperatures because the total storage capacity of the brick diminishes as temperature increases. As a result, if the brick capacity drops below the current amount of $\mathrm{NH}_{3}$ stored, the difference is desorbed regardless of urea dosing control. This is a condition that can easily lead to ammonia slip and should be avoided. Membership function 3 was used to decrease the urea dosing at high temperatures according to Figure 87 (a). Additionally, some reduction was also used at very low temperatures $\left(250-300{ }^{\circ} \mathrm{C}\right)$, where SCR reaction rates may be slow, limiting NOx reduction and increasing the potential for ammonia slip. The thresholds for each membership function were determined through experimentation and observation in the modeling environment over multiple test cycles. 


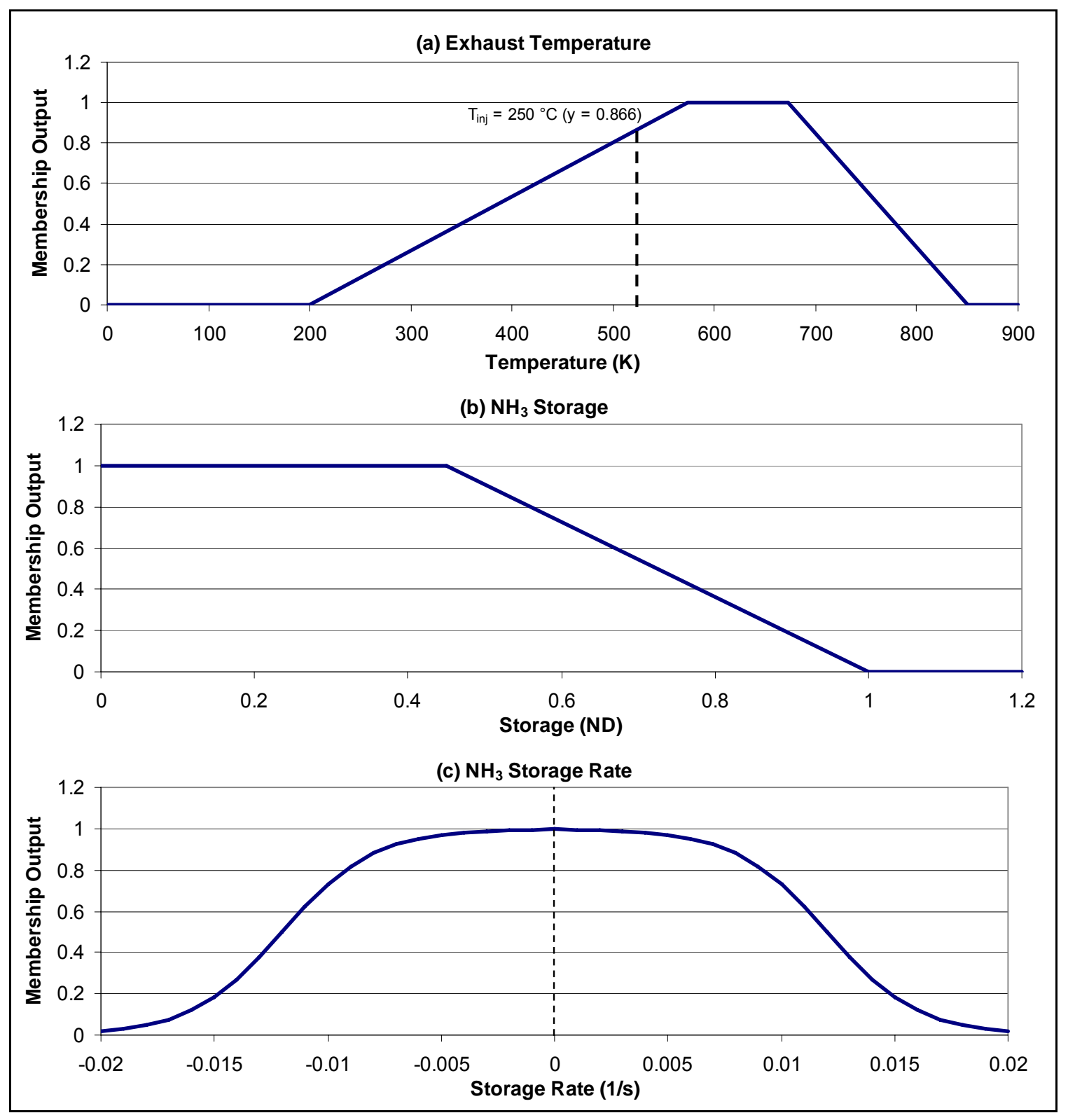

Figure 87. Membership functions (a) exhaust temperature (K), (b) $\mathrm{NH}_{3}$ storage, (c) $\mathrm{NH}_{3}$ storage rate

The model-based portion of the control strategy was only based on the first partition of the SCR brick because that was where the most $\mathrm{NH}_{3}$ storage occurred (see Figure 63, model storage results) and it was sufficient to predict ammonia slip. Additionally, using a single SCR partition would allow simpler implementation in a controller, and reduced development and tuning effort. During development and testing of the model based control strategy, three storage conditions were identified that could lead to significant ammonia slip: (1) the SCR brick became completely full and urea continued to be injected, (2) the rate of desorption exceeded a certain threshold, (3) the rate of adsorption exceeded a certain threshold. If desorption occurred very quickly, more $\mathrm{NH}_{3}$ would be present in the exhaust than could be consumed by $\mathrm{NOx}$, leading to $\mathrm{NH}_{3}$ exiting the exhaust pipe. If adsorption occurred very quickly, it was likely a result of 
a very large urea injection. The rate of $\mathrm{NH}_{3}$ adsorption on the $\mathrm{SCR}$ brick is limited by the chemical kinetics of the adsorption process and thus is finite. If the rate of adsorption became sufficiently high, it was likely that not all of the injected $\mathrm{NH}_{3}$ would be adsorbed or consumed by NOx prior to exiting the SCR catalyst, leading to ammonia slip.

Membership functions for total $\mathrm{NH}_{3}$ storage and rate of $\mathrm{NH}_{3}$ storage were included to adjust the urea dosing factor along with the temperature compensation. Through testing, it was observed that significant ammonia slip occurred at the absolute value of approximately the same adsorption (positive) and desorption (negative) rate $(0.01 \mathrm{1} / \mathrm{s}$, derivative of dimensionless storage). The adsorption/desorption rate and ammonia slip can be seen together for the ACES HHDDT_S cycle in Figure 88 below. It can also be seen that there exists a delay between the large desorption spike and maximum tailpipe ammonia slip spike. The final membership functions for total $\mathrm{NH}_{3}$ storage and adsorption/desorption rate can be seen above in Figure 87 (b) and (c), respectively.

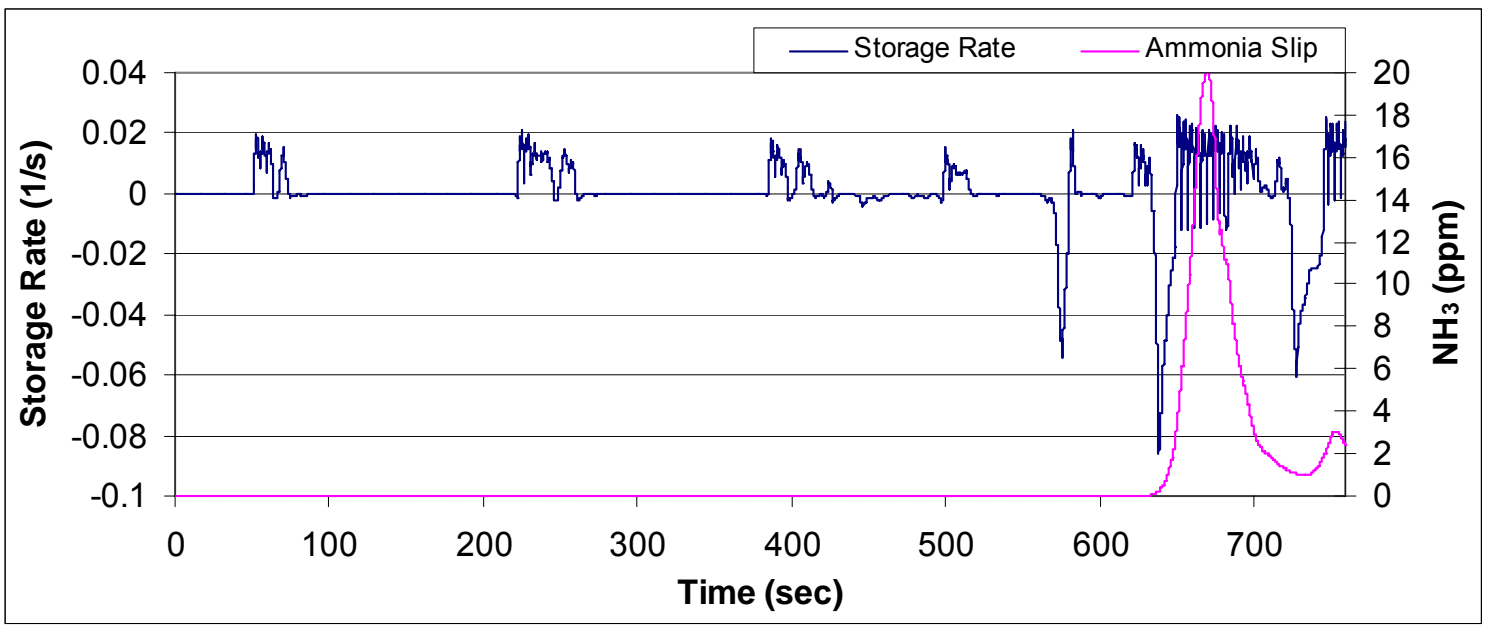

Figure 88. $\mathrm{NH}_{3}$ storage rates, configuration 4, ACES HHDDT_S

In general, the model-based strategy allowed excellent control of ammonia slip $(<25 \mathrm{ppm})$ over transient test cycles (FTP, ACES HHDDT_S). However, reasonably high ammonia slip (62 ppm) was still observed over the second ICOMIA mode. This was the same location as for configurations 1 and 2, and occurred as a result of the requested NOx reduction, high-temperature efficiency of the catalyst and $\mathrm{NH}_{3}$ storage. Additionally, higher reductions over the transient test cycles are clearly possible, but limited by steady-state ammonia slip. The model-based control strategy achieved 57\%, 32\%, and 46\% NOx reductions for the exact model case over the ICOMIA, FTP, and ACES HHDDT_S cycles, respectively. When utilizing the ideal model case, ammonia slip over each cycle was significantly reduced. Overall NOx reductions were slightly reduced for the ideal model, dropping to $53 \%$ and $44 \%$ over ICOMIA and ACES HHDDT_S cycles, but remaining at $32 \%$ over the FTP. Additionally, the ammonia slip and NOx reduction plots over 
the ICOMIA differed greatly, particularly over the second mode. As a result of the ANN NOx predictions, the control strategy decreased and increased injection for the ideal model case in accordance with the adsorption and desorption rates observed. These rates were clearly higher for the ideal model and of sufficient magnitude to halt injection before high ammonia slip occurred. All controller and model settings remained the same between the exact and ideal model cases.

One consequence of this type of control strategy is the possible introduction of oscillatory NOx reduction and ammonia slip behavior (see Figure 89 (b)). While these oscillations are not high frequency or detrimental to overall performance, in some instances they can create unusual $\mathrm{NOx} / \mathrm{NH}_{3}$ traces. A final emissions comparison for all of the control configurations as well as detailed cost and complexity analyses can be seen in subsequent sections.

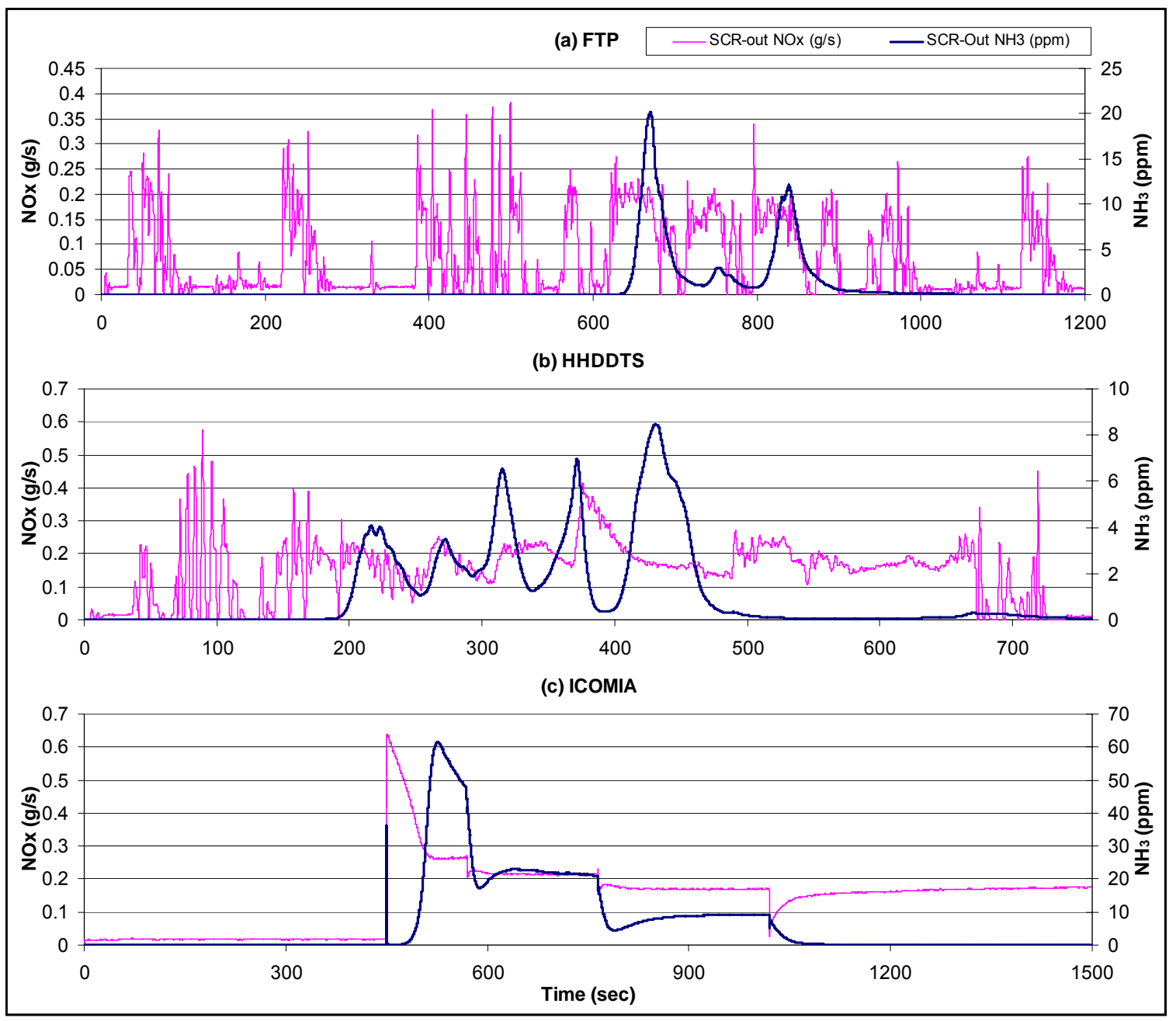

Figure 89. Configuration 4 exact, continuous $\mathrm{NOx}(\mathrm{g} / \mathrm{s})$ and $\mathrm{NH}_{3}(\mathrm{ppm})$ : (a) FTP, (b) ACES HHDDT_S, (c) ICOMIA 


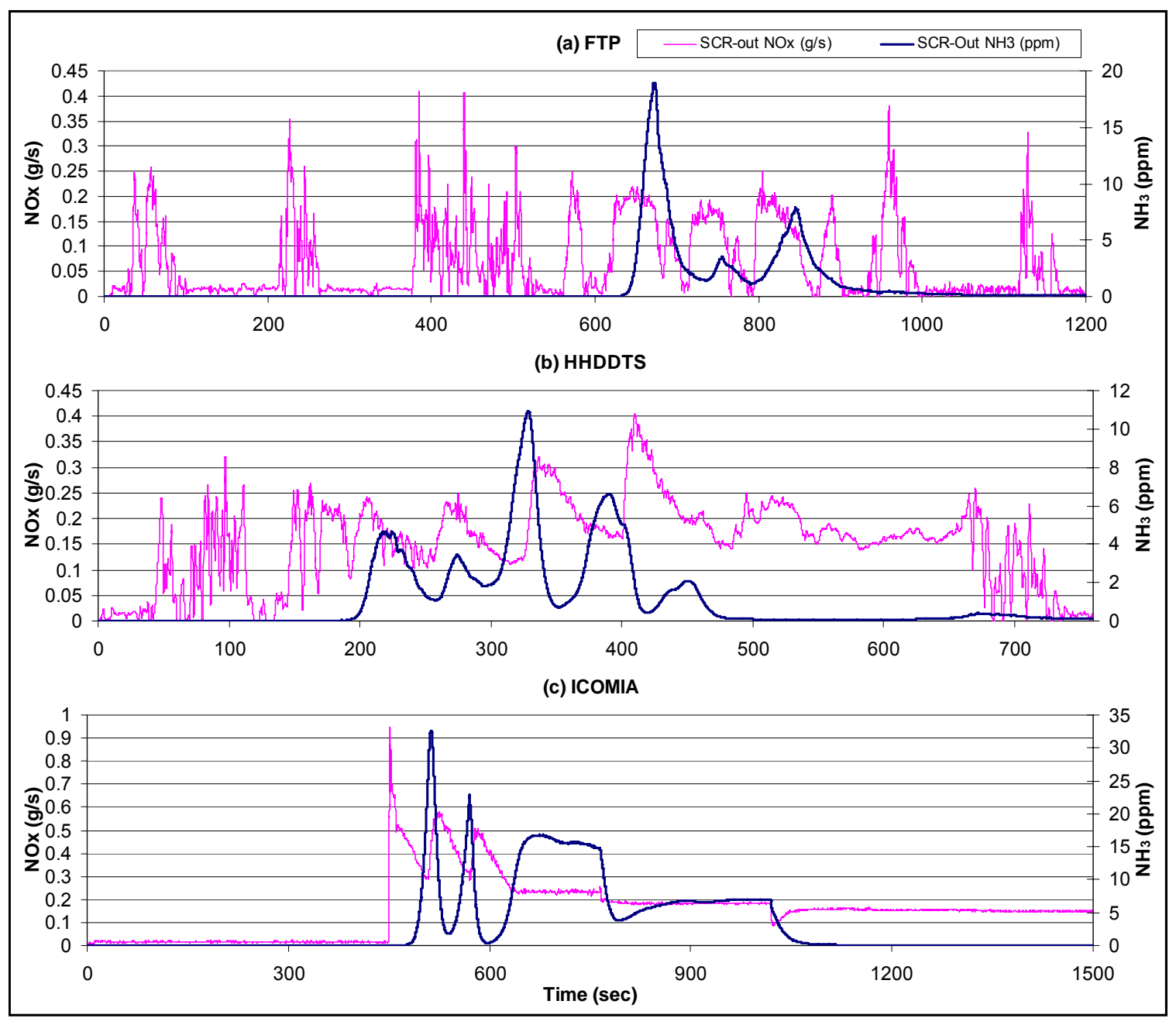

Figure 90. Configuration $4 \underline{\text { ideal }}$, continuous $\mathrm{NOx}(\mathrm{g} / \mathrm{s})$ and $\mathrm{NH}_{3}$ (ppm): (a) FTP, (b) ACES HHDDT_S, (c) ICOMIA 


\subsection{Control Strategy Evaluation}

In order to determine an optimal control configuration, three criteria were considered. First and foremost, emissions performance was compared between control configurations over different types of engine behavior, considering the total NOx reduction (\%), maximum ammonia slip (ppm) and average ammonia slip (ppm). System complexity was evaluated, considering hardware, software, calibration, maintenance, and overall robustness/adaptability for each configuration. Finally, overall cost was determined and compared between control configurations. The cost analysis included system capital, fabrication, software development, control calibration, system maintenance, and urea supply. The final cost to reduce one ton of NOx was presented for each control strategy along with the cost penalty associated with controlling ammonia slip. Results and comparisons for each of the evaluation categories as well as details regarding final control configuration selection can be seen below.

\subsubsection{Emissions Performance}

Based on the emissions performance results in Table 44, it was clear that each control strategy had its own strengths and weaknesses when considering a variety of engine behavior. The original feed-forward control strategy (configuration 1) required adjustment with test cycle. The configuration 1 results in Table 44 include a urea dosing factor of 0.50 for the FTP and ACES HHDDT_S cycles, but 0.25 for the ICOMIA. This decrease was required as a result of high steady-state ammonia slip observed during experimental testing of the system. If a constant 0.25 urea dosing factor was utilized, the reductions over FTP and ACES HHDDT_S cycles were significantly reduced (29\% and 37\%, respectively). As a result of cycle-specific calibrations, the consistent reductions achieved by the feed-forward case are somewhat misleading. However, it was desired to accurately represent the actual urea-SCR system control strategy which was experimentally tested. The feed-forward pre-SCR NOx sensor control configuration demonstrated the ability to produce reasonable NOx reductions, especially over steady-state operation, but lacked appropriate information to properly control ammonia slip. This lead to problems with ammonia slip spikes, calibration, and system adaptability. From a purely emission standpoint, configuration 1 ranked second best for exact and ideal model cases, based on the relative performance indices in Table 44.

When considering only a post-SCR NOx sensor (configuration 2), the most challenging aspect proved to be determining suitable setpoint NOx values without the use of a pre-SCR NOx sensor. Considering DOT helped configuration 2 to circumvent ammonia slip during transient operation. However, determining a calibration with appropriate setpoint variation from steady-state high-NOx situations ( $\approx 1200 \mathrm{ppm}$ raw) to transient low-NOx situations ( $\approx 500 \mathrm{ppm}$ raw) was difficult. In particular, the setpoint NOx often became higher than the engine-out NOx during low NOx/temperature situations (FTP, ICOMIA idle mode). Overall, the emissions performance of the post-SCR NOx sensor configuration demonstrated its suitability to steady-state applications. During steady-state operation, higher exhaust temperatures and NOx concentrations were typically observed. Achievable setpoint NOx values were more easily determined 
under these conditions. Additionally, PID control helped to quickly arrive at steady-state points without excessive overshoot. The meager reduction over the FTP cycle here was primarily a result of utilizing inexact setpoint NOx values during highly transient behavior. However it can be seen that the peak and average ammonia slip over the FTP were dramatically reduced (over an order of magnitude). The challenging conditions of the FTP do not only affect the post-SCR NOx sensor control configuration, but make it difficult for any strategy to achieve both a high NOx reduction and low ammonia slip. Configuration 2 ranked last when only considering emissions performance, primarily limited by low NOx reduction over transient test cycles.

When considering a strategy which implemented pre- and post-SCR NOx sensors, overall emissions performance was excellent. This configuration provided the most information to the control strategy, allowing a specific NOx setpoint to be more accurately determined and followed. This configuration allowed high NOx reduction and low ammonia slip over all test cycles. In literature [51], it was identified that closed-loop applications are limited by slow catalyst dynamics and $\mathrm{NH}_{3}$ slip prevention. Additionally, it was stated that slow catalyst dynamics typically require a large feedback gain to achieve good performance. These limitations were observed firsthand during development and tuning of configuration 3. The largest difficulty was determining PID gains which were sufficiently high to achieve fast response time without considerable urea over-dosing, which lead to ammonia slip. However gains were determined to obtain a compromise between NOx reduction and ammonia slip. Higher ammonia slip was observed with the exact model as a result of the more transient NOx behavior. As more smoothed measurements were used (ideal case), configuration 3 was actually able to achieve higher NOx reductions over all test cycles. As a result, the pre- and post-SCR NOx sensor control configuration was deemed more adaptable, actually benefiting from idealized measurements. Configuration 3 ranked best for the exact model and second best for the ideal model, based on relative performance indices in Table 44.

The final control strategy (configuration 4) included a pre-SCR NOx sensor and a model-based $\mathrm{NH}_{3}$ surface-coverage control strategy. This type of control strategy offered an excellent method of ammonia slip control. This was demonstrated in particular by the low ammonia slip results over the FTP. Ammonia slip control was implemented in a storage dynamic compensation block, which was added to the original feed-forward control strategy. The storage dynamic compensation block continuously determined the urea dosing factor, regardless of engine behavior or test cycle. This demonstrated greater robustness compared to the original feed-forward strategy. However, calibration and adaptability to hardware changes must be considered. Configuration 4 was able to achieve the highest steady-state reduction (57\%) with fairly low ammonia slip (62 ppm peak). Under steady-state conditions, ammonia slip can more easily be predicted according to changes in $\mathrm{NH}_{3}$ surface coverage. Configuration 4 showed a decrease in NOx reduction over ICOMIA and ACES HHDDT_S cycles when moving to a more ideal model case, but an increase over the FTP. The FTP included the most low-temperature and transient behavior of the cycles considered, 
suggesting that ammonia slip prediction became more in-exact using $\mathrm{NH}_{3}$ surface coverage under these conditions. The emissions results obtained (continuous and total) for configuration 4 demonstrated the great promise that $\mathrm{NH}_{3}$ surface-coverage strategies show in urea-SCR system control. Configuration 4 was ranked second to last for the exact model case, but best for the ideal model case. The model-based strategy clearly did not benefit from more exact sensor measurements. These differences showed that a single calibration was not appropriate for the model-based strategy when implementing various levels of measurement accuracy. Additional testing and tuning of the model-based strategy may be able to improve its emissions performance; however the development and calibration effort would be further increased.

Although not considered in the overall emissions comparison, the total amount of urea injected for each of the control strategies was tabulated (Table 43) for both model configurations. The results in Table 43 were not normalized by test cycle length, thus only represent a relative comparison of total injected urea between control strategies.

Table 43. Configuration comparison, total urea injected $(\mathrm{g})$

\begin{tabular}{|c|l|c|c|c|c|}
\hline \multicolumn{2}{|c|}{} & \multicolumn{4}{|c|}{ Total Urea Injected [g] } \\
\cline { 2 - 6 } \multicolumn{2}{|c|}{} & Config 1 & Config 2 & Config 3 & Config 4 \\
\hline \multirow{2}{*}{ FTP } & Exact & 233 & 116 & 284 & 141 \\
\cline { 2 - 6 } & Ideal & 193 & 89 & 314 & 145 \\
\hline \multirow{2}{*}{ HHDDTS } & Exact & 481 & 353 & 349 & 344 \\
\cline { 2 - 6 } & Ideal & 440 & 316 & 366 & 320 \\
\hline \multirow{2}{*}{ ICOMIA } & Exact & 608 & 945 & 873 & 1017 \\
\cline { 2 - 6 } & Ideal & 545 & 914 & 856 & 873 \\
\hline
\end{tabular}


Table 44. Control configuration emissions performance comparison

\begin{tabular}{|c|c|c|c|c|c|c|c|c|c|c|c|}
\hline \multicolumn{4}{|c|}{ Configuration } & \multicolumn{2}{|c|}{1} & \multicolumn{2}{|c|}{2} & \multicolumn{2}{|c|}{3} & \multicolumn{2}{|c|}{4} \\
\hline \multicolumn{4}{|c|}{ Sensor Placement } & \multicolumn{2}{|c|}{ pre-SCR } & \multicolumn{2}{|c|}{ post-SCR } & \multicolumn{2}{|c|}{ pre+post-SCR } & \multicolumn{2}{|c|}{ pre-SCR } \\
\hline \multicolumn{4}{|c|}{ Control Strategy } & \multicolumn{2}{|c|}{ feed-forward } & \multicolumn{2}{|c|}{ feed-back PD } & \multicolumn{2}{|c|}{ feed-back PID } & \multicolumn{2}{|c|}{ model-based } \\
\hline \multicolumn{3}{|c|}{ EMISSIONS PERFORMANCE } & Control Targets & & $R P I$ & & $R P I$ & & $R P I$ & & $R P I$ \\
\hline \multirow{9}{*}{ 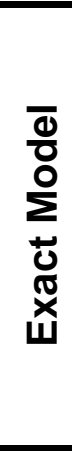 } & \multirow{2}{*}{$\begin{array}{c}\text { NOx Reduction } \\
(\%, g)\end{array}$} & ICOMIA SS & 43 & 43 & 0.00 & 55 & 0.28 & 53 & 0.24 & 57 & 0.34 \\
\hline & & FTP & 42 & 42 & 0.00 & 26 & -0.38 & 44 & 0.03 & 32 & -0.26 \\
\hline & \multirow{3}{*}{$\begin{array}{c}\text { Maximum } \mathrm{NH}_{3} \text { Slip } \\
(\mathrm{ppm})\end{array}$} & ICOMIA SS & 50 & 16 & 0.68 & 47 & 0.06 & 19 & 0.63 & 62 & -0.23 \\
\hline & & FTP & 158 & 158 & 0.00 & 5 & 0.97 & 113 & 0.28 & 20 & 0.87 \\
\hline & & ACES HHDDT_S & 50 & 21 & 0.57 & 8 & 0.84 & 4 & 0.91 & 8 & 0.83 \\
\hline & \multirow{4}{*}{$\begin{array}{c}\text { Average } \mathrm{NH}_{3} \text { Slip } \\
\text { (ppm) }\end{array}$} & ICOMIA SS & 25 & 1 & 0.97 & 3 & 0.87 & 4 & 0.84 & 7 & 0.72 \\
\hline & & FTP & 25 & 7 & 0.72 & 0.3 & 0.99 & 8 & 0.69 & 1 & 0.95 \\
\hline & & ACES HHDDT S & 25 & 4 & 0.84 & 1 & 0.97 & 1 & 0.96 & 1 & 0.95 \\
\hline & & & & & 0.28 & & 0.27 & & 0.32 & & 0.27 \\
\hline \multirow{10}{*}{ 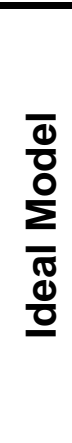 } & \multirow{3}{*}{$\begin{array}{c}\text { NOx Reduction } \\
(\%, g)\end{array}$} & ICOMIA SS & 43 & 38 & -0.10 & 54 & 0.28 & 53 & 0.24 & 53 & 0.23 \\
\hline & & FTP & 42 & 41 & -0.04 & 23 & -0.47 & 44 & 0.04 & 32 & -0.23 \\
\hline & & ACES HHDDT_S & 58 & 55 & -0.05 & 43 & -0.26 & 47 & -0.19 & 44 & -0.24 \\
\hline & \multirow{3}{*}{$\begin{array}{c}\text { Maximum } \mathrm{NH}_{3} \text { Slip } \\
(\mathrm{ppm})\end{array}$} & ICOMIA SS & 50 & 7 & 0.86 & 31 & 0.39 & 24 & 0.53 & 33 & 0.35 \\
\hline & & FTP & 158 & 95 & 0.40 & 2 & 0.98 & 150 & 0.06 & 19 & 0.88 \\
\hline & & ACES HHDDT S & 50 & 17 & 0.66 & 3 & 0.95 & 4 & 0.91 & 11 & 0.78 \\
\hline & \multirow{4}{*}{$\begin{array}{c}\text { Average } \mathrm{NH}_{3} \text { Slip } \\
(\mathrm{ppm})\end{array}$} & ICOMIA SS & 25 & 0.4 & 0.99 & 2 & 0.90 & 3 & 0.87 & 3 & 0.87 \\
\hline & & FTP & 25 & 5 & 0.79 & 0.1 & 1.00 & 15 & 0.39 & 1 & 0.95 \\
\hline & & ACES HHDDT_S & 25 & 3 & 0.87 & 1 & 0.98 & 1 & 0.96 & 1 & 0.95 \\
\hline & & & & & 0.28 & & 0.27 & & 0.28 & & 0.29 \\
\hline
\end{tabular}




\subsubsection{System Complexity}

A simple complexity analysis was performed for each control configuration to show differences in number of sensors, tuning parameters, and robustness/adaptability. The number of tuning parameters for each control configuration was determined by summing the total number of independent parameters that may be varied to alter system performance. This included urea dosing factor, PID gains, cutoff values for membership functions, and slope/y-intercepts for linearly dependent parameters.. The overall variable affected and the corresponding number of "knobs" that may be adjusted were tabulated. The urea injection temperature threshold was not included in the tuning parameter analysis. The robustness and adaptability of each control strategy was particularly important in selecting an optimal configuration. Four criteria were used to evaluate the robustness and adaptability of a given control configuration. This included evaluating each control configuration on how dependent it was to a specific engine or catalyst, the cycle dependence of its calibration, reduction consistency, and ideal adaptation.

The degree to which a given control strategy was tied to a specific engine or catalyst was evaluated on a scale of zero to one. The post-SCR NOx sensor configuration was rated at 0.5 because the setpoint NOx was dependent on the engine-out NOx level, but could be easily scaled to different levels. The model-based strategy however, was developed and validated based on specific experimental data. This implied that in order to utilize the control configuration for different engine sizes, output NOx levels, catalyst sizes, and/or catalyst types, the robustness of predictions would require validation in each situation. Because the modelbased portion assumed a specific engine and SCR catalyst, while other configurations relied less on specific hardware, it was given an engine/catalyst specific rating of one.

It was greatly desired that no software modifications be required when switching between test cycles. As such, the original control strategy received a cycle dependent calibration score of one and the other strategies received scores of zero. The reduction consistency was based on the maintaining high emissions reductions over each test cycle. This was determined by calculating the average NOx reduction percentage over ICOMIA, ACES HHDDT_S, and FTP cycles for each control configuration. Finally, ideal adaptation was evaluated by considering differences in emissions performance when utilizing exact and ideal sensor inputs. The percent increase or decrease in NOx reduction percentage when utilizing ideal sensor inputs was calculated for each test cycle. An average was taken for each control configuration and used to evaluate how well a given control configuration was able to adapt to variations in measurement accuracy.

This comparison can be seen in Table 45 below, along with a complexity rating for each control configuration. The final complexity ratings were determined by first normalizing certain criterion's complexity ratings into a zero to one range. For the number of NOx sensors and calibration/tuning parameters, this involved normalizing by the maximum value in each category. These ranges assumed that low normalized values were desired, corresponding to a less complex, more robust configuration. In order 
to maintain this convention, one minus the average NOx reduction percentage $(0-1)$ was used to evaluate reduction consistency. Additionally, the ideal adaptation criteria were normalized from a fixed range of -10 to 10 . The following equation was utilized to determine an overall complexity rating for each control configuration. Each parameter $n$ represents a normalized value.

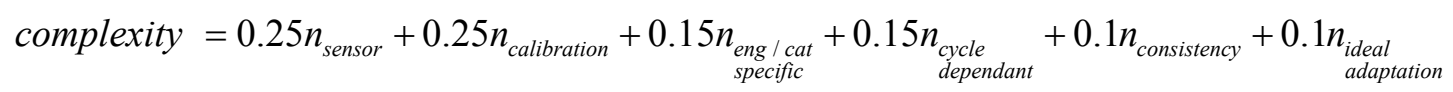

Equation 64

The weights utilized in Equation 64 were determined through good engineering judgment and placing emphasis on obtaining a cycle independent control calibration and minimizing calibration effort. Section 10.9 includes a more in depth discussion of the results in Table 45.

Table 45. Control configuration complexity analysis

\begin{tabular}{|c|c|c|c|c|c|c|}
\hline \multicolumn{3}{|c|}{ Configuration } & 1 & 2 & 3 & 4 \\
\hline \multicolumn{3}{|c|}{ Sensor Placement } & pre-SCR & post-SCR & pre+post-SCR & pre-SCR \\
\hline \multicolumn{3}{|c|}{ Control Strategy } & feed-forward & feed-back PD & feed-back PID & model-based \\
\hline \multicolumn{7}{|c|}{ S'YSTEM $\overline{C O M} \bar{P} \overline{\mathrm{E}} \overline{X I T Y}$} \\
\hline \multicolumn{3}{|c|}{ Number of NOx Sensors } & 1 & - & - & --ー \\
\hline \multirow{3}{*}{\multicolumn{3}{|c|}{ Calibration/Tuning Parameters }} & Urea Equiv. Ratio (1) & Setpoint NOx (7) & Desired Reduction (1) & $d($ Storage $) / d t(4)$ \\
\hline & & & & PD Controller (2) & PID Controller (3) & Storage (4) \\
\hline & & & & & & Exh. Temperature (4) \\
\hline & & Totals: & 1 & 9 & 4 & 16 \\
\hline & & Normalized: & 0.063 & 0.56 & 0.25 & 1.0 \\
\hline \multirow{5}{*}{$\begin{array}{c}\text { System } \\
\text { Robustness/ } \\
\text { Adaptability }\end{array}$} & \multicolumn{2}{|c|}{ Engine/Catalyst Specific } & 0 & 0.5 & 0 & 1 \\
\hline & \multicolumn{2}{|c|}{ Cycle Dependant Calibration } & 1 & 0 & 0 & 0 \\
\hline & $\begin{array}{c}\text { Average } \\
\text { Reduction }\end{array}$ & Average $\left(\%_{\text {red }}\right)$ & $48 \%$ & $42 \%$ & $48 \%$ & $45 \%$ \\
\hline & \multirow{2}{*}{$\begin{array}{c}\text { Ideal } \\
\text { Adaptation }\end{array}$} & Average $\left(\%_{\text {diff }}\right)$ & -6.3 & -6.5 & 0.6 & -3.0 \\
\hline & & Normalized & 0.81 & 0.82 & 0.47 & 0.65 \\
\hline \multicolumn{3}{|c|}{ Total Complexity Ratings: } & 0.37 & 0.42 & 0.36 & 0.59 \\
\hline
\end{tabular}

\section{$\underline{10.8 .3 \text { Cost }}$}

A complete system cost analysis was performed for each control configuration, considering a six year operational time in on-road and marine applications. The final system cost was presented in terms of dollars per ton of NOx reduced annually. In order to present results in this format, total annual NOx production and reduction had to be determined for each configuration. To accomplish this, several assumptions were made.

It was assumed that the ICOMIA E5 cycle could be used to represent typical marine operation and that the FTP cycle could be used to represent typical on-road HHDDT operation. For the marine application, it was assumed that a typical tug or towboat may operate 8-hours per day, 365 days per year. This resulted in a total annual operational time of 2920 hours. For the on-road application, it was assumed that the truck had 
an annual mileage of 125,000 miles and traveled at an average speed of $50 \mathrm{mph}$. This resulted in a total yearly operational time of 2500 hours. These assumptions are consistent with the cost analysis in [55]. In either application, idle operation other than what was present in the ICOMIA or FTP cycles was not considered.

The total NOx over each cycle was used, along with the cycle-average power, to determine the total annual NOx produced. The NOx and average power figures were calculated based on the experimental results obtained with the 1992 DDC S60 engine at WVU. It should be noted that ICOMIA NOx and average horsepower were weighted values, based on the time weighting factors specified in [78]. Additionally, the work specific engine NOx for the FTP represents the engine certification level. The assumed NOx reductions were based on the model results for the exact case, since they were generally lower than the ideal case and allowed a more conservative cost estimate. The annual NOx reduction for each configuration can be seen below in Table 46 .

Table 46. Annual NOx production and elimination

\begin{tabular}{|c|c|c|c|c|c|c|c|c|c|}
\hline & $\begin{array}{c}\text { Assumed } \\
\text { Test } \\
\text { Cvcle }\end{array}$ & $\begin{array}{c}\text { Work } \\
\text { Specific } \\
\text { Engine NOx } \\
\end{array}$ & \begin{tabular}{|c|}
$\begin{array}{c}\text { Annual } \\
\text { Operating } \\
\text { Hours }\end{array}$ \\
\end{tabular} & $\begin{array}{c}\text { Cycle } \\
\text { Average } \\
\text { HP } \\
\end{array}$ & \begin{tabular}{|c|} 
Total \\
Annual \\
NOx \\
\end{tabular} & \multirow[t]{2}{*}{$\begin{array}{c}\text { Control } \\
\text { Configuration }\end{array}$} & \begin{tabular}{|c|} 
Assumed \\
NOx \\
Reduction \\
\end{tabular} & $\begin{array}{c}\text { Annual } \\
\text { NOx } \\
\text { Eliminated } \\
\end{array}$ \\
\hline & & & [g/bhp-hr] & & [hp] & \begin{tabular}{|l} 
[tons] \\
\end{tabular} & & \begin{tabular}{|c|}
{$[\%]$} \\
\end{tabular} & [tons] \\
\hline \multirow{8}{*}{$\begin{array}{l}\frac{7}{0} \\
\frac{\pi}{0} \\
\frac{0}{0} \\
\frac{0}{2}\end{array}$} & \multirow{4}{*}{ On-Road } & \multirow{4}{*}{ FTP } & \multirow{4}{*}{5} & \multirow{4}{*}{2500} & \multirow{4}{*}{66.46} & \multirow{4}{*}{0.92} & Config. 1 & 42 & 0.39 \\
\hline & & & & & & & Config. 2 & 26 & 0.24 \\
\hline & & & & & & & Config. 3 & 44 & 0.40 \\
\hline & & & & & & & Config. 4 & 32 & 0.29 \\
\hline & \multirow{4}{*}{ Marine } & \multirow{4}{*}{ ICOMIA } & \multirow{4}{*}{9.46} & \multirow{4}{*}{2920} & \multirow{4}{*}{123.20} & \multirow{4}{*}{3.75} & Config. 1 & 43 & 1.60 \\
\hline & & & & & & & Config. 2 & 55 & 2.05 \\
\hline & & & & & & & Config. 3 & 53 & 1.98 \\
\hline & & & & & & & Config. 4 & 57 & 2.14 \\
\hline
\end{tabular}

Next, the total system cost was estimated. This included system capital (hardware), fabrication/construction, urea supply, and engineering effort. First, the total system hardware cost was determined by summing the actual purchase costs of the components procured to construct the system at WVU. Because the SCR catalyst was donated to WVU, an appropriate catalyst cost was approximated using information found in literature. Keenan et al. [100] estimated the SCR catalyst cost for a 12 liter HHDDE to be between $\$ 897$ and $\$ 1281$. Similarly, Mira Ltd. And Peter Brett Associates [101] provided estimates between $\$ 306$ and $\$ 2,251$. Using an average value, the SCR catalyst was approximated at $\$ 1,200$. The costs used here assumed a one-off system, rather than mass-production, and do not include any shipping costs. MECA determined that depending on the production scale, cost reductions of up to $75 \%$ could be realized [55]. A detailed breakdown of individual component costs can be seen in Appendix D. The total system hardware cost (plus SCR catalyst canning procedure) for a single NOx sensor was $\$ 6,810$, and for two NOx sensors was $\$ 8,585$. Additionally, fabrication and canning costs estimated here were likely high as a result of the custom nature of the system. 
Machining and fabrication costs were associated with machining the urea injector mount from a solid aluminum block, construction of the urea tank, and miscellaneous fitting, flange, and bung welding. Hourly labor rates of $\$ 18$ and $\$ 10$ were assumed for the machining and welding/fabrication, respectiveley [102]. Additionally, an overhead charge of $\$ 30$ per hour was included, as indicated in [102]. The actual amount of time required for each procedure was used to determine the total fabrication costs (see Table 47). The values represent a one-off system could be significantly reduced in large scale production.

Table 47. Urea-SCR system fabrication and welding costs [102]

\begin{tabular}{|l|c|c|c|c|}
\hline \multirow{2}{*}{ Process } & Time & \multicolumn{3}{|c|}{ Cost } \\
\cline { 3 - 5 } & {$[$ hr:min] } & Labor & Overhead & Total \\
\hline Machining injector mount & $2: 00$ & $\$ 36.00$ & $\$ 60.00$ & $\$ 96.00$ \\
\hline Urea tank cutting, welding, fabricating & $2: 00$ & $\$ 20.00$ & $\$ 60.00$ & $\$ 80.00$ \\
\hline Misc bung, fitting, and flange welding & $1: 00$ & $\$ 10.00$ & $\$ 30.00$ & $\$ 40.00$ \\
\hline Second NOx sensor bung & $0: 20$ & $\$ 3.33$ & $\$ 10.00$ & $\$ 13.33$ \\
\hline
\end{tabular}

Average urea consumption was determined over FTP (on-road) and ICOMIA (marine) test cycles for each control configuration utilizing the exact model case. These values were combined with the annual operational time in each application to determine annual urea cost for each control configuration. These figures, which were dependent on the level of NOx reduction, can be seen in Table 48 below.

Table 48. Urea annual cost comparison

\begin{tabular}{|c|c|c|c|c|c|c|c|c|}
\hline \begin{tabular}{|c|}
$\begin{array}{c}\text { Urea } \\
\text { Quantity }\end{array}$ \\
[gal] \\
\end{tabular} & Price & $\begin{array}{c}\text { Gallon } \\
\text { Price } \\
\text { [\$/gal] }\end{array}$ & Source & & & Configuration & $\begin{array}{c}\begin{array}{c}\text { Annual Urea } \\
\text { Consumption }\end{array} \\
\text { [gal] } \\
\end{array}$ & $\begin{array}{l}\text { Annual } \\
\text { Urea Cost }\end{array}$ \\
\hline \multirow{8}{*}{55} & \multirow{8}{*}{$\$ 152.64$} & \multirow{8}{*}{$\$ 2.78$} & \multirow{8}{*}{ TerraCair } & \multirow{8}{*}{ 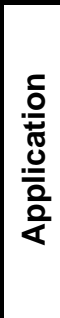 } & \multirow{4}{*}{ On-Road } & Config. 1 & 424 & $\$ 1,177.45$ \\
\hline & & & & & & Config. 2 & 210 & $\$ 583.68$ \\
\hline & & & & & & Config. 3 & 516 & $\$ 1,432.04$ \\
\hline & & & & & & Config. 4 & 257 & $\$ 713.32$ \\
\hline & & & & & \multirow{4}{*}{ Marine } & $\begin{array}{l}\text { Config. } 1 \\
\end{array}$ & 1033 & $\$ 2,867.17$ \\
\hline & & & & & & Config. 2 & 1605 & $\$ 4,453.27$ \\
\hline & & & & & & Config. 3 & 1483 & $\$ 4,116.13$ \\
\hline & & & & & & Config. 4 & 1727 & $\$ 4,793.86$ \\
\hline
\end{tabular}

Finally, the cost of control strategy development, calibration, and maintenance had to be estimated for each control configuration. The cost of development took into account the approximate amount of time required to compose the control software for each configuration. A fixed engineering time cost was estimated using figures from the US Bureau of Labor Statistics [103] and engineering consultation figures from the original WVU/MJB\&A urea-SCR project proposal [74]. The hourly rates varied from $\$ 60$ to $\$ 90[103,74]$. Based on these figures, a final fixed engineering time cost of $\$ 85$ per hour was applied to determine the cost associated with the development of each control strategy. 
The calibration effort (and thus cost) differed widely between each of the control configurations. The approximate calibration time for each control configuration was determined and the above engineering time cost of $\$ 85$ per hour was applied. The time associated with development of the control software and control calibration can be seen in Table 49. The hourly rates were applied to these figures to determine final costs for each control configuration. The high control strategy development time of configuration 4 (model-based strategy) was included because of the significant effort required to develop and validate the SCR catalyst model.

In order to determine appropriate maintenance costs, a general maintenance schedule was defined. The most basic maintenance items included cleaning and checking components for damage. Because of the way in which the system was designed and the robust hardware utilized, PM clogging and component failure should not be an issue. During all testing of the system no issues were observed, other than a urea pump failure. However the cause of this was determined to be corrosion of electrical contacts. A similar in-tank pump with contacts that do not contact the fluid was found at a similar price point. It was assumed that the final system implemented the isolated pump.

Regardless, a yearly cleaning and inspection was included in the maintenance schedule. This procedure included visual inspection of the pitot-tubes, thermocouple probe, NOx sensor probe, and SCR passages for clogging and damage. Any blockages would be removed with compressed air or appropriate tools. It would be verified that the urea pump holds pressure (58 psig) and than no contaminants have been introduced into the tank. Additionally, the urea injector would be removed and the tip inspected for degradation or contamination. Damaged components would be replaced or repaired as necessary (not included in this analysis). These checks would not be time consuming, and thus an inexpensive insurance policy to allow smooth operation of the system.

The system here was constructed using off-the-shelf parts, some of which were designed for laboratory implementation. As such, some components may require routine recalibration. The Siemens NOx sensor and MSD MAP sensor were both designed for OEM integration. As such, it was assumed that annual recalibration of these devices was not required (nor was any specified by the manufacturers). Additionally, since the Motohawk controller was OEM-grade hardware, no calibration or maintenance was assumed. However the differential pressure transducer and thermocouple represent research grade hardware. In order to ensure accurate measurements and consistent system performance, an annual recalibration schedule was assumed. This met the minimum requirements defined in CFR $40 \S 1065.315$, which dictate recalibration upon initial installation and after major maintenance [104]. Recalibration costs were determined using quotes from Omega calibration services [105]. When considering the high thermocouple calibration costs (\$95) it was less expensive to simply replace the device with a new calibrated unit annually (\$24). Because of the high cost of the differential pressure transducer and its importance in performing accurate urea 
dosing, the annual calibration cost $(\$ 150)$ was justified. This cost included a CAL-3 calibration level (National Institution of Standards and Technology (NIST) traceable) with five data points. In order to avoid downtime, the maintenance technician would swap the parts with pre-calibrated devices and ship them out to be independently calibrated. The cost of this swap was not considered here, only the recalibration costs. A fixed maintenance cost of $\$ 40$ per hour was assumed, which was consistent with hourly rates for welding $(\$ 40 / \mathrm{hr})[102]$ and other technical duties $(\$ 42 / \mathrm{hr})$ [103]. The corresponding time and final cost for each maintenance item are detailed in Table 49.

SCR catalyst life was also considered. In literature, it has been stated that the SCR catalyst is robust against thermal shocks and vibration load over the life of an HHDDE [106]. It has been demonstrated that the activity of a catalyst shows no noticeable conversion loss at 120,000 miles of in-use operation [107], and the conversion decreased asymptotically to $\approx 90 \%$ at 270,000 miles [108]. In stationary applications, SCR catalysts are typically replaced every 2 years (17,520 hrs), assuming constant operation [55]. If a similar replacement schedule was implemented in the assumed marine and on-road applications, it would correspond to replacement every 6 and 7 years, respectively. As a result, the price of an SCR catalyst was pro-rated, based on these figures, to an annual cost. The more frequent replacement schedule (6 yr) was assumed for both applications.

Table 49. Engineering, calibration, and annual maintenance cost

\begin{tabular}{|c|c|c|c|c|c|c|c|c|c|c|}
\hline & \multicolumn{2}{|c|}{ Configuration 1} & \multicolumn{2}{|c|}{ Configuration 2} & \multicolumn{2}{|c|}{ Configuration 3} & \multicolumn{2}{|c|}{ Configuration 4} \\
\hline & & & $\begin{array}{c}\text { Time } \\
\text { [hr:min] }\end{array}$ & Cost $[\$]$ & \begin{tabular}{|c|} 
Time \\
[hr:min]
\end{tabular} & Cost [\$] & \begin{tabular}{|c|} 
Time \\
{$[\mathrm{hr}: \mathrm{min}]$}
\end{tabular} & Cost $[\$]$ & $\begin{array}{c}\text { Time } \\
\text { [hr:min] }\end{array}$ & Cost [\$] \\
\hline \multicolumn{3}{|c|}{ Control Strategy Development } & $6: 00$ & $\$ 510.00$ & $14: 00$ & $\$ 1,190.00$ & $10: 00$ & $\$ 850.00$ & $30: 00$ & $\$ 2,550.00$ \\
\hline \multicolumn{3}{|c|}{ Controller Tuning/Calibration } & $1: 00$ & $\$ 85.00$ & $6: 00$ & $\$ 510.00$ & $4: 00$ & $\$ 340.00$ & $4: 00$ & $\$ 340.00$ \\
\hline \multirow{9}{*}{ 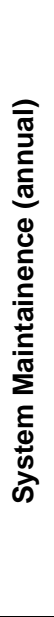 } & \multirow{4}{*}{$\begin{array}{l}\text { Cleaning/ } \\
\text { Inspection }\end{array}$} & Pitot-Tubes & $0: 10$ & $\$ 6.67$ & $0: 10$ & $\$ 6.67$ & $0: 10$ & $\$ 6.67$ & $0: 10$ & $\$ 6.67$ \\
\hline & & \begin{tabular}{|c|} 
Thermocouple \\
Probe
\end{tabular} & $0: 05$ & $\$ 3.33$ & $0: 05$ & $\$ 3.33$ & 0:05 & $\$ 3.33$ & 0:05 & $\$ 3.33$ \\
\hline & & $\begin{array}{c}\text { NOx Sensor } \\
\text { Probe }\end{array}$ & 0:05 & $\$ 3.33$ & 0:05 & $\$ 3.33$ & $0: 10$ & $\$ 6.67$ & $0: 05$ & $\$ 3.33$ \\
\hline & & $\begin{array}{l}\text { SCR Brick } \\
\text { Passages }\end{array}$ & $0: 20$ & $\$ 13.33$ & $0: 20$ & $\$ 13.33$ & $0: 20$ & $\$ 13.33$ & $0: 20$ & $\$ 13.33$ \\
\hline & Replacement & Thermocouple & -- & $\$ 24.00$ & -- & $\$ 24.00$ & -- & $\$ 24.00$ & -- & $\$ 24.00$ \\
\hline & Recalibration & $\begin{array}{l}\text { Differential } \\
\text { Pressure }\end{array}$ & -- & $\$ 150.00$ & -- & $\$ 150.00$ & -- & $\$ 150.00$ & -- & $\$ 150.00$ \\
\hline & \multirow{2}{*}{$\begin{array}{l}\text { General } \\
\text { Check }\end{array}$} & $\begin{array}{l}\text { Urea Pump } \\
\text { Operation }\end{array}$ & $0: 10$ & $\$ 6.67$ & $0: 10$ & $\$ 6.67$ & $0: 10$ & $\$ 6.67$ & $0: 10$ & $\$ 6.67$ \\
\hline & & $\begin{array}{l}\text { Injector } \\
\text { Integrity }\end{array}$ & $0: 15$ & $\$ 10.00$ & $0: 15$ & $\$ 10.00$ & $0: 15$ & $\$ 10.00$ & $0: 15$ & $\$ 10.00$ \\
\hline & $\begin{array}{l}\text { SCR Catalyst } \\
\text { Replacement }\end{array}$ & 6-year Cycle & -- & $\$ 200.00$ & -- & $\$ 200.00$ & -- & $\$ 200.00$ & -- & $\$ 200.00$ \\
\hline
\end{tabular}

In addition to this maintenance schedule, measurement verifications should be performed on a more frequent basis from within the control software. A laptop could be used to perform this task or a basic display could be integrated into the final system. These checks as well as the annual maintenance routine 
could be timed such that they correspond to normal maintenance intervals for the truck, marine vessel, or engine.

Finally, the total costs associated with system development, calibration, and operation for six years in onroad and marine applications were compiled. These figures were combined with the annual NOx estimates to arrive at a final annual cost per ton of NOx reduction. Included in the cost estimate here was an additional cost penalty of $\$ 0.05$ per gallon associated with using ULSD fuel in a marine application [109]. Utilizing such fuel would help to avoid poisoning of SCR catalyst sites, increasing life. Experimental fueling data from the ICOMIA test cycle was utilized to determine annual fuel consumption.

It was also desired to quantify the cost of controlling ammonia slip. This was accomplished by determining the NOx reduction that could be obtained with each control configuration when controlling ammonia slip was disregarded. In order to standardize the comparison between control strategies, the NOx setpoint, desired reduction, or urea dosing factor in each strategy was modified by a factor of two in order to increase NOx reduction. The corresponding NOx reductions were associated with conditions of unacceptable ammonia slip, and the difference in cost per ton of NOx reduced was calculated. While the maximum ammonia slip differed between control configurations in this comparison, it demonstrated a level of reduction that could be achieved if not constrained by ammonia slip and the cost per ton of NOx reduced associated with achieving low levels of ammonia slip. The NOx reductions achieved when disregarding ammonia slip for configurations 1 through 3 were $56 \%, 41 \%$, and $56 \%$ for the on-road application (FTP cycle), and $65 \%, 70 \%$, and $75 \%$ for the marine application (ICOMIA cycle). The model-based control strategy (configuration 4) was not included in the ammonia slip penalty comparison because it was entirely based on ammonia slip reduction. As a result of its integration into the SCR model and adaptation to higher urea injection quantities, the strategy could not be modified in a standardized manner, similar to the other strategies, to achieve a higher NOx reduction. The final cost per ton of NOx reduced for each control configuration along with the corresponding ammonia slip penalty can be seen in Table 50 . 
Table 50. Urea-SCR system and control configuration cost analysis

\begin{tabular}{|c|c|c|c|c|c|c|}
\hline \multicolumn{3}{|c|}{ Configuration } & 1 & 2 & 3 & 4 \\
\hline \multicolumn{3}{|c|}{ Sensor Placement } & pre-SCR & post-SCR & pre+post-SCR & pre-SCR \\
\hline \multirow{2}{*}{\multicolumn{3}{|c|}{ 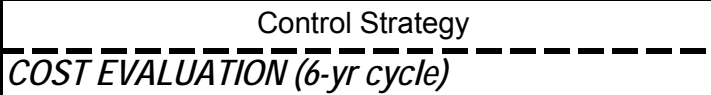 }} & feed-forward & feed-back PD & feed-back PID & model-based \\
\hline & & & & & & \\
\hline \multicolumn{3}{|c|}{ System Capital } & $\$ 6,809.77$ & $\$ 6,809.77$ & $\$ 8,584.77$ & $\$ 6,809.77$ \\
\hline \multicolumn{3}{|c|}{ Fabrication and Construction } & $\$ 216.00$ & $\$ 216.00$ & $\$ 229.33$ & $\$ 216.00$ \\
\hline \multirow{3}{*}{\multicolumn{2}{|c|}{ Engineering Effort }} & Software Development & $\$ 510.00$ & $\$ 1,190.00$ & $\$ 850.00$ & $\$ 2,550.00$ \\
\hline & & Control Calibration & $\$ 85.00$ & $\$ 510.00$ & $\$ 340.00$ & $\$ 340.00$ \\
\hline & & System Maintainence & $\$ 417.33$ & $\$ 417.33$ & $\$ 420.67$ & $\$ 417.33$ \\
\hline \multirow{4}{*}{ 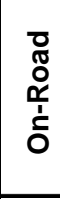 } & \multicolumn{2}{|c|}{ Annual NOx Eliminated (tons) } & 0.39 & 0.24 & 0.40 & 0.29 \\
\hline & \multicolumn{2}{|c|}{ Annual Urea Supply Cost (\$) } & $\$ 1,177.45$ & $\$ 583.68$ & $\$ 1,432.04$ & $\$ 713.32$ \\
\hline & \multicolumn{2}{|c|}{ Total Annual NOx Reduction Cost (\$/ton NOx) } & $\$ 7,369.97$ & $\$ 10,233.80$ & $\$ 8,800.35$ & $\$ 9,633.65$ \\
\hline & \multicolumn{2}{|c|}{ Annual $\mathrm{NH}_{3}$ Slip Cost Penalty (\$/ton NOx) } & $\$ 1,763.14$ & $\$ 3,700.60$ & $\$ 1,912.59$ & -- \\
\hline \multirow{5}{*}{ 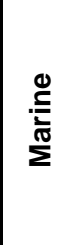 } & \multicolumn{2}{|c|}{ Annual NOx Eliminated (tons) } & 1.60 & 2.05 & 1.98 & 2.14 \\
\hline & \multicolumn{2}{|c|}{ Annual ULSD Fuel Penalty $(\$)$} & $\$ 1,030.02$ & $\$ 1,030.02$ & $\$ 1,030.02$ & $\$ 1,030.02$ \\
\hline & \multicolumn{2}{|c|}{ Annual Urea Supply Cost $(\$)$} & $\$ 2,867.17$ & $\$ 4,453.27$ & $\$ 4,116.13$ & $\$ 4,793.86$ \\
\hline & \multicolumn{2}{|c|}{ Total Annual NOx Reduction Cost (\$/ton NOx) } & $\$ 3,495.43$ & $\$ 3,586.44$ & $\$ 3,651.08$ & $\$ 3,680.93$ \\
\hline & \multicolumn{2}{|c|}{ Annual $\mathrm{NH}_{3}$ Slip Cost Penalty (\$/ton NOx) } & $\$ 1,214.11$ & $\$ 801.67$ & $\$ 1,077.56$ & - \\
\hline
\end{tabular}

The total cost of the stand-alone urea-SCR system (excluding operation, maintenance, and urea) was $\$ 7,621$ based on the prices above. This cost represented a system designed for a $12.7 \mathrm{~L} 350 \mathrm{hp} 5 \mathrm{~g} / \mathrm{bhp}-\mathrm{hr}$ NOx engine, and was less than minimum estimates provided by MECA $(\$ 11,000)$ for a system targeting 300-500 hp heavy-duty diesel engines [55]. However the system price and overall cost per ton of NOx reduced was greater than estimates provided by Krishnan et al. [55]. These estimates assumed a 70\% reduction from 1991 on-road diesel emissions levels, resulting in $\$ 4,320$ per year capital and operating costs and an overall $\$ 1,800$ per ton of NOx reduced over a 5 year period [55]. The cost estimates in Table 50 for a marine application are lower than projections in the original MJB\&A/WVU proposal, which assumed a 50\% NOx reduction and estimated $\$ 7,000$ per ton of NOx reduced [74]. It was noted that retrofit costs of this magnitude are competitive with engine rebuild programs, which may offer a similar $50 \%$ reduction in NOx emissions.

Additionally, regulatory agencies in states which include large areas of PM or ozone non-attainment often provide incentive grants for the development and implementation of retrofit NOx reduction technologies. These grants include strict reduction and cost-effectiveness guidelines to ensure state money is spent wisely. The Texas Emissions Reduction Plan (TERP) dictates that a given retrofit technology must provide at least a $25 \%$ total NOx reduction from the certification level and cost effectiveness of $\$ 15,000$ per ton of NOx reduced [110]. Similarly, CARB dictates a minimum 15\% total NOx reduction and cost effectiveness of $\$ 16,000$ per ton of NOx reduced to be eligible for Carl Moyer grant funding [111]. The optimized 
retrofit urea-SCR system exceeds requirements in both states, and thus can be considered to provide a costeffective NOx reduction.

\subsection{Optimal Control Strategy Selection}

In order to determine an optimal control configuration, the emissions performance, complexity, and cost evaluation results were considered together. The urea-SCR system described above specifically targeted retrofit applications. As a result, the scope of its implementation extends into on-road, off-road, and marine segments over a variety of engine model years and NOx levels. The control configuration must be capable of achieving high NOx reductions in response to various types of engine operation without high setup and calibration effort. Additionally, to be marketed as an attractive retrofit package, capital and operational cost must be low.

Based on the exact model emissions results above, configuration 3 (pre- and post-SCR NOx sensors) offered the best NOx reduction and ammonia slip performance. NOx reductions of $53 \%, 44 \%$, and $47 \%$ and peak ammonia slip of $19 \mathrm{ppm}, 113 \mathrm{ppm}$, and $4 \mathrm{ppm}$ were achieved over ICOMIA, FTP, and ACES HHDDT_S cycles, respectively. In an on-road application, this reduction corresponds to a $2.8 \mathrm{~g} / \mathrm{bhp}-\mathrm{hr}$ certification level (FTP), nearly meeting $2004 \mathrm{NOx}+\mathrm{NMHC}$ standards $(2.5 \mathrm{~g} / \mathrm{bhp}$-hr) with a 1992 model year engine. In a marine application, this corresponds to a $4.47 \mathrm{~g} / \mathrm{bhp}-\mathrm{hr}$ certification level (ICOMIA E5), easily meeting 2004 Tier $2 \mathrm{NOx}+\mathrm{HC}$ standards for $\mathrm{C} 1$ commercial engines (5.37 g/bhp-hr) and nearly meeting 2014 Tier 3 standards for high power density engines ( $4.33 \mathrm{~g} / \mathrm{bhp}-\mathrm{hr}$ ). Additionally, configuration 3 was able to maintain high reductions when ideal sensor inputs were utilized. The original feed-forward control strategy (configuration 1) followed with NOx reductions of $43 \%, 42 \%$, and $58 \%$ and peak ammonia slip of $16 \mathrm{ppm}, 158 \mathrm{ppm}$, and $21 \mathrm{ppm}$. Configuration 4 (model-based) offered the best ammonia slip control $(<25$ ppm peak, FTP) while still maintaining a high NOx reduction.

From the complexity and adaptability analysis, configuration 3 was also selected as best, despite the inclusion of an additional NOx sensor. Configuration 3 offered less calibration effort and more adaptability compared to the other control configurations, as well as offering more consistent NOx reductions. The model-based strategy (configuration 4) was ranked last in the complexity analysis, hindered significantly by its high calibration effort and engine/catalyst specific development. The original feed-forward control configuration was ranked second, primarily hindered by its inability to utilize a single calibration over multiple test cycles.

When considering overall cost in on-road and marine applications, the original feed-forward control strategy (configuration 1) was most cost-effective. It achieved cost performance of $\$ 7,370$ per ton of NOx reduced in an on-road application and $\$ 3,495$ in a marine application. This is not surprising, considering the simple control strategy, single NOx sensor, and minimal calibration effort. However because of adaptability limitations and generally low NOx reduction performance, the original feed-forward control 
strategy could not be selected as optimal. In an on-road application, configuration 3 offered the second best overall cost performance at $\$ 8,800$ per ton of NOx reduced and configuration 4 offered the third best at $\$ 9,634$ per ton of NOx reduced. For a marine application, configuration 2 offered the second best cost performance at $\$ 3,586$ per ton of NOx reduced and configuration 3 offered the third best cost performance at $\$ 3,651$ per ton of NOx reduced.

Based on the overall emissions and complexity analysis results, cost performance in each application segment, and price differences between second and third ranked configurations, configuration 3 (pre- and post-SCR NOx sensors, PID control) was selected as the optimal control configuration for a retrofit application. While utilizing two NOx sensors increased the capital cost, it provided the most information to the control strategy, allowing high NOx reductions and low ammonia slip during a variety of engine behavior. This is particularly important in a stand-alone retrofit application, where no engine communication is established. In order to develop a system that can truly be applied to many engines without high setup and calibration effort, this type of arrangement offers the best solution. Additionally, by utilizing two NOx sensors, the system is better able to adapt to engine and catalyst wear, which could affect the engine-out NOx and SCR conversion efficiency. 


\section{Chapter 11: Conclusions and Recommendations}

\subsection{Summary}

To significantly reduce diesel engine emissions worldwide, NOx control must focus not only on new engines, but older engines still in operation. As a result of the large emissions contributions by legacy engines, viable retrofit solutions must be implemented without requiring high engineering and calibration effort. In the past, urea-SCR technology has been well established in stationary applications, now moving into transient automotive and marine application segments in the wake of increasingly strict emissions standards. While primarily targeting new engines, urea-SCR also has great potential as a retrofit technology. A retrofit urea-SCR system was developed by a WVU research team, which included this author, initially targeting a 50\% total NOx reduction in marine applications. The system was designed to be completely independent of engine communication, implementing exhaust-mounted NOx and flow sensing equipment and an open-loop feed-forward control configuration. The system experimentally demonstrated NOx reductions of $47 \%, 47 \%$ (weighted), and 53\% over FTP, ICOMIA steady-state, and ACES HHDDT_S cycles with a maximum of $258 \mathrm{ppm}$ ammonia slip (NDUV measured) over the FTP.

A comprehensive literature survey was performed to convey understanding of diesel engine operation, emissions formation mechanisms, environmental impact of emissions, and diesel engine emissions standards. A review of current emissions reduction technologies was presented, comparing urea-SCR to other methods of NOx reduction. Ultimately, it was concluded that urea-SCR was the best option for controlling NOx emissions in a retrofit application because of the absence of a fuel economy penalty, the ability to achieve high NOx reductions in steady-state (90\%) and transient (60-80\%) conditions, highly durable catalysts, and overall cost-effectiveness. Neural network modeling strategies were reviewed to determine an appropriate architecture for emissions modeling and determine dominant input variables (example: engine speed and torque). Higher-order and reduced-order SCR catalyst models were reviewed to determine an appropriate modeling strategy. Ultimately, literature $[83,84,85]$ dictated that a 4 -state reduced order model could achieve results similar to higher-order approaches with significantly reduced development and computational effort. Control strategy development and evaluation results from US and European sources were reviewed, considering open-loop, model-based, and closed-loop (NOx and $\mathrm{NH}_{3}$ sensors) strategies. Control strategies reviewed in literature were considered during development of the three additional control strategies considered.

Four distinct control configurations were evaluated to determine an optimal configuration for the retrofit urea-SCR system. The original pre-SCR NOx sensor, open-loop feed-forward control configuration (1) was compared with configurations implementing (2) a post-SCR NOx sensor and PD control, (3) pre- and postSCR NOx sensors and PID control, and (4) a pre-SCR NOx sensor and model-based control. Additionally, 
the cost and complexity of each control configuration were considered in order to suggest an optimal configuration for the stand-alone retrofit urea-SCR system.

To evaluate the emissions performance of each control configuration, separate models were developed for the diesel engine and SCR catalyst system. The diesel engine was modeled using a neural network approach, which implemented a single hidden layer architecture and inputs of engine speed, engine torque, oil temperature, boost pressure, and their derivatives over two time intervals. The engine model was trained and validated using measurement data from the 1992 DDC S60 engine at the WVU engine laboratory, predicting exhaust temperature, $\mathrm{NOx}(\mathrm{g} / \mathrm{s})$, and exhaust volumetric flow rate over transient and steady-state test cycles. The SCR catalyst model implemented separate thermal and chemical components. The thermal model considered energy balances for the exhaust gas and SCR brick, while the chemical model considered species of gaseous $\mathrm{NO}, \mathrm{NO}_{2}$, and $\mathrm{NH}_{3}$, as well as $\mathrm{NH}_{3}$ stored within the catalyst brick. Similar to the engine model, the SCR catalyst model was validated with experimental data. The SCR model exhibited total NOx (g) differences of $9 \%, 1 \%$, and $12 \%$ over the FTP, ICOMIA, and ACES HHDDT_S cycles with respect to experimental results.

Based on emissions, complexity, and cost comparisons, a configuration implementing pre- and post-SCR NOx sensors along with PID control was selected as the optimal for a stand-alone retrofit urea-SCR system. While this configuration required the use of an additional NOx sensor, its excellent emissions performance, greater adaptability, and reduced calibration effort resulted in it being selected as optimal. The importance of these traits is further emphasized considering the intended application of the system as a retrofit technology. Model results utilizing pre- and post-SCR NOx sensors along with PID control demonstrated NOx reductions of $44 \%, 53 \%$, and $47 \%$ over FTP, ICOMIA, and ACES HHDDT_S cycles, with a maximum of 113 ppm ammonia slip over the FTP and < 20 ppm over ICOMIA and ACES HHDDT_S cycles. These results were obtained utilizing a single calibration while the original control configuration required decreased urea dosing during the ICOMIA steady-state cycle. Comparatively, the original feedforward control strategy achieved NOx reductions of $42 \%, 43 \%$, and $58 \%$ over the FTP, ICOMIA, and ACES HHDDT_S cycles, with a maximum of 158 ppm ammonia slip over the FTP.

The original feed-forward control configuration had cost performance of $\$ 7,370$ and $\$ 3,495$ per ton of NOx reduced in on-road and marine applications, respectively. The optimal configuration implementing pre- and post-SCR NOx sensors and PID control had cost performance of $\$ 8,800$ and $\$ 3,651$ per ton of NOx reduced in on-road and marine applications, respectively. The capital cost of utilizing two NOx sensors could be reduced if a virtual or model-based sensor were utilized to predict engine-out NOx. However moving to this type of arrangement would greatly reduce the robustness of the system, requiring considerable engineering and calibration time to tailor the system to specific engines. This would not be 
ideal for a retrofit application, where a universal aftertreatment system that may be installed on any engine in any application segment is beneficial

\subsection{Conclusions}

Experimental characterization of the urea-SCR system demonstrated good hardware durability and the ability to achieve a $50 \%$ NOx reduction, depending on cycle. The aftertreatment system flow and NOx measurement hardware showed good agreement with laboratory analyzers, demonstrating coefficients of determination of 0.96 and 0.902 , respectively. Accurately measuring ammonia slip during transient operation in the laboratory was difficult with the available analyzer hardware; however periods of considerable ammonia slip ( $\approx 260 \mathrm{ppm}$ raw) were able to be identified. Four control configurations were identified, including the original open-loop feed-forward strategy, which were suited to implementation in universal retrofit applications, where engine size, model year and NOx level may vary. These control configurations investigated different NOx sensor placement options and levels of model integration. A modeling strategy was developed, which allowed a quantitative comparison of emissions performance between each control configuration. The model was validated with experimental data and showed good agreement with measured values. The locations of ammonia slip as measured by the NDUV analyzer were validated with model results, although the magnitudes differed. The biggest difficulty in developing the SCR catalyst model was in determining appropriate reaction parameters, which were not always available in literature.

It was stated that greater than $300 \mathrm{ppm} \mathrm{NH}_{3}$ slip is considered to be immediately dangerous to life and health, while $<50 \mathrm{ppm} \mathrm{NH}_{3}$ is acceptable for less than a 15 minute duration [94]. However, without an EPA designated allowable ammonia slip concentration, determining a truly optimal calibration for any SCR control strategy is difficult. Different calibrations and/or control configurations could be tailored to the application segment (on-road vs. marine) for greater emissions performance, while still allowing broad applicability without increased setup effort. Utilizing a fast-response NOx sensor may not necessarily be required, especially during very transient operation. In many cases, urea injection cannot keep up with rapid NOx variations, and when combined with slow catalyst dynamics, could result in ammonia slip. The cost associated with engineering and calibration effort was high, representing $8-41 \%$ of the total development cost, depending on control strategy. By minimizing engineering and calibration effort, significant annual cost savings may be realized. Additionally, by moving from a one-off system to larger production volumes will significantly reduce system capital and manufacturing cost.

Finally, an optimal control configuration was suggested, considering tradeoffs between system complexity, reduction ability, and cost. The open-loop, feed-forward configuration offered a simple and cost effective solution, but its inability to adapt to changes in engine behavior and lack of feed-back data hindered its performance. The post-SCR NOx sensor configuration was best suited to steady-state engine behavior because of its lack of engine-out NOx data. In a purely marine or steady-state application appropriate NOx 
setpoints could be found, however it lacked sufficient sensor information for a transient application. Of all the control configurations, the model-based strategy offered the best control of ammonia slip because of its $\mathrm{NH}_{3}$ surface coverage predictions. Still, catalyst dynamics combined with transient engine operation limited potential reductions. The pre- and post-SCR NOx sensor configuration clearly offered the best emissions performance and adaptability. Despite its higher capital cost, when comparing overall NOx reduction cost, emissions performance, complexity, and robustness together, it offered the best solution. Additionally, considering its application as a retrofit technology, utilizing two NOx sensors allowed universal applicability.

\subsection{Recommendations}

It is recommended that the system hardware be reviewed to see if more cost effective solutions for differential pressure sensor, controller, and NOx sensors could be found. One example is that during an additional round of testing with the retrofit urea-SCR system, a simpler analog controller was implemented with cost in the $\$ 200$ range. A more cost effective slower-response or less accurate NOx sensor solution should be especially considered, seeing that it is difficult for the urea injection to keep up with very accurate NOx signals during transient operation. Additionally, an SCR catalyst with improved temperature performance should be investigated and could be tailored to the expected application segment (on-road vs. marine). The possibility of a $\mathrm{NH}_{3}$ sensor should be considered for a different type of control configuration. At the time of hardware selection, no commercially available $\mathrm{NH}_{3}$ sensors were available, however many researchers and agencies (Delphi) [112,113] are working on development of such hardware, which may be available at a later date. This type of a control configuration would allow urea dosing to be decreased only at a time when it is confirmed that ammonia slip is actually beginning to occur. However issues with time delay, $\mathrm{NH}_{3}$ storage, and catalyst dynamics may still have to be overcome.

Separately, it is recommended that the use of a cleanup catalyst be investigated as an additional method of $\mathrm{NH}_{3}$ slip control. During a third testing period of the urea-SCR system under the MJB\&A contract, not included in the dissertation research, a cleanup catalyst (DOC) was implemented, which all but eliminated $\mathrm{NH}_{3}$ slip. It should be noted however that the inclusion of a cleanup catalyst is not a replacement for accurate urea dosing control. Although even high levels of $\mathrm{NH}_{3}$ slip may be eliminated by a cleanup catalyst, their oxidation may result in the creation of additional NOx emissions. Emissions performance advantages should be weighted against increased system cost and packaging issues for such a configuration. It is also recommended that for actual implementation as a retrofit package, the system be pre-configured with separate calibrations for on-road and marine applications. In this manner, parameters could be more specifically tuned for the application segment and improved emissions performance could be achieved.

For commercial implementation of such a retrofit urea-SCR system, additional fault detection measures should be integrated into the control strategy. This could include being able to perform simple calculations 
to ensure measurement variables are within appropriate ranges, determining failure of hardware components, and tracking catalyst wear or deactivation. One fault detection advantage that a two NOx sensor configuration exhibits is the possibility of defaulting to either a pre-SCR NOx sensor, feed-forward control strategy or a post-SCR feed-back control strategy upon failure of one NOx sensor.

Finally, the optimal control configuration should be evaluated experimentally to confirm model predictions and allow further tuning, if required. During this testing, higher transient ammonia slip accuracy should be prioritized, possibly implementing more accurate $\mathrm{NH}_{3}$ sensing equipment such as the Horiba MEXA$1170 \mathrm{NX}$ analyzer. 


\section{Sources}

1. United States Census Bureau, "World POPClock Projection," US Census Bureau, International Database, http://www.census.gov/ipc/www/popclockworld.html, Accessed 13 Aug 2009.

2. California Environmental Protection Agency Air Resources Board. "Health Effects of Diesel Exhaust Particulate Matter," CARB, Sacramento, CA, 2006.

3. United States Environmental Protection Agency Office of Mobile Sources. "Automobiles and Carbon Monoxide," EPA400-F-92-005, US EPA, Washington, DC, 1993.

4. United States Environmental Protection Agency Office of Air Quality Planning and Standards, "NOx: How Nitrogen Oxides Affect the Way We Live and Breathe," EPA456/F-98-005, US EPA, Washington, DC, 1998.

5. California Environmental Protection Agency Air Resources Board, "Summary of Adverse Impacts of Diesel Particulate Matter," CARB, Sacramento, CA, 2005.

6. United States Environmental Protection Agency, "Diesel Exhaust in the United States," EPA420-F-03-022, US EPA, Washington, DC, 2002.

7. United States Environmental Protection Agency. "Non-Road Diesel Equipment," http://www.epa.gov/nonroad-diesel/, Accessed 10 Jan 2008.

8. National Automobile Dealers Association, “NADA Data 2009,” Autoexec Magazine, pp. 1-20, 2009, www.nada.org/nadadata, Accessed 22 Sept, 2009.

9. United States Environmental Protection Agency, “Automobiles and Ozone," Fact Sheet OMS-4, US EPA, Washington, DC, 1993.

10. Dieselnet Technology Guide. "Diesel Emission Control," Revision 2007.05a, Ecoprint Inc., www.dieselnet.com/tech/engine control.html, Accessed 8 Jan 2008.

11. Pulkrabek, W.W., Engineering Fundamentals of the Internal Combustion Engine, Second Edition, Pearson Prentice-Hall, Upper Saddle River, NJ, 2004.

12. Heywood, J.B., Internal Combustion Engine Fundamentals, McGraw Hill, New York, NY, 1988.

13. Borman, G.L., Ragland, K.W., Combustion Engineering, WCB/McGraw Hill, New York, NY, 1998.

14. United States Environmental Protection Agency, "Emissions Standards Reference Guide for Heavy-Duty and Nonroad Engines," EPA420-F-97-014, US EPA, Washington, DC, 1997.

15. United States Environmental Protection Agency, "Greenhouse Gas Emissions," http://www.epa.gov/climatechange/emissions/index.html, Accessed 8 Jan 2008.

16. Uihlein, J., LeTavec, C., Lev-On, M., Vertin, K., Lawson, D.R., Alleman, T.L., Wayne, S., Gautam, M., Thompson, G.J., Sagebiel, J., Zielinska, B., Chatterjee, S., Hallstrom, K., 
"Chemical Speciation of Exhaust Emissions from Trucks and Buses Fueled on Ultra-Low Sulfur Diesel and CNG," SAE, Warrendale, PA, SAE Paper 2002-01-0432.

17. Lambert, C., Hammerie, R., McGill, R., Khair, M., Sharp, C., "Technical Advantages of Urea SCR for Light-Duty and Heavy-Duty Diesel Vehicle Applications," SAE, Warrendale, PA, SAE Paper 2004-01-1292.

18. Hillard, J.C., Wheeler, R.W., "Nitrogen Dioxide in Engine Exhaust," SAE, Warrendale, PA, SAE Paper 790691, 1979.

19. Pierpont, D.A., Reitz, R.D., "Effects of Injection Pressure and Nozzle Geometry on D.I. Diesel Emissions and Performance," SAE, Warrendale, PA, SAE Paper 950604, 1995.

20. Amann, C.A., Siegla, D.C., "Diesel Particulates- What They Are and Why," Aerosol Science Technology, Taylor and Francis, Philadelphia, PA, Vol. 1, pp. 73-101, 1982.

21. United States Environmental Protection Agency, "Particulate Matter," http://www.epa.gov/oar/particlepollution/, Accessed 10 Jan 2008.

22. Lavoie, G.A., Heywood, J.B., Keck, J.C., "Experimental and Theoretical Investigation of Nitric Oxide Formation in Internal Combustion Engines," Combustion Science and Technology, Taylor and Francis, Philadelphia, PA, Vol. 1, pp. 313-326, 1970.

23. Heywood, J.B., Fay, J.A., Linden, L.H., "Jet Aircraft Air Pollution Production and Dispersion,” AIAA Journal, Reston, VA, Vol. 9, No. 5, pp. 841-850, 1971.

24. United States Environmental Protection Agency. "Hydrocarbons- Mobile Source Emissions," http://www.epa.gov/oms/invntory/overview/pollutants/hydrocarbons.htm, Accessed 18 Dec 2008.

25. United States Environmental Protection Agency, "National Ambient Air Quality Standards," http://www.epa.gov/air/criteria.html, Accessed 31 Dec 2008.

26. United States Environmental Protection Agency, "The Greenbook Nonattainment Areas for Criteria Pollutants," http://www.epa.gov/oar/oaqps/greenbk/index.html, Accessed 19 Dec 2008.

27. United States Environmental Protection Agency, "Federal and California Exhaust and Evaporative Emissions Standards for Light-Duty Vehicles and Light-Duty Trucks," EPA420-B-00-001, US EPA, Washington, DC, 2000.

28. National Research Council, Board on Energy and Environmental Systems, Review of the 21st Century Truck Partnership, National Academies Press, Washington, DC, 2008.

29. California Environmental Protection Agency Air Resources Board, "Supplemental Emission Test Procedures for 2005+ Model Year Heavy-Duty Diesel Engines," CARB, Sacramento, CA, 2000.

30. Protection of Environment, Code of Federal Regulations, Part 86, Title 40, US Government Printing Office, Washington, DC, 2004. 
31. Dieselnet, "Emissions Standards, United States, Marine Diesel Engines," Rev. 2008.05, Ecopoint Inc., http://www.dieselnet.com/standards/us/marine.php, Accessed 8 Jan 2008.

32. United States Environmental Protection Agency, "Overview of EPA's Emissions Standards for Marine Engines,” EPA420-F-04-031, US EPA, Washington, DC, 2004.

33. Challen, B., Baranescu, R., Diesel Engine Reference Book, $2^{\text {nd }}$ Edition, SAE, Warrendale, PA, 1998.

34. Najt P.M and Foster D.E., "Compression-Ignited Homogeneous Charge Combustion," SAE, Warrendale, PA, SAE Paper 830264, 1983.

35. Ryan III T. W., Gray A.W., "Homogeneous Charge Compression Ignition (HCCI) of Diesel Fuel," SAE, Warrendale, PA, SAE Paper 971676, 1997.

36. Westbrook C. K., "Chemical Kinetics of Hydrocarbon Ignition in Practical Combustion Systems," Proceedings of the 28th International Combustion Symposium, Edinburgh, Scotland, 2000.

37. Milovanovic N., Chen R., "A Review of Experimental and Simulation Studies on Controlled Auto-Ignition Combustion," SAE, Warrendale, PA, SAE Paper 2001-011890.

38. Courtney, R.L., Newhall, H.K., "Automotive Fuels for the 1980s," SAE Paper 790809.

39. The Official Site of the National Biodiesel Board. http://www.biodiesel.org/resources/fuelfactsheets/default.shtm. Accessed on 6 July 2006.

40. United States Environmental Protection Agency Office of Transportation and Air Quality, "Questions and Answers on Using a Diesel Particulate Matter Filter in HeavyDuty Trucks and Buses," EPA420-F-03-017, US EPA, Washington, DC, June 2003.

41. United States Environmental Protection Agency, "Questions and Answers on Using a Diesel Oxidation Catalyst in Heavy-Duty Trucks and Buses," EPA420-F-03-016, US EPA, Washington, DC, 2003.

42. Johnson, T.V., "Diesel Emission Control in Review - The Last 12 Months," SAE, Warrendale, PA, SAE Paper 2003-01-0039.

43. California Air Resource Board, "Diesel PM Control Technologies," Appendix IX, CARB, Sacramento, CA, 2000.

44. Emissions Advantage, LLC, "Wrap Offroad Diesel Retrofit Guidance Document," Volume 2, Section IV, Western Regional Air Partnership, Emissions Advantage, LLC, Washington, DC, 2005.

45. Johnson, T.V., "Diesel Emission Control in Review," SAE, Warrendale, PA, SAE Paper 2006-01-0030.

46. Basshuysen, R., Schafer, F., Modern Engine Technology from A to Z, SAE International, Warrendale, PA, 2007. 
47. Anthony, R.G., McKetta, J.J., Encyclopedia of Chemical Processing and Design, CRC Press, Boca Raton, FL, 1998.

48. Gieshoff, J., Pfeifer, M., Schafer-Sindlinger, A., Spurk, P.C., Garr, G., Leprince, T., Crocker, M., "Advanced Urea SCR Catalysts for Automotive Applications," SAE, Warrendale, PA, SAE Paper 2001-01-0514.

49. Johnson, T.V., "Diesel Emission Control Technology- 2003 in Review," SAE, Warrendale, PA, SAE Paper 2004-01-0070.

50. Schar, C.M., Onder, C.H., Geering, H.P., Elsener, M., "Control-Oriented Model of an SCR Catalytic Converter System,” SAE, Warrendale, PA, SAE Paper 2004-01-0153.

51. Willems, F., Cloudt, R., Eijnden, E., Genderen, M., Verbeek, R., Jager, B., Boomsma, W., Heuvel, I., "Is Closed-Loop Control Required to Meet Future Emissions Requirements," SAE, Warrendale, PA, SAE Paper 2007-01-1574.

52. Shost, M., Noetzel, J., Wu, M., Sugiarto, T., Bordewyk, T., Fulks, G., Fisher, G.B., "Monitoring, Feedback and Control of Urea SCR Dosing Systems for NOx Reduction: Utilizing an Embedded Model and Ammonia Sensing," SAE, Warrendale, PA, SAE Paper 2008-01-1325.

53. Chatterjee, D., Burkhardt, T., Weibel, M., Tronconi, E., Nova, I., Ciardelli, C., "Numerical Simulation of $\mathrm{NO} / \mathrm{NO}_{2} / \mathrm{NH}_{3}$ Reactions on SCR-Catalytic Converters: Model Development and Applications," SAE, Warrendale, PA, SAE Paper 2006-01-0468.

54. Gekas, I., Gabrielsson, P., Johansen, K., Nyengaard, L., Lund, T., "Urea-SCR Catalyst System Selection for Fuel and PM Optimized Engines and a Demonstration of a Novel Urea Injection System,” SAE, Warrendale, PA, SAE Paper 2002-01-0289.

55. Krishnan, R., Tarabulski, T.J., "Economics of Emission Reduction for Heavy Duty Trucks," Dieselnet Technical Report, http://www.dieselnet.com/papers/0501krishnan/ Accessed 30 July 2009.

56. Perhinschi, Mario G., "MAE 593J Spring 2007 Handout: Artificial Intelligence Techniques in Engineering," Department of Mechanical and Aerospace Engineering, West Virginia University, Morgantown, WV, 2007.

57. Khatri, D., Kumar, S., "Feasibility Study on Neural Network Approach in Engine Management System in S.I. Engine,” SAE, Warrendale, PA, SAE Paper 2000-01-1426.

58. Arsie, I., Pianese, C., Rizzo, R., Serra, G., "Development and Validation of a Model for Mechanical Efficiency in a Spark-Ignition Engine," SAE, Warrendale, PA, SAE Paper 1999-01-0905.

59. Duyar, A., Merrill, W., "A Failure Diagnosis System Based on a Neural Network Classifier for the Space Shuttle Main Engine," Proceedings of the 29th IEEE Conference on Decision and Control, Honolulu, HI, Part 4, pp. 2391-2400, 1990. 
60. Winsel, T., Ayeb, M., Lichtenthaler, D., Theuerkauf, H.J., “A Neural Estimator for Cylinder Pressure and Engine Torque,” SAE, Warrendale, PA, SAE Paper 1999-01-1165.

61. Jarrett, R.P., Clark, N.N., "Weighting of Parameters in Artificial Neural Network Prediction of Heavy-Duty Diesel Engine Emissions," SAE, Warrendale, PA, SAE Paper 2002-02-2878.

62. Perhinschi, M.G., Wayne, W.S., Clark, N.N., Lyons, D.W., "Neural Network Modeling of Emissions from Medium-Duty Vehicles Operating on Fisher-Tropsch Synthetic Fuel," SAE, Warrendale, PA, SAE Paper 2007-01-1080.

63. Clark, N.N., Tehranian, A., Jarrett, R.P., Nine, R.D., "Translation of Distance Specific Emissions Rates between Different Heavy-Duty Vehicle Chassis Test Schedules," SAE, Warrendale, PA, SAE Paper 2002-01-1754.

64. Clark, N.N., Bedick, C.R., Wang, L., Thompson, G., McKain, D., Ralston, B., "Emissions from a Legacy Diesel Engine Exercised through the ACES Engine Test Schedule," SAE, Warrendale, PA, SAE Paper 2008-01-1679.

65. Thompson, G.J., Atkinson, C.M., Clark, N.N., Long, T.W., Hanzevack, E., "Neural Network Modeling of the Emissions and Performance of a Heavy-Duty Diesel Engine," Proceedings of the Institution of Mechanical Engineers, London, UK, Vol. 214, Part D, pp. 111-126, 2000.

66. Hashemi, N., Clark, N.N., “Artificial Neural Network as a Predictive Tool for Emissions from Heavy-Duty Diesel Vehicles in Southern California," International Journal of Engine Research, Professional Engineering Publishing, London, UK, Vol. 8, 2007.

67. Song, Q., Zhu, G., "Model-based Closed-loop Control of Urea SCR Exhaust Aftertreatment System for Diesel Engine," SAE, Warrendale, PA, SAE Paper 2002-010287.

68. Upadhyay, D., Nieuwstadt, M.V., "Model Based Analysis and Control Design of a UreaSCR deNOx Aftertreatment System," Journal of Dynamic Systems, Measurement, and Control, ASME, New York, NY, Vol. 128, pp. 737-741, 2006.

69. Johnson, Derek, "Testing and Implementation of an Independently Controlled Urea-SCR in Marine Applications," Mechanical Engineering Masters Thesis, West Virginia University, 2008 (available at http://www.libraries.wvu.edu/etds/).

70. Omega Engineering Inc., "Data Sheet: PX2300 Wet/Wet Differential Pressure Sensor," http://www.omega.com/Pressure/pdf/PX2300.pdf, Accessed 18 May 2008.

71. Omega Engineering Inc., "Data Sheet: Universal Temperature Transmitter-Connector for RTDs and Thermocouples," http://www.omega.com/Temperature/pdf/SPRTX_STCTX.pdf, Accessed 18 May 2008. 
72. Terra Industries Inc., "TerraCair Ultrapure Diesel Exhaust Fluid: Technical Data/Specifications," http://www.tet-terra.com/mobile/technical-data.php, Accessed 15 May 2008.

73. Siemens VDO Automotive, "Smart NOx-Sensor Brochure," VDO, Regensburg, Germany, 2008.

74. MJ Bradley and Associates, "Development of an Independently Controlled Urea-SCR System for Deep NOx Reduction in Marine Applications," TERC NTRD RFGA-07 Proposal, Manchester, NH, 2006.

75. West Virginia University, "CAFEE Emissions Laboratory Standard Procedures, Calibration Procedures and Scheduled Maintenance Checks, Center for Alternative Fuels, Engines and Emissions," West Virginia University, Morgantown, WV, Version $20070305,2007$.

76. Clark, N.N., Gautam, M., Wayne, W.S., Thompson, G., Lyons, D.W., Zhen, F., Bedick, C., Atkinson, R.J., McKain, D.L. "Creation of the 'Heavy Heavy-Duty Diesel Engine Test Schedule' for Representative Measurement of Heavy-Duty Engine Emissions," CRC Report No. ACES-1, Coordinating Research Council, Alpharetta, GA, 2007.

77. Advanced Optima Continuous Gas Modules, "AO2000 Series Data Sheet," ABB Automation GmbH, Germany, 2008.

78. Horn, M., Steven, H., Haberkorn, U., Schulte, L., "Pollutant and Noise Emissions of Motorboats, a Basis for Updating the EU Directive 94/25/EC for Limiting the Emissions of Motorboats," Federal Environmental Ministry, Germany, 2005.

79. Clark, N.N., Gautam, M., Wayne, W.S., Lyons, D.W., Thompson, G., "Heavy-Duty Vehicle Chassis Dynamometer Testing for Emissions Inventory, Air Quality Modeling, Source Apportionment and Air Toxics Emissions Inventory," CRC Report No. E55/59, Coordinating Research Council, Alpharetta, GA, 2007.

80. Gautam, M., Clark, N.N., Riddle, W., Nine, R., Wayne, W.S., Maldonado, H., Agrawal, A., Carlock, M., "Development and Initial Use of a Heavy Duty Diesel Truck Test Schedule for Emissions Characterization," SAE, Warrendale, PA, SAE Paper 2002-011753.

81. Clark, N.N., Gautam, M., Riddle, W., Nine, R.D., Wayne, W.S., "Examination of a Heavy-Duty Diesel Truck Chassis Dynamometer Schedule," SAE, Warrendale, PA, SAE Paper 2004-01-2904.

82. Matlab R2007b Product Help, "Trainlm Help," The Mathworks Inc., 2007.

83. Chi, J.N., DaCosta, H.F.M., "Modeling and Control of a Urea-SCR Aftertreatment System," SAE, Warrendale, PA, SAE Paper 2005-01-0966. 
84. Devarakonda, M., Parker, G., Johnson, J.H., Strots, V., Santhanam, S., "Model-Based Estimation and Control System Development in a Urea-SCR Aftertreatment System,” SAE, Warrendale, PA, SAE Paper 2008-01-1324.

85. Devarakonda, M., Parker, G., Johnson, J.H., Strots, V., Santhanam, S., “Adequacy of Reduced Order Models for Model-Based Control in a Urea-SCR Aftertreatment System," SAE, Warrendale, PA, SAE Paper 2008-01-0617.

86. Mills, A.F., Heat Transfer, $2^{\text {nd }}$ Edition, Prentice Hall, Upper Saddle River, NJ, 1998.

87. Madireddy, M.R., Clark, N.N., "Sequential Inversion Technique and Differential Coefficient Approach for Accurate Instantaneous Emissions Measurement,” International Journal of Engine Research, Professional Engineering Publishing, London, UK, Vol. 7, pp. 437-446, 2006.

88. Ramamurthy, R., Clark, N.N., Atkinson, C.M., Lyons, D.W., "Models for Predicting Transient Heavy Duty Vehicle Emissions," SAE, Warrendale, PA, SAE Paper 982652.

89. Ajtay, D., Weilenmann, M., “Compensation of the Exhaust Gas Transport Dynamics for Accurate Instantaneous Emissions Measurements," Environmental Science and Technology, Iowa City, IA, Vol. 38, pp. 5141-5148, 2004.

90. Kar, K., Roberts, S., Stone, R., "Instantaneous Exhaust Temperature Measurements Using Thermocouple Compensation Techniques," SAE, Warrendale, PA, SAE Paper 2004-01-1418.

91. Omega Engineering Inc., "Comparison of Time Constant vs. Overall Outside Diameter of Bare Thermocouple Wires or Grounded Junction Thermocouples In Air," http://www.omega.com/temperature/Z/pdf/z051.pdf, Accessed 11 May 2009.

92. Gnielinski, V., "New Equations for Heat and Mass Transfer in Turbulent Pipes and Traversed Canals," Research in Engineering, Germany, Vol. 41, pp. 8-16, 1975.

93. Gnielinski, V., "Calculating Medium Heat and Mass Transfer Coefficients in Laminar and Turbulent Overflowed Individual Bodies with the Help of a Single Equation," Research in Engineering, Germany, Vol. 41, pp. 145-153, 1975.

94. Terra Industries Inc., "TerraCair ${ }^{\mathrm{TM}}$ Urea Solution, AUS 32 Material Safety Data Sheet," MSDS Number 2047, Terra Industries, Sioux City, IA, 2007.

95. E.H. Pechan \& Associates, Inc., "AirControNET Version 4.1 Documentation Report," Pechan Report No. 06.05.003/9011.002, . E.H. Pechan \& Associates, Springfield, VA, 2006.

96. Clean Air Online 5.2.7, “Ammonia,” Environment Canada, http://www.ec.gc.ca/cleanairairpur/default.asp?lang=En\&n=27A52116-1, Accessed 24 Sept 2009.

97. National Fire Protection Association, "NFPA 704: Standard System for the Identification of the Hazards of Materials for Emergency Response,” NFPA, Quincy, MA, 2007. 
98. Ogata, Katsuhiko, Modern Control Engineering, Fourth Edition, Prentice Hall, Upper Saddle River, NJ, 2002.

99. Li, Y., Ang, K.H., Chong, G.C.Y., "PID Control System Analysis and Design," IEEE Control Systems Magazine, IEEE Control Systems Society, Ann Arbor, MI, Vol. 26, pp. 32-41, 2006.

100. Keenan, M., "Review of NOx Reduction Technologies to Meting Light Duty Diesel 2010 and 2015 and Heavy Duty Diesel 2013 European Legislative Limits," RD.04/330601.2, Ricardo Consulting Engineers Ltd, UK 2004.

101. Mira Ltd., Peter Brett Associates, "Emission Control Technology for Heavy-Duty Vehicles, Final Report,” ETD/00/503430, UK, 2002.

102. Creese, R.C., Introduction to Manufacturing Processes and Materials, Marcel Dekker, Inc., New York, NY, 1999.

103. Rosenbaum, A., "Measuring Output Prices for Engineering Services in the United States," Producer Price Index, US Bureau of Labor Statistics, Washington, DC, 2002.

104. Protection of Environment, Code of Federal Regulations, Part 1065, Title 40, US Government Printing Office, Washington, DC, 2008.

105. Omega Engineering Inc.; "Omega Calibration and Testing Services," http://www.omega.com/cservice/isection/index.html, Accessed 6 Aug 2009.

106. Schedel, H., Fischer, S., Ballmert, B., "Durability of Extruded Homogeneous SCR Catalyst," SAE, Warrendale, PA, SAE Paper 2004-01-0075.

107. Cheng, Y., Xu, L., Hangas, J., Jagner, M., Lambert, C., "Laboratory Postmortem Analysis of 120k mi Engine-Agfed Urea SCR Catalyst," SAE, Warrendale, PA, SAE Paper 2007-01-1579.

108. Amon, B., Keefe, G., "On-Road Demonstration of NOx Emission Control for HeavyDuty Diesel Trucks using SINOx ${ }^{\mathrm{TM}}$ Urea SCR Technologies $\sim$ Long-Term Experience and Measurement Results,” SAE, Warrendale, PA, SAE Paper 2001-01-1931.

109. US Environmental Protection Agency, "Introduction of Cleaner-Burning Diesel Fuel Enables Advanced Pollution Control for Cars, Trucks, and Buses,” Program Update, EPA420-F-06-037, US EPA, Washington, DC, 2006.

110. Air Quality Division, "Texas Emissions Reduction Plan: Guidelines for Emissions Reduction Incentive Grants," RG-388, Texas Commission on Environmental Quality, Austin, TX, April 2008.

111. Air Resources Board California Environmental Protection Agency, "The Carl Moyer Program Guidelines," Approved Revision 2008, CARB, Sacramento, CA, April 2008.

112. Wang, D.Y., Sheng, Y., Shost, M., Yoo, J., Cabush, D., Racine, D., Cloudt, R., Willems, F., "Ammonia Sensor for Closed-Loop SCR Control," SAE, Warrendale, PA, SAE Paper 2008-01-0919. 
113. Wang, D.Y., Yao, S., Cabush, D., Racine, D., “Ammonia Sensor for SCR NOx Reduction," Proceedings of the Department of Energy Diesel Engine-Efficiency and Emissions Research Conference, Detroit, MI, 2007. 
Appendix A. Urea-SCR Test Plan

Project Title: Stand-Alone Urea-SCR System Testing, Round 2

Source of Funds: MJ Bradley and Associates

Estimated Staff Requirements:

Engineer: Brad Ralston

Graduate Students: Clint Bedick, Derek Johnson, Francisco Posada

Testing Dates: January 5-9, 2009

\section{Experimental Setup:}

Engine: 1992 Detroit Diesel Series 60

Dilution Tunnel: pre-2007 tunnel

Dynamometer: General Electric 500hp, connected via driveshaft and Vulkan coupling

Measured Parameters/Emissions: $\mathrm{CO}, \mathrm{CO}_{2}, \mathrm{HC}, \mathrm{NOx}, \mathrm{NH}_{3}, \mathrm{PM}$ (total), fuel weight, urea tank weight

Gases Needed: Zero and span for all standard analyzers, zero and span for $\mathrm{NDUV} \mathrm{NH}_{3}$ analyzer

Details: Second round of testing for the stand-alone urea-SCR system, including the addition of a mixing device downstream of the urea injector. ICOMIA, FTP, and ACES test cycles will be run for more comprehensive data collection. Prior to operating the aftertreatment system, urea dosing parameters may require calibration in the control code. If necessary, the urea dosing parameters will be calibrated in real time by monitoring instantaneous ammonia slip while running a transient cycle or selecting steady-state points. Ammonia slip will be measured during transient testing using an Ecophysics NOx analyzer running in $\mathrm{NOx} / \mathrm{NH}_{3}$ mode. An Advanced Optima NDUV $\mathrm{NH}_{3}$ analyzer will be run in parallel for increased accuracy during steady-state measurements.

Test Plan: All runs are hot starts, with 20-minute hot soaks in between, utilizing the same ultra-low-sulfur diesel fuel, urea dosing parameters, and mixing device. Each day, a warm up FTP run (cold start test in the software) will be performed to bring the engine up to operating temperature. Background emissions will be taken at the beginning or end of each test day and the tunnel integrity verified with propane injections at least once during the duration of testing.

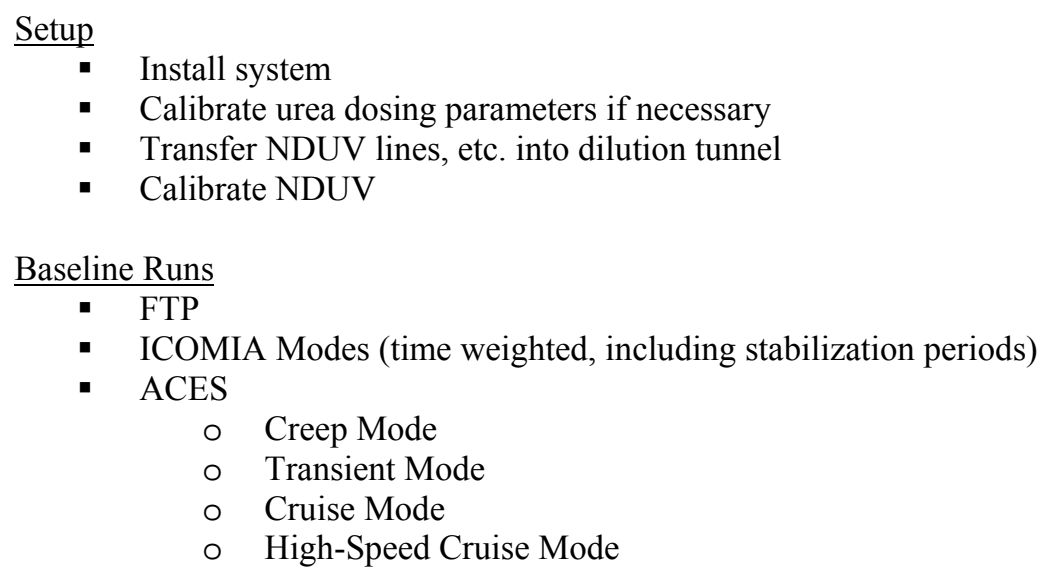


Urea Injection Runs

- FTP

- ICOMIA Modes (time weighted, including stabilization periods)

- ACES

o Creep Mode

o Transient Mode

o Cruise Mode

o High-Speed Cruise Mode

Catalyst Storage Run

Periods of no-injection and over-injection will be performed in order to observe how $\mathrm{NH}_{3}$ may be adsorbed and desorbed from the SCR catalyst, as well as to determine what maximum quantity of $\mathrm{NH}_{3}$ may be stored. For these injection strategies, Test Stage 3 from the ICOMIA points will be utilized. All emissions, engine, and aftertreatment system data will be continuously recorded during this run.

- Run the engine without urea injection for five minutes to ensure all $\mathrm{NH}_{3}$ is removed from the catalyst substrate.

- Over-saturate the catalyst with $\mathrm{NH}_{3}$ until analyzer shows breakthrough of urea, indicating that the maximum amount of $\mathrm{NH}_{3}$ has been stored in the substrate.

- Run the engine without urea injection again until all NH3 is desorbed from the catalyst.

ICOMIA Steady-State Test Cycle

\begin{tabular}{|c|c|c|c|c|c|}
\hline Test Cycle - EN ISO 8178 - 4 cycle E5 (diesel engines, < 25m craft length) \\
\hline Test Stage & 1 & 2 & 3 & 4 & 5 \\
\hline \%Speed & 100 & 91 & 80 & 63 & Low Idle \\
\hline \%Power & 100 & 75 & 50 & 25 & 0 \\
\hline Time Weighting & 0.08 & .13 & 0.17 & 0.32 & 0.30 \\
\hline Time Duration (sec) & 120 & 195 & 255 & 480 & 450 \\
\hline
\end{tabular}


Appendix B. Transient Test Cycle Engine Speed and Torque Plots

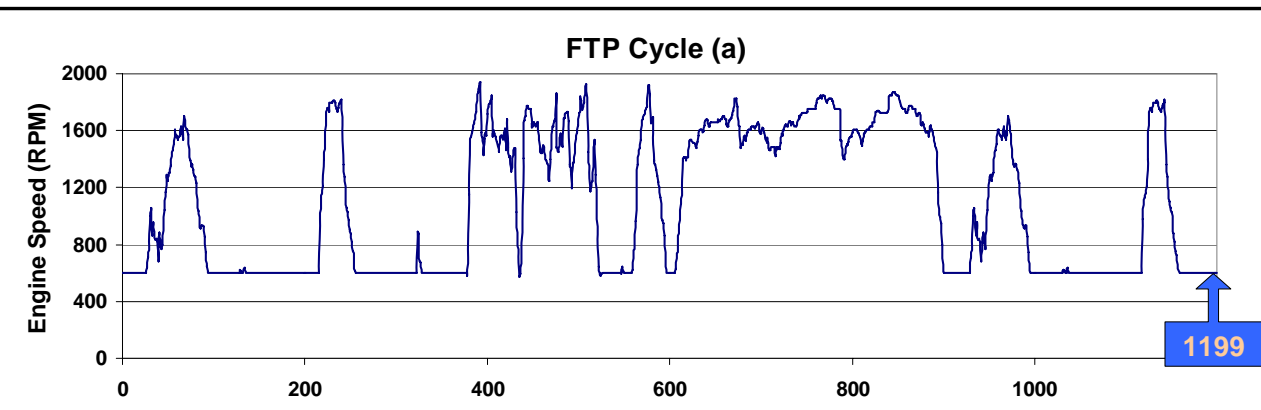

Transient Mode (b)
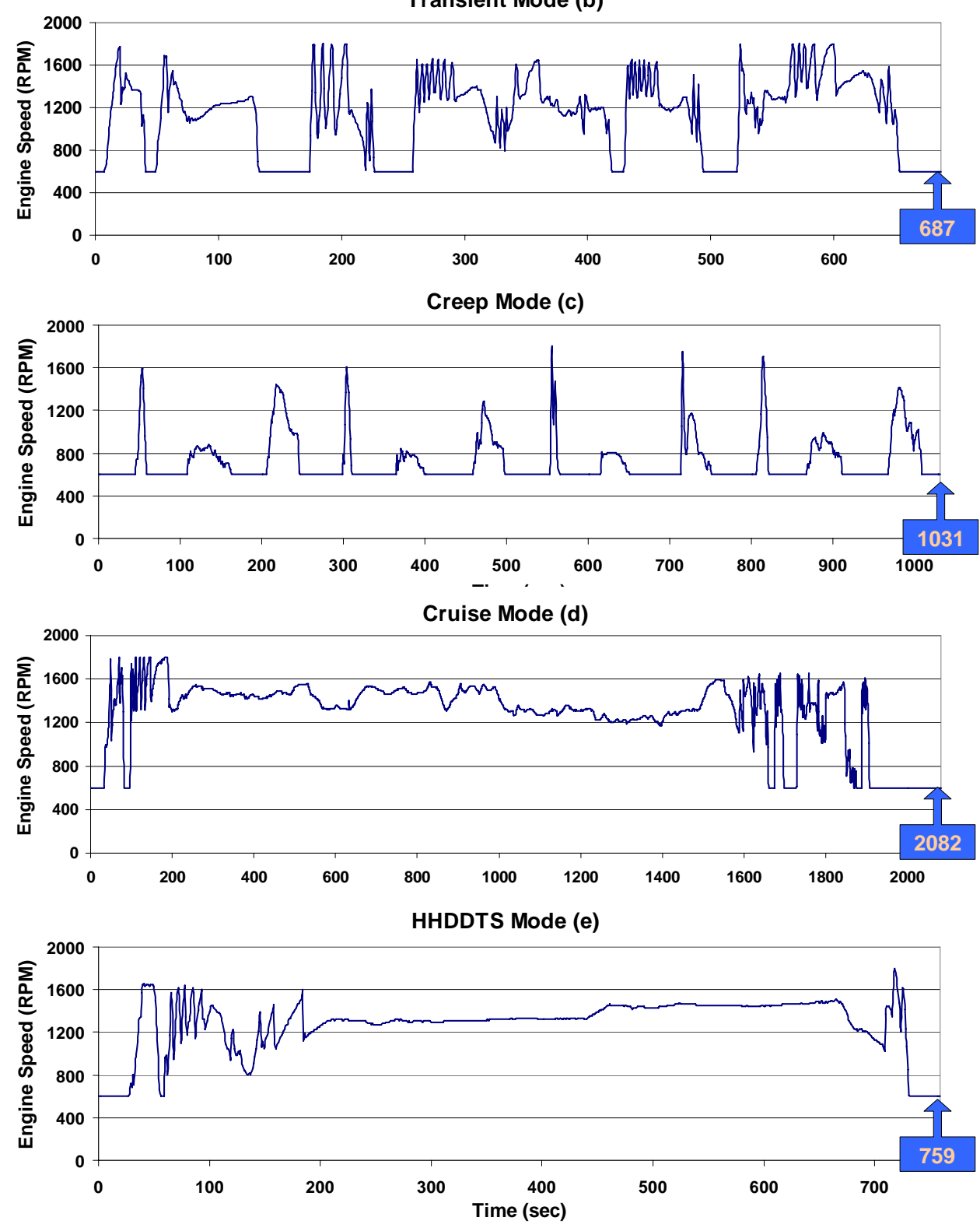

Figure 91. Transient test cycles, engine speed (rpm) 


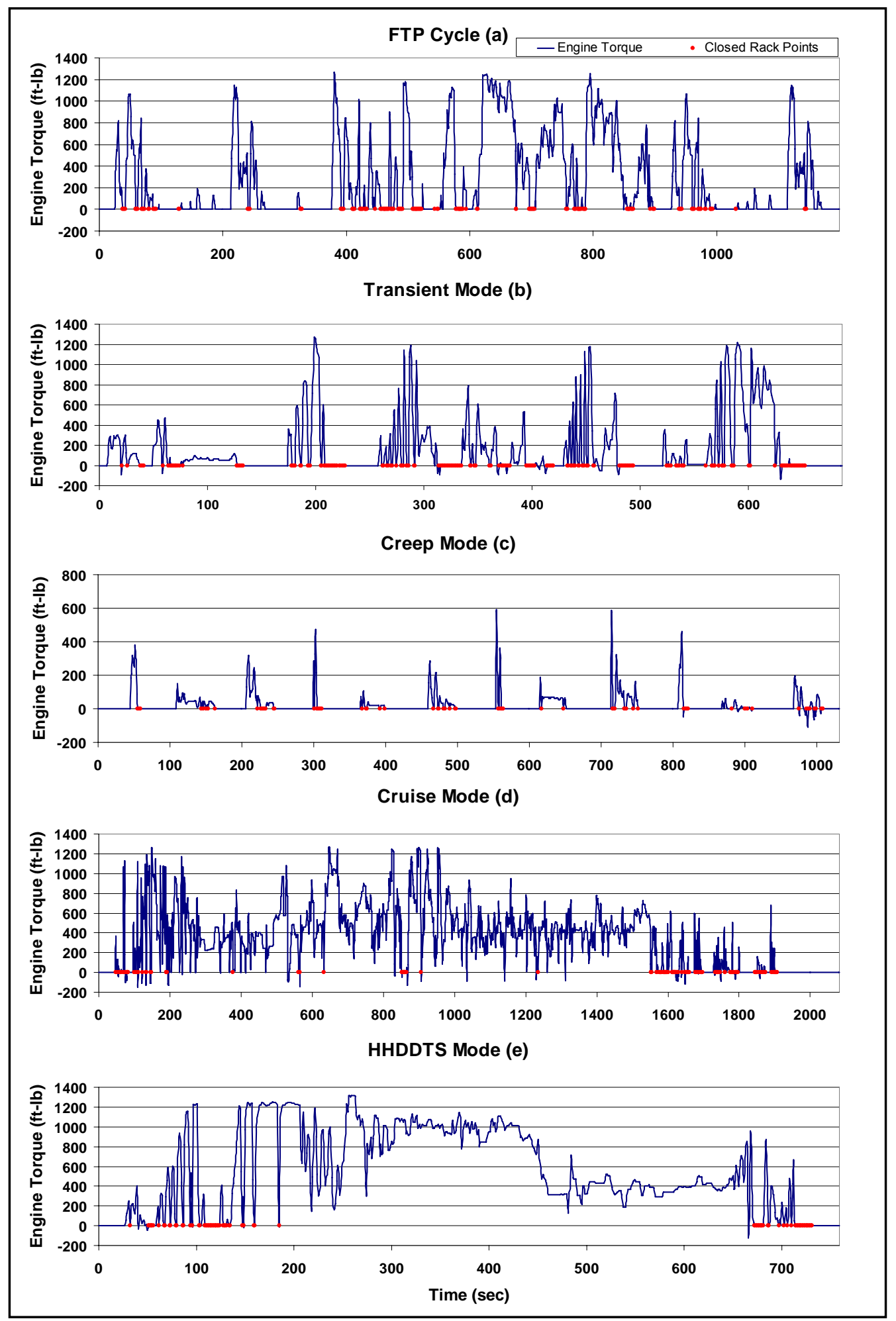

Figure 92. Transient test cycles, engine torque (ft-lb) 
Appendix C. Experimental Test Run Summary

Table 51. Experimental test run summary

\begin{tabular}{|c|c|c|c|c|c|}
\hline Date and Time & Event/Test Name & Event/Test Description & $\begin{array}{l}\text { Start } \\
\text { Type }\end{array}$ & Urea & $\begin{array}{l}\text { Urea } \\
\text { Factor }\end{array}$ \\
\hline 1/6/09 4:36 PM & EO2541-91 & Engine MAP 1 & -- & -- & -- \\
\hline 1/6/09 4:41 PM & EO2541-92 & Engine MAP 2 & -- & -- & -- \\
\hline 1/6/09 4:46 PM & EO2541-93 & Engine MAP 3 & -- & -- & -- \\
\hline 1/6/09 4:51 PM & EO2541-94 & Engine MAP 4 & -- & -- & -- \\
\hline 1/7/09 10:32 AM & EO2542-01 & ICOMIA SS (practice) & -- & $\mathrm{n}$ & -- \\
\hline 1/7/09 11:18 AM & EO2543-01 & FTP & w & $\mathrm{n}$ & -- \\
\hline 1/7/09 11:58 AM & EO2543-02 & FTP & $\mathrm{h}$ & $\mathrm{n}$ & -- \\
\hline 1/7/09 12:38 PM & EO2543-03 & ACES Transient & $\mathrm{h}$ & $\mathrm{n}$ & -- \\
\hline 1/7/09 1:09 PM & EO2543-04 & ACES Creep & $\mathrm{h}$ & $\mathrm{n}$ & -- \\
\hline 1/7/09 1:47 PM & EO2543-05 & ACES Cruise & $\mathrm{h}$ & $\mathrm{n}$ & -- \\
\hline 1/7/09 2:42 PM & EO2543-06 & ACES HHDDTS & $\mathrm{h}$ & $\mathrm{n}$ & -- \\
\hline 1/7/09 3:15 PM & EO2543-07 & ICOMIA SS (mode bashing) & -- & $\mathrm{n}$ & -- \\
\hline 1/7/09 4:05 PM & EO2543-08 & Background & -- & -- & -- \\
\hline 1/8/09 2:24 PM & EO2544-01 & Background to check NDUV operation w/ $\mathrm{NH}_{3}$ & -- & -- & -- \\
\hline 1/8/09 3:07 PM & EO2544-02 & Background to check Ecophysics operation w/ $\mathrm{NH}_{3}$ & -- & -- & -- \\
\hline 1/8/09 4:15 PM & EO2545-01 & ICOMIA SS & -- & $\mathrm{n}$ & -- \\
\hline 1/8/09 5:08 PM & EO2545-02 & FTP & $\mathrm{h}$ & $\mathrm{n}$ & -- \\
\hline 1/8/09 5:35 PM & EO2545-03 & Background & -- & -- & -- \\
\hline 1/9/09 3:23 PM & EO2546-01 & FTP & w & $\mathrm{n}$ & -- \\
\hline 1/9/09 4:03 PM & EO2546-02 & FTP (trial w/ fuzzy control) & $\mathrm{h}$ & $\mathrm{y}$ & 0.75 \\
\hline 1/9/09 4:43 PM & EO2546-03 & FTP (trial w/ fuzzy control) & $\mathrm{h}$ & $\mathrm{y}$ & 0.6 \\
\hline 1/9/09 5:10 PM & EO2546-04 & Background & -- & -- & -- \\
\hline 1/12/09 2:51 PM & EO2547-01 & FTP & $\mathrm{w}$ & $\mathrm{n}$ & -- \\
\hline 1/12/09 3:31 PM & EO2547-02 & FTP & $\mathrm{h}$ & $\mathrm{n}$ & -- \\
\hline 1/12/09 4:11 PM & EO2547-03 & FTP (trial w/ increased NDUV sample pressure of $0.8 \mathrm{psig}$ ) & $\mathrm{h}$ & $\mathrm{n}$ & -- \\
\hline 1/12/09 4:37 PM & EO2547-04 & Background & -- & -- & -- \\
\hline 1/13/09 11:26 AM & EO2548-01 & Background & -- & -- & -- \\
\hline 1/13/09 12:15 PM & EO2548-02 & FTP & w & $\mathrm{y}$ & 0.5 \\
\hline 1/13/09 12:55 PM & EO2548-03 & FTP (NDUV on zero first $180 \mathrm{sec}$ ) & $\mathrm{h}$ & $\mathrm{y}$ & 0.5 \\
\hline 1/13/09 1:42 PM & EO2548-04 & FTP (restarted NDUV, lost hot start window) & w & $\mathrm{y}$ & 0.5 \\
\hline 1/13/09 2:22 PM & EO2548-05 & FTP (urea factor incorrect) & $\mathrm{h}$ & $\mathrm{y}$ & 1.0 \\
\hline 1/13/09 3:02 PM & EO2548-06 & FTP & $\mathrm{h}$ & $\mathrm{y}$ & 0.5 \\
\hline 1/13/09 3:42 PM & EO2548-07 & ACES Transient & $\mathrm{h}$ & $\mathrm{y}$ & 0.5 \\
\hline 1/13/09 4:14 PM & EO2548-08 & ACES Creep & $\mathrm{h}$ & $\mathrm{y}$ & 0.5 \\
\hline 1/13/09 4:51 PM & EO2548-09 & ACES Cruise & $\mathrm{h}$ & $\mathrm{y}$ & 0.5 \\
\hline 1/13/09 5:46 PM & EO2548-10 & ACES HHDDTS & $\mathrm{h}$ & $\mathrm{y}$ & 0.5 \\
\hline 1/13/09 6:19 PM & EO2548-11 & ICOMIA SS ( $\mathrm{NH}_{3}$ slip) & -- & $y$ & 0.5 \\
\hline 1/14/09 11:59 AM & EO2549-01 & $\mathrm{NH}_{3}$ Storage Run & -- & $y$ & 0.5 \\
\hline 1/14/09 12:49 PM & EO2549-02 & ICOMIA SS & -- & $\mathrm{y}$ & 0.25 \\
\hline 1/14/09 1:14 PM & EO2549-03 & Background & -- & $\mathrm{y}$ & -- \\
\hline & & \multicolumn{4}{|l|}{ Final Baseline Runs } \\
\hline & & \multicolumn{4}{|l|}{ Final Urea Injection Runs } \\
\hline & & \multicolumn{4}{|l|}{ Final $\mathrm{NH}_{3}$ Storage Run } \\
\hline
\end{tabular}


Appendix D. Urea-SCR System Individual Component Cost

Table 52. Urea-SCR system individual component cost

\begin{tabular}{|c|c|c|c|}
\hline Item/Process & Size/Quantity & Cost & Source \\
\hline $\begin{array}{l}\text { Exhaust pipe section, aluminized } \\
\text { steel }\end{array}$ & 5 in diameter, 36 in length & $\$ 31.49$ & Summit Racing \\
\hline Stainless steel pitot tubes & $\begin{array}{l}\text { (x2), } 1 / 4 \text { in inner diameter, } 12 \text { in } \\
\text { length }\end{array}$ & $\$ 25.06$ & Mcmaster Carr \\
\hline Teflon tubing & $1 / 8$ in diameter, $25 \mathrm{ft}$ length & $\$ 33.00$ & Protein Technologies, Inc \\
\hline Automotive fuel line & $3 / 8$ in diameter, $12 \mathrm{ft}$ length & $\$ 8.00$ & Summit Racing \\
\hline Stainless steel standoff tube & $1 / 8$ in diameter, 2.5 in length & $\$ 8.81$ & Mcmaster Carr \\
\hline Aluminum heat shield & 10 in $\times 10$ in, $1 / 64$ in thick & $\$ 55.22$ & Mcmaster Carr \\
\hline Turbo flanges & $(x 3), 5$ in diameter & $\$ 64.47$ & NAPA \\
\hline Aluminum block (injector mount) & 2 in $\times 3$ in $\times 6$ in & $\$ 23.88$ & Mcmaster Carr \\
\hline Injector Mount Bolts & $(x 3), 1 / 4$ in diameter, 5 in length & $\$ 6.79$ & Mcmaster Carr \\
\hline Injector exhaust gasket & & $\$ 4.00$ & Summitracing.com \\
\hline Injector teflon spacer & & $\$ 1.00$ & Mcmaster Carr \\
\hline Urea injector & GM 5.3L V8, gasoline/flex fuel (E85) & $\$ 114.29$ & General Motors \\
\hline Urea pump (in-tank) & GM 5.3L V8, gasoline/flex fuel (E85) & $\$ 352.38$ & General Motors \\
\hline Automotive pressure gauge & $0-100 \mathrm{psi}$ & $\$ 13.95$ & Summitracing.com \\
\hline Type K Thermocouple & & $\$ 24.00$ & Omega \\
\hline STCTX-K2 thermocouple transmitter & 0-5V output & $\$ 75.00$ & Omega \\
\hline MSD automotive MAP sensor & 2 bar & $\$ 59.95$ & Summitracing.com \\
\hline $\begin{array}{l}\text { Omega PX2300 differential pressure } \\
\text { sensor }\end{array}$ & 0-1 psi & $\$ 480.00$ & Omega \\
\hline Siemens VDO SmartNOx sensor & & $\$ 1,775.00$ & Siemens USA \\
\hline Mototron Motohawk controller & 80-pin & $\$ 800.00$ & Mototron \\
\hline SCR brick (vanadium-based) & $(\mathrm{x} 4), 150 \mathrm{~mm} \times 150 \mathrm{~mm} \times 450 \mathrm{~mm}$ & $\$ 1,200.00$ & Keenan, et al., Mira, et al. \\
\hline Unifrax fiberous brick wrap & CC-Max $4 \mathrm{HP}, 12$ in $x 12$ in core & $\$ 25.00$ & Unifrax \\
\hline Canning process (local) & & $\$ 1,100.00$ & Wilson Works \\
\hline Fuse block and fuses & & $\$ 5.00$ & Advance Auto \\
\hline Swagelock fittings & $\begin{array}{l}\text { pitot-tube }(x 2), \text { thermocouple, } \\
\text { absolute pressure }\end{array}$ & $\$ 18.48$ & Swagelok \\
\hline Voltage Regulator & & $\$ 1.00$ & Radioshack \\
\hline $\begin{array}{l}\text { Automotive relays (pump, fuse block } \\
\text { power) }\end{array}$ & $(x 2)$ & $\$ 4.00$ & Advance Auto \\
\hline ACS Industries Wire Mesh Mixer & 5 in diameter, 2 in length & $\$ 500.00$ & estimate \\
\hline & Total (one NOx sensor) & $\$ 6,809.77$ & \\
\hline & Total (two NOx sensors) & $\$ 8,584.77$ & \\
\hline
\end{tabular}

